\title{
Decision Analysis for Mobilizing and Retrieving Sludge from Double-Shell Tanks
}
A. J. Brothers
N. C. Williams
J. S. Dukelow
R. I. Hansen

Pacific Northwest National Laboratory

R. D. Claghorn

C. E. Grenard

Numatec Hanford Corporation

R. M. Marusich

Fluor Daniel Northwest Inc.

September 1997

Prepared for the

U.S. Department of Energy

under Contract DE-AC06-76RLO 1830

Pacific Northwest National Laboratory

Richland, Washington 99352 


\section{DISCLAMIER}

Portions of this docoment may be illegible in electronic image products. Images are produced from the best available original document. 


\section{DISCLAIMER}

This report was prepared as an account of work sponsored by an agency of the United States Government. Neither the United States Government nor any agency thereof, nor any of their employees, make any warranty, express or implied, or asumes any legal liability or responsibility for the accuracy, completeness, or usefulness of any information, apparatus, product, or process disclosed, or represents that its use would not infringe privately owned rights. Reference herein to any specific commercial product, process, or service by trade name, trademark, manufacturer, or otherwise does not necessarily constitute or imply its endorsement, recommendation, or favoring by the United States Government or any agency thereof. The views and opinions of authors expressed herein do not necessar. ily state or reflect those of the United States Government or any agency thereof. 


\section{Preface}

The work reported here is part of a broader effort to bring the quantitative analysis tools of operations research/systems analysis (ORSA) to bear on specific Tank Waste Remediation System (TWRS) problems and decisions. The ORSA activity was initiated by Lockheed Martin Hanford Company (LMHC) and Pacific Northwest National Laboratory (PNNL) under the direction and guidance of the DOE-RL TWRS program. Dan Francis and Randy Unger, DOE-RL, provided the impetus and leadership; and Bruce Zimmerman, LMHC, and David Seaver, PNNL, were responsible for managing contractor efforts.

In fiscal year 1997, three additional analyses were performed as part of this activity. Monte Carlo Risk Analysis of Phase I Feed Delivery, led by Bruce Zimmerman, analyzed the schedule risk of delivering waste feed to the private contractors by the required date and identified specific activities that need to be managed effectively to reduce the risk. The Piping Network Routing Assistant Analysis of Privatization Phase I Waste Transfer Capability, led by Bruce Zimmerman, updated and applied a network model of the 200-Area underground piping transfer system to locate transfer system bottlenecks and to estimate the availability requirements that will be placed on the transfer system components by currently planned Phase I transfer activities. The third analysis, led by Peter McLaughlin, PNNL, analyzed alternative privatization Phase I processing capacities to determine preferred processing capacities and durations. This work is "business sensitive," so is not publicly available.

These ORSA applications jointly demonstrated the value of quantitative analysis. Each was or will be a significant contributor to major TWRS decisions and has been noted as such by TWRS management. The goal of achieving recognition of the value of ORSA methods is a small step closer as a result. 


\section{Summary}

This decision analysis evaluates alternative technologies for the initial mobilization and retrieval of sludges in double-shell tanks (DSTs). The analysis is from the perspective of the need to move sludges from one DST to another for interim retrieval. It supports the more general decision of which technologies to use to retrieve various types of DST waste. The initial analysis is from the perspective of a typical DST with $2 \mathrm{ft}$ of sludge to mobilize. During the course of the analysis, it became clear that it was important to also consider sludge mobilization in support of the high-level waste (HLW) vitrification demonstration plant, and in particular the risks associated with failing to meeting the minimum order requirements for the vendor, as well as the cost of mobilization and retrieval from the HLW vitrification source tanks.

The alternatives considered in the analysis are

- mixer pumps

- sluicing

- mechanical with pipeline for transport

- mechanical with truck for transport.

Chemical dissolution was considered initially. It was dropped from the analysis because it requires the use of strong acid and is not compatible with the tank container, which would dissolve.

The impacts of the alternatives were evaluated on a variety of criteria ranging from Environment, Safety, \& Health (ES\&H) to retrieval effectiveness to cost and schedule. The criteria considered were a combination of criteria from a generic list developed specifically for the Tank Waste Remediation System (TWRS), as well as criteria that are more specific to the logistics and engineering requirements for this particular decision.

Criteria fall into two categories: ends objectives and means objectives. Ends objectives are fundamental objectives that are important in and of themselves. These objectives are ES\&H, retrieval effectiveness, cost, and schedule. The means objectives are important to the extent they affect the ends objectives. For example, reliability is important in that it affects cost and schedule.

Scores were obtained for each of the alternatives on both the means and the ends objectives. In addition, the impacts of the means objectives on the ends objectives were obtained, and the final values for the ends objectives were adjusted to reflect these impacts. The scores on the ends objectives were rolled up into an overall score for each of the alternatives. This process required value tradeoffs, which were obtained by pricing out the specific units of the ends objectives. Most of the unit prices were based on elicitations from nationally recognized experts on public values and decision analysis (Keeney and von Winterfeldt 1996). The potential impacts to ES\&H are small; thus, the important drivers for this decision are retrieval effectiveness, cost, and schedule. 
Assuming a typical tank with $2 \mathrm{ft}$ of sludges to be mobilized and transferred, the impacts of the alternatives on cost, schedule, and retrieval effectiveness can be summarized as follows:

- Retrieval effectiveness for all alternatives except mixer pumps is expected to be $99 \%$.

- Retrieval effectiveness for standardized mixer pumps is a function of shear strength (Grams 1995). The median shear strength for double-shell tanks is about $24,000 \mathrm{dy} / \mathrm{cm}^{2}$.

- Mixer pumps would mobilize approximately $50 \%$ of the sludge for such a tank, assuming that none of the solids dissolve as a result of dilution and agitation.

- While mixer pumps are the least effective in retrieving the waste, they are also the least costly. Costs for the alternatives are estimated to be:

- mixer pump system

- sluicing system

- mechanical retrieval w/pipeline transfer

- mechanical retrieval w/truck transfer
$\$ 24.4$ million

$\$ 32.5$ million

$\$ 36.2$ million

$\$ 58.2$ million.

These costs are dominated by capital costs. Operating costs are a small fraction of the total costs. The total operating costs per tank were estimated to be

- mixer pump

- sluicer

- mechanical/pipeline
$\$ 398 \mathrm{~K}$

$\$ 408 \mathrm{~K}$

$\$ 562 \mathrm{~K}$.

Operating costs for both mixing and sluicing are based on estimated daily operating costs of $\$ 5.1 \mathrm{~K}$. These costs are quite small compared with the capital costs, and the mixer pump has both the least operating cost and the least capital costs.

Cost per metric ton (MT) delivered, however, tells a different story. Cost for an average tank with $2 \mathrm{ft}$ of sludge works out to

- $\$ 387 \mathrm{~K} / \mathrm{MT}$ for sluicers

- $\$ 581 \mathrm{~K} / \mathrm{MT}$ for mixers.

On a cost/MT delivered basis, mixer pumps become more cost-effective as their retrieval effectiveness increases. The retrieval effectiveness is inversely related to the shear strength of the sludge. The breakeven point between sluicers and mixers is a retrieval effectiveness of $75 \%$, which corresponds to a sludge shear strength of approximately $14,000 \mathrm{dy} / \mathrm{cm}^{2}$. Less than $25 \%$ of the DSTs have sludge shear strength of $10 \mathrm{dy} / \mathrm{cm}^{2}$ or less; thus mixer pumps are more cost-effective than sluicers for less than $25 \%$ of the DSTs when calculated on a cost/MT basis. 
Cost/MT for a given tank decreases as the amount of sludge in the tank increases. For mixer pumps, operating costs are constant; thus, the cost per MT is halved when the amount of sludge doubles. For sluicers, operating costs increase slightly as sludge increases; however, because costs are dominated by capital costs, the cost per MT decreases only slightly. If cost/MT is important, this would suggest looking for tanks with more sludges per tank.

From the life-cycle perspective, a decision based on cost is even more complicated. Mixers leave a significant portion of the waste in the tank for most tanks, and eventually sluicers would likely have to be installed for ultimate cleanout. This cost is in the future, however, and should be discounted. The best option, then, will depend on the time that elapses until the sluicer is installed and the discount rate. For instance, $\$ 33$ million (capital cost of the sluicer) discounted for 20 years at $6 \%$ is approximately $\$ 10 \mathrm{mil}-$ lion, which is approximately the difference in price between the two alternatives.

In addition to calculating costs for mobilizing sludge in a generic DST, we also calculated the cost to mobilized the sludges in the source tanks for the HLW vitrification demonstration plant. The source tanks for which costs were calculated were 101-AZ, 102-AZ, 102-AY, and C-106. In all cases, it is assumed that $\mathrm{C}-106$ would be sluiced and transferred into 102-AY. The mixer pump alternative consists of putting mixer pumps in all three DSTs and pumping directly from each DST to the vendor. Sluicing and mechanical would require mixer pumps in 101-AZ for sludge washing; waste from other tanks would be transferred there for that purpose and then to the vendor. Total costs were the least for mixers at $\$ 83$ million, sluicers were $\$ 100$ million, and mechanical with pipeline transfer is $\$ 108$ million. Mixers are expected to retrieve $323 \mathrm{MT}$ or $71 \%$ of the $452 \mathrm{MT}$ of sludge in the four source tanks for Phase 1B. Sluicers are expected to retrieve $388 \mathrm{MT}$ or $86 \%$ of the sludge. The cost per metric ton is $\$ 257 \mathrm{~K}$ for both systems. Thus, mixers are less costly overall and retrieve $65 \mathrm{MT}$ less; but, on a cost-per-metric-ton basis, the two alternatives are equivalent for Phase 1B.

A risk analysis was carried out for the purpose of assessing the risk and potential consequences of failure to meet the minimum order requirements for $\mathrm{HLW}$ vitrification demonstration plant. Sluicing and mechanical systems are expected to mobilize and transfer approximately $99 \%$ of the sludge. The four source tanks contain approximately $130 \mathrm{in}$. or $379 \mathrm{MT}$ of sludge. Thus, sluicing and mechanical are estimated to deliver $375 \mathrm{MT}$ of waste to the vendor. Although less than the maximum of $485 \mathrm{MT}$, this amount would easily meet the 245 MT minimum order requirement. For mixing, the amount mobilized depends on the shear strength, which varies from tank to tank. Also to be considered is that C-106, which contains $55 \%$ of the sludge, is a SST which will be sluiced into 102-AY. The amount of C-106 sludge mobilized will depend on its shear strength at the time it is mobilized from 102-AY, which will most likely depend on the amount of time it sat in 102-AY and whether steps were taken to prevent it from recompacting.

Probability distributions of shear strengths of sludges were obtained for each of the source tanks for each distinct layer of waste. Monte Carlo simulation was used to obtain a probability distribution for the MT delivered using mixer pumps. The key uncertainty in these estimates is the shear strength of C-106 at the time of mobilization from 102-AY. If C-106 sludge is allowed to return to its current shear strength, there is nearly a $50 \%$ chance of failing to meet the minimum order requirement of $245 \mathrm{MT}$. If $80 \%$ of the 
C-106 sludge, exclusive of hard pan, is mobilized and delivered to the vendor, then the best estimate is that $280 \mathrm{MT}$ would be delivered; and there is less than $1 \%$ chance of failing to meet the minimum order requirements. Idle time penalties if the minimum requirement is not delivered to the HLW vitrification plant are also an important factor that affects the cost/MT delivered. 


\section{Contents}

Preface $\ldots \ldots \ldots \ldots \ldots \ldots \ldots \ldots \ldots \ldots \ldots \ldots \ldots \ldots \ldots \ldots \ldots \ldots \ldots \ldots \ldots \ldots \ldots \ldots \ldots$

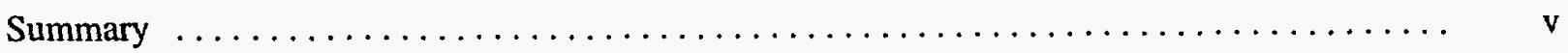

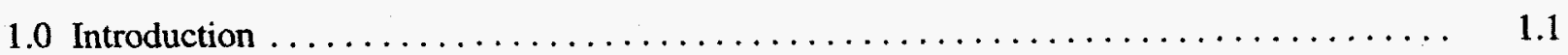

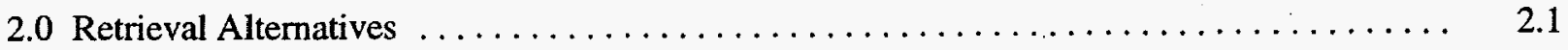

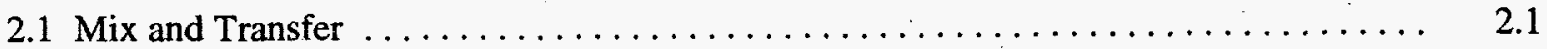

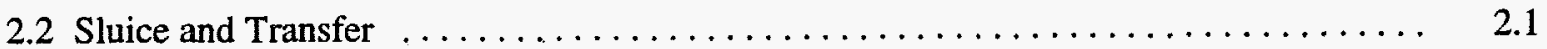

2.3 Mechanical Retrieval - Truck or Rail Car $\ldots \ldots \ldots \ldots \ldots \ldots \ldots \ldots \ldots \ldots \ldots$

2.4 Mechanical Retrieval - Pipeline Transfer $\ldots \ldots \ldots \ldots \ldots \ldots \ldots \ldots \ldots \ldots \ldots \ldots$

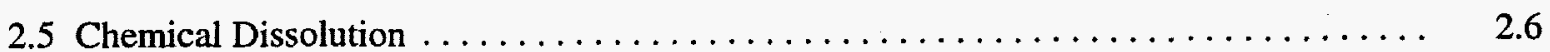

2.6 Combinations and Enhancements $\ldots \ldots \ldots \ldots \ldots \ldots \ldots \ldots \ldots \ldots \ldots \ldots \ldots \ldots \ldots \ldots \ldots \ldots$

3.0 Multiattribute Tradeoff Analysis $\ldots \ldots \ldots \ldots \ldots \ldots \ldots \ldots \ldots \ldots \ldots \ldots \ldots \ldots \ldots \ldots \ldots \ldots \ldots \ldots$

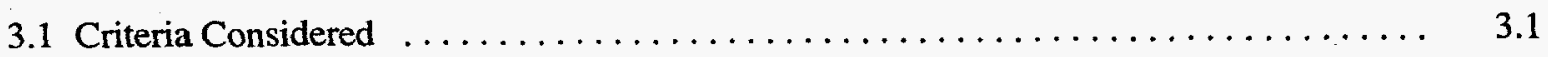

3.2 Basis for Scores in Alternative/Criteria Matrix $\ldots \ldots \ldots \ldots \ldots \ldots \ldots \ldots \ldots \ldots \ldots$

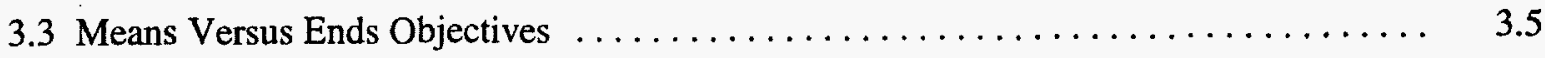

3.4 Performance of Alternatives on Criteria $\ldots \ldots \ldots \ldots \ldots \ldots \ldots \ldots \ldots \ldots \ldots \ldots$

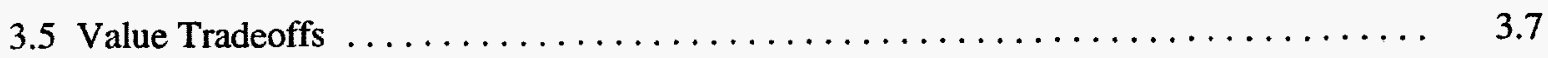

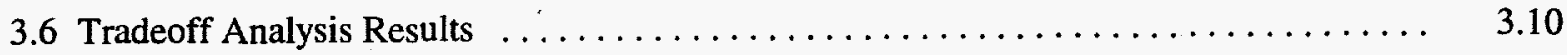

3.7 Sensitivity Analysis on Weights $\ldots \ldots \ldots \ldots \ldots \ldots \ldots \ldots \ldots \ldots \ldots \ldots \ldots \ldots \ldots \ldots \ldots \ldots \ldots$

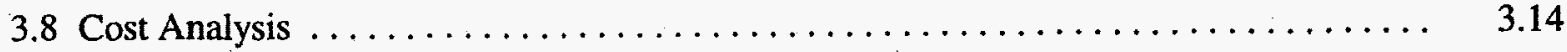

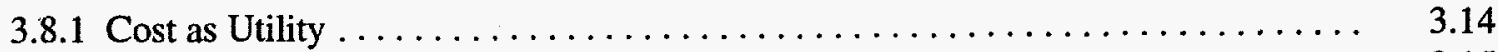

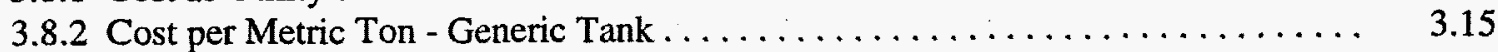

3.8.3 Cost per Metric Ton - Phase 1B . . . . . . . . . 3.16

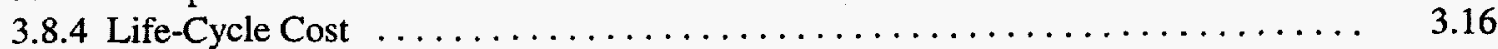


4.0 Cost and Schedule for Generic Tank $\ldots \ldots \ldots \ldots \ldots \ldots \ldots \ldots \ldots \ldots \ldots \ldots \ldots \ldots \ldots \ldots \ldots \ldots$

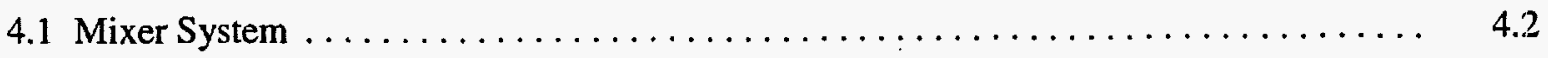

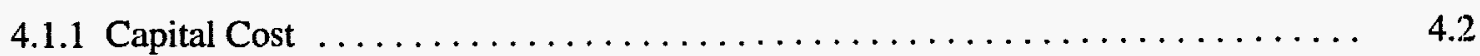

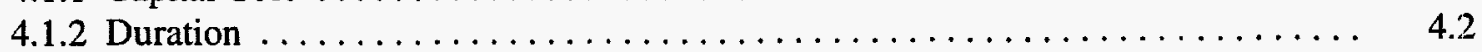

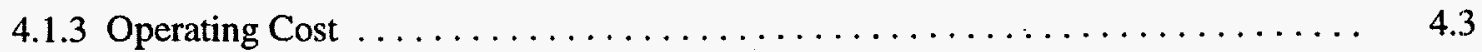

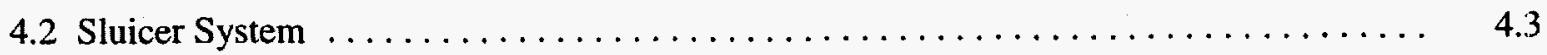

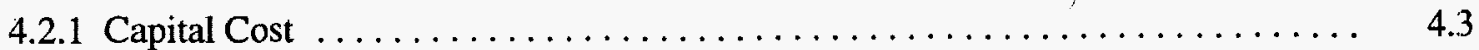

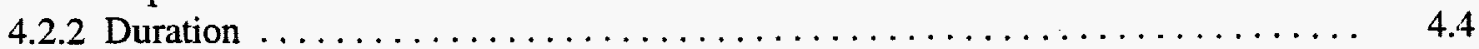

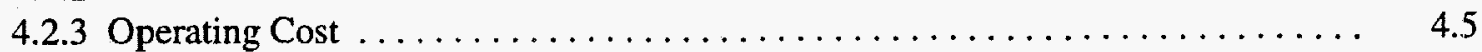

4.3 Mechanical System with Pipeline Transfer $\ldots \ldots \ldots \ldots \ldots \ldots \ldots \ldots \ldots \ldots \ldots \ldots$

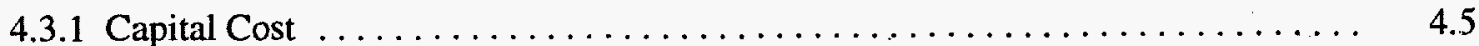

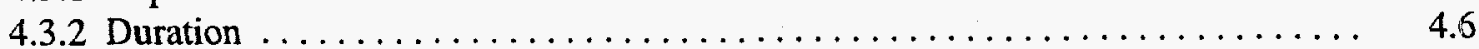

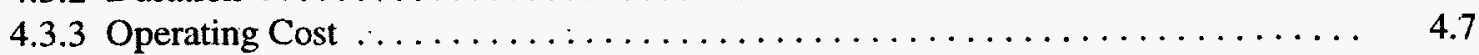

4.4 Mechanical System with Truck Transfer $\ldots \ldots \ldots \ldots \ldots \ldots \ldots \ldots \ldots \ldots \ldots \ldots \ldots$

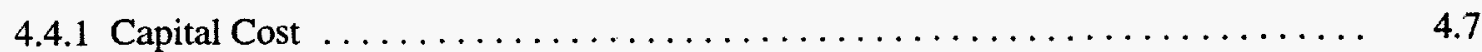

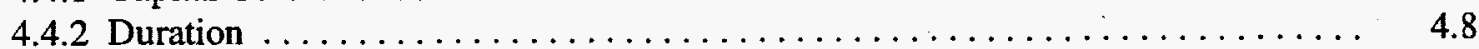

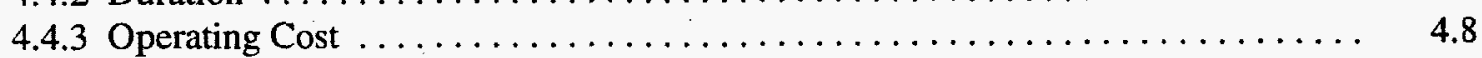

4.5 Other Cost and Schedule Impacts $\ldots \ldots \ldots \ldots \ldots \ldots \ldots \ldots \ldots \ldots \ldots \ldots \ldots \ldots$

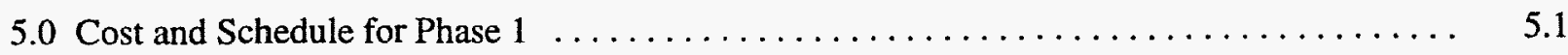

5.1 Mixers in 101-AZ, 102-AZ, and 102-AY $\ldots \ldots \ldots \ldots \ldots \ldots \ldots \ldots \ldots \ldots \ldots \ldots \ldots \ldots \ldots \ldots \ldots$

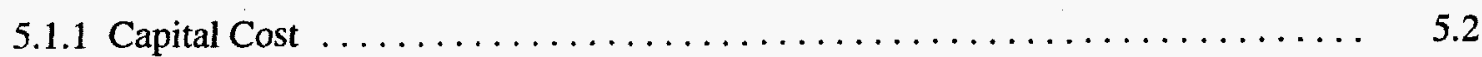

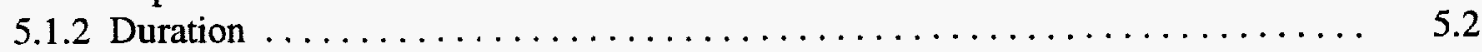

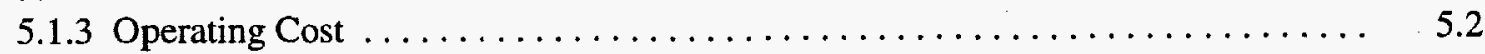

5.2 Sluicer in $102-\mathrm{AZ}$ and $102-\mathrm{AY}$, Mixer in $101-\mathrm{AZ} \ldots \ldots \ldots \ldots \ldots \ldots \ldots \ldots \ldots \ldots$

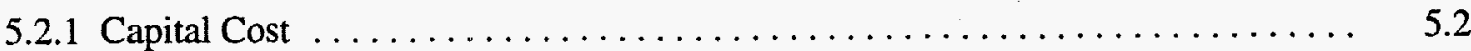

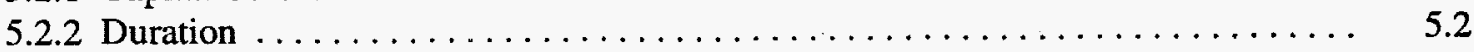

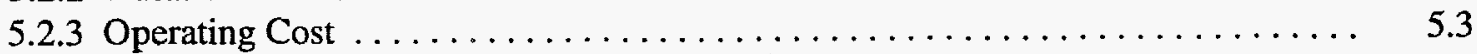

5.3 Mechanical Arm in 102-AZ and 102-AY, Mixer in 101-AZ . . . . . . . . 5.3

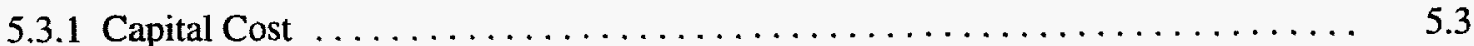

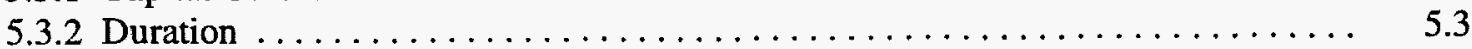

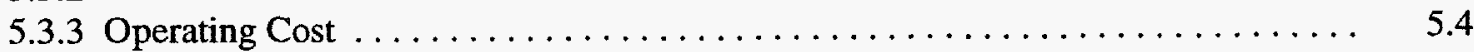


6.0 Retrieval Effectiveness Risk Analysis $\ldots \ldots \ldots \ldots \ldots \ldots \ldots \ldots \ldots \ldots \ldots \ldots \ldots \ldots \ldots \ldots$

6.1 Sludge Mobilization Calculations $\ldots \ldots \ldots \ldots \ldots \ldots \ldots \ldots \ldots \ldots \ldots \ldots \ldots \ldots \ldots \ldots \ldots \ldots \ldots .2$

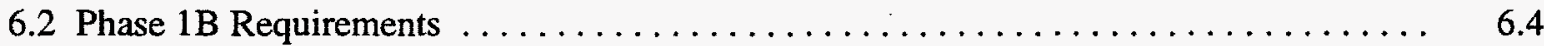

6.3 Shear Strength Elicitation Process $\ldots \ldots \ldots \ldots \ldots \ldots \ldots \ldots \ldots \ldots \ldots \ldots \ldots \ldots \ldots \ldots \ldots \ldots$

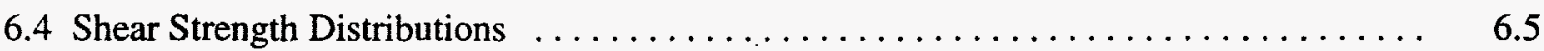

6.5 Monte Carlo Simulation Process and Results $\ldots \ldots \ldots \ldots \ldots \ldots \ldots \ldots \ldots \ldots \ldots \ldots$

7.0 Operating Efficiency Risk Analysis $\ldots \ldots \ldots \ldots \ldots \ldots \ldots \ldots \ldots \ldots \ldots \ldots \ldots \ldots \ldots \ldots \ldots \ldots$

7.1 Burn-in Versus No Burn-in $\ldots \ldots \ldots \ldots \ldots \ldots \ldots \ldots \ldots \ldots \ldots \ldots \ldots \ldots \ldots \ldots \ldots \ldots \ldots \ldots \ldots$

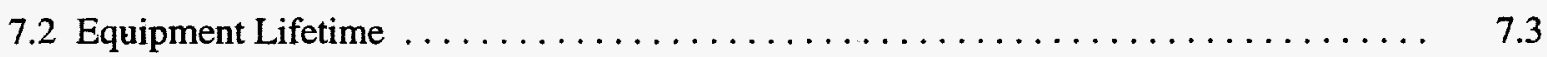

7.3 Reliability Risk $\ldots \ldots \ldots \ldots \ldots \ldots \ldots \ldots \ldots \ldots \ldots \ldots \ldots \ldots \ldots \ldots \ldots \ldots \ldots \ldots \ldots$

8.0 References $\ldots \ldots \ldots \ldots \ldots \ldots \ldots \ldots \ldots \ldots \ldots \ldots \ldots \ldots \ldots \ldots \ldots \ldots \ldots \ldots \ldots \ldots \ldots \ldots \ldots .1$

Appendix A - Environment, Health, and Safety Analysis $\ldots \ldots \ldots \ldots \ldots \ldots \ldots \ldots \ldots \ldots \ldots \ldots$ A.1

Appendix B - Activities and Durations for the Alternative Retrieval Systems $\ldots \ldots \ldots \ldots \ldots$ B.1

Appendix C - Operating Efficiency Risk Analysis $\ldots \ldots \ldots \ldots \ldots \ldots \ldots \ldots \ldots \ldots \ldots \ldots \ldots$ 


\section{Figures}

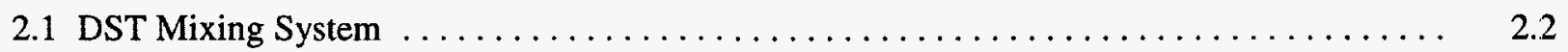

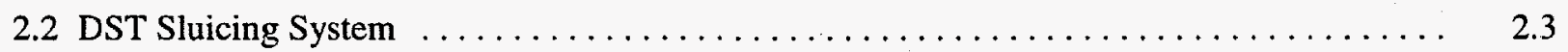

2.3 DST Mechanical Retrieval System with Truck Transfer $\ldots \ldots \ldots \ldots \ldots \ldots \ldots \ldots \ldots$

2.4 DST Mechanical Retrieval System $\ldots \ldots \ldots \ldots \ldots \ldots \ldots \ldots \ldots \ldots \ldots \ldots \ldots \ldots \ldots \ldots$

2.5 DST Retrieval Dissolution System $\ldots \ldots \ldots \ldots \ldots \ldots \ldots \ldots \ldots \ldots \ldots \ldots \ldots \ldots$

3.1 Criteria and Measures Considered in the Decision Analysis $\ldots \ldots \ldots \ldots \ldots \ldots \ldots \ldots .2$

3.2 Means and Ends Objectives for DST Sludge Mobilization Decision $\ldots \ldots \ldots \ldots \ldots \ldots$

3.3 Performance of Alternatives on Criteria $\ldots \ldots \ldots \ldots \ldots \ldots \ldots \ldots \ldots \ldots \ldots \ldots \ldots \ldots$

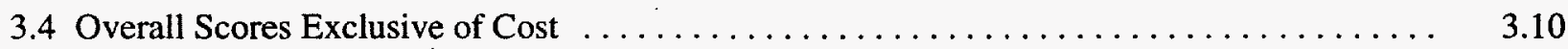

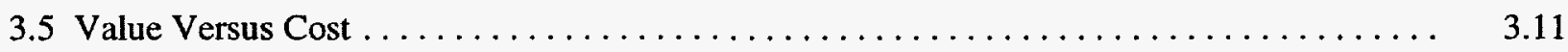

3.6 Performance Profiles for Sludge Mobilization Alternatives $\ldots \ldots \ldots \ldots \ldots \ldots \ldots \ldots \ldots$

3.7 Sensitivity Analysis for Selected Criteria $\ldots \ldots \ldots \ldots \ldots \ldots \ldots \ldots \ldots \ldots \ldots \ldots \ldots \ldots$

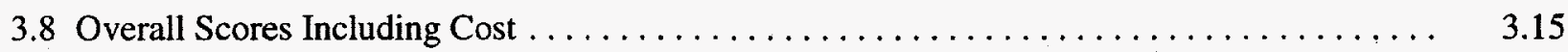

6.1 Relationship Between Sludge Mobilization and Shear Strength $\ldots \ldots \ldots \ldots \ldots \ldots \ldots \ldots$

6.2 Distribution of Shear Strength Data Among Double Shell Tanks . . . . . . . . . . 6.3

6.3 Distribution of Shear Strength for Tank $101-\mathrm{AZ} \ldots \ldots \ldots \ldots \ldots \ldots \ldots \ldots \ldots \ldots \ldots$

6.4 Distribution of Shear Strength for Tank $102-\mathrm{AZ} \ldots \ldots \ldots \ldots \ldots \ldots \ldots \ldots \ldots \ldots \ldots$

6.5 Distribution of Shear Strength for Tank 102-AY $\ldots \ldots \ldots \ldots \ldots \ldots \ldots \ldots \ldots \ldots \ldots$

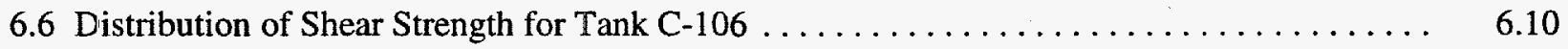

6.7 Metric Tons Delivered Assuming Current Shear Strengths in Tank C-106 $\ldots \ldots \ldots \ldots .11$

6.8 Metric Tons Delivered Assuming Different Amounts of C-106 $\ldots \ldots \ldots \ldots \ldots \ldots \ldots \ldots$

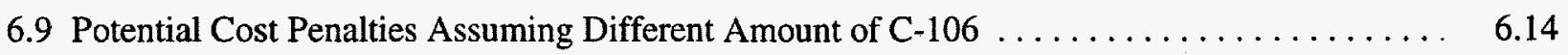

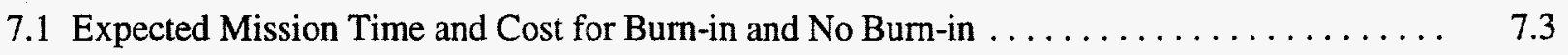




\section{Tables}

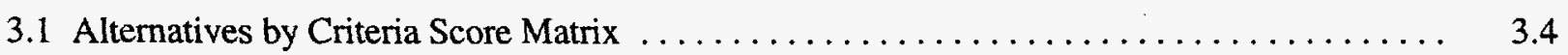

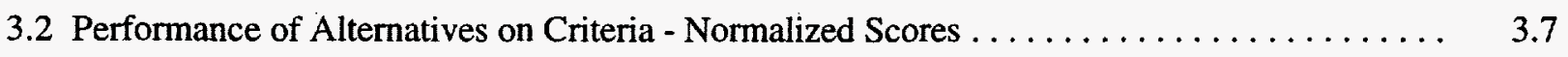

3.3 Weights Used in the Multiattribute Analysis $\ldots \ldots \ldots \ldots \ldots \ldots \ldots \ldots \ldots \ldots \ldots$

4.1 Summary Table of Cost and Schedule for a Generic Tank $\ldots \ldots \ldots \ldots \ldots \ldots \ldots \ldots$

5.1 Summary Table of Costs and Schedules for Alternative Retrieval Systems Evaluated . . . . 5.1

6.1 Summary of Results from Retrieval Effectiveness Risk Analysis $\ldots \ldots \ldots \ldots \ldots \ldots \ldots \ldots$

6.2 Source Tanks and Their Sludge Amounts for HLW Feed $\ldots \ldots \ldots \ldots \ldots \ldots \ldots \ldots$

6.3 Shear Strength of Sludges in HLW Source Tanks for Phase $1 B \ldots \ldots \ldots \ldots \ldots \ldots \ldots$

7.1 Summary Table of Reliability Study $\ldots \ldots \ldots \ldots \ldots \ldots \ldots \ldots \ldots \ldots \ldots \ldots \ldots \ldots \ldots \ldots \ldots \ldots$

7.2 Assumed Component/Subsystem Lifetimes $\ldots \ldots \ldots \ldots \ldots \ldots \ldots \ldots \ldots \ldots \ldots \ldots$

7.3 Mixer Pump Evaluation with $2000-\mathrm{hr}$ and $6000-\mathrm{hr}$ MTTF $\ldots \ldots \ldots \ldots \ldots \ldots \ldots \ldots$

7.4 Systems with High Probability of Mission Success with No Failures and Systems with High Probability of Multiple Failures Prior to Successful Completion of Mission . . . . . 7.5 


\subsection{Introduction}

This decision analysis addresses technology alternatives for mobilization and retrieval of sludges from double-shell tanks (DSTs). The analysis is in support of the Retrieval Program's decision on the appropriate technology for DST retrieval. The 28 DSTs at Hanford have a variety of waste forms such as solids, liquids, slurries, and sludges. A past study by Grams (1995) considered retrieval alternatives for DSTs that recommended mixer pumps regardless of waste type. Depending on waste type, this may not be as cost-effective as using alternative retrieval systems. The current strategy is to provide a recommendation that is appropriate to the waste type, and the analysis was carried out to provide the technical basis for that recommendation. In addition, the analysis supports the high-level waste (HLW) demonstration plant planning.

Section 2.0 of the report presents a discussion of the retrieval alternatives considered in this study. Section 3.0 presents a multiattribute tradeoff analysis of sludge mobilization alternatives. The analysis shows the important drivers for this decision to be cost- and retrieval-effective. A detailed cost analysis is presented in Section 4.0 that addresses the cost of mobilization and retrieval of a generic DST, and Section 5.0 presents the cost of retrieval systems for Phase IB HLW sludge mobilization. Section 6.0 presents a risk analysis for retrieval effectiveness of mixer pumps to assess the likelihood of failing to meet the minimum order requirements for the HLW vitrification demonstration plant and associated penalties. Section 7.0 presents an operating risk analysis that has implication for whether mobilization systems should be "burned-in" prior to installation and the value of longer life mixer pumps currently under development.

Appendix A presents more detail on the ranking of the alternatives relative to the "safety" and "environment" criteria. Appendix B consists of tables that show the activities and durations for the alternative retrieval systems. Appendix $\mathrm{C}$ provides supporting detail for the reliability analysis presented in Section 7.0. 


\subsection{Retrieval Alternatives}

This analysis considers the following alternatives for sludge mobilization and retrieval: mix and transfer, sluice and transfer, mechanical retrieval with truck or rail car transfer, mechanical retrieval with pipeline transfer, chemical dissolution, and combinations and enhancements of the preceding alternatives.

\subsection{Mix and Transfer}

Mixer pumps create submersed liquid jets to dislodge/break up and suspend waste solids and to create a slurry that can be transferred to other DSTs or to a processing facility. The configuration of a DST mix and transfer system is shown in Figure 2.1. Two mixer pumps with 300-hp motors are located in the DSTs in diametrically opposed 42-in. risers in the $\mathrm{AN}, \mathrm{AW}, \mathrm{AY}$, and $\mathrm{AZ}$ tank farms. In the AP tank farms, the 42 -in. risers are only $90^{\circ}$ apart.

Extended mixer pump operation will be required to initially mobilize sludge that has been allowed to settle for several years. Once the sludge is mobilized, only limited pump operation will be required for subsequent mobilization. Operation of the mixer pumps causes the waste temperature to rise slowly; the temperature limits of the tank may be reảched in approximately 14 days depending on the ventilation rate. It will then be necessary to shut down to allow the waste to cool. The waste will then be resuspended and transferred.

The mixed slurry will be removed by a waste transfer pump located in the central pump pit; it will then be transferred to either another (receiver) DST for interim storage or to a processing facility. Receiver DSTs will have a slurry distributor to distribute the waste solids throughout the tank and mixer pumps to keep the solids suspended or to remobilize the solids if they are allowed to settle.

The waste transfer system will have a short recirculation loop with waste being returned to the retrieval tank through a separate riser in the central pump pit. The transfer pump would be started in the recirculation mode to verify the waste meets transfer requirements before beginning the transfer. The only exception will be for tanks with concentrated waste that cannot be adequately diluted in-tank. In-line dilution will have to be used for transfer of concentrated waste.

\subsection{Sluice and Transfer}

Sluicing uses a water jet directed at the waste to dislodge/break up waste. The DST sluicing system is shown in Figure 2.2. The system comprises a sluicing pump, an adjustable sluicing nozzle, a slurry transfer pump, a slurry distributor, and the associated transfer lines. A closed-circuit TV (CCTV) system is used to identify how much waste is left in the tank and where to aim the sluicing nozzle.

The sluicing pump transfers supernate from the receiver DST to the sluicer nozzle in the retrieval tank. A booster pump may be required to provide the required flow. Supernate discharged from the nozzle can reach sludge almost anywhere in the tank. Some waste will be hidden behind in-tank hardware such as 


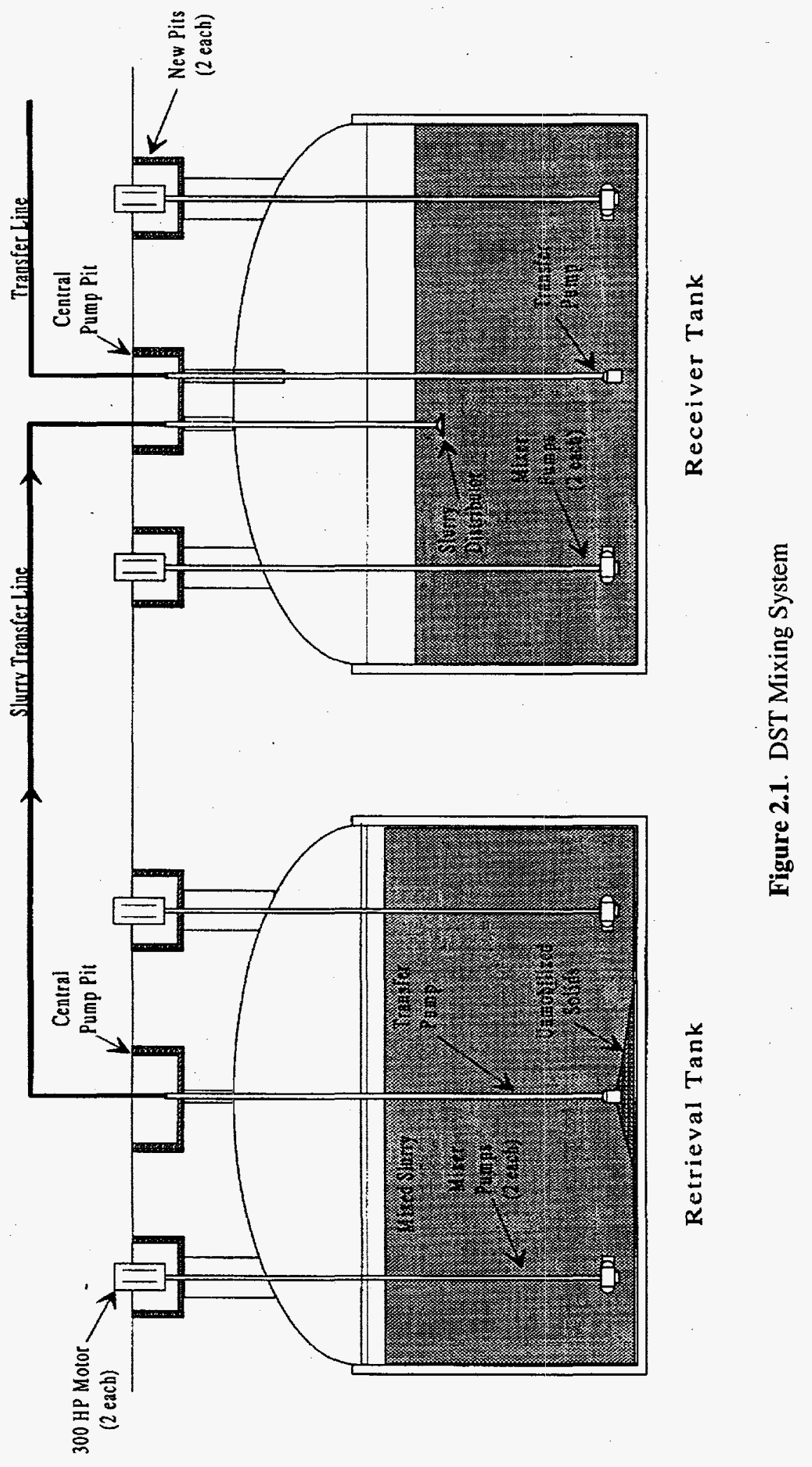




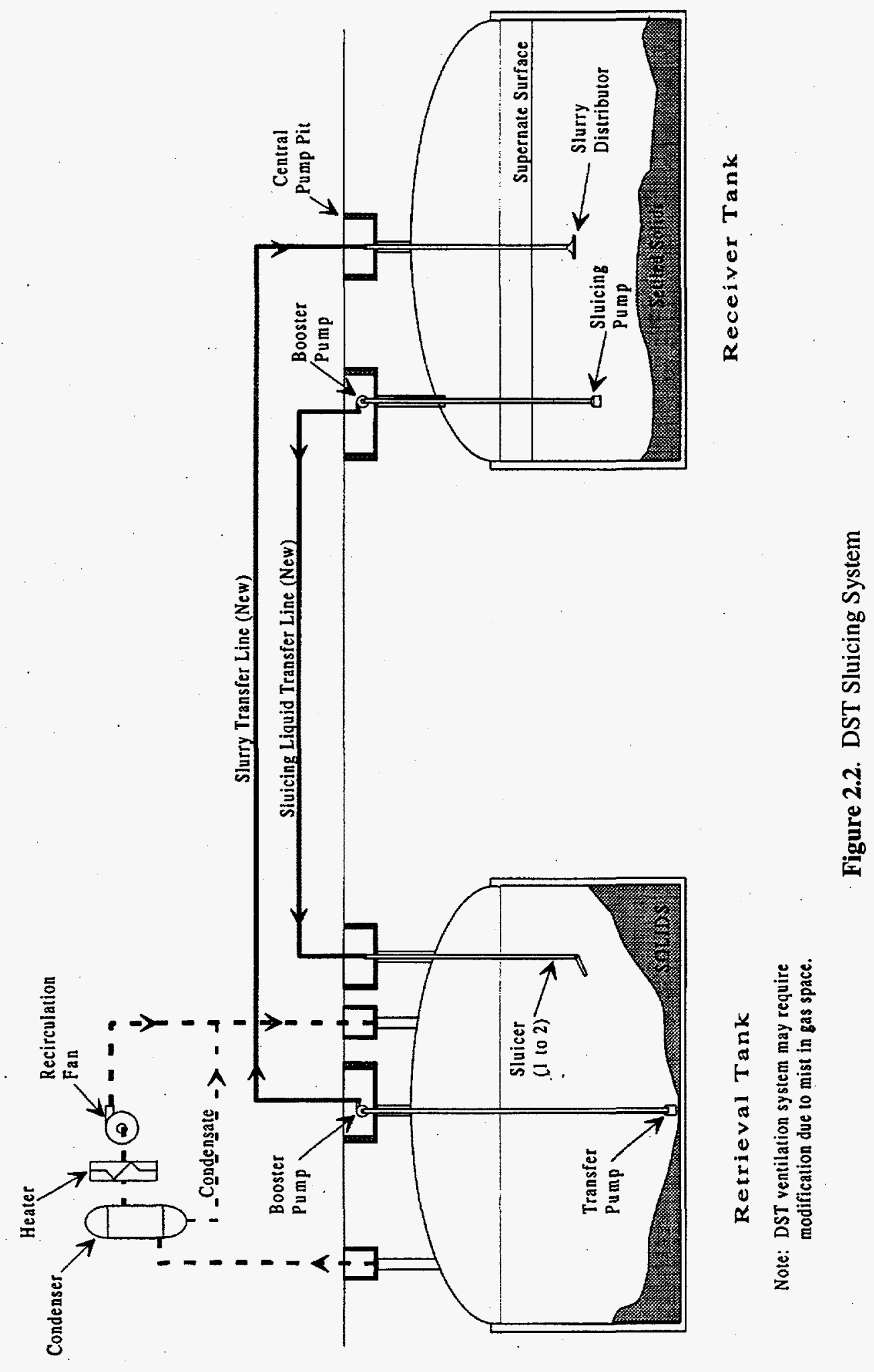


instrument trees and air-lift circulators. The need for a second sluicing nozzle and/or addition of articulation of the sluicing arm has not been assessed.

Before retrieval begins, the receiver DST is filled with sufficient chemically adjusted water or supernate to support the retrieval process. Liquid from the receiver is pumped into the retrieval tank through a sluicing nozzle, creating a slurry. This slurry is then transferred to the receiver DST where the solids will settle out. The clarified liquid is then pumped back to the retrieval tank to continue the process.

The process will continue until retrieval of the tank is complete or the receiver DST is full. Retrieval of the next tank is assumed to begin almost immediately after the first tank is completed. When the receiver is full, retrieval will stop. Mixer pumps will be used to create a homogeneous slurry in the receiver DST. Much of the soluble waste, not previously dissolved, will be dissolved during mixer pump operation. After characterization, the waste will be transferred to another DST for interim storage or to a staging tank at the processing facility. Chemically adjusted water or supernate will be added to the receiver DST and the retrieval process will be resumed.

\subsection{Mechanical Retrieval - Truck or Rail Car}

A schematic of this alternative is shown in Figure 2.3. A typical mechanical retrieval system uses either an articulated arm or a remotely controlled vehicle to move mobilization tools (e.g., a hydraulic scarifier) inside the tank to dislodge/break up sludge and remove it from the tank. It is assumed that supernate will be pumped out of the tank before mechanical retrieval is initiated. Waste will be removed from the tank pneumatically or hydraulically. Operators will use a CCTV system to help control arm or vehicle movement.

A pneumatic system will vacuum waste out of the tank to a cyclone separator or a similar device in the loading station to separate suspended solids and liquids from the gas. The gas will be returned to the tank. Solids and liquids will be removed from the separator by a rotary valve and dumped into a 1000 - to 5000 -gal tank on a truck or rail car for transport to the receiver DST. The rotary valve avoids drawing a high vacuum in the receiver DST.

The truck or rail car moves the waste to an unloading station at the receiver DST. A commercial, sluicing system is used to transfer waste from the truck. A sluicing pump will transfer liquid from the receiver tank to the commercial sluicer. A slurry pump will move waste from the truck or rail car to the receiver. The commercial sluicer uses "random" motion to ensure the tank is cleaned out. A CCTV system is not required to monitor the process. The vehicle will be assumed to be empty when the transfer of solids stops.

Hydraulic removal differs in that waste will be diluted while in the retrieval tank and then pumped out of the tank to the truck or rail car. A water jet going through an eductor will create a vacuum to pick up the waste, which will then mix with the water and be pumped into the truck or rail car for transport to the receiver tank. Solids are assumed to settle during transport. These solids will be mobilized by mixers to form a slurry that will then be pumped out of the truck or rail car. 


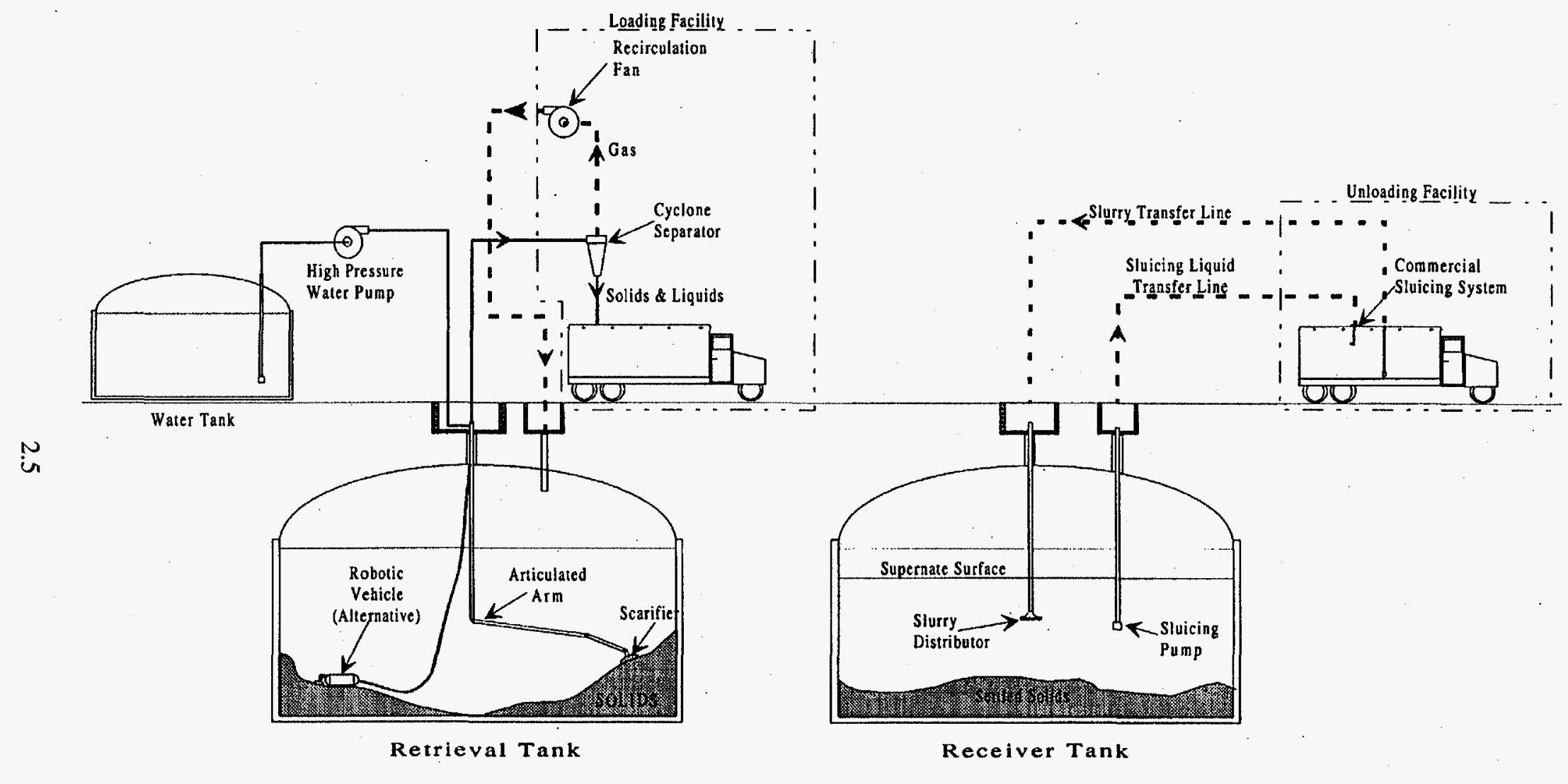

LOADING PROCESS

UNLOADING PROCESS

Figure 2.3. DST Mechanical Retrieval System with Truck Transfer 


\subsection{Mechanical Retrieval - Pipeline Transfer}

A. DST mechanical retrieval system is shown in Figure 2.4. The in-tank portion of this system is identical to that used for mechanical retrieval/truck. Use of this process is also based on the assumption that supernate will be pumped out of the tank before mechanical retrieval begins and that waste will be removed from the tank either pneumatically or hydraulically.

A pneumatic system vacuums waste out of the tank to a cyclone separator or a similar device at the receiver DST, where suspended solids and liquids are separated from the gas. The gas is returned to the retrieval tank. Solids and liquids are removed from the separator by a rotary valve and dumped into the receiver. The rotary valve limits the vacuum drawn in the receiver DST.

Hydraulic removal differs in that waste is diluted while in the retrieval tank and then pumped out of the tank. A water jet going through an eductor will create a vacuum to pick the waste up. The waste is then rnixed with the water and pumped into the truck or rail car. The rate at which the waste is removed is not sufficient to keep solids suspended in the transfer lines. Therefore, waste is pumped into a recirculating loop of clarified liquid that will keep the solids suspended during transfer to the receiver tank.

\subsection{Chemical Dissolution}

Chemical dissolution uses aggressive acids to dissolve the sludge. This system is shown in Figure 2.5. A small mixer pump or other stirring device is used to accelerate dissolution, but does not provide submerged jets sufficient to break up or dislodge the waste. Acid prepared in a portable tank or vehicle attacks the carbon steel tank walls, making it necessary to dissolve and remove the waste quickly. Neutralization of residual acid in the heel left in the tank and on the tank walls and in-tank components will be required after the waste is removed.

In-line neutralization is required to satisfy transfer and interim storage requirements. Caustic is prepared in a portable tank or vehicle before being mixed with the acidified waste. Sludges, which are not soluble in caustic, will precipitate during neutralization. Therefore, waste rates must be sufficient to keep the sludge precipitate suspended until it reaches the interim storage tank. New stainless steel lines would be required to allow the waste to be transferred to the processing facility without neutralization.

\subsection{Combinations and Enhancements}

The systems described above are the basic processes for retrieving DST sludges. These systems could, however, be enhanced by combining the systems or by adding equipment. Dissolution could be added to retrieve wastes that could not be retrieved by mixer pumps or sluicing alone. Because of the additional costs associated with combining systems, such combinations will be employed on a tank-by-tank basis when a need for extensive cleanout is required (e.g., terminal cleanout). 


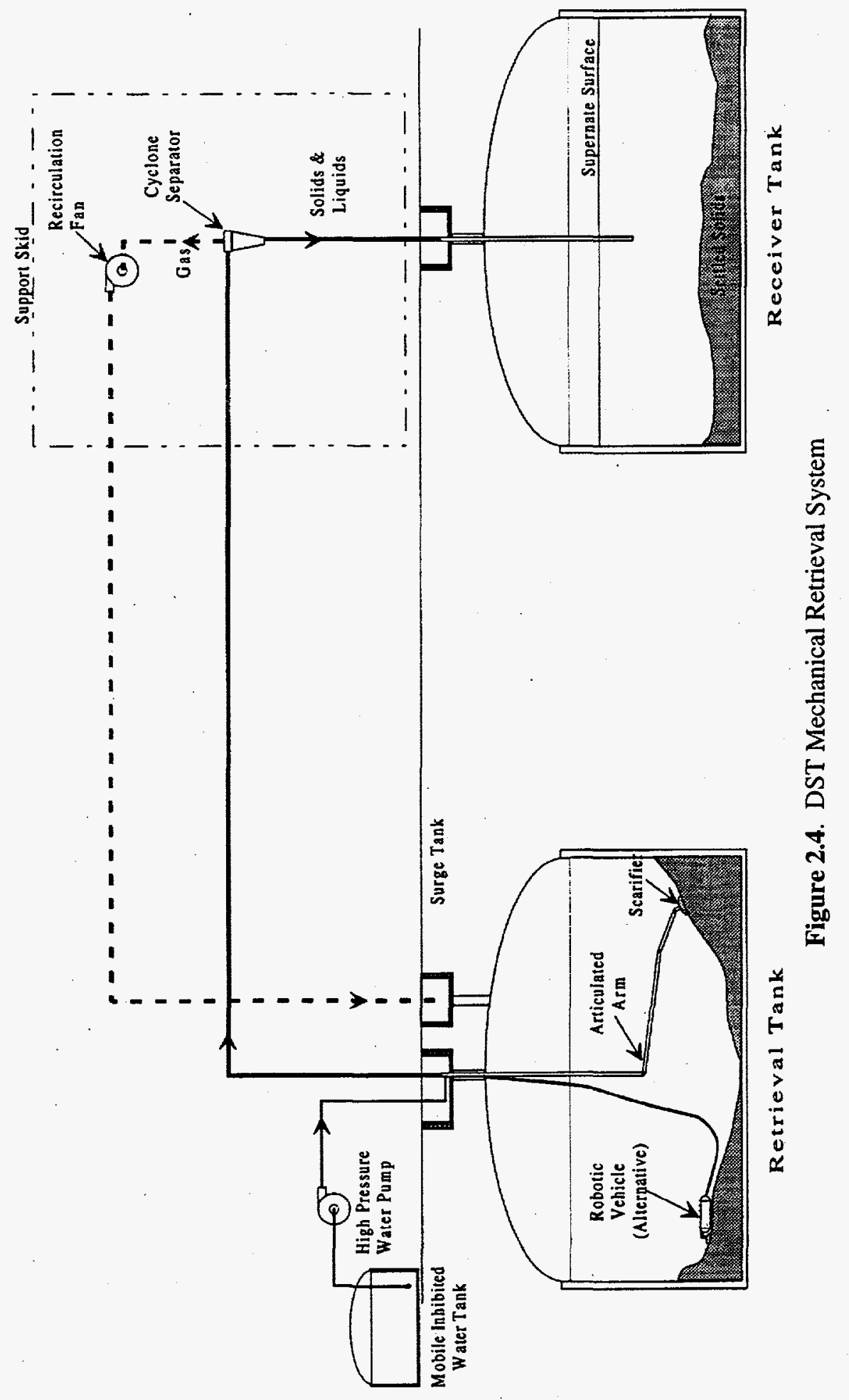




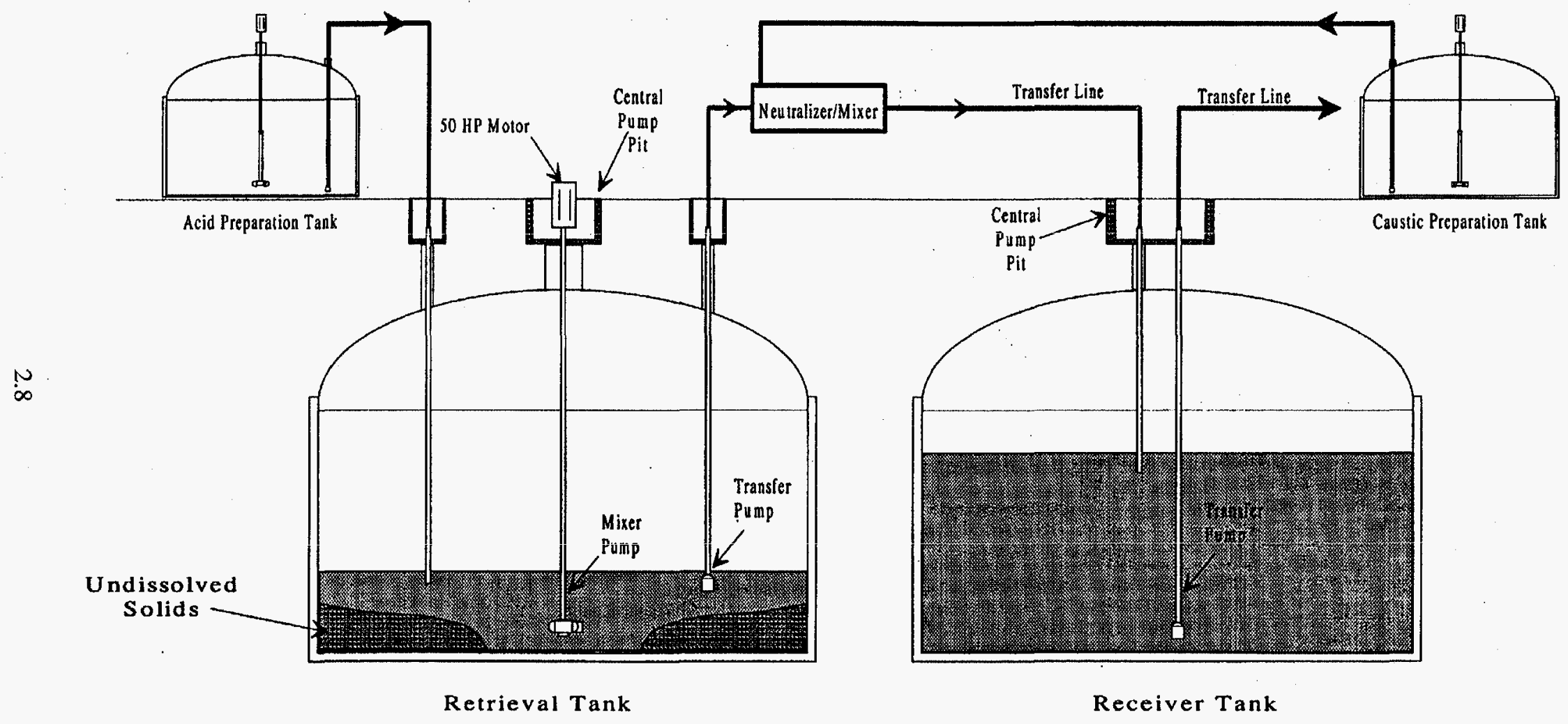

Figure 2.5. DST Retrieval Dissolution System 
One process enhancement that has been identified is the addition of a sonic probe to mixer pumps to reduce the waste shear strength. The shear strength reduction increases the effective cleaning radius of the mixer pumps, allowing additional waste to be mobilized. It is assumed that the sonic probe is used only for initial mobilization of the waste and is not be needed to remobilize the solids. 


\subsection{Multiattribute Tradeoff Analysis}

This section describes a multiattribute value analysis of technical alternatives for DST sludge mobilization and retrieval. Decision criteria and specific performance measures were identified, and an engineering analysis was carried out to determine the expected performance of the alternatives on these measures. None of the alternatives is best on all the criteria; consequently, an analysis of the tradeoffs among the criteria is also presented.

The tradeoff analysis reveals that the important criteria for this decision are cost and retrieval effectiveness. Retrieval effectiveness is primarily important because of its potential to impact cost. An analysis that considers cost from various perspectives is presented.

\subsection{Criteria Considered}

The decision criteria capture the expected outcomes that are considered important in the evaluation of alternatives. The criteria considered in this analysis are a combination of generic criteria that were developed for Tank Waste Remediation System (TWRS) and criteria that were deemed to be important considerations for this specific TWRS analysis. Generic criteria for TWRS were identified by Keeney and von Winterfeldt (1996) for the purpose of developing a consistent, quantifiable set of measures that could be used to assess alternatives against stakeholder values. These generic criteria should be considered for all significant TWRS decisions. Additional criteria capture impacts that are important considerations for this particular decision context.

The criteria used in this analysis are shown in Figure 3.1 The criteria and specific measures used in this analysis evolved through several iterations that originated at Pacific Northwest National Laboratory (PNNL), were modified as a result of several informal workshops with Numatec Engineers, and were slightly modified during the data collection process to accommodate the realities of available data. The following criteria were considered in this analysis:

- Worker health and safety-measured in total worker rems and lost worker hours

- Public heath and safety-measured by rems/year

- Environmental impact-measured by potential for leaks, air emissions and secondary waste

- Retrieval effectiveness - measured by the quantity retrieved for a generic 1-million gal tank containing $2 \mathrm{ft}$ of compact sludge. In addition, a risk analysis was carried out to evaluate the likelihood that the quantity retrieved will meet minimum requirements for the HLW vitrification demonstration plant. 


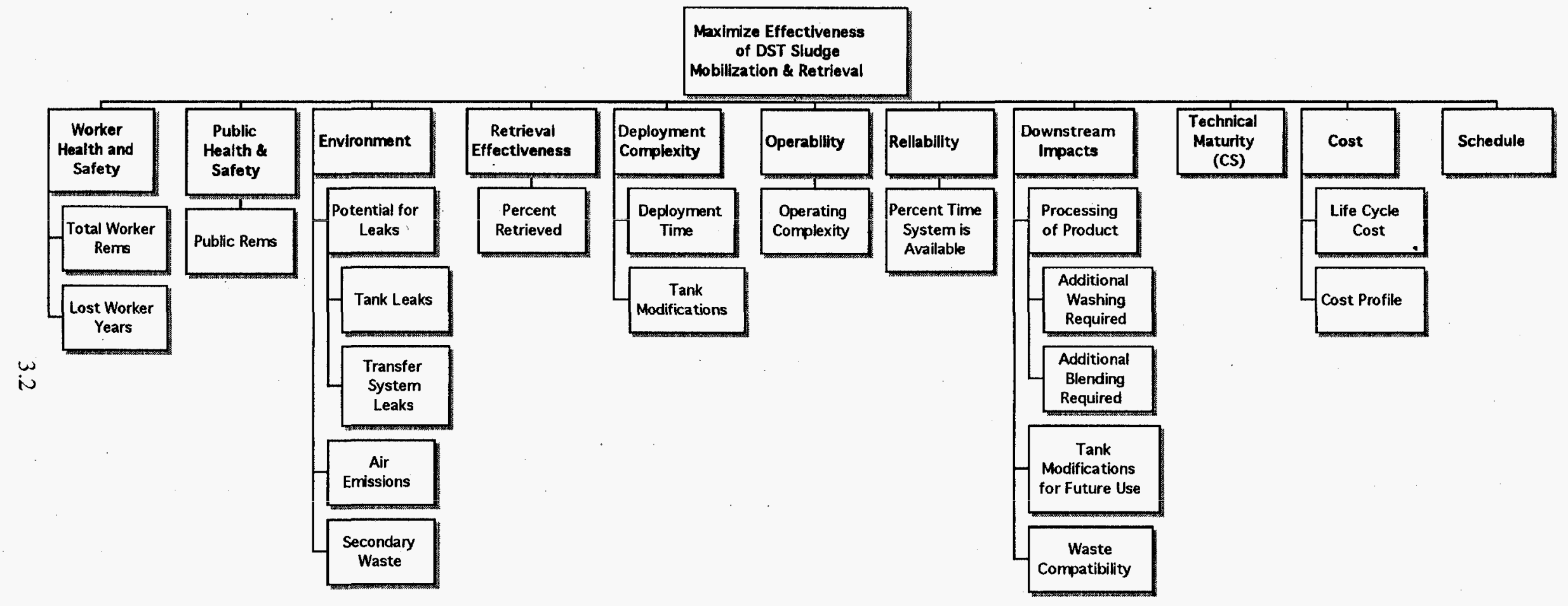

Figure 3.1. Criteria and Measures Considered in the Decision Analysis 
- Deployment complexity-measured by deployment time in years and actions required to prevent potential damage to internal tank hardware

- Operability-measured by complexity in terms of the number of people and/or controls necessary to operate

- Reliability-measured by the operating efficiency (i.e., percent time the entire system including the transfer line is available)

- Technical maturity-important for reliability which is being measured directly with a risk analysis

- Downstream impacts-measured by the extent of additional washing required, the extent of additional blending required measured by number of samples required, modification of hardware/risers necessary to support future uses, and the ability to receive other waste on top of the waste heel

- Life-cycle cost-(includes design, construction, and operating costs) measured in 1996 dollars and cost profile

- Schedule-measured by the time required to deploy the retrieval system, retrieval time necessary to supply feed to the HLW vitrification demonstration plant, and the risk of failing to meet minimum order quantities on time.

\subsection{Basis for Scores in Alternative/Criteria Matrix}

The scores of the alternatives on these criteria are shown in Table 3.1. The data were generated as a result of detailed engineering analysis, which fell into the broad categories of ES\&H analysis, and retrieval operations. The later included costs, reliability, and retrieval effectiveness and is based upon a generic DST that contains $2 \mathrm{ft}$ of sludge to be mobilized and retrieved.

The ES\&H analysis focused on worker health and safety, public health and safety, and environmental impacts. Worker rems were calculated by determining the activities associated with the technology and applying referenced dose levels for each activity. These radiological exposure levels were then summed for all the activities. Similarly, worker accidents, which include workdays lost from construction and normal operations, were calculated by determining the activities associated with each technology and applying nationally referenced accident rates to estimate the lost work days associated with each activity. Public dose in rems is the offsite dose to the public, calculated from likelihoods and consequences for dominate representative accidents. The potential for tank leaks is derived from a probability measure based on operating scenarios; for all alternatives, the probability of a leak is very unlikely (range $10^{-4}$ to $10^{-6}$ ). Leaks from the transfer system is the total risk in rems determined by multiplying the probability of the leak by the onsite exposure for each leak source and summing them. 
Table 3.1. Alternatives by Criteria Score Matrix

\begin{tabular}{|c|c|c|c|c|}
\hline $\begin{array}{c}\text { GOAL: MAXIMIZE COST EFFECTIVENESS OF INITIAL } \\
\text { DST RETRIEVAL OF SLUDGES }\end{array}$ & $\begin{array}{l}\text { 응 } \\
\text { 음 } \\
\text { 을 } \\
\text { 음 }\end{array}$ & 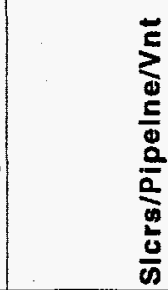 & 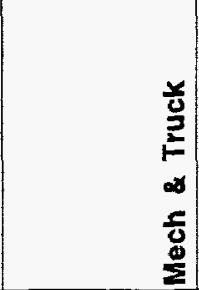 & 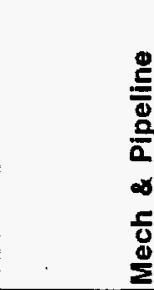 \\
\hline & ENDS & & & \\
\hline \multicolumn{5}{|l|}{ 1) Worker Health \& Safety } \\
\hline A) Total Worker Rems (Constr \% Oper) & 16.2 & 11.6 & 9 & 8.4 \\
\hline 3) Accidents (Lost wrkr days--constr\&oper) & 5.15 & 5.24 & 3.7 & 4.54 \\
\hline \multicolumn{5}{|l|}{ 2) Public Health \& Safety } \\
\hline Public dose (Rems) & 1.92 & 11.52 & 11.20 & 0.208 \\
\hline \multicolumn{5}{|l|}{ 3) Environment } \\
\hline A) Potential for leaks from tanks (CS) & 75 & 75 & 75 & 75 \\
\hline B) Leaks from transfer system (Rems) & $1.20 E-03$ & $7.20 E-03$ & $7.00 E-03$ & $1.20 \mathrm{E}-04$ \\
\hline C) Air Emissions (Ratio of vapor concent. in dome) & 1 & 30 & 30 & 30 \\
\hline \multicolumn{5}{|l|}{ 4) Retrieval Effectiveness } \\
\hline A) Retrieval \%(quantity: see assumptions) & 50 & 99 & 99 & 99 \\
\hline \multicolumn{5}{|l|}{ 5) Schedule } \\
\hline Duration in Days & 78 & 80 & 107 & 92 \\
\hline Deployment Time in Years & 3.5 & 3.5 & 4.5 & 3.5 \\
\hline \multicolumn{5}{|l|}{ (5) Cost } \\
\hline A) Total Life Cycle Costs 1997 dollars (millions) & 24.4 & 32.5 & 58.2 & 36.2 \\
\hline \multicolumn{5}{|l|}{ MEANS OBJECTNES } \\
\hline \multicolumn{5}{|l|}{ 7) Deployment Complexity } \\
\hline B) Actions Required to prevent damaga to internal & 4 & 4 & 4 & 4 \\
\hline \multicolumn{5}{|l|}{ B) Operability } \\
\hline \multicolumn{5}{|l|}{ A) Complexity: number of people and controls needed } \\
\hline operators & 3 & 3 & 4 & 3 \\
\hline engineers & 1 & 1 & 1 & 1 \\
\hline \multicolumn{5}{|l|}{ 9) Reliability } \\
\hline A) Operating Efficiency (\% time system available) & 0.67 & 0.61 & 0.70 & 0.66 \\
\hline \multicolumn{5}{|l|}{ 10) Downstream Impacts } \\
\hline \multicolumn{5}{|l|}{ A) Processing of Product } \\
\hline A1) Extent of addl Washing Required (CS) & No & Yes & Yes & Yes \\
\hline A2) Extent of Addl Blending Required (\# of smpls) & 2 & $5+$ & $5+$ & $5+$ \\
\hline \multicolumn{5}{|l|}{ B) Future use of Tank } \\
\hline 131) Modifications of hardware/risers necessary to & No & Yes & Yes & Yes \\
\hline 132) Waste compatability (CS) & No & Yes & Yes & Yes \\
\hline 11) Technical Maturity (CS) & 100 & 100 & 70 & 70 \\
\hline
\end{tabular}

Air emissions are assumed to be proportional to the radionuclide concentration in the dome space and the duration of the activity. Mixing releases fewer radionuclides into the dome space and has a shorter duration. The amount of secondary waste was judged not to be significant and difficult to measure and was therefore not used in the analysis. 
Retrieval effectiveness is expected to be $99 \%$ for all alternatives except mixer pumps, which were expected to retrieve $50 \%$ of the waste for an average DST. The retrieval effectiveness of mixer pumps is based upon work by Grams (1995), which provided empirical data showing the relationship between the shear strength and percentage of sludge mobilized. The data were fitted with an equation that captures this relationship. Grams also gives the distribution of sludge shear strength in the 28 DSTs. The median shear strength of sludges in DSTs was used in the analysis. A more in-depth discussion of shear strength and retrieval effectiveness can be found in Section 6.0.

The cost shown in Table 3.1 is based upon a generic tank with $2 \mathrm{ft}$ of sludge to be mobilized. The costs include both the capital costs and the operating cost. The capital cost is the cost of the system hardware and the modifications to the tanks and tank farm that are necessary to make the system operable. The operating costs are based upon a detailed analysis of the number of personnel required and the durations and costs of each type of operation. A detailed cost analysis for the generic tank case with $2 \mathrm{ft}$ of sludge is provided in Section 4.0. Section 5.0 presents the costs for the alternative systems to mobilize and retrieve sludges from the four source tanks for HLW feed in Phase I of privatization.

Schedule durations are based upon the same detailed analysis used to develop the cost data.

Deployment complexity and operability were also based upon an operational analysis.

\subsection{Means Versus Ends Objectives}

The criteria considered in this analysis consist of both ends and means objectives. Both are important when we evaluate the alternatives. Ends objectives are the objectives of primary concern. They represent values that are fundamentally important in their own right. The scores for the means objectives, on the other hand, are primarily important only to the extent that they impact the ends objectives. The relationship between the means and ends objectives for this analysis is shown graphically in Figure 3.2. For example, the extent of additional washing required (a means objective) is important because of its impacts on cost and schedule. Technical maturity (a means objective) is important because of its impact on reliability (also a means objective), which is important because of its impact on cost and schedule (ends objectives).

None of the alternatives scored best on all the criteria. Consequently, the "best" alternative will depend on the relative importance assigned to the criteria. Also, the scores on the means objectives should be considered in light of their potential to impact the ends objectives. The scores for both means and ends objectives are shown in Table 3.1; however, only the ends objectives were rolled-up in subsequent analysis to get an overall score. Also, the scores for the ends objectives include the impact that the means objectives has on them. In some cases, these impacts were considered when the scores were originally calculated for an alternative. For example, cost, as originally calculated, included the impact of operating complexity, which was measured by the number of operators. On the other hand, the extent of additional washing required for an alternative was added to the cost of an alternative, the amount added depending on the number of additional washes required and the cost per wash. 
Means Objectives

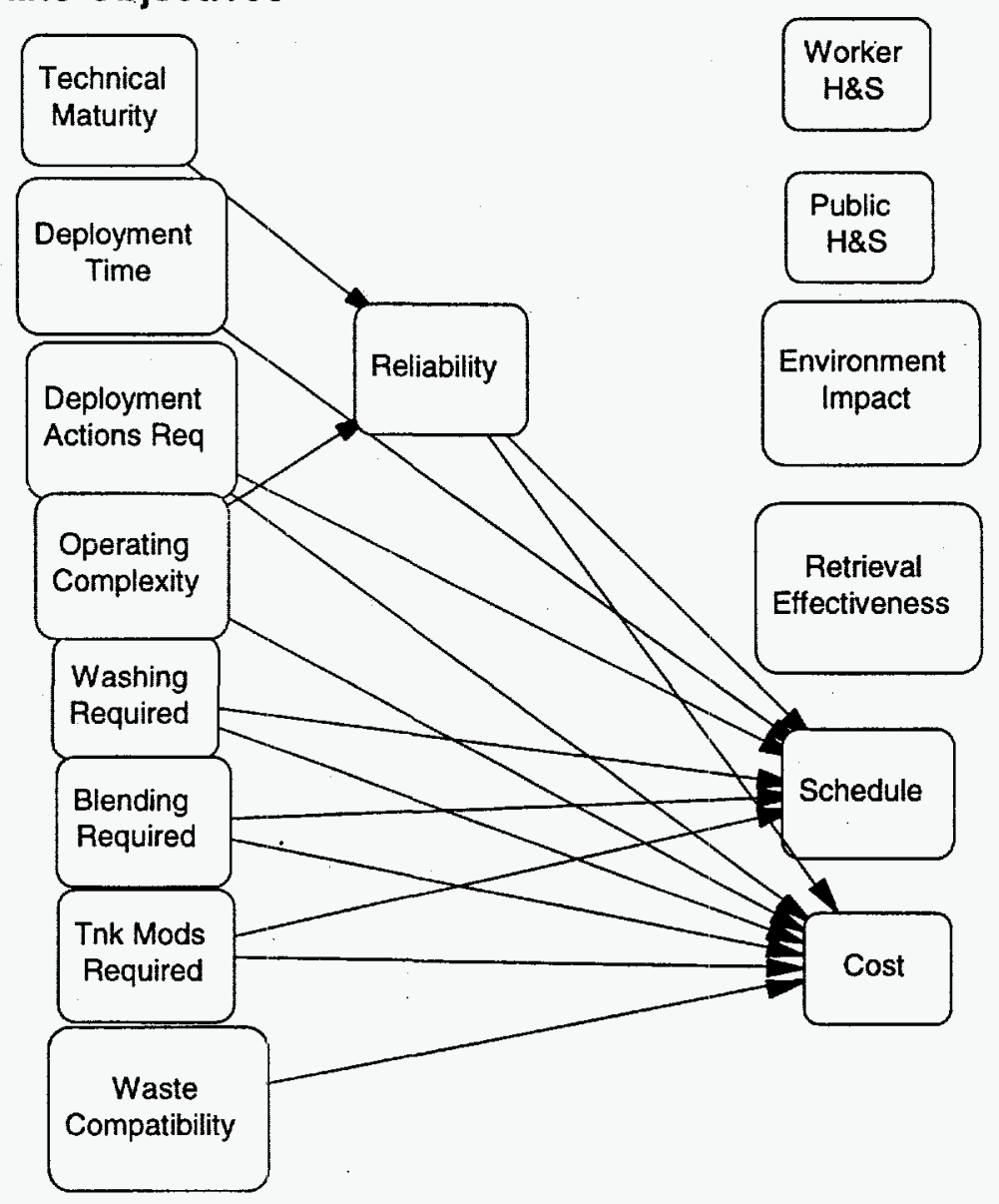

Figure 3.2. Means and Ends Objectives for DST Sludge Mobilization Decision

\subsection{Performance of Alternatives on Criteria}

The scores shown in Table 3.1 are in their natural units. For some of these units, such as operating efficiency, bigger numbers are better; in other cases, such as cost or rems, smaller numbers are better. To facilitate comparison, these numbers have been normalized onto a 0 to 1 scale in which 1 is the best for any alternative and 0 is the worst. These are presented in Table 3.2 and portrayed graphically in Figure 3.3. Normalizing the scores makes it easier to compare alternatives and provides a common metric so that the scores can be rolled up into a single overall score or weighted average. A score of zero does not mean that the alternative score is unacceptably poor on that criteria-just that it scored the lowest.

Only the normalized scores for the ends objectives are shown. As can be seen from either the table or the figure, none of the alternatives dominates the others; i.e., no alternative scores the best on all the criteria. Consider mixer pumps. Mixer pumps score the best on cost and the worst on retrieval effectiveness. The mixer pumps alternative is nearly $\$ 8$ million dollars cheaper than any other alternative; 
Table 3.2. Performance of Alternatives on Criteria - Normalized Scores

\begin{tabular}{|l|l|l|l|l|}
\hline \multicolumn{1}{|c|}{ GOAL: MAXIMIZE COST EFFECTIVENESS OF INITIAL } & MxrPump & SIcrs & Mech/Truck & Mech/Pipe \\
\hline \multicolumn{1}{|c|}{ END OBJECTIVES } & & & & \\
\hline 1) Worker Health \& Safety & & & & \\
\hline A) Total Worker Rems (Constr \% Oper) & 0.00 & 0.59 & 0.92 & 1.00 \\
\hline B) Accidents (Lost wrkr days--constr\&oper) & 0.06 & 0.00 & 1.00 & 0.45 \\
\hline 2) Public Health \& Safety & & & & \\
\hline Public dose (Rems) & 0.85 & 0.00 & 0.03 & 1.00 \\
\hline 3) Environment & & & & \\
\hline A) Potential for leaks from tanks (CS) & 0.75 & 0.75 & 0.75 & 0.75 \\
\hline B) Leaks from transfer system (Rems) & 0.85 & 0.00 & 0.03 & 1.00 \\
\hline C) Air Emissions (Ratio of vapor concent. in dome) & 1.00 & 0.00 & 0.00 & 0.00 \\
\hline 4) Retrieval Effectiveness & & & & \\
\hline A) Retrieval \%(quantity: see assumptions) & 0.00 & 1.00 & 1.00 & 1.00 \\
\hline 5) Schedule (Duration in days) & & & & \\
\hline Duration in Days & 1.00 & 0.93 & 0.00 & 0.52 \\
\hline Deployment Time in Years & 1.00 & 1.00 & 0.00 & 1.00 \\
\hline 6) Cost & & & & \\
\hline A) Total Life Cycle Costs in 1997 dollars & 1.00 & 0.76 & 0.00 & 0.65 \\
\hline
\end{tabular}

however, it mobilizes only half the waste for a typical tank. This alternative scores well on some of the criteria and poorly on others. For example, mixer pumps score at the bottom for worker health and safety. However, the differences are probably too small to be of concern, and the scores are still well within acceptable health and safety limits.

Because there is no dominant alternative, the selection of an alternative will require that tradeoffs be made concerning the relative importance of the criteria. In particular, the tradeoff between retrieval effectiveness and cost is of primary concern; as for cost, there are a variety of ways of perceiving it. To better evaluate the tradeoffs among the criteria, a formal process was used to assign weights and calculate an overall score for each of the alternatives.

\subsection{Value Tradeoffs}

To capture the relative importance of each criteria and to arrive at an overall score for each of the alternatives, weights were assigned to each of the ends objectives (see Table 3.3). Weights were assigned to the ends objectives only. Including means objectives into an overall score would, in effect, be doublecounting because scores for the ends objectives already reflect the impact of the means objectives.

The weights were obtained by "pricing out" the ranges over which the alternatives varied and then normalizing the prices so that they summed to one. Table 3.3 shows for each of the criteria the best and worst an alternative could score. Also shown for each criteria are the weight basis, the price, and the normalized weight. Pricing out a criteria consists of estimating how much it would be worth to improve an alternative from its worst possibility to its best possibility. For example, the weight basis used for worker rems is $\$ 3600 / \mathrm{rem}$; the range from worst to best is 7.8 rems. Thus, the price for this criteria is $\$ 28,080$ - the weight before it is normalized. 


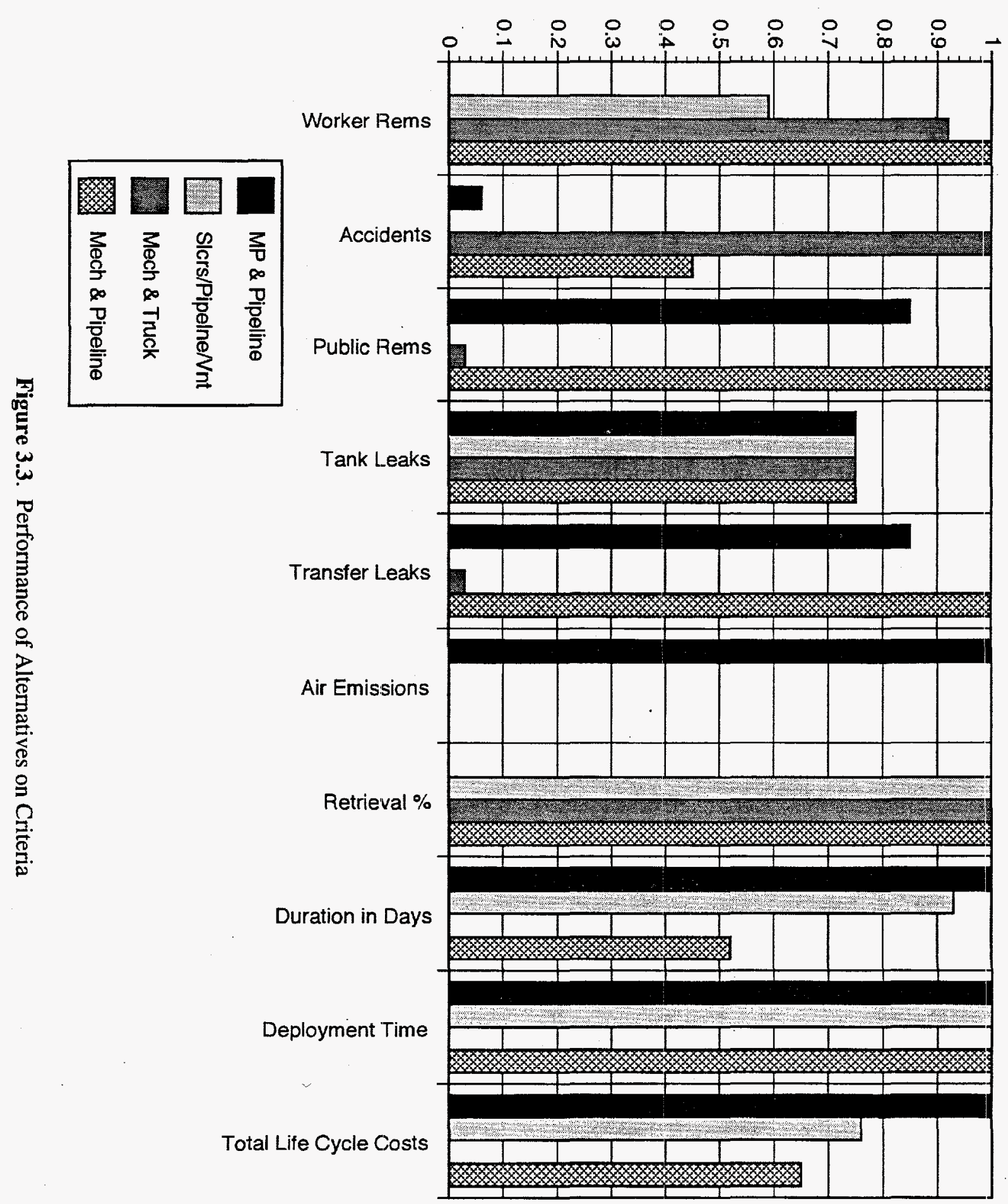


Table 3.3. Weights Used in the Multiattribute Analysis

\begin{tabular}{|c|c|c|c|c|c|c|}
\hline $\begin{array}{c}\text { GOAL: MAXIMIZE COST EFFECTIVENESS OF INITIAL } \\
\text { DST RETRIEVAL OF SLUDGES }\end{array}$ & Best & Worst & Weight basis & Price & 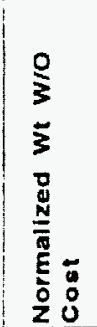 & 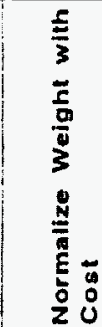 \\
\hline \multicolumn{7}{|l|}{ ENDS OBJECTIVES } \\
\hline \multicolumn{7}{|l|}{ 1) Worker Health \& Safety } \\
\hline A) Total Worker Rems (Constr \% Oper) & 8.4 & 16.2 & $\$ 3600 /$ Rem & 28,080 & 0.06 & BE.04 \\
\hline (8) Accidents (Lost wrkr days--constr\&oper) & 3.7 & 5.24 & $\$ 300 / d a y$ & 462 & 0.00 & $1 E-05$ \\
\hline \multicolumn{7}{|l|}{ 2) Public Health \& Safely } \\
\hline Public dose (Rems) & 0.208 & 11.52 & $\$ 12.600 / \mathrm{Rem}$ & 142,531 & 0.31 & $4 E \cdot 03$ \\
\hline \multicolumn{7}{|l|}{ 3) Environment } \\
\hline A) Potential for leaks from tanks (CS) & 75 & 75 & No Diflerence & 0 & 0.00 & 0.00 \\
\hline B) Leaks from transfer system (Rems) & $1.20 \mathrm{E} \cdot 03$ & $7.20 E-03$ & $\$ 12600 /$ Rem & 76 & 0.00 & $2 E-06$ \\
\hline C) Air Emissions (Aatio of vapor concent. in dome) & 1 & 30 & Vent. sys. upgrade & 60,000 & 0.13 & $2 E \cdot 03$ \\
\hline \multicolumn{7}{|l|}{ (4) Retrieval Effoctivenass } \\
\hline A) Retrieval \%(quantity: see assumptions) & 99 & 50 & See Note 1 & 203,000 & 0.44 & 0.006 \\
\hline 5) Schedule & & & & 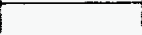 & 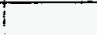 & \\
\hline Duration in Days & 78 & 107 & 1 K/daySee Note2 & 29,000 & 0.06 & 0.001 \\
\hline \multicolumn{7}{|l|}{ Deployment Time in Years } \\
\hline \multicolumn{7}{|l|}{ 6) Cost } \\
\hline \multirow[t]{2}{*}{ A) Total Life Cycle Costs in 1997 dollars } & 24.4 & 58.2 & & $33,800,000$ & & 0.986 \\
\hline & & & & & & \\
\hline \multicolumn{7}{|c|}{ Note 1: Retrieval priced out on basis of operating cost for sluicing $1 \mathrm{ft}$ of sludge. } \\
\hline Note 2: Priced out at $1 \mathrm{~K}$ day value over and above op & eratine costs & & & & & \\
\hline
\end{tabular}

The normalized weight is the proportion of the total price across all of the weights. Normalized weights are shown both with and without cost included among the criteria. For the most part, the prices were obtained using guidance from Keeney and von Winterfeldt (1996). For that study, the authors interviewed nationally recognized experts on stakeholder values and decision making to obtain unit prices for measures that would be relevant to TWRS decisions.

The price basis for all the ES\&H, with the exception of air emissions, came from Keeney and von Winterfeldt (1996). The scale for air emissions is a proxy scale for exposure. The potential impact from air emission is thought to be minimal and was priced out accordingly. The price shown is the cost of ventilation system upgrades. This was further explored with sensitivity analysis as described below.

Retrieval effectiveness was priced-out based upon the cost of sluicing the additional $1 \mathrm{ft}$ of sludge that would remain in the generic tank if mixer pumps were used to mobilize the sludge. Under the most likely scenario, sluicers will be required in any case for ultimate cleanout for closure. Consequently, the capital cost of installing the sluicers would be incurred in any case, and the only difference would be the extra operating time to sluice the $1 \mathrm{ft}$ of sludge that the mixer pumps did not remove.

None of the schedule differences was thought to affect milestones if the private vendor has sufficient lag storage. While difficult to judge for a generic tank, in the Phase I analysis, there is enough slack time 
to accommodate the schedule differences among the alternatives. Duration was priced out at $\$ 1 \mathrm{~K}$ per day. This amount is over and above the operating cost of $\$ 5 \mathrm{~K}$ per day. This was also further explored with sensitivity analysis and is described below.

As can be seen in Table 3.3, the weights exclusive of cost are dominated by retrieval effectiveness, followed by public dose and air emissions. The only other criteria having significant weights are worker rems and duration. The impacts of all other criteria are so small their weights are essentially zero. When cost is included, it dominates all the other criteria, which are extremely small.

\subsection{Tradeoff Analysis Results}

An overall score for each alternative was calculated by multiplying the normalized scores shown in Table 3.2 by the weights, exclusive of cost, shown in Table 3.3. The results are shown in Figure 3.4 as a stacked bar graph. The length of the bars indicates the overall scores, and the individual segments show the contributions of the objectives. The possible range of scores is from 0 to 1 . For these weights, mechanical retrieval scores the best. The mixer pump scores last; its low score is primarily due to its poor score on retrieval effectiveness.

$\begin{array}{ll}\text { Alternative } & \text { Utility } \\ \text { MP \& Pipeline } & 0.454 \\ \text { Sluice/Pipe/Ventil. } & 0.532 \\ \text { Mech Retr. \& Truck } & 0.504 \\ \text { Mech Retr. \& Pipe } & 0.839\end{array}$

Utility

0.532

0.504

0.839

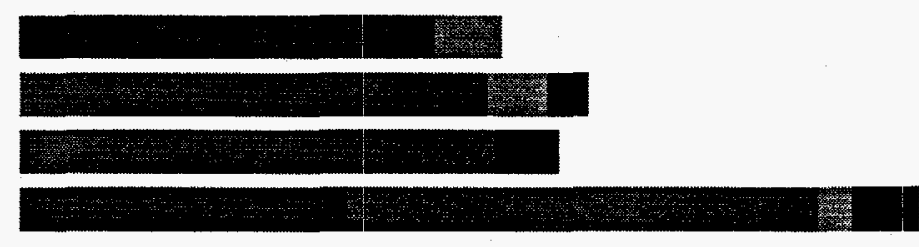

Environment
Schedule

PublicHealth/Safety ․ㅣㄹ Retrieval Effectiveness
WorkerHealth/Safety

Figure 3.4. Overall Scores Exclusive of Cost

Figure 3.5 shows the Total Cost and Overall Value for each alternative. While mixer pump has less value, its cost is also $\$ 12$ million less than mechanical retrieval. This result gives rise to the question whether mechanical retrieval or sluicing is worth the additional cost. As can also be seen in Figure 3.5, mechanical/truck is dominated by both sluicing and mechanical/pipeline; i.e., mechanical/truck provides slightly less value for more cost. The other three alternatives are on the Pareto frontier in that they involve tradeoffs of cost versus value, and no alternative dominates the other in that it provides more value for less cost. 


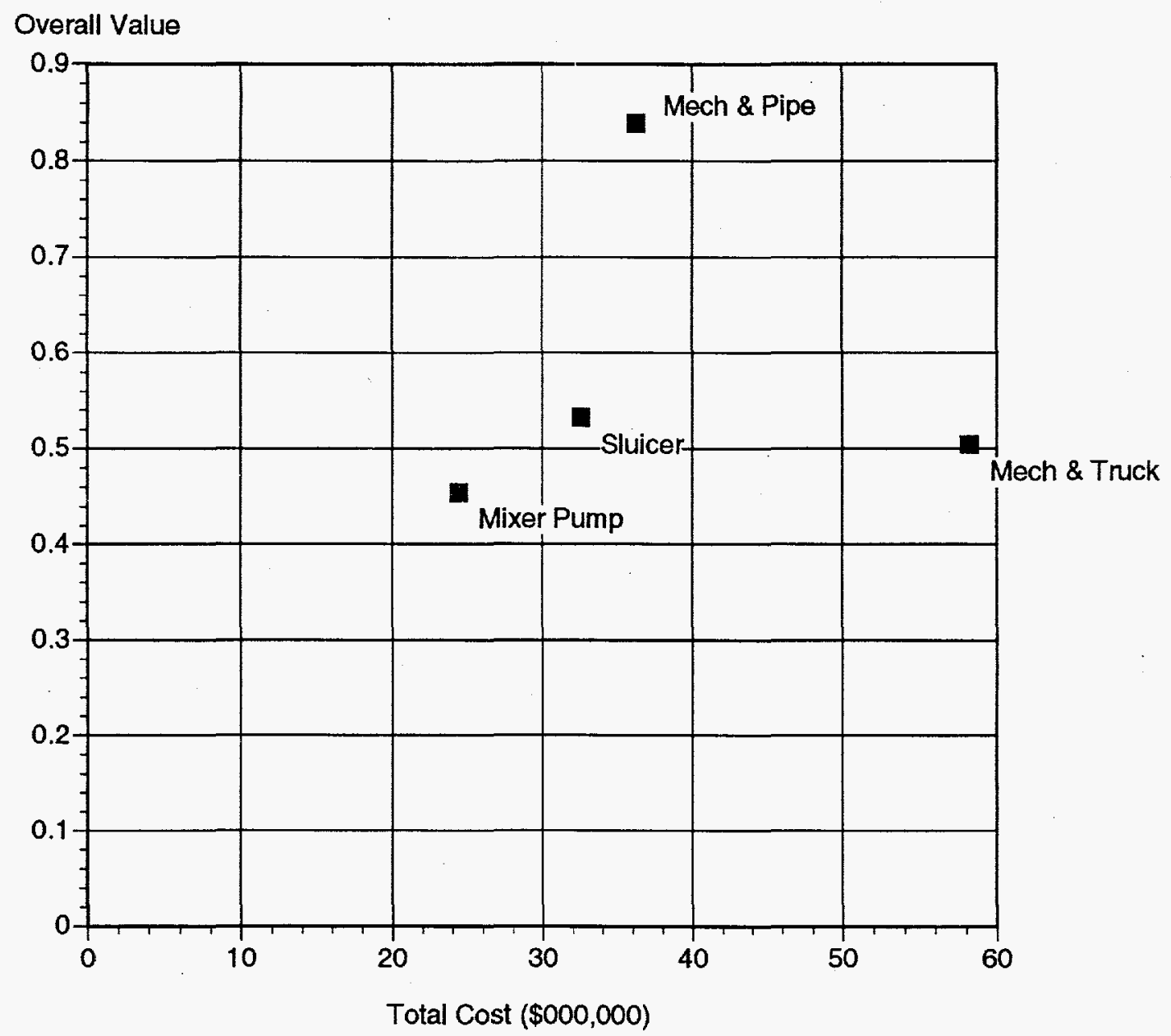

Figure 3.5. Value Versus Cost

Performance profiles for each of the alternatives are shown in Figure 3.6. Depicted graphically for each of the alternatives is the alternatives score on each of the criteria and the weight assigned to the criteria. The scores are represented by the heights of the bars and the weights by the bar widths. The weights are the same for all alternatives. (The order of the bars is such that retrieval effectiveness is leftmost and worker health safety is rightmost.) The scores are the zero to one normalized scores, where zero is the lowest any alternative scored and one is the best. Again, it should be emphasized that a zero score does not mean an unacceptable performance-just the lowest for the alternative considered. The overall score is the total area of all the bars. The performance profiles shown in Figure 3.6 depict graphically the basis for the scores shown in Figure 3.4. They provide insight as to how the overall scores were arrived at. As can be seen in the figure, mixer pumps' lowest overall score is the result of its scoring worst on retrieval effectiveness. Mixer pump received high scores on schedule, environment, and public health and safety. It scored least of the alternatives on worker health and safety. A comparison of sluicer with mechanical/pipeline shows that sluicer scores worse on public health and safety and on worker health and safety, but better on schedule. An earlier draft had sluicing close to mechanical in value. Sluicing came down in value as a 
Mixer Pump

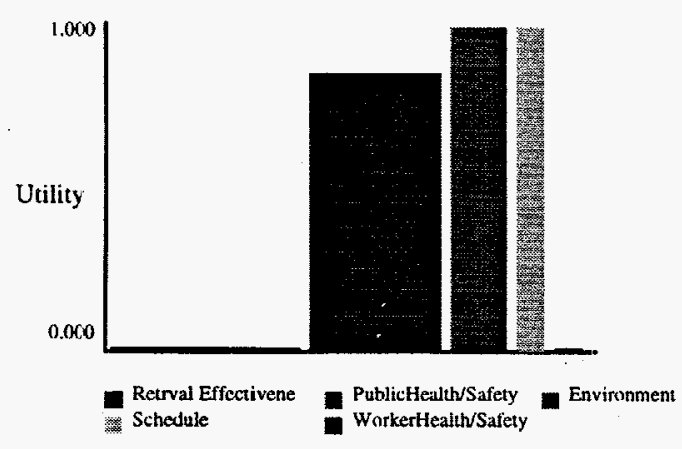

Mechanical and Pipeline

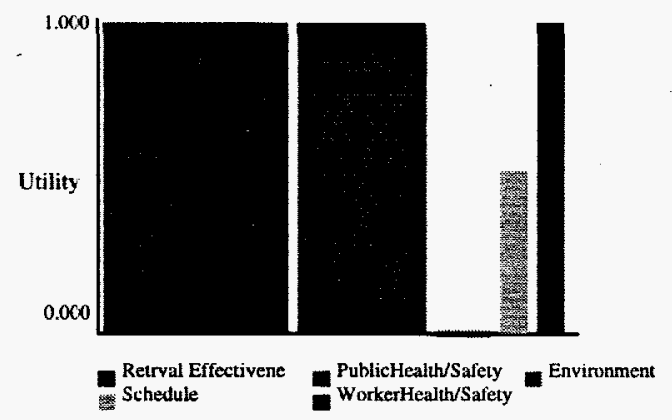

Sluicer

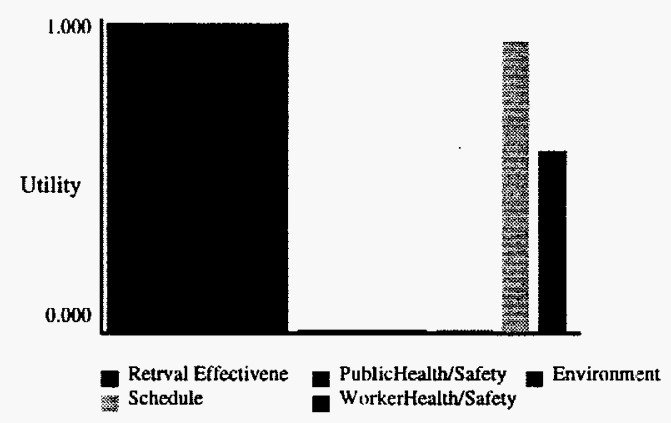

Mechanical and Truck

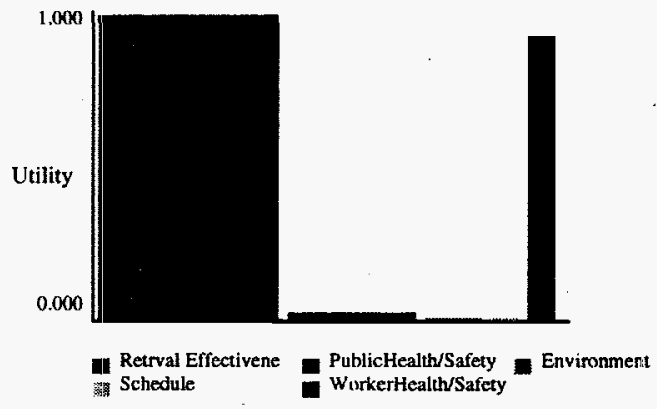

Figure 3.6. Performance Profiles for Sludge Mobilization Alternatives

result of more weight being put on public dose. (Maximally exposed individual was multiplied by 16,000 to get a population dose.) A comparison of mechanical and pipeline with mechanical and truck shows that mechanical and pipeline does better on public health and safety and on schedule and worker health and safety.

\subsection{Sensitivity Analysis on Weights}

A sensitivity analysis on the weights assigned to criteria was carried out for Retrieval Percentage, Air Emissions, Duration, and Public Dose. These three criteria were chosen for a sensitivity analysis either because they were a significant contributor to the overall score (Retrieval Percentage) or there was uncertainty concerning the basis for assigning their weights. The sensitivity analysis consists of looking at the change in the overall scores and the ranking of alternatives as the weight that is assigned to specific criteria is varied from 0 to 1 . The weights of the other criteria retain their prior proportions and are varied so that the total weight sums to 1.0 . 
The results of the sensitivity analysis are displayed in Figure 3.7. The results for retrieval effectiveness are shown in the upper left panel. The horizonal axis indicates the percentage weight assigned to retrieval percentage. The vertical axis is the overall score for the alternatives. The vertical line at $44 \%$ is the weight assigned to retrieval percentage in the original scoring. The lines for each alternative show how their scores vary with the changing weights. The lines for each alternative in the legend correspond to the rightmost side of the figure at $100 \%$ weight. The analysis shows that the weight on retrieval percentage would have to be reduced to approximately $8 \%$ before mixer pumps would be the highest scored alternative. Recall that the basis for the weight on retrieval percentage was the operating cost of sluicing $1 \mathrm{ft}$ of sludge- $\$ 203 \mathrm{~K}$. Thus $8 \%$ weight on retrieval percentage would correspond to a willingness to pay only $\$ 16 \mathrm{~K}$ per foot of sludge.
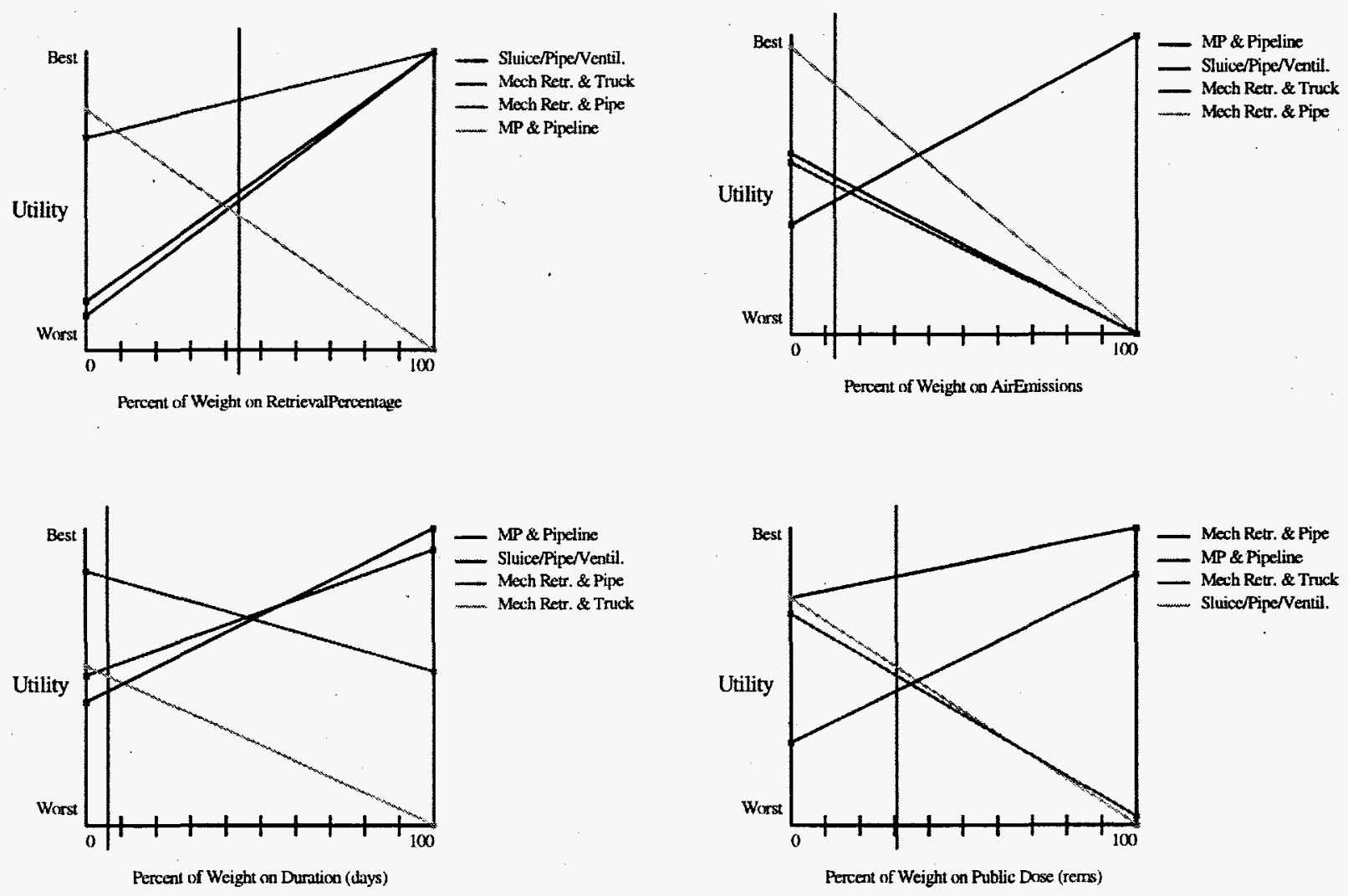

Figure 3.7. Sensitivity Analysis for Selected Criteria

The results of the sensitivity analysis for air emissions is shown in the upper right panel of Figure 3.7. The analysis shows that putting less weight on air emissions would not change the result. The ranking order of alternatives will change with an increase in weight on air emissions, but only if the weight is increased to approximately $38 \%$. At that point, mixer pumps would be the highest ranking alternative. Thus, the ranking of the alternatives is insensitive to changes in the weight assigned to air emissions over its range of credible weights. 
The lower left panel of Figure 3.7 shows the results of the sensitivity analysis for schedule as measured by duration. The duration used in this analysis does not include 28 days for washing, which was judged to be required by all the alternatives except mixer pumps. Schedule duration was priced out at $\$ 1 \mathrm{~K}$ a day, which corresponded to a normalized weight of $6 \%$; however, there was not a firm basis for this number. This $\$ 1 \mathrm{~K} /$ day cost is meant to capture concerns in addition to operating costs of $\$ 5 \mathrm{~K} /$ day, which is already included in the analysis. Putting less weight on schedule does not change the rankings. If the weight on schedule is increased to $47 \%$, sluicing becomes the number one alternative. At $56 \%$, mixer pumps become number one. Thus, while the schedule impacts were judged to be insignificant in that there was not a perceived impact on meeting milestones, if duration were to become more of an issue, sluicing or mixer pumps might become more desirable alternatives.

The lower right panel of Figure 3.7 shows the results of the sensitivity analysis on Public Dose. Mechanical/pipe ranked number one regardless of the weight put on Public Dose; however, as seen in the figure, the lower ranked alternatives change rank if more weight is put on Public Dose. Mixer pump is second if the weight is increased to $47 \%$.

\subsection{Cost Analysis}

The value tradeoff analysis indicates that cost is the major consideration for the sludge mobilization decision. Further, the impact on criteria other than retrieval effectiveness and cost is minimal for this decision. ES\&H criteria were explored in depth. With the exception of Public Dose which may be inflated, the potential impacts of the alternatives on these measures is minimal and only marginally different for different alternatives. The means criteria that were primarily concerned with potential engineering complexities were accounted for in cost and schedule. As to schedule, none of the duration or deployment times are thought to adversely impact any milestones. Retrieval effectiveness represents a deferred cost. Consequently, cost appears to be the major driver in this decision.

Cost for these alternatives can be considered in a variety of ways, however. We will explore three perspectives of cost: cost as utility, cost on a per metric ton basis, and life cycle cost.

\subsubsection{Cost as Utility}

In the multiattribute analysis discussed above, all the attributes except cost were rolled up into an overall value; cost was then compared with this value. The analysis provides valuable insight in that it shows the cost and the net utility for each of the alternatives. However, because the criteria were all "priced out" to obtain their normalized weights, it is natural to calculate an overall utility function that includes cost. Cost is "priced out" by the difference in cost between the most costly and least costly alternative. The normalized weights that include cost are shown in the right-most column of Table 3.3. As can be seen in the table, cost accounts for $99 \%$ of the weight.

The results of multiplying these weights by the utility scores (shown in Table 3.2) are the rankings shown in Figure 3.8. Mixer pump is the most cost-effective alternative and mechanical with truck transfer 


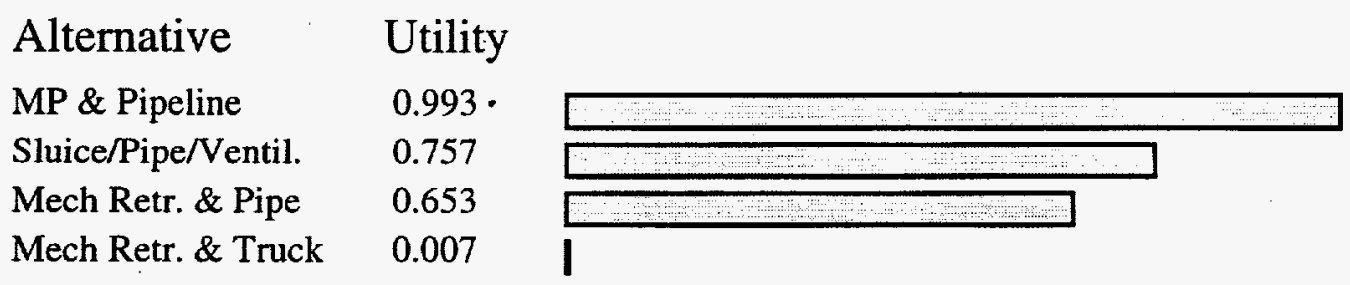

Figure 3.8. Overall Scores Including Cost

is the least cost-effective. Sluicing is ranked second. Regarding whether the increase in value associated with mechanical was worth the additional $\$ 12$ million cost-a question posed earlier-this analysis would answer "no." By implication, the mixer pump alternative is clearly the best choice from this perspective.

\subsubsection{Cost per Metric Ton - Generic Tank}

In the cost utility analysis, costs are rolled up with the other criteria. Because the cost of alternatives overwhelmed the prices for the other criteria, the overall utilities were nearly proportional to the cost of the alternatives. Mixer pumps, as the least costly of the alternatives, had the highest utility. Another perspective is to compare alternative costs on a production basis. Operating costs are a small fraction of the total costs and are similar: $\$ 398 \mathrm{~K}$ for the mixer pump and $\$ 407 \mathrm{~K}$ for the sluicer (however, see cost/MT below). The total operating costs both for mixing and for sluicing are based on estimated daily operating costs of $\$ 5: 1 \mathrm{~K}$. These costs are quite small compared with the capital costs, and the mixer pump has both the least operating cost and the least capital costs.

Cost per metric ton (cost/MT) provides an alternative perspective on the cost-effectiveness of an alternative. For a tank with $2 \mathrm{ft}$ of sludge, cost $/ \mathrm{MT}$ works out to $\$ 387 \mathrm{~K} / \mathrm{MT}$ for sluicers and $\$ 581 \mathrm{~K} / \mathrm{MT}$ for mixers. Thus, sluicing is more cost-effective on a cost/MT basis. On a cost/MT basis, mixer pumps become more cost-effective as their retrieval effectiveness increases. The retrieval effectiveness is inversely related to the shear strength of the sludge. The break-even point between sluicers and mixers is a retrieval effectiveness of $75 \%$, which corresponds to a sludge shear strength of approximately $14,000 \mathrm{dy} / \mathrm{cm}^{2}$. Less than $25 \%$ of the DSTs have shear strength of $14,000 \mathrm{dy} / \mathrm{cm}^{2}$ or less; thus on a cost/MT basis, mixer pumps are more cost-effective than sluicers for only $25 \%$ or less of the DSTs.

Cost/MT for a given tank decreases as the amount of sludge in the tank increases. Because the cost per tank is constant for mixer pumps, the cost/MT is halved when the amount of sludges doubles. For sluicers, operating costs increase slightly as the amount of sludge increases; however, because costs are dominated by capital costs, the cost/MT decreases only slightly.

If cost/MT is important, this would suggest looking for tanks with more sludges per tank. On a per metric ton delivered (MT/delivered ) basis, the break-even point between mixers and sluicers changes only slightly with increased sludge volume per tank. Thus, for $6 \mathrm{ft}$ of sludge in a tank, rather than the $2 \mathrm{ft}$ used in the analysis, mixers must still retrieve $74 \%$ of the sludge, which, for the estimated distribution of shear 
strengths in the tanks, will still only be the case for about $25 \%$ of the DSTs. Thus, if cost is evaluated on a MT/delivered basis, sluicers appear to be the better alternative. However, if cost is evaluated on a per tank basis for mobilization of sludge, then mixers are $\$ 8$ million less than sluicers per tank.

\subsubsection{Cost per Metric Ton - Phase 1B}

In addition to calculating costs for mobilizing sludge in a generic DST, we also calculated the cost to mobilized the sludges in the source tanks for the HLW vitrification demonstration plant. The source tanks for which costs were calculated were 101-AZ, 102-AZ, 102-AY, and C-106. In all cases, it is assumed that C-106 would be sluiced and transferred into 102-AY. The mixer pump alternative consists of putting mixer pumps in all three DSTs and pumping directly from each DST to the vendor. Sluicing and mechanical would require mixer pumps in 101-AZ for sludge washing; waste from other tanks would be transferred there for that purpose and then to the vendor. Total costs were the least for mixers at $\$ 83$ million, sluicers were $\$ 100$ million, and mechanical with pipeline transfer is $\$ 108$ million. Mixers are expected to retrieve $323 \mathrm{MT}$ or $71 \%$ of the $452 \mathrm{MT}$ of sludge in the four source tanks for Phase $1 \mathrm{~B}$. Sluicers are expected to retrieve $388 \mathrm{MT}$ or $86 \%$ of the sludge. The cost per metric ton is $\$ 257 \mathrm{~K}$ for both systerns. Thus, mixers are less costly overall, retrieves $65 \mathrm{MT}$ less; but, on a cost-per-metric-ton basis, the two alternatives are equivalent for Phase 1B.

\subsubsection{Life-Cycle Cost}

Mixers leave a significant portion of the waste in the tank for most tanks, and eventually sluicers would most likely have to be installed for ultimate cleanout. Because this cost is in the future, it should be discounted. The amount will depend on how much time elapses until the sluicer is installed and the discount rate. Assuming $\$ 32.5$ million discounted for 20 years at $6 \%$ gives approximately $\$ 10$ million, which is about the difference in price between the two alternatives. 


\subsection{Cost and Schedule for Generic Tank}

The costs outlined in this section include the capital and operating cost for the four retrieval options in a generic tank: mixer system, sluicer, mechanical system with pipeline transfer, and mechanical system with truck transfer. The capital costs include the equipment and piping costs, as well as installation costs. The operating costs include labor for operation of the retrieval system. The following table provides the capital and operating costs for each retrieval system and the following paragraphs outline the assumptions involved in developing the costs. The operating cost is dependent on the duration of the tank retrieval. The durations assumed for this study are for the retrieval of the contents of a single double shell tank.

Table 4.1. Summary Table of Cost and Schedule for a Generic Tank

\begin{tabular}{|c|c|c|c|c|}
\hline Cost & Mixer & Sluicer & $\begin{array}{c}\text { Mechanical } \\
\text { with Pipeline } \\
\text { Transfer }\end{array}$ & $\begin{array}{l}\text { Mechanical with } \\
\text { Truck Transfer }\end{array}$ \\
\hline Capital Cost & $\$ 24 \mathrm{M}$ & $\$ 32.1 \mathrm{M}$ & $\$ 35.6 \mathrm{M}$ & $\$ 56.6 \mathrm{M}$ \\
\hline $\begin{array}{c}\text { Operating Cost } \\
\text { Unit Cost }\end{array}$ & $\begin{array}{l}\$ 397.8 \mathrm{~K} \\
\$ 5.1 \mathrm{~K} / \text { day }\end{array}$ & $\begin{array}{l}\$ 407.7 \mathrm{~K} \\
\$ 5.1 \mathrm{~K} / \text { day }\end{array}$ & $\begin{array}{l}\$ 562.6 \mathrm{~K} \\
\$ 6.1 \mathrm{~K} / \text { day }\end{array}$ & $\begin{array}{l}\$ 1.6 \mathrm{M} \\
\$ 15.2 \mathrm{~K} / \text { day }\end{array}$ \\
\hline $\begin{array}{l}\text { Additional Cost Impacts } \\
\text { Deployment Time } \\
\text { Deployment Actions } \\
\text { Operating Complexity } \\
\text { Washing Required } \\
\text { Blending Required } \\
\text { Tank Modifications } \\
\text { Waste Compatibility } \\
\text { Reliability }\end{array}$ & $\begin{array}{l}\text { NA } \\
-- \\
- \\
- \\
-- \\
-- \\
-- \\
--\end{array}$ & $\begin{array}{l}\text { NA } \\
-- \\
-- \\
-- \\
\$ 120 \mathrm{~K} \\
-- \\
-- \\
--\end{array}$ & $\begin{array}{l}\text { NA } \\
-- \\
-- \\
-- \\
\$ 120 \mathrm{~K} \\
-- \\
-- \\
--\end{array}$ & $\begin{array}{l}\text { NA } \\
-- \\
-- \\
- \\
\$ 120 \mathrm{~K} \\
-- \\
-- \\
--\end{array}$ \\
\hline Total Cost & $\$ 24.4 \mathrm{M}$ & $\$ 32.5 \mathrm{M}$ & $\$ 36.2 \mathrm{M}$ & $\$ 58.2 \mathrm{M}$ \\
\hline Duration & 78 days & 80 days & 92 days & 107 days \\
\hline $\begin{array}{l}\text { Schedule Impacts } \\
\text { Deployment Time }\end{array}$ & -- & -- & -- & -- \\
\hline
\end{tabular}




\subsection{Mixer System}

\subsubsection{Capital Cost}

The mixer pump system is based on the system evaluated and estimated by Project W-211. The tank contents are mixed by two 300 -hp mixer pumps. The tank contents are transferred from the tank with a 60 -hp transfer pump. Upgrades to the tank include

- extend existing risers and add concrete slabs

- install new nitrogen bottle station

- modify raw water piping

- remove miscellaneous equipment

- install new central pump pit cover blocks

- install new instrument and control building

- install new temperature probe/tree.

The basic mixer pump system has a capital cost of $\$ 21.9$ million (Salzano et al. 1997). This cost includes $\$ 4.9$ million for design and management and $\$ 1.8$ million for general support.

A hot water/caustic addition system is used to condition the waste by injecting a diluent into the transfer pump supply line. The dilution ratio is adjusted to attain the required fluid properties for transfer and storage. The system consists of a mobile hot water boiler and caustic unloading pump. Hot water is mixed with the caustic in an in-line static mixer to provide the solution/diluent. The caustic solution bleeds into a 4000 -gal flush tank. A 40 -hp diluent/flush pump is located at the storage tank for discharge. The hot water/caustic system is approximately \$2.1 million (Salzano et al. 1997); this cost includes the following tank upgrades:

- install new concrete support pads

- install $500 \mathrm{ft}$ of new 3-in./6-in. encased transfer line

- install core drill and nozzle in valve pit

- modify raw and sanitary water lines.

The total capital cost for this system is $\$ 24$ million. This cost includes the mixer pump system and hot water/caustic addition system.

\subsubsection{Duration}

A duration of 78 days is assumed for the retrieval of a single tank. Fourteen days of pumping are required to dislodge and break up the agglomerated sludge. The purnps are shut off for approximately 16 days to allow the tank contents to cool down. The sludge is then resuspended for 3 days, and the slurry is then pumped out of the tank for 5 days. 
Repair time is estimated at about 1 week for the failure of any one of the contact maintenance parts, such as the motors and limit switches, and 1 month for the submerged parts. It is assumed that half of the failures would allow contact maintenance and half would require non-contact maintenance. Repair time equates to $444 \mathrm{hr}$ (18.5 days). In the event of a failure, it is assumed that when the repair is complete, 3 additional days of mixing will be required to return the waste tank to its pre-failure condition. A more detailed discussion of possible failures is available in Section 7.0 and Appendix C.

The times given are for the major activities. Other activities, such as preparation, setup, and takedown, account for an additional 18 days. The duration used in calculating the operating cost, including the preparation, setup, operation, repair, and takedown time for the mixer system, is 78 days. A complete accounting of activities and their duration are provided in Appendix B.

\subsubsection{Operating Cost}

The operating cost assumes 24 -hr operation for the entire 78 days. The staff for operation includes the following:

- 2 operators for the day shift and 1 operator for the back shifts

- 1 radiation protection technologist 24 hours a day

- 0.1 job control per day

- 0.5 maintenance personnel per shift

- 0.5 engineer per day.

A total of 9.1 staff is required to operate the mixer system. At an average rate of $\$ 70 / \mathrm{hr}$, the operating cost is $\$ 5100$ per day or $\$ 397,488$ for the retrieval of the contents of one tank. This amount is based on the assumption that the entire crew is required for the duration of the operation.

Utility costs are not estimated for this preliminary comparison study. The kWh is unknown and would be difficult to estimate without system specifics. The utility costs for the four retrieval systems are assumed to be within $10 \%$ to $15 \%$ of each other, which should not impact this comparative analysis.

\subsection{Sluicer System}

\subsubsection{Capital Cost}

The sluicing system costed is based on the system evaluated and estimated by Project W-320. The sluicing system is continuous. A stream of pressurized water is used to loosen, suspend, and transport the resulting slurry in a sluice tank to a pump suction. This system requires a dedicated receiver DST for solid/liquid separation and for the waste as it is retrieved. Two pumps are used, one to deliver the sluice stream to the storage tank and a second to recirculate slurry into the sluice tank. Other equipment includes 
a sluicer system, a slurry distributor, and piping to complete a closed-loop sluicing system. Capital cost for a basic sluicing system is $\$ 30$ million (Salzano et al. 1997). The cost covers upgrades required for the systern installation, including the following:

- provide new central pump pit jumper arrangements

- iristall central pump pit core drills

- iristall central pump pit cover blocks

- iristall booster pump pits

- install $1600 \mathrm{ft}$ of 4-in./6-in. transfer lines

- remove miscellaneous equipment in the tank.

A hot water/caustic addition system is used to condition the waste by injecting a diluent into the transfer pump supply line. The dilution ratio is adjusted to attain the fluid properties required for transfer and storage. The system consists of a mobile hot water boiler and caustic unloading pump. The hot water is mixed with the caustic in an in-line static mixer to provide the solution/diluent. The caustic solution will bleed into a 4000-gal flush tank. A 40-hp diluent/flush pump is located at the storage tank for discharge. The hot water/caustic system is approximately $\$ 2.1$ million (Salzano et al. 1997). This cost includes the following tank upgrades:

- install new concrete support pads

- install $500 \mathrm{ft}$ of new 3-in./6-in. encased transfer line

- install core drill and nozzle in valve pit

- modify raw and sanitary water lines

- provide instrument and control building.

The total capital cost for the sluicing system is $\$ 32.1$ million (Salzano et al. 1997). The sluicing capital cost includes $\$ 5.2$ million for ventilation upgrades and $\$ 5$ million for design and management. Procurement and construction of the piping upgrades are about $\$ 5.3$ million, which includes fabrication and irstallation of jumpers.

\subsubsection{Duration}

The durations used for calculating the operating costs in this study are based on activity durations estimated for sluicing operations for tank $\mathrm{C}-106$. The operation involves transferring the contents of tank C-106 to tank AY-102. The schedule for the C-106 sluicing operations is broken down into campaigns, with operation outages between each batch transfer to observe the tank levels. For this study, these outages are not included. The seven sluicing batch transfers required approximately 81.5 days $(6 \mathrm{ft}$ of sludge). For the generic tank containing $2 \mathrm{ft}$ of sludge, the duration is 28 days. Retrieval operations in the first two or so weeks include time for equipment calibration and wring-out, temperature equalization, and process control refinements. The duration also accounts for a drop-off in the retrieval rate as sluicing nears 
completion and waste sluiced from the tank walls is retrieved. ${ }^{(a)}$ Four weeks is included as the estimate for maintenance required during sluicing operations and for potential leak evaluations. ${ }^{\text {(a) }}$

The times given are for the major activities. Other activities, including system preparation, setup, removal of supernatant, and system takedown, account for another 25 days. A total duration of the system preparation, setup, operation, repair, and takedown time is assumed to be 80 days for the sluicer retrieval system. Appendix B provides the complete listing of activities included and the activity durations.

\subsubsection{Operating Cost}

The operation of the sluicer system is assumed to be similar to the mixer system. The staff for operation includes

- 2 operators for the day shift and 1 operator for the back shifts

- 1 radiation protection technologist $24 \mathrm{hr}$ a day.

- 0.1 job control per day

- 0.5 maintenance personnel per shift

- 0.5 engineer per day.

At an average rate of $\$ 70 / \mathrm{hr}$, the operating cost for 24 -hr operation is $\$ 5100 /$ day or $\$ 407,700$ for sludge retrieval from one tank. This amount is based on the assumption that the entire crew is required for the duration of the operation.

Utility costs are not estimated for this preliminary comparison study. The kWh is unknown and would be difficult to estimate without system specifics. The utility costs for the four retrieval systems are assumed to be within $10 \%$ to $15 \%$ of each other, which should not impact this comparative analysis.

\subsection{Mechanical System with Pipeline Transfer (Confined Sluicing System)}

\subsubsection{Capital Cost}

The mechanical system costed includes a two-stage retrieval system. In the first phase, a vehicle-based tank waste retrieval system is used. A remotely operated vehicle is deployed to retrieve non-pumpable debris or to move sludge within reach of the mechanical arm system, which is the second stage of the retrieval system. The mechanical arm system includes an end effector tool that uses a waterjet to dislodge solid waste from the tank surface. A conveyance system retrieves the dislodged waste and fluids from the end effector and transfers the material to a storage or processing facility. The installation of the mechanical retrieval system with pipe transfer of the material includes the following upgrades to the tank:

(a) Westinghouse Hanford Company. 1996. Tank 241-C-106 Waste Retrieval Sluicing System (WRSS) Process Control Plan. 
- provide new central pump pit jumper arrangement

- install central pump pit cover blocks

- install new equipment support platform

- install conveyance system

- install $900 \mathrm{ft}$ of transfer lines.

The capital cost for the basic mechanical retrieval system with pipe transfer is $\$ 31.7$ million (Salzano et al. 1997). Some of the primary components of this cost include $\$ 21.1$ million for the mechanical arm system, $\$ 4.6$ million for the conveyance system pit, and $\$ 6$ million for piping.

A hot water/caustic addition system is used to condition the waste by injecting a diluent into the transfer pump supply line. The dilution ratio is adjusted to attain the fluid properties required for transfer and storage. The system consists of a mobile hot water boiler and caustic unloading pump. The hot water is mixed with the caustic in an in-line static mixer to provide the solution/diluent. The caustic solution bleeds into a 4000-gal flush tank. A 40-hp diluent/ flush pump is located at the storage tank for discharge. The hot water/caustic system costs approximately $\$ 2.1$ million (Salzano et al. 1997). This cost includes the following tank upgrades:

- install new concrete support pads

- install $500 \mathrm{ft}$ of new 3-in./6-in. encased transfer line

- install core drill and nozzle in valve pit

- modify raw and sanitary water lines

- provide instrument and control building.

A portable exhauster system is also installed for the mechanical system. The system consists of a heater, high-efficiency particulate air (HEPA) filter train, fan, fan motor, stack, and stack emissions monitoring system which is attached to an existing riser. The cost for the portable exhauster is approximately $\$ 1.8$ million.

The total capital cost for this system is $\$ 35.6$ million. "This includes the mechanical arm system, the hot water/caustic addition system, and a portable exhauster system.

\subsubsection{Duration}

The durations for the mechanical arm system are based on time required to setup, retrieve, and take down the Light Duty Utility Arm (LDUA). Verification of access to the tank farm and risers and verification of the riser diameter will require 4 days to complete. Setup of the mechanical arm system will require 5 days. Retrieval and repair times are assumed to be similar to the sluicer durations. Other activities, including system preparation, setup, takedown, and removal of supernatant, require an additional 27 days. The total time for system preparation, setup, operation, repair, and takedown is assumed to be 92 days for the mechanical arm retrieval systems with pipeline transfer. Appendix B contains the specific activities included in the operations of the mechanical arm and the activity durations. 


\subsubsection{Operating Cost}

The operating cost for the mechanical system is assumed to be similar to the mixer system plus $20 \%$ for additional heating, ventilation, and air conditioning (HVAC) and separator activities and uncertainties in the articulating arm. At an average rate of $\$ 70 / \mathrm{hr}$, the operating cost is $\$ 6100 / \mathrm{day}$. Assuming a duration of 92 days, the total operating cost for the mechanical arm system with pipe transfer is $\$ 562,600$.

Utility costs are not estimated for this preliminary comparison study. The kWh is unknown and would be difficult to estimate without system specifics. The utility costs for the four retrieval systems are assumed to be within $10 \%$ to $15 \%$ of each other, which should not impact this comparative analysis.

\subsection{Mechanical System with Truck Transfer (Confined Sluicing System)}

\subsubsection{Capital Cost}

The mechanical system costed includes a two-stage retrieval system. In the first phase, a vehicle-based tank waste retrieval system is used. A remotely operated vehicle is deployed to retrieve non-pumpable debris or to move sludge within reach of the mechanical arm system, which is the second stage of the retrieval system. The mechanical arm system includes an end effector tool that uses a waterjet to dislodge solid waste from the tank surface. A conveyance system retrieves the dislodged waste and fluids from the end effector and transfers the material to a storage or processing facility. The installation of the mechanical retrieval system with truck transfer of the material includes the following upgrades to the tank:

- provide new central pump pit jumper arrangement

- install central pump pit cover blocks

- install new equipment support platform

- provide new high-level waste unloading facility.

The capital cost for the basic mechanical retrieval system with truck transfer is $\$ 42.7$ million (Salzano et al. 1997). Included in this cost is $\$ 21.1$ million for the mechanical arm system, $\$ 4.6$ million for the conveyance system pit, and $\$ 17$ million for a new loading station (Salzano et al. 1997).

A hot water/caustic addition system is used to condition the waste by injecting a diluent into the transfer pump supply line. The dilution ratio is adjusted to attain the fluid properties required for transfer and storage. The system consists of a mobile hot water boiler and caustic unloading pump. The hot water is mixed with the caustic in an in-line static mixer to provide the solution/diluent. The caustic solution bleeds into a 4000-gal flush tank. A 40-hp diluent/flush pump is located at the storage tank for discharge. The hot water/caustic system is approximately $\$ 2.1$ million (Salzano et al. 1997). This cost includes the following tank upgrades:

- install new concrete support pads

- install $500 \mathrm{ft}$ of new 3-in./6-in. encased transfer line 
- install core drill and nozzle in valve pit

- modify raw and sanitary water lines

- provide instrument and control building.

A portable exhauster system is also installed for the mechanical system. The system consists of a heater, high-efficiency particulate air (HEPA) filter train, fan, fan motor, stack, and stack emissions monitoring system which is attached to an existing riser. The cost for the portable exhauster is approximately $\$ 1.8$ million.

The trucks used to transfer the materials retrieved from the tank are LR-56 containers. The system would require two transfer trucks at $\$ 5$ million each. ${ }^{(a)}$

The total capital cost for this system is $\$ 56.6$ million. This includes the mechanical arm system, the hot water/caustic addition system, a portable exhauster system, and two transfer trucks.

\subsubsection{Duration}

The durations for the mechanical arm system are based on time required to set up, retrieve and take down the LDUA. Verification of access to the tank farm and risers and verification of the riser diameter are activities of system preparation and will require 4 days to complete. Setup of the mechanical arm system will require 5 days. The operation and repair times for the mechanical arm systems are assumed to be similar to the sluicer. Appendix B provides the detailed durations for each activity included in the operation.

The sludge retrieved from the tank will be shipped via the LR-56 cask system. The cask is designed and certified to carry $4000 \mathrm{~L}$ (1060 gallons) of liquid effluents (WHC-SD-TP-PDC-021, Rev.0, 1994). If two trucks are operating, each truck will be required to make 37 transports. The duration of each transport is derived from the transfer durations for shipments to 204-AR. Each transport will take 2 days, including loading, transportation, and unloading. ${ }^{(b)}$ The 204-AR transfer data are outlined in Appendix B.

Other activities, including system preparation, setup, takedown and removal of supernatant, require an additional 27 days. Total time for the system preparation, setup, operation, repair, takedown, and transportation is assumed to be 107 days for the mechanical arm retrieval systems with truck transfer. Note that truck transport will occur during sludge retrieval operations, so durations are not additive. Refer to Appendix B for a schedule of events.

\subsubsection{Operating Cost}

In addition to the operating cost for the mechanical system with pipeline transfer, the mechanical system with truck transfer requires

(a) Personal communication with J. D. Galbraith, Numatec Hanford Corporation, March 1997.

(b) Laney, T., Lockheed Martin Hanford Corporation. March 19, 1997. Cc:mail message to R. Claghorn. 
- 2 truck drivers per shift (6 total)

- 2 radiation protection technologists per shift (6 total)

- 2 maintenance personnel per day

- 2 engineers per day

- 2 job control per day.

The mechanical system with truck transfer will operate over a period of 107 days. At an average rate of $\$ 70 / \mathrm{hr}$, the operating cost is estimated at $\$ 15,200 /$ day. The total operating cost for this system is $\$ 1,623,800$.

\subsection{Other Cost and Schedule Impacts}

For this comparative analysis, other system factors that impact the cost and/or schedule of one or more of the four retrieval systems are evaluated. These factors include deployment time, deployment actions required, operating complexity, blending requirements, tank modification requirements, waste compatibility, and reliability. These system factors are described below, and the cost and schedule impacts are calculated. The costs are then added to the system costs outlined in the above sections.

An additional year is required to deploy the mechanical retrieval system with truck transfer. The time to construct and set up the retrieval systems is approximately 3.5 years for the mixer, sluicer, and mechanical with pipeline systems (WHC 1995b). The mechanical retrieval system with truck transfer requires a deployment time of 4.5 years to account for the construction of the loading and unloading facilities.

There is no difference in the deployment actions required from one system to another. All four retrieval systems require similar actions and so no cost or duration impacts are included.

The costs developed in the above sections for the four systems already account for the operating complexity of the systems, i.e., the number of operators required to operate the system. As described, the mechanical system with truck transfer requires more personnel for operation than the other three systems. Therefore, no additional consideration of operating complexity is required.

The sluicer and the two mechanical retrieval systems will require additional blending, which implies more sampling activities. The mixer system requires two samples, and it is estimated that these three systems will require at least an additional three samples. Assuming a core sample with a nominal solids content of $2 \%$, a sample will cost an additional $\$ 41,200$ (WHC-SD-TWR-AGA-001, Rev. 0). The three samples will cost $\$ 124,000$.

Tank and tank penetration modifications required for the retrieval systems are included in the cost estimates described in the above sections. No additional cost or schedule adjustments are needed.

Waste compatibility because of transuranic (TRU) content is not a differentiator of retrieval systems. No cost or schedule impacts are estimated for waste compatibility.

For a discussion of reliability impacts to cost and schedule see Section 7.0. 


\subsection{Cost and Schedule for Phase 1}

Phase 1 includes the removal of sludge from tanks 101-AZ, 102-AZ, and 102-AY in the 200 Area Tank Farms on the Hanford Site. Three different retrieval systems were evaluated for removing the sludge from these tanks

- place mixers in all three tanks

- sluice the sludge in 102-AZ and 102-AY into 101-AZ, which would contain a mixer for sludge retrieval

- retrieve the sludge in 102-AZ and 102-AY with a mechanical arm and transfer the contents to 101-AZ, which would contain a mixer.

The sludge contents of tank C-106 will have already been retrieved and sent to tank 102-AY; the volume increase due to this transfer is included in this evaluation. The operating and capital costs for transferring the C-106 sludge contents to 102-AY are not included in this evaluation.

The duration and costs for each of these systems are summarized in Table 5.1. The costs and durations are based on the costs and durations developed in the previous sections for a generic tank; those costs and durations were described in Sections 4.1 through 4.5.

Table 5.1. Summary Table of Costs and Schedules for Alternative Retrieval Systems Evaluated

\begin{tabular}{|l|c|c|c||}
\hline $\begin{array}{l}\text { Retrieval } \\
\text { System }\end{array}$ & $\begin{array}{c}\text { Mixer in 101-AZ, } \\
102-\mathrm{AZ} \text { and 102-AY }\end{array}$ & $\begin{array}{c}\text { Mixer in 101-AZ } \\
\text { Sluicer in 102-AZ } \\
\text { and 102-AY }\end{array}$ & $\begin{array}{c}\text { Mixer in 101-AZ } \\
\text { Mech Arm in } \\
102-\mathrm{AZ} \text { and 102-AY }\end{array}$ \\
\hline Duration & 1260 days & 1369 days & 1389 days \\
\hline Operating Cost & $\$ 11.03 \mathrm{M}$ & $\$ 11.65 \mathrm{M}$ & $\$ 13.19 \mathrm{M}$ \\
\hline $\begin{array}{c}\text { Capital Cost } \\
\text { 101-AZ }\end{array}$ & $\$ 24 \mathrm{M}$ & $\$ 24 \mathrm{M}$ & $\$ 24 \mathrm{M}$ \\
$102-\mathrm{AZ}$ & $\$ 24 \mathrm{M}$ & $\$ 32.1 \mathrm{M}$ & $\$ 35.6 \mathrm{M}$ \\
$102-\mathrm{AY}$ & $\$ 24 \mathrm{M}$ & $\$ 32.1 \mathrm{M}$ & $\$ 35.6 \mathrm{M}$ \\
\hline Total Cost & $\$ 83.03 \mathrm{M}$ & $\$ 99.85 \mathrm{M}$ & $\$ 108.39 \mathrm{M}$ \\
\hline \hline
\end{tabular}




\subsection{Mixers in 101-AZ, 102-AZ, and 102-AY}

Mixers are placed in the three tanks included in Phase 1 activities: 101-AZ, 102-AZ, and 102-AY. The rnixers are used to break up and suspend the waste solids in the supernate, which is then pumped out of the tank and sent to the vendor for treatment.

\subsubsection{Capital Cost}

The capital cost for the alternative with mixers in all three tanks is estimated at $\$ 72$ million. This cost includes the three mixer systems and appropriate modifications to the tanks.

\subsubsection{Duration}

The operating cost is based on a duration of 1260 days for the sludge in the three tanks to be transferred to the treatment contractors. This is based on the assumption that approximately a month is required for each tank transfer. The number of washes depends on the consistency and accessibility of the sludge. It is assumed that three washes are required for 101-AZ sludge, four for 102-AZ, and one for 102-AY. The activities included in the estimates of duration and operating costs are provided in Appendix B.

\subsubsection{Operating Cost}

The operating cost for a generic tank was estimated at $\$ 5100$ per day or $\$ 212.50$ per hour. Some activities require the involvement of everyone in the tank farm program, making the charge-out rate $\$ 476$ per hour. The total operating cost for the Phase 1 mixer system, which includes three mixers, is estimated at $\$ 11$ million.

\subsection{Sluicer in 102-AZ and 102-AY, Mixer in 101-AZ}

In this alternative, the sludge in 102-AZ and 102-AY is sluiced and transferred to 101-AZ. A mixer will be used in 101-AZ to suspend the solid materials. The slurry will be transferred to the treatment contractor from tank 101-AZ.

\subsubsection{Capital Cost}

The capital cost for this alternative includes two sluicing systems and a mixer. The total capital cost is $\$ 111.25$ million. This estimate is based on the costs developed for a generic tank in which a mixer system costs $\$ 24$ million and the sluicing systems $\$ 32.1$ million each.

\subsubsection{Duration}

The duration for this alternative is 1369 days. Each transfer is assumed to require approximately a month: Before the sludge is sent to the treatment contractor, the solids are washed in 101-AZ. The contents of 101-AZ are washed in three steps, the contents of 102-AZ in four, and the contents of 102-A.Y 
in one. Assuming approximately $2 \mathrm{ft}$ of sludge, the duration of the sluicing operations was estimated as 27 days. This duration was adjusted according to the amount of sludge material in the tank. Tank 102-AY contains approximately twice the volume of sludge assumed in the generic tank study (including C-106 sludge) and so the duration of sluicing was doubled ( -54 days). The sluicing duration for 102-AZ was equal to that determined for the generic tank ( 27 days). The duration for each activity included for the operating cost is included in Appendix B.

\subsubsection{Operating Cost}

The operating cost for a generic tank was estimated at $\$ 5100$ per day or $\$ 212.50$ per hour. Some activities require the involvement of everyone in the tank farm program, making the charge-out rate $\$ 476$ per hour. Assuming a total duration of 1369 days, the operating cost is estimated at $\$ 11.7$ million.

\subsection{Mechanical Arm in 102-AZ and 102-AY, Mixer in 101-AZ}

A mechanical arm system will be installed in 102-AZ and 102-AY to retrieve the sludge material out of these tanks. The sludge will be transferred to 101-AZ where a mixer will be used to suspend the solid material so that the slurry can be transferred to the treatment contractor. Tank 102-AY will contain the sludge material from C-106.

\subsubsection{Capital Cost}

The capital cost for this alternative includes two mechanical arm systems and a mixer. The total capital cost is $\$ 108.39$ million. This estimate is based on the costs developed for a generic tank in which a mixer system costs $\$ 24$ million and the mechanical arm systems $\$ 35.6$ million each. Two mechanical arm systems were evaluated for the generic tank. Because the tanks included in Phase 1 are located near the site of the treatment contractor's planned receiving location, the mechanical arm system with truck transfer is not applicable. Thus, the mechanical arm system with pipeline transfer is the system represented in the costs developed for this alternative.

\subsubsection{Duration}

The total duration for this alternative is 1389 days. Each transfer is assumed to require approximately a month. Before the sludge material is sent to the treatment contractor, the solids are washed in 101-AZ. The contents of 101-AZ are washed in three steps, the contents of $102-\mathrm{AZ}$ in four, and the contents of 102-AY in one. Assuming approximately $2 \mathrm{ft}$ of sludge, the duration of the sluicing operations was estimated for the generic tank as 27 days. This duration was adjusted according to the amount of sludge material in the tank. Tank 102-AY contains approximately twice the volume of sludge assumed in the generic tank study (including C-106 sludge) and so the sluicing duration was doubled ( $\sim 4$ days). The sluicing duration for 102-AZ was equal to the 27 days determined for the generic tank. The activities and the activity durations used in developing the operating cost are provided in Appendix B. 


\subsubsection{Operating Cost}

For the generic tank, the operating cost for the mechanical arm system was estimated at $\$ 6100$ per day or $\$ 254.17$ per hour and the mixer system at $\$ 5100$ per day or $\$ 212.50$ per hour. Some activities require the irivolvement of everyone in the tank farm program, making the charge-out rate $\$ 476$ per hour. Assuming a total duration of 1389 days, the operating cost is estimated at $\$ 13.2$ million. 


\subsection{Retrieval Effectiveness Risk Analysis}

In Section 3.0, the retrieval effectiveness for mixer pumps was given as $50 \%$. The other alternatives were all estimated to mobilize and retrieve $99 \%$ of the sludge. The question that immediately arises is: what are the adverse consequences of mobilizing only $50 \%$ of the waste? One answer to that question, given in Section 3.0, is to consider the cost of eventually retrieving the unmobilized sludge from the tank. For a generic tank with $2 \mathrm{ft}$ of sludge, this was estimated to be $\$ 204 \mathrm{~K}$-the operating cost of sluicing $1 \mathrm{ft}$ of sludge. This cost was the basis for "pricing out" that criteria in the multiattribute tradeoff analysis.

In addition to the cost of retrieving the unmobilized waste, another possible adverse consequence is failure to provide sufficient feed to the HLW vitrification demonstration plant. The Phase 1B privatization HLW vitrification demonstration plant is being sized to process a given amount of waste. The minimum amount DOE provides to the vitrification plant will be specified by contract as the minimum order requirement. This amount is necessary both to recover costs to the plant and provide a valid demonstration of the feasibility of the vitrification process. Failure to provide the minimum order requirements will result in significant idle time penalties and potentially cast doubt on the validity of the demonstration. Consequently, to better understand the impact of mobilizing only $50 \%$ of the sludge, a risk analysis was carried out to assess the likelihood of failing to meet the minimum order requirements and incurring cost penalties for putting the plant on idle time.

Four tanks have been identified as the source tanks for HLW feed: three DSTs and one SST. If mixer pumps are the technology chosen for sludge mobilization, the amount of sludge mobilized will depend on the amount of sludges in those tanks and the shear strengths of the sludge. The amount of sludge in these tanks is known; however, there is considerable uncertainty concerning the shear strengths. There have been a limited number of samples that measured the shear strength of sludges in these tanks. The uncertainty of the shear strengths was quantified using a formal elicitation process. This involved the help of an expert who had an understanding of the sampling process and the sampling results. The resulting probability distributions of shear strengths provided the key input to the risk analysis.

The result of this primary risk analysis is a probability distribution of the number of metric tons of waste that would be delivered to the HLW vitrification plant. The uncertainty in the metric tons delivered is a reflection of the uncertainties of the shear strengths of the sludges in the source tanks. We used a formal elicitation process to obtain probability distributions for the shear strength of the sludges for distinct regions in each of the source tanks. A spreadsheet model was developed to calculate metric tons delivered as a function of the shear strengths and the amount of waste in each of the source tanks. The model also calculates expected penalties for failure to meet the minimum order requirements. A Monte Carlo simulation made it possible to propagate the uncertainties of the shear strengths through the model to get uncertainties in the outputs of metric tons delivered and penalty costs. These output parameters were expressed as probability distributions. The results from this analysis are summarized in Table 6.1 and described in detail below. The table shows the results from five scenarios representing different assumptions concerning the amount of waste that would be mobilized in C-106. The first scenario is that the shear strength in C-106 after it is mobilized and transferred to 102-AY would be reestablished at its current 
Table 6.1. Summary of Results from Retrieval Effectiveness Risk Analysis

\begin{tabular}{||l|c|c|c||}
\hline $\begin{array}{c}\text { Scenario: C-106 } \\
\text { Assumptions }\end{array}$ & $\begin{array}{c}\text { Expected Value of } \\
\text { Metric Tons Delivered }\end{array}$ & $\begin{array}{c}\text { Probability of Failure } \\
\text { to Meet Minimum } \\
\text { Order Requirement }\end{array}$ & Cost Risk \\
\hline \hline $\begin{array}{l}\text { Shear strength } \\
\text { reestablishes after } \\
\text { transfer to DST }\end{array}$ & 250 & $47 \%$ & $\begin{array}{c}10 \% \text { chance }> \\
\$ 390 \text { million }\end{array}$ \\
\hline $100 \%$ upper & 300 & $0 \%$ & zero \\
\hline $80 \%$ of upper & 260 & $15 \%$ & $\begin{array}{c}10 \% \text { chance }> \\
\$ 32 \text { million }\end{array}$ \\
\hline $60 \%$ of upper & 225 & $90 \%$ & $\begin{array}{c}10 \% \text { chance }> \\
\$ 260 \text { million }\end{array}$ \\
\hline $40 \%$ of upper & 185 & $100 \%$ & $\begin{array}{c}10 \% \text { chance }> \\
\$ 480 \text { million; } \\
\end{array}$ \\
& & & $\begin{array}{c}90 \% \text { chance }> \\
\$ 248 \text { million }\end{array}$ \\
\hline
\end{tabular}

values. This most likely would not be the case; however, this scenario could also be representative of obtaining all the Phase 1B waste from double shell tanks. The other scenarios assume that $100 \%, 80 \%$, $60 \%$, and $40 \%$, respectively, will be retrieved from the upper portion of C-106 and that no waste will be retrieved from $\mathrm{C}-106$ hardpan.

The second column in the summary table shows the expected value (EV) or average for the number of metric tons (MT) that would be delivered for each of these scenarios. The third column shows the probability that the metric tons delivered would be less than the $245 \mathrm{MT}$ specified by the contract. The last column provides risk information concerning probabilities of likely cost penalties.

\subsection{Sludge Mobilization Calculations}

Mobilization effectiveness is a function of shear strength. Grams (1995) provides empirical data on the relationship between shear strength of sludge waste and the percent mobilized by mixer pumps. These empirical data were fitted with a curve that establishes the relationship between shear strength and percent sludge mobilized. The data and the fitted curve are shown in Figure 6.1. The equation for the curve is given by

$$
\text { Percent mobilized }=6.96+135.57 * \operatorname{EXP}(-\mathrm{A} / 19.86)
$$

where $A$ is a shear strength in thousands of $\mathrm{dy} / \mathrm{cm}^{2}$. 


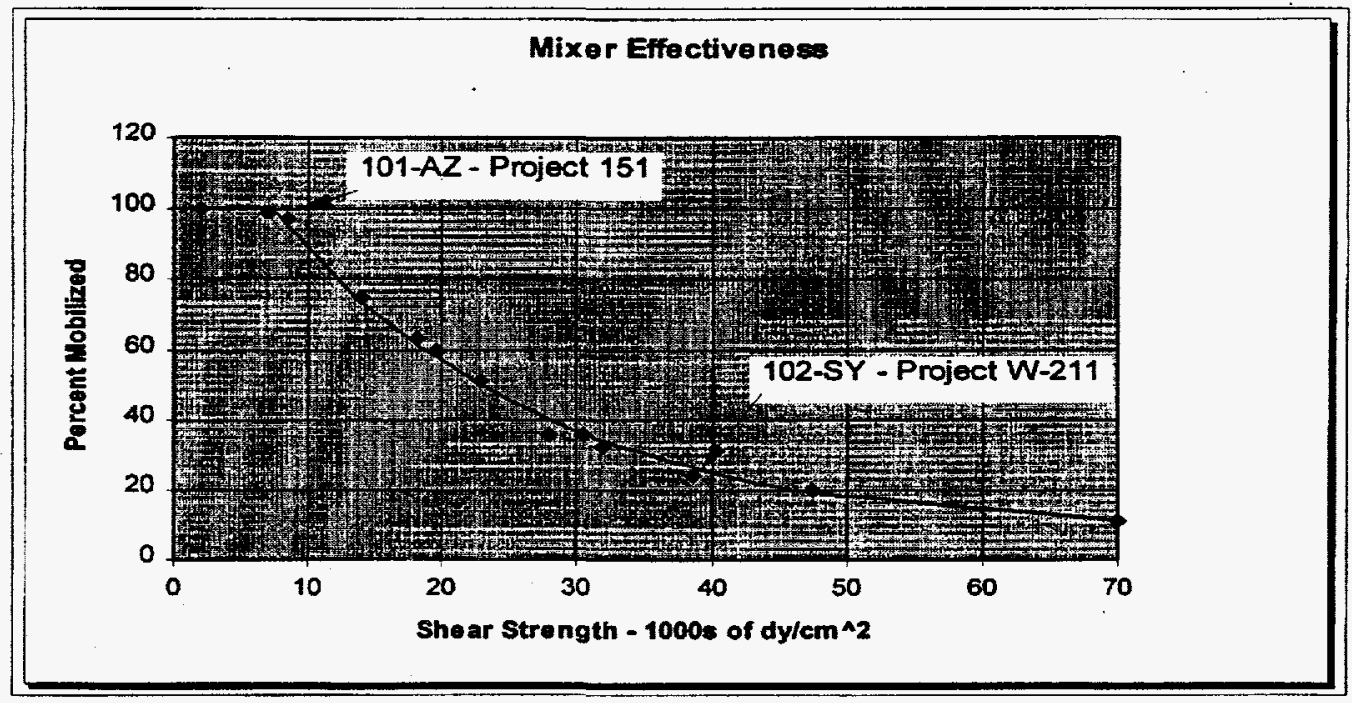

Figure 6.1. Relationship Between Sludge Mobilization and Shear Strength

Grams (1995) also provides data showing how shear strength is distributed over the 28 DSTs. This distribution is shown in Figure 6.2. Shown in the figure is both the cumulative distribution and the probability density function. As can be seen in the figure, the average shear strength in a tank is $24 \mathrm{~K} \mathrm{dy} / \mathrm{cm}^{2}$.

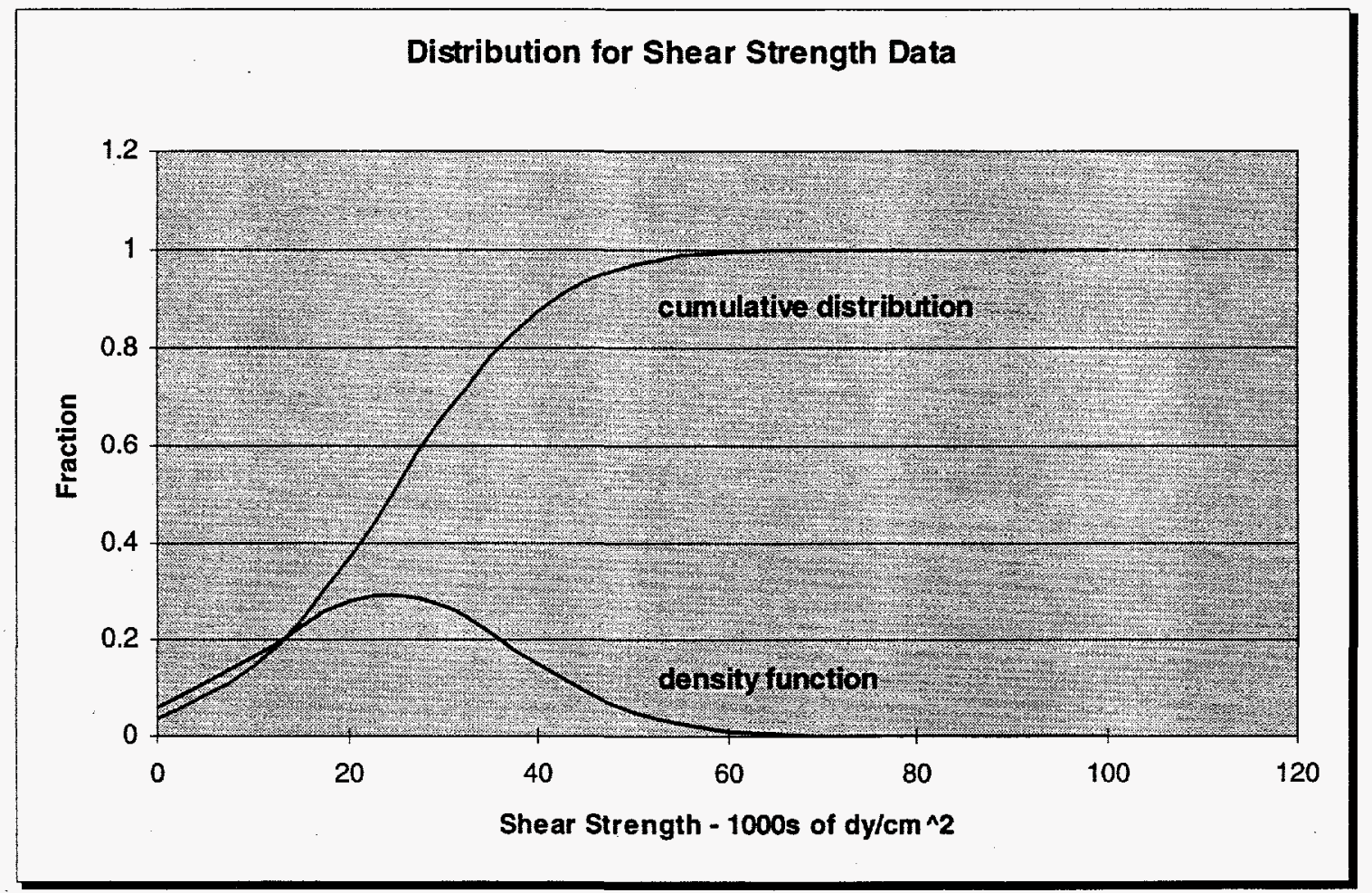

Figure 6.2. Distribution of Shear Strength Data Among Double-Shell Tanks 
This corresponds to approximately $50 \%$ mobilization and is the basis for the retrieval effectiveness score for mixer pumps presented in Section 3.0. Average shear strength was assumed for the generic tank that provided the basis for the multiattribute tradeoff analysis. The amount of sludge actually mobilized for Phase 1B of privatization will depend on the particular source tanks chosen and the amount and shear strengths of sludges in those tanks.

\subsection{Phase 1B Requirements}

Phase 1, Part B, of privatization will process low- and HLW. HLW will be processed in a HLW vitrification demonstration plant. The minimum amount of waste to be provided is currently thought to be 245 MT of nonvolatile waste oxides excluding sodium and silicon. The maximum that could be provided is $465 \mathrm{MT}$. Four tanks have been identified as source tanks for HLW feed. These tanks and their sludge contents are shown in Table 6.2.

Tank C-106 is a single-shell tank that will be sluiced to 102-AY before its waste is mobilized for HLW feed. Note that $\mathrm{C}-106$ contains nearly half the sludge waste to be mobilized. The amount of $\mathrm{C}-106$ sludge that will be mobilized will depend on how much is sluiced from C-106 and how much is subsequently mobilized from AY-102 using mixer pumps. The amount of C-106 waste mobilized from AY-102 will depend on the extent to which it has recovered shear strength while settling in AY-102.

The total amount of sludge available from these tanks is $130 \mathrm{in}$. If all of this sludge were to be mobilized, it would be equivalent to approximately $452 \mathrm{MT}$ delivered to the vitrification plant. This clearly would meet the $245 \mathrm{MT}$ minimum order requirement and still be less than the $465 \mathrm{MT}$ maximum. Of course, the amount mobilized if mixer pumps are used will depend on the shear strength of the sludges in those tanks. A limited number of samples have been taken from these tanks, and some shear strength measurements were made. The measurements were not always made under the best of conditions and the number of samples is limited; consequently, considerable uncertainty surrounds the shear strengths of the sludges in these tanks. A formal process was used to quantify the uncertainty in these tanks.

Table 6.2. Source Tanks and Their Sludge Amounts for HLW Feed

\begin{tabular}{|c|c|c|c|}
\hline Tank & Amount (in.) & Tank & Amount (in.) \\
\hline 101-AZ Upper & 6.5 & C-106 Upper & 62.64 \\
\hline 101-AZ Heel & 6.2 & C-106 Hardpan & 9. \\
\hline 102-AZ Upper & 25 & 102-AY Top & 3.6 \\
\hline 102-AZ Heel & 9.8 & 102-AY Bottom & 7.2 \\
\hline \multicolumn{3}{|r|}{ Total } & 129.94 \\
\hline
\end{tabular}




\subsection{Shear Strength Elicitation Process}

A formal elicitation process was used to obtain probability distributions of shear strength for each of the eight regions of the four HLW source tanks shown in Table 6.2. The elicitation process used is a variation on the Stanford Research Institute approach to probability elicitation (Spetzler and Stael von Hestein 1979). An expert who was familiar with the available shear strength data and the history of the relevant tank sampling and their results was identified. This person was informed as to the nature of the required elicitation, giving him time to prepare by reviewing the available literature.

The elicitation process consisted of agreeing on a clear definition of variables and the units to be used, providing some training in common probabilistic biases, encoding the probabilities, verifying, and modifying as needed. The training primarily focused on the well-known tendency for overconfidence, with resulting distributions that are too narrow. Practice was given by eliciting answers to almanac questions so the expert could experience this bias first hand, which would help him guard against it.

The actual elicitation consisted of first exploring the potential for extreme values and their possible explanations. This was followed by obtaining judgments for the 50th, 90th, and 10th percentiles. A curve was fitted and its validity verified by checking other points on the curve. The points obtained were then fitted with a Weibull probability distribution, which was used in the subsequent Monte Carlo analysis.

\subsection{Shear Strength Distributions}

The points elicited for each of the sludge regions are shown in Table 6.3. Also shown in the table are the parameters of the Weibull distribution that was fitted to these points. The equation for the Weibull distribution is given by

$$
\mathrm{F}(\mathrm{x})=1-\exp \left[-[\text { alpha/beta }]^{\wedge} \text { alpha }\right]
$$


Table 6.3. Shear Strength of Sludges in HLW Source Tanks for Phase 1B

\begin{tabular}{|c|c|c|c|c|c|c|c|}
\hline \multirow[b]{2}{*}{ Tank } & \multicolumn{5}{|c|}{ Shear Strength $\left(1000\right.$ dynes $\left./ \mathrm{cm}^{2}\right)$} & \multicolumn{2}{|c|}{ Parameters } \\
\hline & $1 \%$ & $10 \%$ & $50 \%$ & $90 \%$ & $99 \%$ & alpha & beta \\
\hline \multicolumn{8}{|c|}{ 101-AZ } \\
\hline Upper & 2 & 5 & 15 & 33 & 50 & 1.6 & 19.5 \\
\hline Heel & 2 & 5 & 20 & 35 & 55 & 2 & 24 \\
\hline \multicolumn{8}{|c|}{ 102-AZ } \\
\hline Upper & 4. & 8 & 14.4 & 22 & 45 & 3 & 16.6 \\
\hline Heel & 5 & 13 & 20 & 27 & 55 & 3.8 & 22.2 \\
\hline \multicolumn{8}{|c|}{ C-106 } \\
\hline Upper & 2 & 5 & 15 & 33 & 50 & 1.6 & 19.5 \\
\hline Hardpan & 5 & 8 & 27 & 40 & 55 & 2.6 & 30.1 \\
\hline \multicolumn{8}{|c|}{. $\quad 102-\mathrm{AY}$} \\
\hline Upper & 0 & & 30 & 48 & 55 & 2.1 & 35.6 \\
\hline Lower & 7 & 8 & 19 & 37 & 55 & 1.9 & 23.5 \\
\hline
\end{tabular}

The fitted Weibull cumulative distributions of shear strength for each of the tanks are shown in Figures 6.3 through 6.6. (Note that the difference in shading under the curves is just an artifact.) These distributions are inputs into the spreadsheet model in which the risk analysis was carried out using Monte Carlo simulation. 


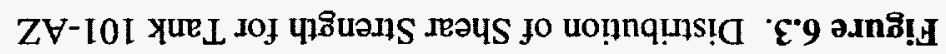
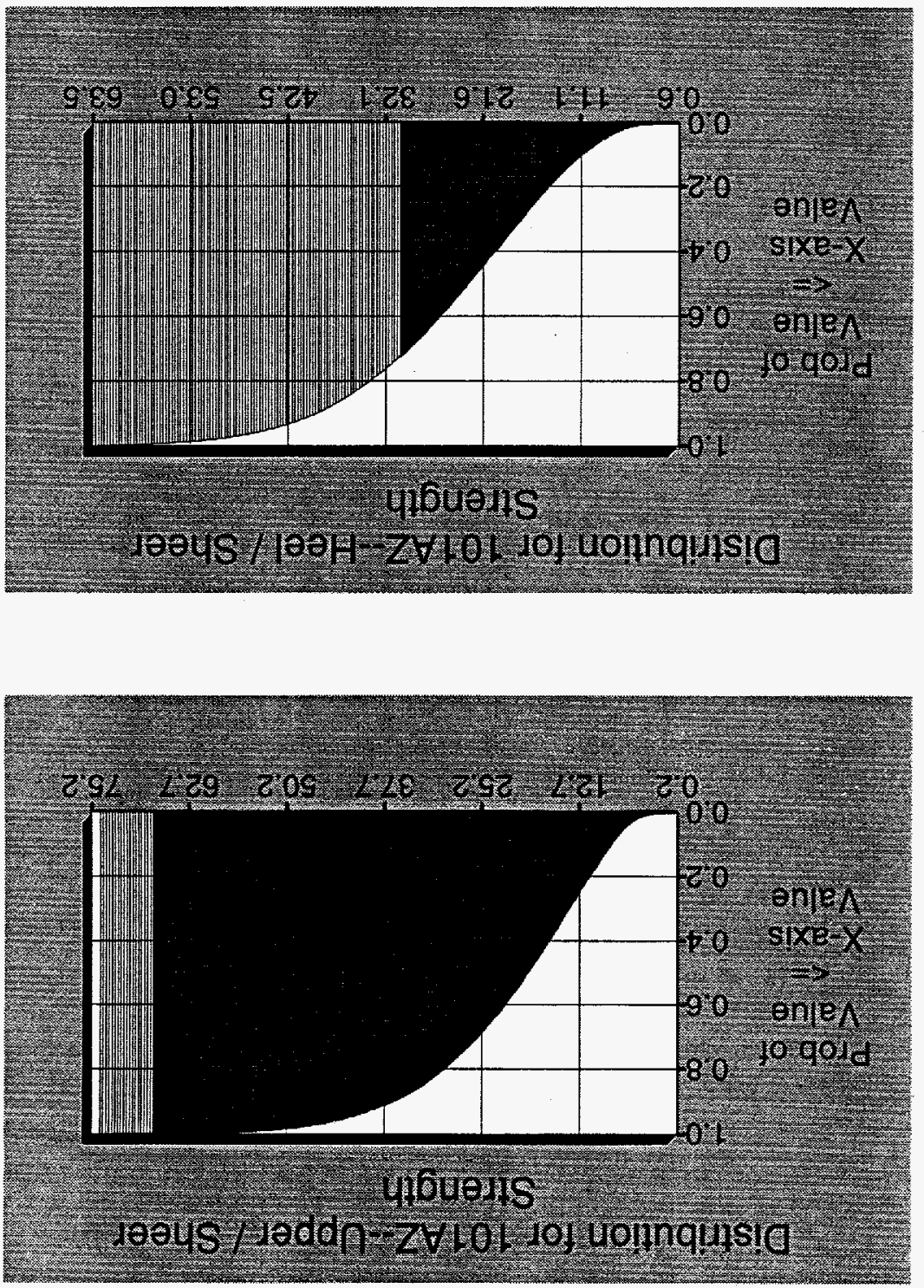


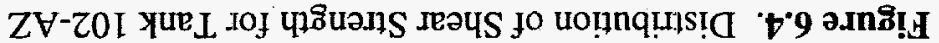
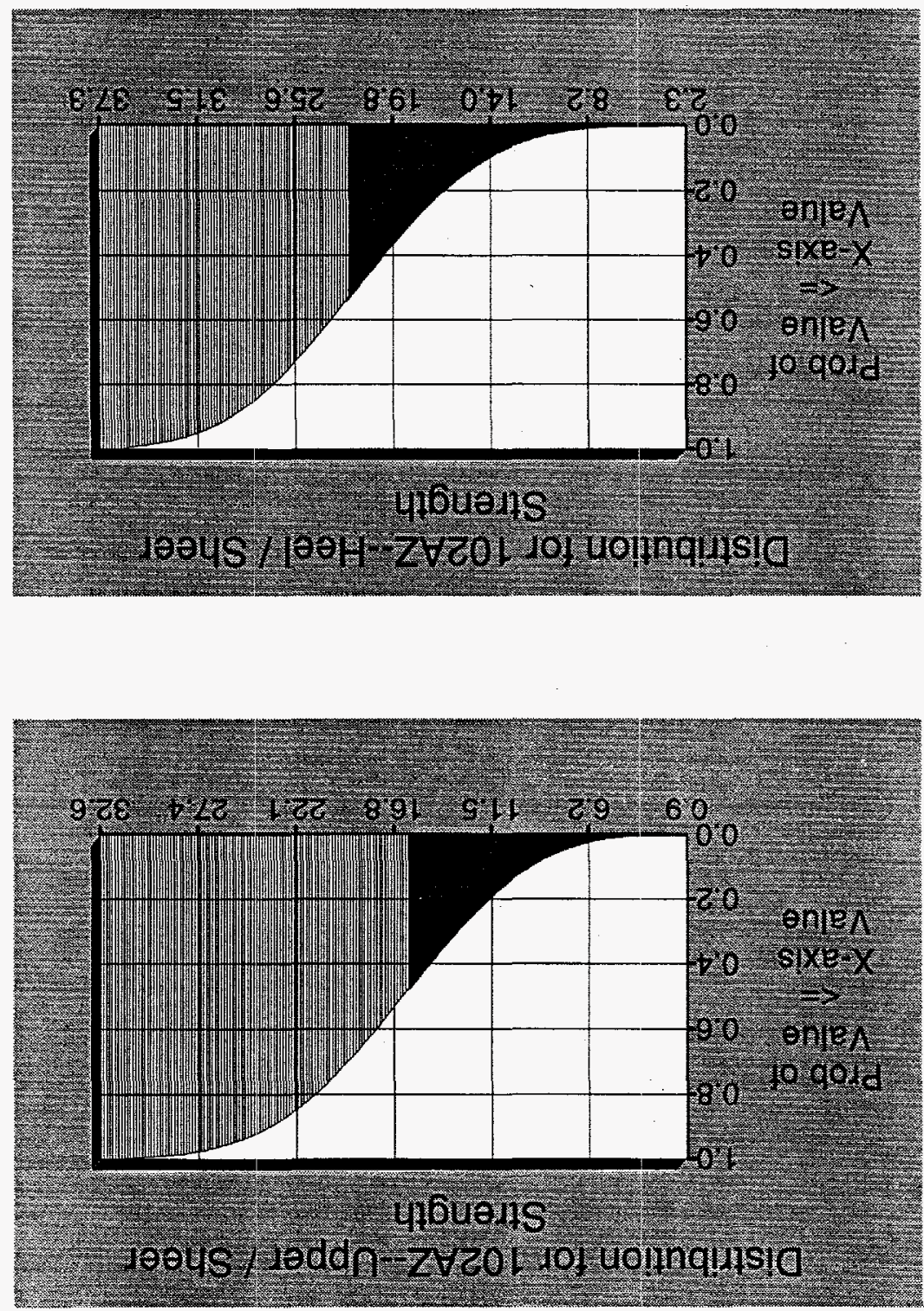

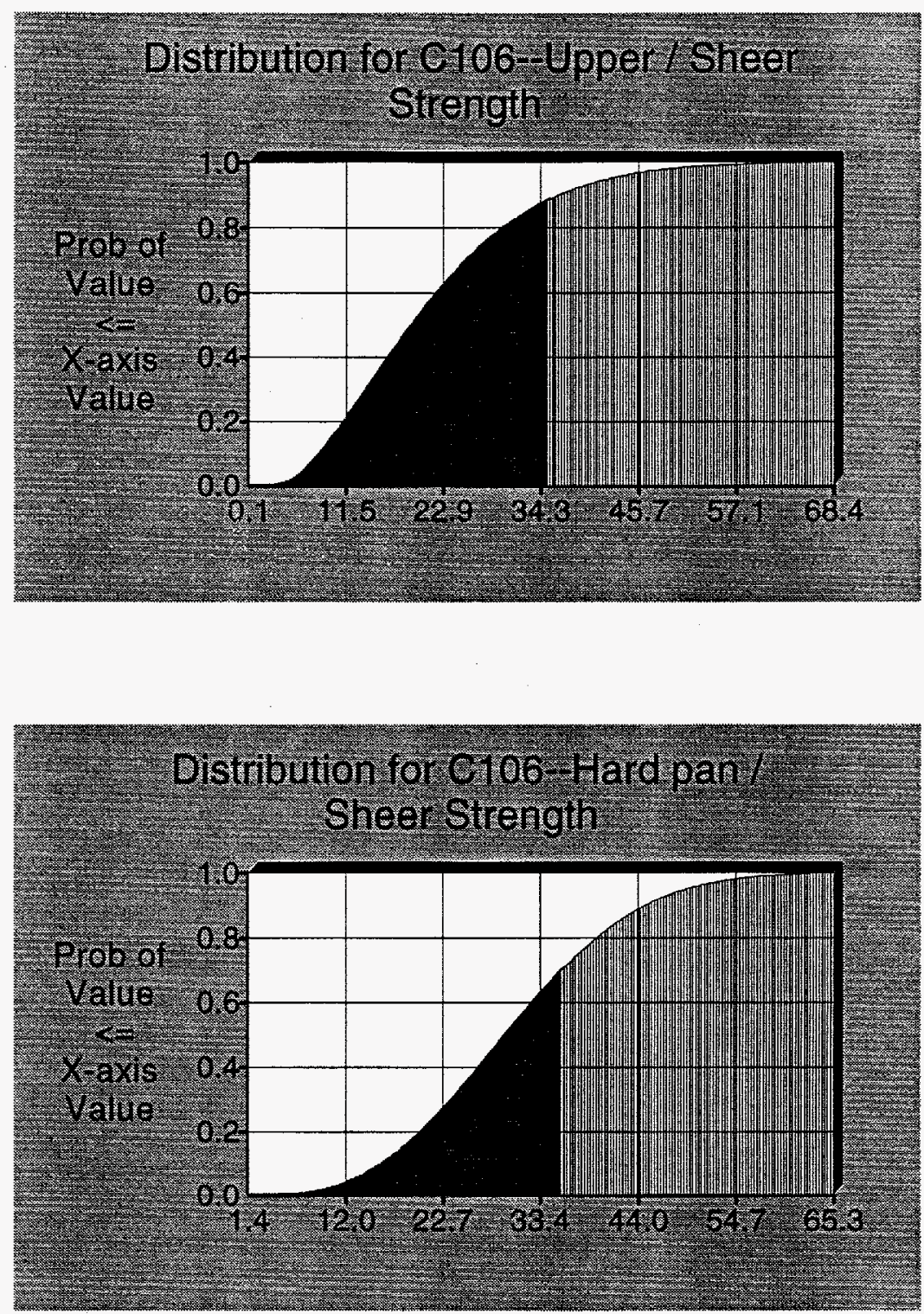

Figure 6.5. Distribution of Shear Strength for Tank 102-AY 

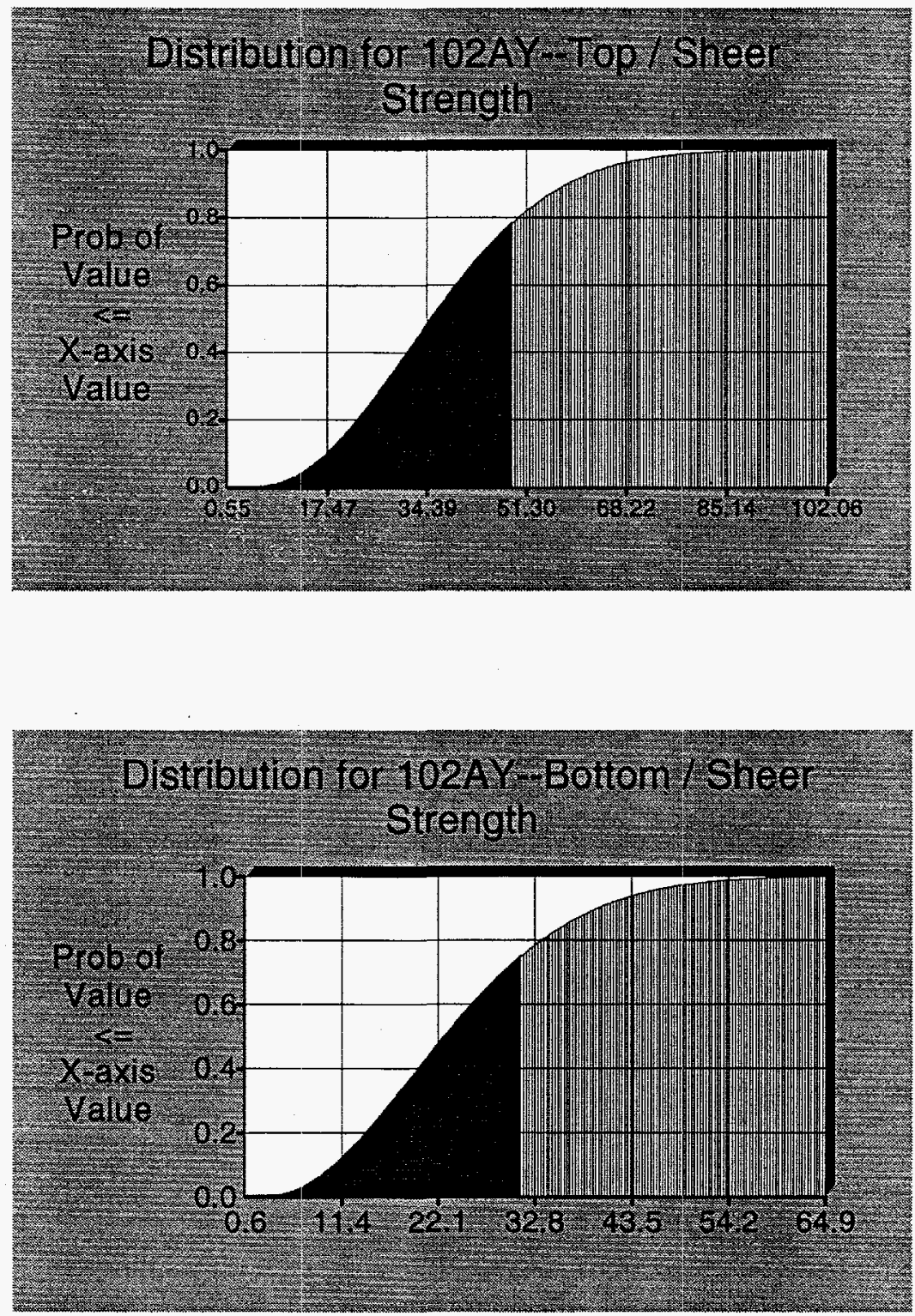

Figure 6.6. Distribution of Shear Strength for Tank C-106

\subsection{Monte Carlo Simulation Process and Results}

A spreadsheet model was constructed in order to calculate metric tons delivered as a function of shear strength and amount of sludge waste in the source tanks. The model calculates proportion retrieved as a function of the shear strength and applies this to the amount of waste in the tank to get the amount retrieved. A fluff factor is applied to get the amount in inches that is delivered to the HLW vitrification plant; this amount is converted to metric tons. The amount delivered is calculated for each of the eight regions in the four tanks and summed to get the total number of metric tons delivered. 
The Monte Carlo simulation consists of sampling from each of the shear strength distributions and performing the model calculations with the sample values. The output values are saved. This process is repeated to get a distribution of outputs. The resulting metric tons delivered were calculated for several different assumptions concerning the ability to retrieve $\mathrm{C}-106$ sludge from $\mathrm{AY}-10$, which will depend on the shear strength of $\mathrm{C}-106$ sludge at the time it is retrieved from AY-102.

One possibility is that the shear strength of C-106 sludge at the time it is retrieved from AY-102 is the same as its currently estimated values. This would be the case if it sat in AY-102 for a significant length of time and was allowed to reestablished its original shear strength as a result of no efforts at periodic mobilization. The results of this simulation are shown in Figure 6.7. The cumulative distribution shows the probability, on the $\mathrm{Y}$ axis, that the amount delivered would be less than or equal to the amount on the $\mathrm{X}$ axis. Under these assumptions, the most likely amount delivered would be $250 \mathrm{MT}$; however, there is a $47 \%$ chance that the amount delivered would be less than $245 \mathrm{MT}$.

A currently held assumption is that it will be possible to sluice $100 \%$ of the upper portion of C-106, and none of the hardpan. This led us to run the model in which it is assumed that $100 \%$ of $\mathrm{C}-106$ upper goes to the vitrification plant, with the amounts from the other tanks depending on their shear strengths. The result of this simulation is shown in the upper left panel of Figure 6.8. As can be seen in the figure, it is nearly certain that the minimum order requirement of $245 \mathrm{MT}$ would be met. The simulation assumes that all the sludge from $\mathrm{C}-106$ that was sluiced to AY-102 would subsequently be mobilized and

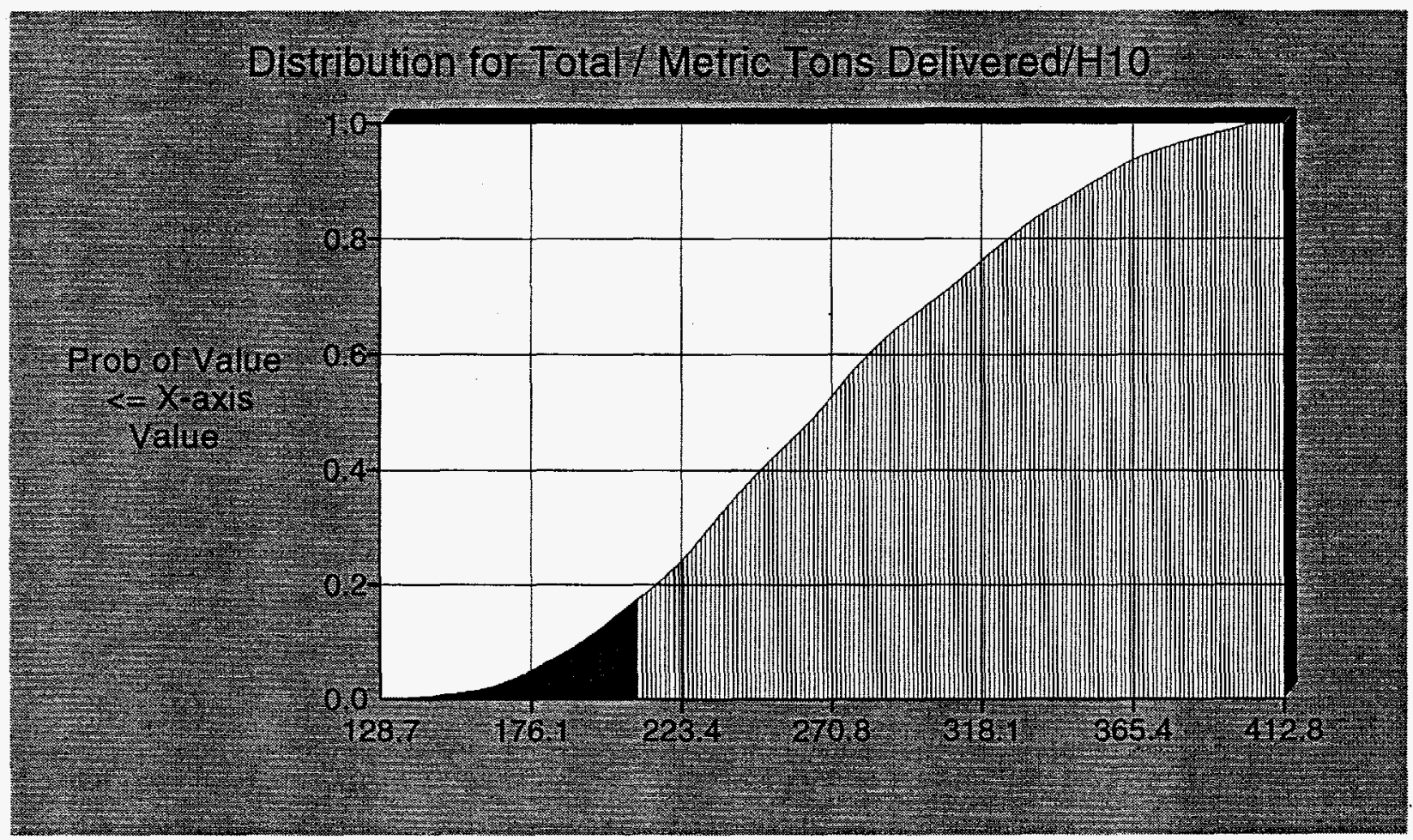

Figure 6.7. Metric Tons Delivered Assuming Current Shear Strengths in Tank C-106 
$21{ }^{\circ} 9$
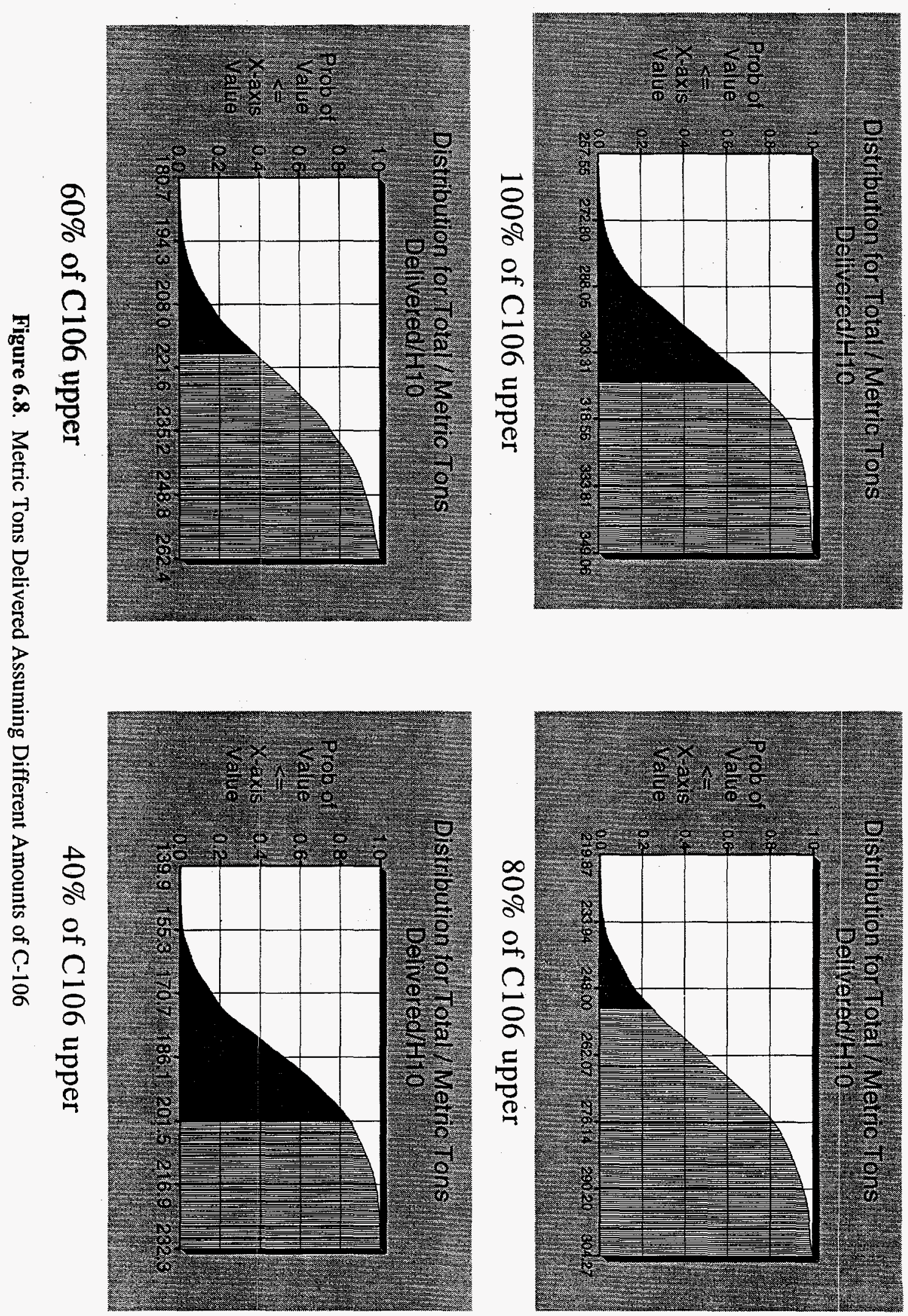
retrieved. It is difficult to know to what extent the shear strength of C-106 sludge would reestablish itself in AY-102 prior to mobilization and retrieval from that tank. It may not reestablish its shear strength for years. However, three other simulations are provided that assume that $80 \%, 60 \%$, and $40 \%$ of C-106 upper-level sludge is ultimately provided to the vitrification plant. As can be seen from these distributions, there is approximately a $15 \%$ chance of failing to meet the minimum order requirements if $80 \%$ of C-106 sludge were mobilized; there is only about a $10 \%$ chance of meeting the minimum order requirements if only $60 \%$ were mobilized; and it would be impossible to meet these requirement if only $40 \%$ were mobilized.

Failure to meet the minimum order requirements can result in substantial penalties for putting the HLW vitrification plant on idle time. Also, failure to meet the minimum order requirements will result in the need to process and pay for waste in Phase 2 that should have been processed in Phase 1. Idle time costs are estimated to be $\$ 800 \mathrm{~K}$ a day, and $5 \mathrm{MT}$ of waste is equivalent to 30 days of idle time. Thus, each MT short of the minimum order requirements represents $\$ 4.8$ million in idle time costs. In addition, this waste must be processed in Phase 2, and it is estimated to cost $\$ 1$ million per MT for Phase 2 processing. Thus, each metric ton of waste not processed in Phase 1 that is short of the minimum order requirements has the potential to cost DOE $\$ 5.8$ million dollars.

For each of the scenarios involving different assumptions concerning the amount of C-106 waste that would be mobilized, Monte Carlo simulations were carried out to calculate possible cost penalties. The results of these simulations are shown in Figure 6.9; specific risks were identified in the last column of Table 6.1. Figure 6.9 shows cumulative distributions for the cost penalties for all the scenarios except the assumption of $100 \%$ retrieved from the upper portion of C-106. This later assumption had zero risk of incurring a penalty and represents the current planning assumption. 

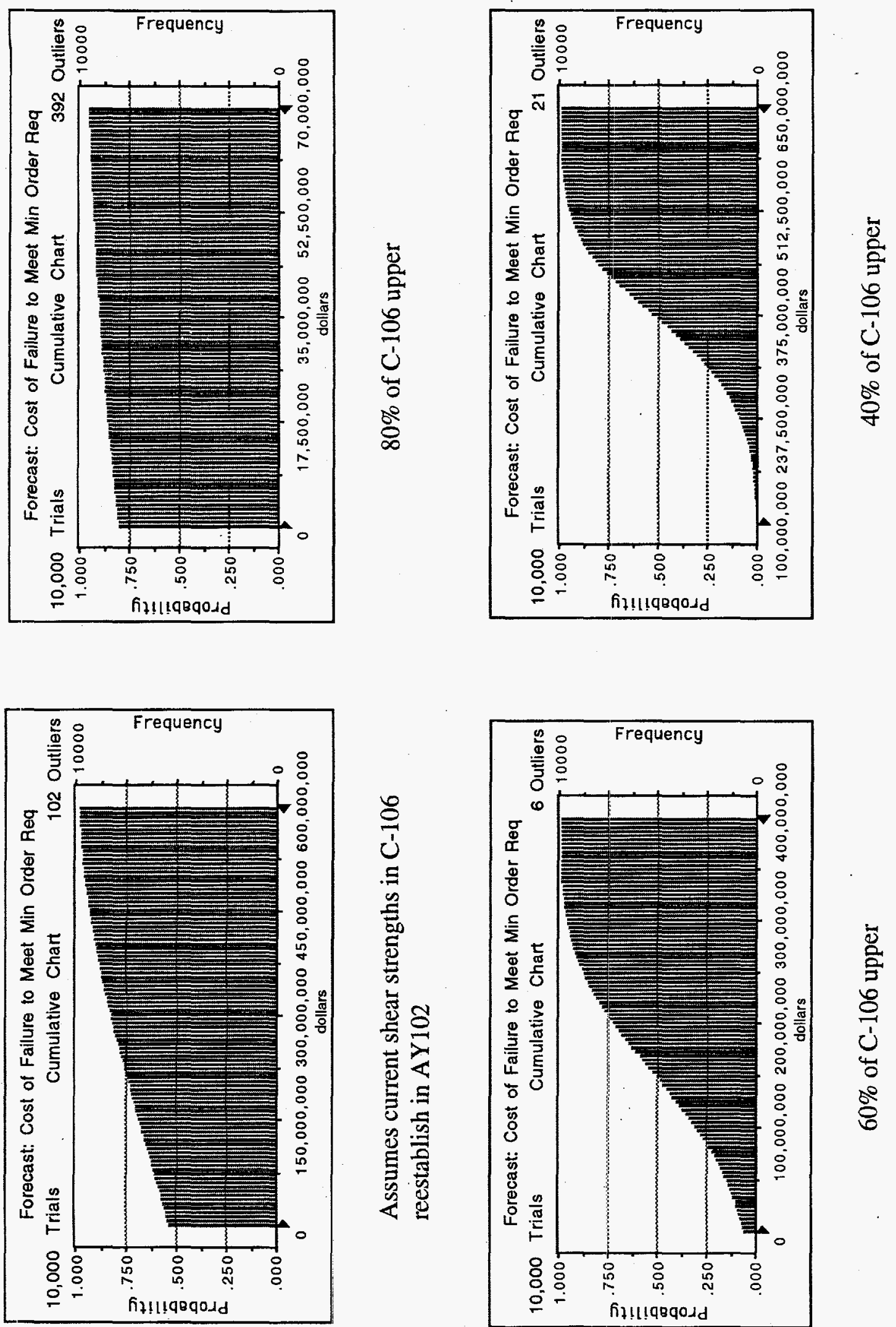

号

\subsection{4}




\subsection{Operating Efficiency Risk Analysis}

A reliability study was performed to predict expected mission times and expected mission costs for the alternative retrieval systems. Major retrieval subsystem reliabilities and unreliabilities were calculated based on assumed mission durations (determined in the cost and schedule section) and assumed failure distributions for major components of the system. The reliabilities and unreliabilities were used to calculate the probability of occurrence for the most likely scenarios. The expected mission times and costs were then determined for each of these scenarios. Mission times and costs were evaluated for different design lifetimes and "burn-in" strategies.

The systems evaluated included the mixer pump system, the sluicing system, and the mechanical arm system. Two transfer alternatives were included with the mechanical arm retrieval system; however, only the pipeline transfer is used in summarizing the results. Each alternative was evaluated on the basis of retrieval of $2 \mathrm{ft}$ of sludge (approximately 70,000 gal) from a double-shell tank. All systems are included in the complete study results in Appendix C.

\subsection{Burn-in Versus No Burn-in}

Equipment and systems are often "burned in" to eliminate the "infant mortality" failures at the beginning of the equipment or system lifetime. The manufacturer will run the system/equipment for a period of time to verify that it runs adequately. For this study, the systems that were burned in are modeled using a triangular failure distribution, and the systems with no burn-in period with an exponential failure distribution.

Intuitively, the exponential distribution is a reasonable model for equipment with significant infant mortality for which the manufacturer uses no burn-in period to eliminate the infant failures. The exponential distribution is most appropriate for equipment that tends to suffer "infant mortality" but has no tendency to wear out. The triangular distribution represents equipment with no significant infant mortality but with an upper bound on life length and a tendency to wear out. Appendix C, Section C.2, has additional discussion of the rationale for choosing these two failure distribution assumptions.

The reliability of a component with a triangular failure distribution will depend on how much of the component lifetime has been used prior to the start of the retrieval campaign. To account for this, each evaluation is done three times: for beginning of life (BOL) conditions, for middle of life (MOL) conditions, and for end of life (EOL) conditions.

For both distributions, the reliabilities and unreliabilities were used to calculate the probability of occurrence of the following scenarios:

- The mission is completed with no failures.

- A defined component or system fails and is repaired; the mission resumes and is completed. 
- Multiple pieces of required equipment fail and are repaired; the mission resumes and is completed. (The assumed sequence is retrieval, failure 1, repair 1, retrieval, failure 2, repair 2, completion of mission). Notice that, although a probability is calculated for "multiple" failures, only two failure/ repair episodes will be assumed for calculation of expected mission time and expected mission cost.

A mean time to repair (MTTR) of one week is assumed for failures allowing contact maintenance (rough.ly, aboveground failures) and a MTTR of one month for failures requiring non-contact maintenance (roughly, in-tank failures). In these calculations, half of the failures are assumed to allow contact maintenance and half to require non-contact maintenance.

Table 7.1 provides the results for the most likely cases where the MTTF is $2000 \mathrm{hr}$ for most components and systems and the equipment is new when placed in the tank. It is assumed that the mixer pump and other retrieval systems will only be used in a single tank and not re-used for other tanks; therefore the BOL case is considered for the burn-in scenario.

The mixer/pump retrieval system maintains lower expected mission times and costs than either the sluicing system or the mechanical arm system. As shown in this table, the expected mission time is longer and the mission cost higher for the cases where no burn-in was applied. This suggests that there is a significant benefit to burning in equipment before it is placed in service. Figure 7.1 also depicts the burnin versus no burn-in for each of the systems.

The operating efficiency is higher for those systems that are burned in. The operating efficiency is calculated as the ratio of no-failure mission time to the expected mission time and is the percent time the entire system is available for operation. As the above table shows, the mixer/pump system that is burned in has an operating efficiency of $91 \%$; thus, the system is available for operation $91 \%$ of the time. The expected mission times and the no-failure mission times are provided in Table C. 2 of Appendix C. These are used to determine the system's operating efficiency.

Table 7.1. Summary Table of Reliability Study (2000-hr equipment life)

\begin{tabular}{||l|l|r|r||}
\hline \multicolumn{1}{|c|}{ Retrieval System } & \multicolumn{1}{|c|}{ Category } & \multicolumn{1}{c|}{ Burn-in } & No Burn-in \\
\hline Mixer/Pump System & Expected Mission Time & 62 days & 83 days \\
& Expected Mission Cost & $\$ 574,000$ & $\$ 646,000$ \\
& Operating Efficiency & 0.91 & 0.67 \\
\hline Sluicing System & Expected Mission Time & 67 days & 85 days \\
& Expected Mission Cost & $\$ 683,000$ & $\$ 839,000$ \\
& Operating Efficiency & 0.78 & 0.61 \\
\hline Mechanical Arm System & Expected Mission Time & 84 days & 97 days \\
w/ Pipe Transfer & Expected Mission Cost & $\$ 874,000$ & $\$ 1,074,000$ \\
& Operating Efficiency & 0.76 & 0.66 \\
\hline
\end{tabular}




\section{Expected Mission Time for Alternative Retrieval Systems}

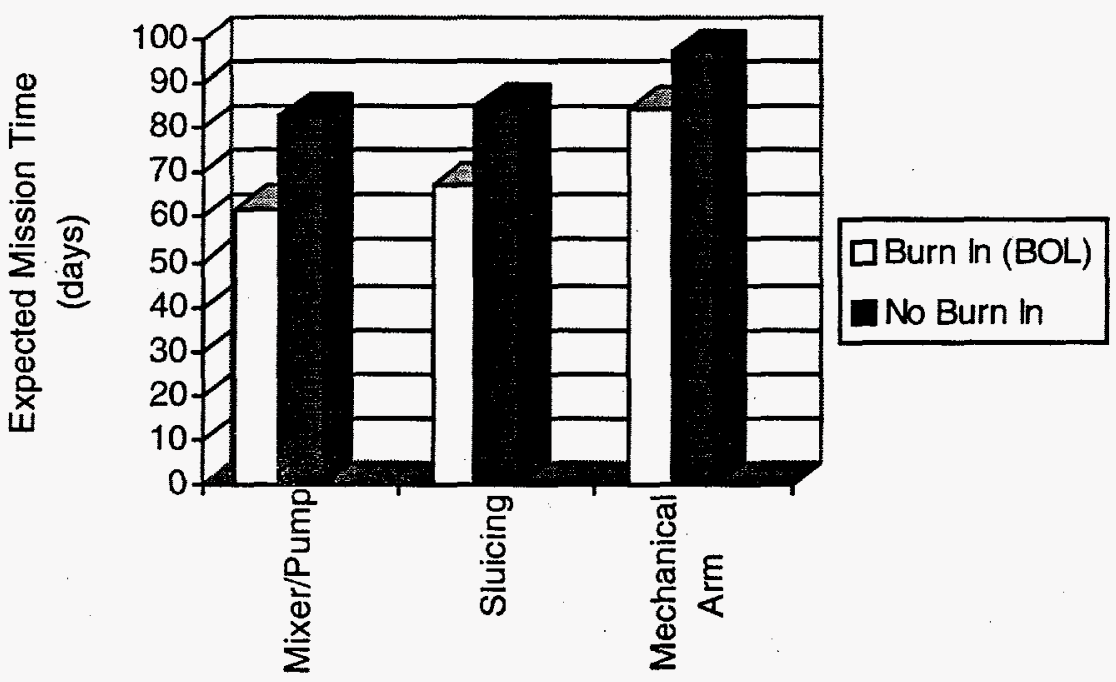

Alternative Retrieval Systems

Expected Mission Cost for Alternative Retrieval Systems

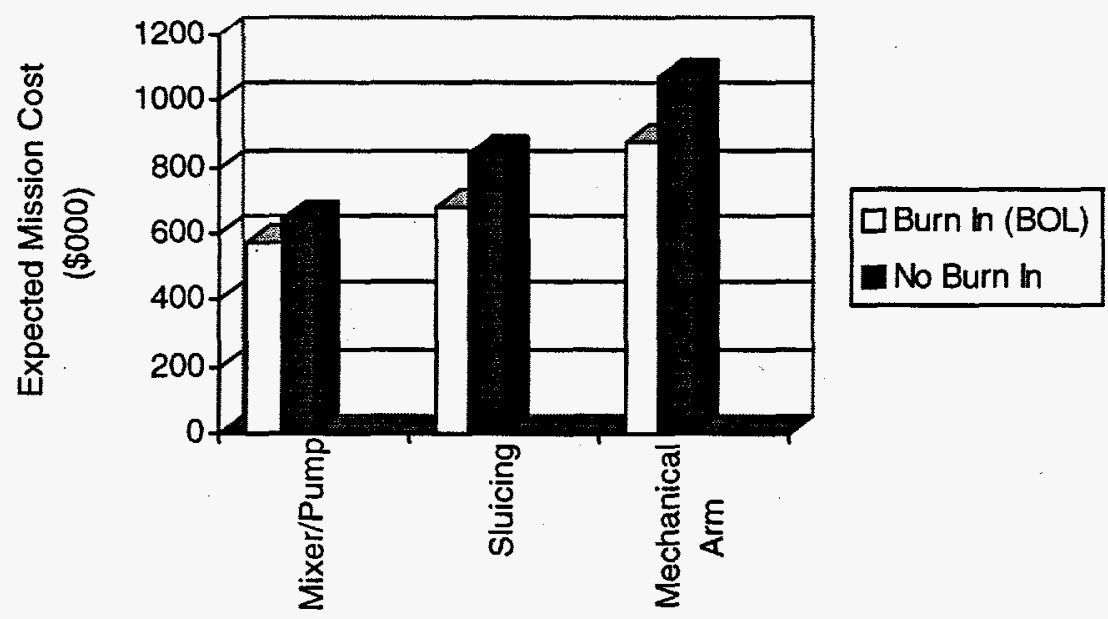

Alternative Retrieval Systems

Figure 7.1. Expected Mission Time and Cost for Burn-in and No Burn-in

\subsection{Equipment Lifetime}

The above results assumed design lifetimes of equipment to be $2000 \mathrm{hr}$. The various component lifetimes that were evaluated are provided in Table 7.2. As shown, the mixer pumps were evaluated for three different MTTFs: $2000 \mathrm{hr}, 6000 \mathrm{hr}$, and $7000 \mathrm{hr}$. 
Table 7.2. Assumed Component/Subsystem Lifetimes

\begin{tabular}{||l|c||}
\hline \multicolumn{1}{|c|}{ Component } & $\begin{array}{c}\text { Mean Time to } \\
\text { Failure }\end{array}$ \\
\hline Mixer pumps (3 evaluations) & $\begin{array}{c}2000,6000, \\
\text { and } 7000 \mathrm{hr}\end{array}$ \\
\hline All other pumps & $2000 \mathrm{hr}$ \\
\hline Control systems & $6000 \mathrm{hr}$ \\
\hline Pump/sluicer turntables & $6000 \mathrm{hr}$ \\
\hline Cyclone separator and associated equipment & $2000 \mathrm{hr}$ \\
\hline Truck transfer systern & $2000 \mathrm{hr}$ \\
\hline Retrieval tank HVAC system & $2000 \mathrm{hr}$ \\
\hline Other HVAC systems & $6000 \mathrm{hr}$ \\
\hline Robotic arm & $1000 \mathrm{hr}$ \\
\hline
\end{tabular}

The burn-in of equipment can lead to a higher rate of failure towards the end of the equipment mission time. When the equipment is run for the burn-in, its lifetime is reduced. This has lead to a major program for developing advanced mixer pumps with longer mean life than the current pumps. The burn-in and no burn-in scenarios were evaluated for both the 2000-hr and 6000-hr MTTF mixer/pump system. The results are provided in Table 7.3 .

As Table 7.3 shows, the mission time and mission cost are reduced using a 6000 -hr pump rather than the currently used mixer pump with a 2000 -hr MTTF. The operating efficiency increases significantly with the longer MTTF pumps. As shown, the 6000 -hr pump has a $97 \%$ operating efficiency; thus there is little time that the system will be down and not operating.

Table 7.3. Mixer Pump Evaluation with 2000-hr and 6000-hr MTTF

\begin{tabular}{||l|l|r|r||}
\hline \hline Mixer/Pump System & \multicolumn{1}{|c|}{ Category } & \multicolumn{1}{c|}{ Burn-in } & \multicolumn{1}{|c|}{ No Burn-in } \\
\hline $2000-$ hr MTTF & Expected Mission Time (days) & 62 days & 83 days \\
& Expected Mission Cost $(\$ 000)$ & $\$ 574,000$ & $\$ 646,000$ \\
& Operating Efficiency & 0.91 & 0.67 \\
\hline \multirow{2}{*}{$5000-$ hr MTTF } & Expected Mission Time (days) & 58 days & 73 days \\
& Expected Mission Cost $(\$ 000)$ & $\$ 540,000$ & $\$ 559,000$ \\
& Operating Efficiency & 0.97 & 0.77 \\
\hline
\end{tabular}




\subsection{Reliability Risk}

The expected mission durations and costs are a probability-weighted average of the mission times and costs for each scenario. There is some probability that the mission time will be longer or shorter and the cost higher or lower than the expected values. For summarizing the probability, the high no-failure and high multiple-failure probabilities were evaluated. Table 7.4 provides these cases.

Table 7.4. Systems With High Probability of Mission Success with No Failures and Systems with High Probability of Multiple Failures Prior to Successful Completion of the Mission

\begin{tabular}{|c|c|c|c||}
\hline System & $\begin{array}{c}\text { Probability of } \\
\text { No Failures }\end{array}$ & System & $\begin{array}{c}\text { Probability } \\
\text { of Multiple } \\
\text { Failures }\end{array}$ \\
\hline $\begin{array}{c}\text { Mixer/Pump, } \\
6000 \text {-hr MTTF } \\
\text { No Burn-in }\end{array}$ & $45 \%$ & $\begin{array}{c}\text { Mixer/Pump } \\
\text { 2000-hr MTTF } \\
\text { No Burn-in }\end{array}$ & $49 \%$ \\
\hline $\begin{array}{c}\text { Mixer/Pump } \\
\text { 7000-hr MTTF } \\
\text { No Burn-in }\end{array}$ & $47 \%$ & $\begin{array}{c}\text { Sluicer } \\
\text { No Burn-in }\end{array}$ & $81 \%$ \\
\hline $\begin{array}{c}\text { Mixer/Pump } \\
\text { 2000-hr MTTF } \\
\text { Burn-in (BOL) }\end{array}$ & $76 \%$ & $\begin{array}{c}\text { Mech Arm } \\
\text { No Burn-in }\end{array}$ & $85 \%$ \\
\hline $\begin{array}{c}\text { Mixer/Pump } \\
\text { 6000-hr MTTF } \\
\text { Burn-in (BOL) }\end{array}$ & $93 \%$ & $\begin{array}{c}\text { Mixer/Pump } \\
\text { 2000-hr MTTF } \\
\text { Burn-in (EOL) }\end{array}$ & $97 \%$ \\
\hline $\begin{array}{c}\text { Sluicer } \\
\text { Burn-in (BOL) }\end{array}$ & $41 \%$ & $\begin{array}{c}\text { Mixer/Pump } \\
\text { 6000-hr MTTF } \\
\text { Burn-in (EOL) }\end{array}$ & $45 \%$ \\
\hline Mixer/Pump \\
6000 -hr MTTF, \\
Burn-in (BOL)
\end{tabular}


The mixer pump systems with no burn-in and assumed MTTF of 6000 and 7000 hours have a probability of $45 \%$ and $47 \%$, respectively, of no failures throughout the mission. This is due to their longer lifetime over the mixer pumps assumed to have 2000 hour MTTF. Other systems with high nofailure probabilities are mixer/pump and sluicer systems with burn-in when they are used at the beginning of their lifetime. The burn-in eliminates most failures at the beginning of the mission. Because those components/systems have a full lifetime at the start of the mission, failures during the mission are minimized.

Systems with high multiple-failure probabilities are those that are operated with no burn-in and have a 2000-hr MTTF or those with burn-in operated at the MOL or EOL. As shown in Table 7.4, the sluicer and mechanical arm systems that are placed in operation at the end of their life have a $100 \%$ probability of multiple failures. 


\subsection{References}

Boomer, K.D., S.K.Baker, A.L. Boldt, J.D. Gailbreath, J.S. Garfield, C.E. Goldberg, B.A. Higley, L.J. Johnson, M.J. Kupfer, R.M. Marusich, R.J. Parazin, G.W. Praga, G.W. Reddick, L.M. Swanson, T.L. Waldo, and C.E. Wircester. 1993. Tank Waste Technical Options Report. WHC-EP-0616, Westinghouse Hanford Company, Richland, Washington.

Grams, W.H. 1995. Double Shell Tank Retrieval Allowable Heel Trade Study Analysis. WHC-SD-WM-TA-162, Westinghouse Hanford Company, Richland, Washington.

Keeney, R.L. and D. von Winterfeldt. 1996. Value-Based Performance Measures for Hanford Tank Waste Remediation System (TWRS) Program. PNNL-10946, Pacific Northwest National Laboratory, Richland, Washington.

Leigh, J.P. 1987. "Estimates of the Probability of Job-Related Death in 347 Occupations." J. of Occupational Medicine 29(6).

Lockheed Martin Hanford Corportaion (LMHC). 1996. Tank Waste Remediation System Final Safety Analysis Report. WHC-SD-WM-SAR-067, Lockheed Martin Hanford Corporation, Richland, Washington.

Los Alamos National Laboratory (LANL). 1996a. A Safety Assessment for Proposed Mixing Operations to Mitigate Episodic Gas Releases in Tank 241-SY-101: Hanford Site, Richland, Washington. WHC-SDWM-SAD-033, Los Alamos National Laboratory, Los Alamos, New Mexico.

Los Alamos National Laboratory (LANL). 1996b. A Safety Assessment for Saltwell Jet Pumping Operations in Tank 241-A-101: Hanford Site, Richland, Washington. WHC-SD-WM-SAD-036, Westinghouse Hanford Company, Richland, Washington.

National Safety Council (NSC). 1986. Accidents Facts - 1986 Edition. Itasca, Illinois.

Powell, W.J., R.G. Brown, J.D. Galbraith, C.E. Jensen, D.E. Place, G.W. Reddick, W.F. Zuroff, and A.J. Brothers. 1996. Neutralized Current Acid Waste Consolidation Management Plan. WHC-SD-WMER-532, Revision OA, Westinghouse Hanford Company, Richland, Washington.

Salzano, T.B., E.L. Dalpiaz, and A.N. Palit. 1997. Double-Shell Tank Retrieval System Alternative Generation Analysis Support. Fluor Daniel Northwest, Inc., Richland, Washington.

Saski, L.M. 1997. Tank Characterization Report for Double Shell Tank 241-AY-102.

WHC-SD-WM-ER-454, Rev. 0, Westinghouse Hanford Company, Richland, Washington. 
Sathyanarayana, K. 1994. Summary Report Thermal Hydraulic Safety Analysis of Aging Waste Tank 101$A Z$. WHC-SD-WM-ER-335, Revision 0, Westinghouse Hanford Company, Richland, Washington.

Sathyanarayna, K. 1996a. Thermal Hydraulic Evaluation of Consolidating Tank C-106 Waste into Tank AY-102. WHC-SD-WM-ER-534, Revision 0, Westinghouse Hanford Company, Richland, Washington.

Sathyanarayna, K. 1996b. Evaluation of Potential and Consequences of Steam Bump in High Heat Waste Tanks and Assessment and Validation of GOTH Computer Code. WHC-SD-WM-CN-022, Revision 0, Westinghouse Hanford Company, Richland, Washington.

Scheele, R.D., M.E. Peterson, and J.M. Tingey. 1989. Characterization of the First Core Sample of Neutralized Current Acid Waste From Double-Shell Tank 101-AZ. PNL-7758, Pacific Northwest Laboratory, Richland, Washington.

Spetzler, C.S., and C.A.S. Stael von Holstein. 1975. "Probability Encoding in Decision Analysis." Management Science, 22, No 3.

State of Washington. 1993. Washington State Occupational Injury and Illness Survey 1991. State of Washington, Department of Labor and Statistics, Olympia, Washington.

Westinghouse Hanford Company (WHC). 1995a. Interim Chapter 3, Hazard and Accident Analysis. WHC-SD-WM-SAR-065, Westinghouse Hanford Company, Richland, Washington.

Westinghouse Hanford Company (WHC). 1995b. Title 1 Design Summary Report Initial Tank Retrieval Systems Project W-211. WHC-SD-W211-TDR-001, Rev. 0B, Westinghouse Hanford Company, Richland, Washington. 
Appendix A

Environment, Health, and Safety Analysis 


\section{Appendix A}

\section{Environment, Health, and Safety Analysis}

\section{A.1 Introduction and Assumptions}

This study presents the rationale for deciding on the best alternative to retrieve double-shell tank (DST) sludge. This portion of the study presents the basis for ranking the attributes of "safety" and "environment."

The data for the scoring comes from previous engineering studies and safety documents such as safety analysis reports or safety assessments. The ranking for each attribute is performed on an alternativespecific basis; the score is a combination of a number of inputs. (The ranking process for each attribute is explained in the specific section.)

It is assumed that all waste (including single-shell tank [SST] waste) will be transported to the privatization plants by one of these options. All of the waste to be transferred (both SST and DST) is assumed to initially reside in the DSTs. The waste to be retrieved is either in existing DST waste or in sluiced waste from SSTs. The waste residing in the DSTs prior to retrieval is assumed to meet the design specifications for DSTs (including aging waste tanks). The safety documentation and operational safety limits (technical safety requirements) are assumed to have been prepared, reviewed, and approved.

The waste transferred to the privatization plant is assumed to reside for some short period of time in that facility's staging tank. The waste in the staging tank is assumed to be of such a form that the safety issues associated with it are minor. An example of that form is liquid waste with little sludge or solids with a low heat generation rate (e.g., less than $70,000 \mathrm{Btu} / \mathrm{hr}$ ) as opposed to waste that has a high heat load and is sludgelike with a high solids fraction.

It is assumed that the tank being retrieved and the receiver tank can (and do) contain waste that poses a threat for retention of flammable gas and the potential for release at a rate larger than the generation rate. As such, measures to control ignition and mitigate gas retention measures may need to be taken to keep the risks of operation within acceptable limits (see Section A.2).

\section{A.2 Safety Issues that Require Resolution Before Waste Retrieval}

A number of potential safety issues have been raised as a result of the preparation of safety documentation for Project W-320. The safety issues pertain to two types of waste to be retrieved: waste that has been removed from a SST and placed in a DST or waste already in a DST. Examples are the safety issues associated with Tank AY-102 after C-106 waste has been transferred to it (Project W-320) or the safety 
issues associated with retrieval of flammable gas DST as described in the W-211 safety documentation. The issue will need to be addressed and resolved before the retrieval of waste from any DST considered in this study.

\section{A.2.1 Tank Bump}

Sathyanarayana (1996a) describes the thermal hydraulic analysis performed to provide the technical basis for storage of Tank C-106 waste in Tank AY-102. The analysis shows that a heat load of $125,000 \mathrm{Btu} / \mathrm{hr}, 11 \mathrm{ft}$ of sludge based on a fluff factor of 2.0 (that is, $5 \mathrm{ft}$ of C-106 sludge transferred to Tank AY-102) results in $10 \mathrm{ft}$ of sludge in Tank AY-102. At a primary exhaust flow of $630 \mathrm{ft}^{3} / \mathrm{min}$, the annulus ventilation must operate at a flow rate of $2000 \mathrm{ft}^{3} / \mathrm{min}$ to prevent waste temperatures from exceeding the local saturation (i.e., boiling) temperature. The peak steady state temperature is a function of the effectiveness of the annulus ventilation; effectiveness being a function of cooling channel design, whether the cooling channels are open, the size of the flow distribution system, and the actual flow split between the annulus flow and cooling channel flow. Assurance of adequate flow is very important in extending the amount of time the ventilation system can be out of service before a tank bump occurs. With $2000 \mathrm{ft}^{3} / \mathrm{min}$ annulus ventilation (i.e., tank cooling channel) flow and $30 \mathrm{ft}$ of waste in the tank (19 ft of liquid on top of the $11 \mathrm{ft}$ of sludge), a ventilation system outage of at least 60 days is needed before a tank bump can occur (Sathyanarayana 1996b).

Not only is a tank bump possible in aging waste tanks if the sludge level is high, but one can occur in DSTs if the sludge level is great enough. The results presented in Sathyanarayana (1996a) can be approximated by modeling the sludge as a slab that generates heat internally and transfers that heat to the cooling channels and surface temperature equal to the liquid temperature. Sathyanarayana (1996a) shows that with no cooling channel ventilation flow, the peak sludge temperature with $11 \mathrm{ft}$ of sludge and $125,000 \mathrm{Btu} / \mathrm{hr}$ is $520^{\circ} \mathrm{F}$. If the cooling channel heat removal capability is $30 \%$ of design, the peak temperature is about $220^{\circ} \mathrm{F}$. Using slab geometry, an internal heat source, and no heat transfer to the cooling channels, the peak sludge temperature is $560^{\circ} \mathrm{F}$. The simplified model results match reasonably well. Using this model with $11 \mathrm{ft}$ of sludge and an internal heat generation rate of $40,000 \mathrm{Btu} / \mathrm{hr}$ (DST design), the peak temperature with no cooling channel flow is $300^{\circ} \mathrm{F}$. This is above the local saturation (boiling) temperature, thus, a tank bump is possible if the cooling channel flow is stopped for a long enough period of time. It is estimated that a 180-day outage ( 3 times larger than the 60-day outage needed for an aging waste tank at $125,000 \mathrm{Btu} / \mathrm{hr}$ ) is needed to develop conditions conducive to a tank bump, provided the initial waste temperatures were initially $30^{\circ} \mathrm{F}$ subcooled.

We conclude that an analysis of conditions necessary to result in a tank bump is required, along with an assessment of the likelihood of obtaining those conditions for any SST waste capable of creating a deep sludge within a DST or aging waste tank.

\section{A.2.2 Flammable Gas}

It has been postulated that as waste is retrieved from C-106 into 'Tank AY-102, Tank AY-102 might become a "flammable gas tank," i.e., a tank in which the concentration of dome space hydrogen might exceed $25 \%$ of the lower flammability limit (LFL) if a spontaneous or activity-induced gas release event 
occurs or if the ventilation flow degrades to the point that hydrogen can build to a concentration exceeding $25 \%$ of the LFL. A gas release event is a release of flammable gas from the waste at a rate much greater than the generation rate.

The transformation of a nonflammable gas tank into a flammable gas tank as a result of waste transfer is "unacceptable." Project W-320, "C-106 waste retrieved into AY-102," is currently trying to determine the effects of the commingling of these wastes. No long-term path forward has yet been determined. The current solution is to transfer only $2 \mathrm{ft}$ of $\mathrm{C}-106$ waste and monitor tank AY-102. This issue will require study and experimentation if it remains unacceptable for the retrieved or receiver tank to become a flammable gas tank.

In addition to the issues raised by Project W-320, Project W-211 also raised safety issues regarding the retrieval of double-shell flammable gas tanks. WHC ${ }^{(a)}$ considered the following safety issues, which also need to be resolved. No resolution was documented.

1. If the mixer and transfer pumps fail at the same time and remain inoperable for a long period, the suspended solids will settle, creating the potential for episodic gas releases of unknown size and frequency. The potential for this occurrence needs to be understood and either accepted or prevented.

2. If the waste requires dilution with chemicals (e.g., sodium hydroxide), the effect of operational upsets might be the generation and release of excessive amounts of ammonia or the formation of undesirable solids (like aluminum oxides or hydroxides).

3. As the waste level is lowered, the saltcake on the wall becomes exposed. This exposed saltcake could be dispersed should a hydrogen burn occur or could pose a variety of structural concerns should it remain on the wall (moment about the tank wall/floor area) or fall off (waste berg impact on instrumentation or possibly the pump).

4. Dilution of the waste could result in the release of flammable gas within the waste transfer piping.

5. A final concern raised in both projects is the identification of long-term effects on the waste left in the retrieved tank. If only a thin heel is left in the retrieved tank, the safety issues are inconsequential. However, if a few feet are to be left, there may be safety concerns (see LANL 1996b).

\section{A.2.3 Justification for Continued Operation}

Along with the study and experimentation needed to determine the effects of commingling wastes on the generation and retention of flammable gas, activities performed in waste tanks must meet certain requirements with respect to release and ignition of existing flammable gas. These requirements are

(a) Westinghouse Hanford Company (WHC). 1996. Safety Assessment for Initial Tank Retrieval Systems Project W-211. WHC-SD-W211-PSAD-001, DRAFT, Westinghouse Hanford Company, Richland, Washington. 
specified in the December 20th version of the East Tank Farms Standing Order 96-36, Revision 3, entitled "Compensatory Actions for Open Discovery Unreviewed Safety Questions." These standing orders contain the requirements for work in or around all waste tanks.

All tanks are placed into either Facility Group 1, Group 2, Group 3 or "other." The West Tank Farms Standing Order reads identically. If the DST being retrieved only contains waste of one of the tanks in the groupings, then the DST can be considered of the group. If the waste in the DST is an accumulation of more than one SST or DST, then the DST is considered in Facility Group 2 under the assumption that the resolution implemented for those issues raised in Section 2.2 was completed and the results were that the waste is not like that of Facility Group 1. A similar argument is made for the receiver tank.

The ignition control set for each facility group is a function of activity. Retrieval is classified as a globally waste-disturbing operation with waste-intruding equipment.

The December 20 version of the Standing Orders also contains controls with regards to organic-nitrate reactions.

\section{A.2.4 Criticality}

A concern has been raised regarding the potential for a criticality within the inlet to the mixer pump. The concern is that waste containing highly concentrated plutonium might exist in a lens directly beneath the mixer pump or transfer pump. It is postulated that the quantity of plutonium within the lens exceeds that needed for a criticality and that sometime during mixer pump operation, this lens is drawn into the inlet, changes shape into one that is much more spherical and then goes critical. This issue is currently being resolved for Project W-320 and will need to be addressed again as part of other waste retrieval operations.

\section{A.2.5 Waste Compatibility}

Transfer of waste to a receiver tank requires a compatibility assessment. Aspects of compatibility that need to be addressed are

- corrosion, waste temperature, and other aspects that affect the tank structure

- chemical reactions forming toxic gases, flammable gases, reactive compounds, corrosive products, etc.

- waste characteristics needed by the privatization companies

- heat load, sludge volume, and other aspects that might result in high waste temperatures

- waste characteristics that might hinder retrieval and transfer to the privatization company.

In addition, the long-term effects of wastes left in tanks (e.g., $20 \%$ or more of the waste is not retrieved) needs to be addressed with regards to the above. 


\section{A.3 Alternatives Considered}

Five retrieval alternatives were considered: mix and transfer, sluice and transfer, mechanical retrieval with truck or rail car, mechanical retrieval with pipeline transfer, and chemical dissolution. Each alternative is described in some detail in Section 2.0.

\section{A.4 Data for Ranking the Alternatives}

This section provides data for ranking worker safety both during construction activities and operation, public health during in-tank operations and transfer, and environment with respect to potential for leaks and air emissions. The data for worker safety are obtained from government statistics. The data for public health and environment are obtained from approved safety documents required by DOE Orders. In general, the data are obtained as follows:

$$
\text { Input }=(\text { Generic Data }) *(\text { Option-Specific Data })
$$

where Generic Data = data such as injury rate for heavy construction or consequences of a spray release of tank waste

Option-Specific Data = data such as time the transfer line is pressurized, relative number of workers for a specific operation compared with other operations.

While Section 2.0 refers to a chemical dissolution alternative, that alternative was eliminated based on its failure to meet the fundamental requirements. Thus, no worker or public safety data are provided.

\section{A.4.1 Worker Safety}

Data for the non-radiological input for "Worker Safety" come from Washington (1993), Leigh (1987), and NSC (1986). Data for the radiological portion come from Boomer et al. (1993) and Powell (1996). Table A.1 provides a listing of the worker dose data from Boomer et al. (1993) and Powell (1996). These data will be used to develop option-specific worker doses as described later. Table A.2 provides a listing of the non-radiological injury and death rates to be used to develop option-specific worker injuries for each option. One of the pieces of data used from Table A.2 is "Lost Work Day Cases." This is changed into "Lost Work Days" using a multiplier "M" where

$$
M=(\text { Lost Work Days }) /(\text { Lost Work Day Cases). }
$$

The data for "M" come from Washington (1993).

Tables A.3 through A.6 provide the total lost work days and fatalities as a function of option using the data in Table A.2.

Tables A. 7 through A.10 provide the total exposure for workers as a function of option using the data in Table A.1. 
Table A.1. Generic Worker Dose Estimates

\begin{tabular}{||l|l||}
\hline From Powell et al. (1996) \\
\hline Pull mixer pump & $1.2 \mathrm{rem}-3 \mathrm{rem}$ \\
\hline Take a grab sample & $100 \mathrm{mrem}$ \\
\hline Change jumper out & $0.5-4 \mathrm{rem}$, average $2 \mathrm{rem}$ \\
\hline Tank Farm background dose rate & $10 \mathrm{mr} / \mathrm{hr}$ in field $<0.5 \mathrm{mr} / \mathrm{hr}$ in control rooms \\
\hline Core sampling & $200 \mathrm{mrem}$ \\
\hline From Boomer et al. (1993) & \\
\hline Radiation workers & $400 \mathrm{mrem} / \mathrm{yr}$ \\
\hline Engineering staff, managers & $40 \mathrm{mrem} / \mathrm{yr}$ \\
\hline Administrative personnel & $7 \mathrm{mrem} / \mathrm{yr}$ \\
\hline
\end{tabular}

Table A.2. Tank Farm/Pumping Surrogate Industrial Accident Rates ${ }^{(a)}$

\begin{tabular}{|c|c|c|c|c|c|}
\hline Job Category-Activity & $\begin{array}{c}\text { Lost } \\
\text { Workday } \\
\text { Cases }\end{array}$ & $\begin{array}{l}\text { Lost } \\
\text { Work } \\
\text { Days }\end{array}$ & $\begin{array}{l}\text { Fatality } \\
\text { Rate }\end{array}$ & Reference & $\begin{array}{l}\text { Industry or Occupation Surrogate } \\
\text { Rates Were Derived From }\end{array}$ \\
\hline $\begin{array}{l}\text { 1a) Moving and installing } \\
\text { pumps and cover blocks }\end{array}$ & 8.1 & 142 & & Washington 1993 & "Heavy construction except highway" \\
\hline 1b) & & & 0.026 & Leigh 1987 & $\begin{array}{l}\text { "Crane operator" and "construction } \\
\text { laborer" (average) }\end{array}$ \\
\hline $\begin{array}{l}\text { 2a)Excavation and concrete to } \\
15 \mathrm{ft} \text { depth }\end{array}$ & 9.3 & 158 & & Washington 1993 & "Concrete work" \\
\hline 2b) & & & 0.039 & Leigh 1987 & $\begin{array}{l}\text { "Structural metal worker" and } \\
\text { "cement and concrete finishers" } \\
\text { (average) }\end{array}$ \\
\hline 3a) Excavate and lay pipe & 7.3 & 110 & & Washington 1993 & "Highway and street construction" \\
\hline 3b) & & & 0.016 & Leigh 1987 & $\begin{array}{l}\text { "Excavating, grading and road } \\
\text { machine oper." and "plumbers and } \\
\text { pipe fitters" (average) }\end{array}$ \\
\hline $\begin{array}{l}\text { 4a) Operate pump(s) at the } \\
\text { tank (control room, maint.) } \\
\text { and pipeline }\end{array}$ & 10.2 & 120 & & Washington 1993 & "Plastics products" \\
\hline 4b) & & & 0.0037 & Leigh 1987 & $\begin{array}{l}\text { "Power station operators" and "meter } \\
\text { readers-utilities" (average) }\end{array}$ \\
\hline $\begin{array}{l}\text { 5) Load and unload liquid } \\
\text { waste truck }\end{array}$ & 12.3 & 3.0 & & Washington 1993 & "Trucking local and long distant" \\
\hline $5 b)$ & & & .012 & Leigh 1987 & "Delivery and route workers" \\
\hline 6) Construct facilities & 12.2 & 225 & 0.03 & $\begin{array}{c}\text { Boomer et al. } 1993 \\
\text { Washington } 1993\end{array}$ & $\begin{array}{l}\text { DOE - Waste repository "Non } \\
\text { Residential Building Construction" }\end{array}$ \\
\hline $\begin{array}{l}\text { Incidence rates are num } \\
\text { one year }(2000 \mathrm{hrs} / \mathrm{yr})\end{array}$ & $\mathrm{f} T$ & rida & Work & atality accidents per & 00,000 hrs or 100 workers working \\
\hline
\end{tabular}


Table A.3. Non-Radiological Worker Safety Data for the Mix and Transfer Option

\begin{tabular}{||l|c|c|l||}
\hline \multicolumn{1}{|c|}{ Activity } & Lost Work Days & Fatalities & \multicolumn{1}{|c|}{ Basis, Manpower Estimate } \\
\hline Extend two risers & 3 & 0.0008 & Table A.2, Item 2, 2 worker years \\
\hline Modify pump pit & 1.6 & 0.0004 & Table A.2, Item 2, 1 worker year \\
\hline Install 2 mixer pumps & 0.3 & 0.00005 & $\begin{array}{l}\text { Table A.2, Item 1, 0.1 worker- year, each } \\
\text { pump }\end{array}$ \\
\hline Install TV cameras & 0.07 & 0.00001 & Assume half as bad as "install 1 pump" \\
\hline Run pump 14 days & 0.12 & neg. & Table A.2, Item 4, 0.1 worker-year \\
\hline Pump 3 days & 0.03 & neg. & Assume 1/4 that of "run pump 14 days" \\
\hline TOTALS: Construction & $\begin{array}{c}\mathbf{5 . 0} \\
\mathbf{0 . 1 5}\end{array}$ & $\begin{array}{c}\mathbf{0 . 0 0 1 3} \\
\text { neg. }\end{array}$ & \\
\hline
\end{tabular}

Table A.4. Non-Radiological Worker Safety Data for the Sluice and Transfer Option

\begin{tabular}{||l|c|c|l||}
\hline \multicolumn{1}{|c|}{ Activity } & Lost Work Days & Fatalities & \multicolumn{1}{|c|}{ Basis, Manpower Estimate } \\
\hline Modify pump pit & 1.6 & 0.0004 & Same as "Mix \& Transfer" option \\
\hline Construct transfer lines & 5.5 & 0.0008 & Table A.2, Item 3, 5 worker-years \\
\hline Install TV cameras & 0.07 & 0.00001 & See "Mix and Transfer" option \\
\hline Install sluice arm & 0.03 & neg. & Assume half as bad as "Install TV camera" \\
\hline Sluice for 42 days & 0.24 & neg. & $\begin{array}{l}\text { Table A.2, Item 4, 0.1 worker-year each, } \\
\text { 2 operators }\end{array}$ \\
\hline TOTALS: Construction \\
Operation
\end{tabular}


Table A.5. Non-Radiological Worker Safety Data for the Mechanical Retrieval-Truck Option

\begin{tabular}{||l|c|c|l||}
\hline \multicolumn{1}{|c|}{ Activity } & Lost Work Days & Fatalities & \multicolumn{1}{|c|}{ Basis } \\
\hline Construct load - Unload station & 2.25 & 0.0015 & Table A.2, Item 6, 1 worker-year \\
\hline Construct vacuum system & 0.5 & 0.0003 & Table A.2, Item 6, 0.2 worker-year \\
\hline Insert scarifier & 0.03 & neg. & Same as "Install Sluice Arm" \\
\hline Operate scarifier 37 days & 0.24 & neg. & Same as "sluice 42 days" \\
\hline Unload truck & 0.006. & 0.000024 & Table A.2, Item 5, 0.2 worker-years \\
\hline TOTALS: Construction & $\mathbf{2 . 8}$ & $\mathbf{0 . 0 0 1 2}$ & \\
Operation & $\mathbf{2 . 4}$ & & \\
\hline
\end{tabular}

Table A.6. Non-Radiological Worker Safety Data for the Mechanical Retrieval-Pump Option

\begin{tabular}{|c|c|c|c|}
\hline Activity & Lost Work Days & Fatalities & Basis \\
\hline Build storage tank & 2.25 & 0.0015 & Same as "Construct load - Unload station" \\
\hline Modify pump pits system & 1.6 & 0.0004 & See "Sluice and Transfer" option \\
\hline Construct pneumatic systems & 0.5 & 0.0003 & $\begin{array}{l}\text { See "Construct vacuum system" for } \\
\text { Mechanical Retrieval-Truck }\end{array}$ \\
\hline Operate pump 37 days & 0.24 & neg. & Same as "sluice 42 days" \\
\hline TOTALS: $\begin{array}{l}\text { Construction } \\
\text { Operation }\end{array}$ & $\begin{array}{c}4.3 \\
0.24\end{array}$ & $\begin{array}{l}0.0022 \\
\text { neg. }\end{array}$ & \\
\hline
\end{tabular}

Table A.7. Radiological Worker Safety Data for the Mix and Transfer Option

\begin{tabular}{|c|c|c|}
\hline Activity & Dose & Basis \\
\hline Extend two risers & $\begin{array}{l}4 \text { rem each } \\
8 \text { rem total }\end{array}$ & $\begin{array}{l}\text { Used high value for jumper change-out since working near a. } \\
\text { large open riser for a long time }\end{array}$ \\
\hline Modify pump pit & $4 \mathrm{rem}$ & $\begin{array}{l}\text { Used high value for jumper change-out. Same reason as } \\
\text { above. }\end{array}$ \\
\hline Install two mixer pumps & $\begin{array}{l}1.2 \text { rem each } \\
2.4 \text { rem tolal }\end{array}$ & $\begin{array}{l}\text { Use low end of "pull mixer pump" data as the pumps are } \\
\text { clean. }\end{array}$ \\
\hline Install TV camera & $0.6 \mathrm{rem}$ & $\begin{array}{l}\text { Use half of low end of "pull mixer pump" value as the } \\
\text { operation takes less time. }\end{array}$ \\
\hline $\begin{array}{l}\text { Run mixer pump for } 14 \\
\text { days }\end{array}$ & $\begin{array}{l}0.07 \text { rem each } \\
0.14 \text { rem total }\end{array}$ & Used $400 \mathrm{mrem} / \mathrm{yr}$ or $0.2 \mathrm{mrem} / \mathrm{hr}$ for $24 \mathrm{hrs}, 2$ operators. \\
\hline Pump slurry for 3 days & $\begin{array}{l}0.014 \text { rem each } \\
0.028 \text { rem total }\end{array}$ & Same bases as "Run mixer pump for 14 days." \\
\hline $\begin{array}{ll}\text { TOT'ALS: } & \begin{array}{l}\text { Construction } \\
\text { Operation }\end{array} \\
\end{array}$ & $\begin{array}{l}15 \text { rem } \\
0.2 \text { rem }\end{array}$ & \\
\hline
\end{tabular}


Table A.8. Radiological Worker Safety Data for the Sluice and Transfer Option

\begin{tabular}{||l|l|l||}
\hline \multicolumn{1}{|c|}{ Activity } & \multicolumn{1}{c|}{ Dose } & \multicolumn{1}{c|}{ Basis } \\
\hline Modify pump pit & 4 rem & See "Mix and Transfer" \\
\hline Construct transfer lines & $\begin{array}{l}\text { 2 rem attachment of line to each tank } \\
4 \text { rem total }\end{array}$ & $\begin{array}{l}\text { Based on average value for jumper } \\
\text { change out. }\end{array}$ \\
\hline Install TV camera & 0.6 rem & See "Mix and Transfer" \\
\hline $\begin{array}{l}\text { Install Sluice Arm and } \\
\text { transfer pump }\end{array}$ & $\begin{array}{l}1.2 \text { rem for transfer pump } \\
0.6 \text { rem for Sluice Arm } \\
2.4 \text { rem total }\end{array}$ & $\begin{array}{l}\text { See "Mix and Transfer" - "Install } \\
\text { mixer pumps" and "Install TV } \\
\text { camera" }\end{array}$ \\
\hline Sluice for 42 days & $\begin{array}{l}0.2 \text { rem each } \\
0.4 \text { rem total }\end{array}$ & $\begin{array}{l}\text { Same basis as "Run mixer pump" } \\
\text { under "Mix and Transfer" option }\end{array}$ \\
\hline TOTALS: Construction & $\begin{array}{l}\mathbf{1 0 . 4} \text { rem } \\
\mathbf{0 . 4} \text { rem }\end{array}$ & \\
\hline
\end{tabular}

Table A.9. Radiological Worker Safety Data for the Mechanical Retrieval-Truck Option

\begin{tabular}{|c|c|c|}
\hline Activity & Dose & Basis \\
\hline Insert scarifier and vacuum & $0.6 \mathrm{rem}$ & Same as "Install TV Camera" \\
\hline Operate scarifier 37 days & $\begin{array}{l}0.06 \text { rem } \\
0.12 \text { rem total }\end{array}$ & $\begin{array}{l}\text { Use the same basis as "Run mixer pump for } 14 \text { days" but } \\
\text { assume } 8 \mathrm{hr} / \text { day not } 24 \mathrm{hr} / \text { day as the truck is gone the rest } \\
\text { of the time. }\end{array}$ \\
\hline Operate 2 trucks 37 days & $\begin{array}{l}0.03 \text { rem each } \\
0.06 \text { rem total }\end{array}$ & $\begin{array}{l}\text { Use same as "Operate Scarifier" but assume dose rate is } \\
0.1 \mathrm{mrem} / \mathrm{hr} \text { due to good truck design and assume } \\
1 \text { operator per truck, } 8 \mathrm{hr} \text { per day. }\end{array}$ \\
\hline $\begin{array}{l}\text { Load and unload truck for } \\
73 \text { trips }\end{array}$ & 8 rem total & $\begin{array}{l}\text { Lowest dose for jumper change-out is } 473 \mathrm{mrem} \text {. Assume } \\
100 \mathrm{mrem} \text { for load-out and } 10 \mathrm{mrem} \text { for load in based on } \\
\text { good design practices, } 110 \mathrm{mrem} \text { per trip. }\end{array}$ \\
\hline $\begin{array}{ll}\text { TOTALS: } & \begin{array}{l}\text { Construction } \\
\text { Operation }\end{array}\end{array}$ & $\begin{array}{l}1 \text { rem } \\
8 \text { rem }\end{array}$ & • \\
\hline
\end{tabular}


Table A.10. Radiological Worker Safety Data for the Mechanical Retrieval-Pump Option

\begin{tabular}{||l|l|l||}
\hline \multicolumn{1}{|c|}{ Activity } & \multicolumn{1}{|c|}{ Dose } & \multicolumn{1}{c|}{ Basis } \\
\hline Build storage tank & $\begin{array}{l}\text { 2 rem for attachment to retrieved } \\
\text { tank and to staging tank } \\
4 \text { rem total } \\
8 \text { rem total }\end{array}$ & $\begin{array}{l}\text { See "Construct Transfer Lines," "Sluice } \\
\text { and Transfer" option. }\end{array}$ \\
\hline Modify pump pit & 4 rem & See "Mix and Transfer." \\
\hline Construct pneumatic piping & $\begin{array}{l}2 \text { rem for each attachment } \\
4 \text { rem total }\end{array}$ & See "Build storage tanks." \\
\hline Operate tank for 37 days & $\begin{array}{l}0.18 \text { rem each } \\
0.36 \text { rem total }\end{array}$ & $\begin{array}{l}\text { Assume 24 hr per day, 0.2 mrem/hr, for } \\
\text { operators (see "Mix and Transfer - Run } \\
\text { mixer pump"). }\end{array}$ \\
\hline TOTALS: Construction & $\begin{array}{l}\mathbf{1 2} \text { rem } \\
\mathbf{0 . 4} \text { rem }\end{array}$ & \\
\hline
\end{tabular}

\section{A.4.2 Public Health}

In this section, the data needed to rank alternatives with regards to public health will be derived. Public health will be assessed based on the combination of the likelihood and consequences of accidents. The values will be based on calculations of offsite dose as presented in safety documents. The values are also applicable to nearby site workers (e.g., onsite worker at $100 \mathrm{~m}$, the worker in the nearest occupied facility) with the use of a single multiplier. For example, the dose to the maximally exposed worker at $100 \mathrm{~m}$ is 800 times the dose for the maximally exposed offsite individual.

The accidents chosen are judged to be the largest contributors to risk and were chosen to be representative of the options. The insertion accidents are

- load drop

- deflagration due to installation

- spill during removal (i.e., failure to properly insert).

The potential in-tank operations accidents were arrived at by a review of the W-211 and W-320 safety documents and the Tank Farms Final Safety Analysis Report (FSAR). It is assumed that the waste in the DST to be retrieved is in a composition and physical state such that the conditions impacting (identified in Section 2.0) are either resolved or controlled. The tank bump and flammable gas issues are assumed to be controlled by operational limits or constraints placed on equipment such that the likelihood of these events is quite remote. The criticality is assumed to be "not credible." Compatibility issues have been addressed such that the waste to be retrieved poses no new hazards over those considered previously.

Each option has the potential to release and ignite flammable gas. As a result, the " $\mathrm{H}_{2}$ Deflagration" accident is postulated for each option. The "Mix and Transfer" option has the potential for a tank bump. 
All of the options have the potential for operation under conditions when the high-efficiency particulate air (HEPA) filters have failed or could continue to add aerosol into the dome space with no ventilation operable. As a result these three accidents are considered the "operations accidents":

- tank bump due to pump heat

- ignition of $\mathrm{H}_{2}$ released

- loss of confinement.

The waste transfer accidents are dominated by pool releases due to pipe leaks or spray release accidents within the pump pits, valve pits, or diversion boxes.

The frequency of the potential accidents-assuming failure of all of the controls put in-place and working (or adhered to) as a result of efforts to resolve the issues raised in Section A.2-is quite low (i.e., less than $10^{-6}$ ) in most cases, but the consequences are quite high. Assuming all of the controls work as designed results in initiating events but no consequences in most cases. Therefore it will be assumed that the initiating event occurs along with a worst case single failure. This places the accidents on more of an equal basis. The frequency and consequences of this event will be used to obtain the data needed for ranking the options.

The data used to rank the options are now presented. Most of the data will be taken from the Tank Farm FSAR (LMHC 1996), hereafter called the FSAR. A summary table follows the detailed discussion for each option.

\section{A.4.3 Mix and Transfer}

In the "Mix and Transfer" option, two mixer pumps and a transfer pump are inserted in the tank to be retrieved. The waste is mixed and sent to a sludge wash tank and from there to the staging tank at the privatization plant. It is assumed that the equipment is in place within the sludge wash tank prior to waste transfer. It is assumed that over the course of 3 days of sludge washing there is no concern for tank bump or gas release as the waste entering is well mixed and will remain that way. As a result, the only safety concerns have to do with the tank being retrieved.

\section{Installation}

\section{Load Drop}

The FSAR shows that only the inadvertent drop of a mixer pump could result in dome damage and suspension of waste. No other equipment has the right combination of weight plus impact area needed to penetrate the dome. Other equipment would have to be dropped while positioned over an open riser to cause a suspension of waste. The initiating event is some failure that results in a load drop while the pump is over the pump pit. The worst case single failure is to fail to follow the control on load height. The probability of the load drop is given in the FSAR as $6 \times 10^{-4}$ to $5 \times 10^{-5}$. A value of $10^{-4}$ will be used. The probability of failure to heed the load weight control is taken to be $10^{-3}$ because the control is on Technical Safety Requirement (TSR) control. The total probability is $10^{-7}$. 
The FSAR provides the consequences of this load drop. If the pump is dropped onto the pump pit flow, the pump and debris will impact the waste. The diameter of the debris is $4 \mathrm{ft}$. Assuming the top of the waste is rigid and dry and that the pump is dropped from the top of the crane (rather than a few feet above the pump pit floor), the onsite dose is $3 \mathrm{rem}$ and the offsite dose is $0.003 \mathrm{rem}$.

\section{Pump Ejection and Spill During Removal}

The Mixer Pump Safety Assessment (LANL 1996a) provides the consequences of pump ejection and spill during removal. The scenario is as follows: while the pump is being inserted it is found that it must be immediately removed because of some reason (e.g., it does not fit in the riser, etc). Pump ejection requires a gas release event triggered by pump insertion and ignition of that gas release. The probability for the ejection is $10^{-7}$. The ejection can cause a spill or the spill can occur simply as a result of pump removal and drop. The probability of this event is $10^{-4}$, the same as that for the load drop.

The consequences of pump ejection are 51 rem onsite and 0.01 rem offsite. The consequences of the spill are 0.05 rem onsite and $10^{-5}$ rem offsite. The material spilled is $12.8 \mathrm{~kg}$, of which $10^{-3}$ is respirable.

\section{Gas Release and Ignition}

LANL (1996a) also provides the consequences of a gas release and burn as a result of pump insertion. LANL. (1996a) assumes a $4000 \mathrm{ft}^{3}$ gas release event occurs during insertion. The release is based on the assumption of initial conditions in which the amount of retained gas is minimized. The tank considered is Tank 101-SY, which had gas releases three times greater. The DSTs to be retrieved are not expected to resemble 101-SY in their ability to retain gas. Therefore, a $4000 \mathrm{ft}^{3}$ gas release can only occur under faulted conditions. The likelihood of this with a spark is taken to be $10^{-6}$ based on LANL (1996a).

The consequences of gas release and ignition are 13 rem onsite and 0.004 rem offsite.

\section{Operation}

\section{Flammable Gas Release}

For this analysis, it is assumed that the mixer pump, if operated outside the operation envelope, could release a large quantity of gas. The Mixer Pump Safety Assessment provides the consequences of a $6000 \mathrm{ft}^{3}$ gas release with ignition. The value of $6000 \mathrm{ft}^{3}$ is based on release from Tank 101-SY with the controls on operational level as the reason for the gas quantity. The DST to be retrieved will not have the ability to retain gas to the extent that Tank 101-SY did. Therefore, $6000 \mathrm{ft}^{3}$ release is a faulted condition. The probability of the release is judged to be $10^{-3}$. This is based on a failure of operations to remain within the envelope (a TSR control). The probability of ignition is taken to be $10^{-3}$ as well (LANL 1996a).

The consequences are 15 rem onsite and 0.005 rem offsite. 


\section{Tank Bump}

Section A.2 showed that it was possible for a tank bump to occur in DSTs, given the right combination of head load and sludge depth. Operation of the mixer pump adds energy to the waste.

Sathyanarayana (1994) performed analyses to determine the conditions under which a tank bump might occur under conditions of mixer pump operation. He showed that with 36 inches of washed sludge (about $500,000 \mathrm{Btu} / \mathrm{hr}$ ) and operation of the mixer pumps on a 7 days on - 7 days off cycle. Failure of the pump to start on one of the cycles results in tank bump conditions being achieved in about 12 days. This analysis shows that a bump is possible due to mixer pump failure. The analysis described in Section A.2 shows a bump is possible should ventilation be lost. Both are possible under a long duration loss of power event or a seismic event. Therefore the probability of the initiating event is $10^{-4}$. Failure to recover in time (on the order of 10-100 days depending on heat load, sludge depth, waste temperature history prior to the initiating, etc.) is given a probability of $10^{-2}$. The total probability is $10^{-6}$.

The dose from a tank bump is taken from the FSAR and is 250 rem onsite and 0.2 rem offsite.

\section{Loss of Confinement}

The analysis of the consequences of a loss of confinement accident are provided in WHC (1995a). The onsite dose due to the complete failure of a HEPA filter ( $0 \%$ filtering capability) for 14 days is 0.5 rem onsite and 0.0005 rem offsite. The likelihood is taken to be $10^{-4}$ on the basis that over a 2 -week period of time some one would notice the lack of filter pressure, drop in the high stack monitor readings, ground contamination or the like. Note that 14 days is also the duration of the option within one tank.

\section{Transfer}

In the "Mix and Transfer" option, waste is transferred to the staging tank at $140 \mathrm{gpm}$. A transfer of $10^{-6}$ gallons would require $120 \mathrm{hrs}$ at $140 \mathrm{gpm}$. This will be rounded to 336 hours (14 days) to account for inefficiencies.

The frequency of a leak is given in WHC (1995a) as $3 \times 10^{-7} / \mathrm{hr}-\mathrm{ft}$. Assuming $40 \mathrm{ft}$ of transfer line in the valve pits, diversion boxes and pump pits and $336 \mathrm{hrs}$ of pumping, the probability is then $4 \times 10^{-3}$. It is assumed that the pits have leak detectors, but that they fail (as the worst case single failure). The probability of failure is taken to be $10^{-2}$ per demand. The total probability is then $4 \times 10^{-5}$.

The consequences are based on the assumption that a mass balance is completed every 4 hrs and that the leak is noticed then. The leak occurs an average of $2 \mathrm{hrs}$ after initiation for a total of 17,000 gallons. An additional 2000 gal drains back with 4000 gal of the total caught in the pit. ${ }^{(a)}$ The total on the ground is

(a) Westinghouse Hanford Company (WHC). 1996. Safety Assessment for Initial Tank Retrieval Systems Project W-211. WHC-SD-W211-PSAD-001, DRAFT, Westinghouse Hanford Company, Richland, Washington. 
15,000 gal or about $96 \%$ of that assumed in the "unmitigated" pool release in WHC. (a) WHC preserited the results of a 36,000 -gal spill. The offsite dose is $0.6 \mathrm{rem}$. This release is half of that analyzed in WHC. ${ }^{\text {(a) }}$ The dose is approximately proportional to the volume spilled so the offsite dose will be about half of that for $36,000 \mathrm{gal}$. The doses are 30 rem onsite and 3 rem offsite (from the FSAR).

\section{Comparison to $W-320$ and $W-211$}

As a check, the draft W-211 and W-320 safety documents were reviewed to determine the consequences they provide for the two dominant accidents. The results are shown in Table A.11. A summary of the accidents considered is provided in Table A.12.

\section{A.4.4 Sluice and Pump}

In the "sluice and pump" option, a sluice arm and transfer pump are installed in the tank along with a TV camera. Waste from a DST containing mostly liquid is used as the sluice fluid. This sluice waste is mixed using a mixer pump and transfered to the staging tank at the privatization plant. As a result, there are accident potentials within both the sluice tank receiver tank.

\section{Installation - Sluice Tank}

\section{Load Drop}

The FSAR showed that only the mixer pump could penetrate the dome if dropped from a great enough height. The transfer pump, if dropped through the 42-in. riser, could suspend some radionuclides if the crust were hard. Assuming that the transfer pump is dropped, the impact velocity will be the same as that of a dropped mixer pump, but the weight is about $20 \%$ of the mixer pump. Using the data in Section 3.4.2.1 of the FSAR, the penetration depth will be about half that of the mixer pump and the area of impact will be about $1 / 4$ as the dome does not fail (2-ft diameter of impact for the mixer pump versus an estimated $1-\mathrm{ft}$. diameter for the transfer pump). As a result, the volume affected is about $1 / 8$ and the

Table A.11. Comparison of Consequences Between this Analysis and that for Project W-211 and W-320

\begin{tabular}{||l|l|l|l|l||}
\hline \hline Accident & \multicolumn{1}{|c|}{ Condition } & \multicolumn{1}{c|}{ This Analysis } & \multicolumn{1}{c|}{ W-211 } & \multicolumn{1}{c|}{ W-320 } \\
\hline \hline \multirow{3}{*}{$\begin{array}{l}\text { Pool } \\
\text { Release }\end{array}$} & Pool size, gal & 15,000 & 15,600 & 80,000 \\
\cline { 2 - 6 } & Unit liter dose, Sv/L & $5.1 \times 10^{-6}$ & $5.1 \times 10^{-5}$ & $4 \times 10^{-4}$ \\
\cline { 2 - 6 } & Offsite dose, rem & 0.3 & 0.36 & 0.036 \\
\cline { 2 - 6 } & Probability & $2 \times 10^{-5}$ & $\begin{array}{l}2 \times 10^{-5}\left(1.7 \times 10^{-3} \text { with }\right. \\
\text { a single failure of } 10^{-2}\end{array}$ & $\begin{array}{l}\text { about } 10^{-4} \text { to } 10^{-5} \text { (non- } \\
\text { seismic event probabilities) }\end{array}$ \\
\hline \multirow{3}{*}{ Total Bump } & Offsite dose, rem & 0.22 & N/A & 0.17 \\
\cline { 2 - 6 } & Probability & $\begin{array}{l}10^{-4} \text { plus a single } \\
\text { failure of } 10^{-2}\end{array}$ & N/A & same \\
\hline
\end{tabular}

(a) Westinghouse Hanford Company (WHC). 1996. Safety Assessment for Initial Tank Retrieval Systems Project W-211. WHC-SD-W211-PSAD-001, DRAFT, Westinghouse Hanford Company, Richland, Washington. 
Table A.12. Consequences and Probability for Dominant Accidents of the "Mix and Transfer" Option

\begin{tabular}{||l|l|c|c|c||}
\hline \multirow{2}{*}{ Accident } & \multirow{3}{*}{ Condition } & \multicolumn{2}{c|}{ Dose, rem } & \multirow{2}{*}{ Probability } \\
\cline { 3 - 5 } & Onsite (100 $\mathbf{~ m})$ & Offsite & $10^{-7}$ \\
\hline \hline 1. Load Drop & Installation & 3 & 0.003 & $10^{-4}$ \\
\hline 2. Spill & Installation & 0.05 & neg. & $10^{-7}$ \\
\hline $\begin{array}{l}\text { 3. Gas Release and Ignition - } \\
\text { a. pump ejection }\end{array}$ & Installation & & 1 & $1.4 \times 10^{-6}$ \\
b. gas burn & & 51 & 0.01 & $10^{-6}$ \\
\hline 4. Gas release and Ignition & & 13 & 0.004 & $10^{-6}$ \\
\hline 5. Tank Bump & Operation & 15 & 0.005 & $10^{-4}$ \\
\hline 6. Loss of confinement & Operation & 250 & 0.2 & $4 \times 10^{-5}$ \\
\hline 7. Pool Release & Operation & 0.5 & 0.0005 & \\
\hline 8. Total of "offsite dose times probability" for all accidents $1.2 \times 10^{-4}$ rem. & 3 & \\
\hline
\end{tabular}

energy impacted to the volume is about $1 / 5$ of that of the mixer pump. The respirable fraction will be about the same, but the respirable quantity will be about $1 / 8$ that of the mixer pump, as will the dose. The doses are

- onsite 0.4 rem

- offsite $4 \times 10^{-4}$ rem.

The probability is the same as it was for the drop of the mixer pump in the "Mix and Transfer" case.

\section{Spill During Removal}

The consequences of a spill during removal are smaller than that for the mixer pump case as the transfer pump is much smaller and does not have the confinement rings the mixer pump had. Since the doses for spill were already small, the consequences in this case will be negligible.

\section{Gas Release and Ignition}

In this case, the liquid waste is first removed from the DST. The removal of liquid waste might result in the release of gas from the sludge as the hydrostatic head is removed. The release will be quite gradual, however, if the sludge is watery and has little strength and is easily diluted by the ventilation system. There is, however, a potential for a large gas release if the sludge has strength.

As a result of the studies carried out to resolve the Section A.2 issues, the probability of a gas release is assumed to be less than that for the "Mix and Transfer" option. A gas release, however, is still possible. 
The probability of gas release and ignition is lowered from $1.4 \times 10^{-6}$ to $1.4 \times 10^{-7}$, but the consequences remain the same. Note that there is no pump ejection accident in this case.

\section{Installation - Receiver Tank}

The receiver tank receives the sluiced waste. A mixer pump mixes the waste and a transfer pump transfers it to the staging tank at the privatization plant.

\section{Load Drop}

A. mixer pump could be dropped onto the tank dome and cause a failure. However, unlike the "Mix and Transfer" case, the waste will not have a hard saltcake on top of it. The FSAR showed that the consequences of a drop onto a liquid surface is $1 \%$ that for a drop onto a hard surface. Therefore the onsite dose is 0.03 rem and the offsite dose is negligible.

\section{Spill}

Because the equipment and scenario are the same, the consequences of a spill are the same as for "Mix and Transfer."

\section{Gas Release and Ignition}

The tank waste is initially liquid; thus, no gas is released as a result of insertion.

\section{Operation - Sluice Tank}

\section{Gas Release and Ignition}

The consequences and likelihood of a gas release during draw-off of the liquid over the sludge was considered in "Installation" above. The consequences and likelihood of a gas release due to removal of the sludge is found in the Saltwell Pumping Safety Assessment (LANL 1996b).

The consequence of a gas burn during sluicing is based on the same methodology as that used in "Mix and Transfer." The difference is that the waste suspended is solid particles rather than liquid droplets. The FSAR and LANL (1996b) both show an onsite dose of $655 \mathrm{rem}$ and an offsite dose of $0.35 \mathrm{rem}$. The difference in the onsite dose of $655 \mathrm{rem}$ and $19 \mathrm{rem}$ is that from the unit liter doses (ULD). The ULD for SST solids is $2 \times 10^{-5} \mathrm{~Sv} / \mathrm{L}$ and for DST liquids is $7 \times 10^{-3} \mathrm{~Sv} / \mathrm{L}-\mathrm{a}$ difference of about 30 .

\section{Tank Bump}

Sluicing does not result in a tank bump. However, prolonged loss of ventilation can result in a steam release accident. The steam release accident occurs when a pocket of steam is formed within the waste. 
The pressure produced will eventually result in a release to the dome space. This event was analyzed in the safety documentation for Project W-320. The consequences were

- onsite dose 3.9 rem

- offsite dose 0.02 rem.

The probability is based on the fact that a prolonged outage is needed in addition to sluicing. While this accident is possible, the likelihood is given as $10^{-6}$.

\section{Loss of Confinement}

Sluicing creates more aerosol than does mixing. The likelihood of failure is assumed to be the same, but the doses are 10 times greater -5 rem onsite and 0.005 rem offsite.

\section{Operation - Receiver Tank}

\section{Gas Release or Tank Bump}

It is assumed that no gas release or tank bump occurs in the receiver tank because the waste does not reside there long enough for these accidents to be of concern. If the operation is such that the waste remains in the receiver tank for a long period, the accidents, consequences and probabilities will be the same as those for "Mix and Transfer."

\section{Loss of Confinement}

The consequences and probabilities are the same as those for "Mix and Transfer."

\section{Transfer}

The consequences of transfer are double those of "Mix and Transfer" due to the greater transfer rate. The probability is 3 times greater due to the greater operating time (42 days versus 14 ).

\section{Summary}

Table A.13 presents the summary of the accidents and their consequences. 
Table A.13. Consequences and Probability for Dominant Accidents of the "Sluice and Pump" Option

\begin{tabular}{|c|c|c|c|c|}
\hline \multirow[b]{2}{*}{ Accident } & \multirow[b]{2}{*}{ Condition } & \multicolumn{2}{|c|}{ Dose, rem } & \multirow[b]{2}{*}{ Probability } \\
\hline & & Onsite & Offsite & \\
\hline 1A Load Drop & Installation - Sluice Tank & 0.4 & $4 \times 10^{-4}$ & $10^{-7}$ \\
\hline 2A Spill & Installation - Sluice Tank & neg. & neg. & $5 \times 10^{-4}$ \\
\hline $\begin{array}{l}\text { 3A Gas Release and Ignition } \\
\text { a. pump ejection } \\
\text { b. gas burn }\end{array}$ & Installation - Sluice Tank & $\begin{array}{c}\text { N/A } \\
13\end{array}$ & $\begin{array}{c}\text { N/A } \\
0.004\end{array}$ & $\begin{array}{c}10^{-7} \\
1.4 \times 10^{-7}\end{array}$ \\
\hline 1B Load Drop & Installation - Receiver Tank & 0.03 & neg & $10^{-7}$ \\
\hline 2B Spill & Installation - Receiver Tank & 0.05 & neg & $5 \times 10^{-4}$ \\
\hline 2C Gas Release and Ignition & Installation - Receiver Tank & N/A & $\mathrm{N} / \mathrm{A}$ & N/A \\
\hline 4A Gas Release and Ignition & Operation - Sluice Tank & 655 & 0.36 & $10^{-6}$ \\
\hline 5A Tank Bump & Operation - Sluice Tank & 3.9 & 0.02 & $10^{-6}$ \\
\hline 6A Loss of Confinement & Operation - Sluice Tank & 5 & 0.005 & $10^{-4}$ \\
\hline 4B Gas Release and Ignition & Operation - Receiver Tank & $19 *$ & $0.02 *$ & $10^{-6 *}$ \\
\hline 5B Tank Bump & Operation - Receiver Tank & $250 *$ & $0.2^{*}$ & $10^{-6 *}$ \\
\hline 6B Loss of Confinement & Operation - Receiver Tank & 0.5 & 0.0005 & $10^{-4}$ \\
\hline 7 Pool Release & Transfer & 60 & 6 & $1.2 \times 10^{-4}$ \\
\hline \multicolumn{5}{|c|}{8 Total of "offsite dose times probability" for all accidents $7.2 \times 10^{-4}$ rem. } \\
\hline
\end{tabular}

\section{A.4.5 Mechanical Retrieval - Truck}

\section{Installation and Operation}

The accidents associated with installation and operation are the same as those in the sluice tank for the "Sluice and Transfer" option. This is because scarifying is similar to sluicing with regards to operation and the equipment.

\section{Transfer}

The transfer truck is assumed to be similar to the French design waste transfer truck recently discussed at Hanford. The French truck can handle 1000 gal of waste. If this option is to be viable, a bigger truck is probably needed. A truck volume of $5000 \mathrm{gal}$ is assumed. 
A spill is possible. A spill could occur as a result of a truck accident, a faulty load-in, or a faulty loadout operation. Both the load-in and load-out operations will be well designed, and there will be close operator supervision. Even so, it is still possible to spill all 5000 gal either due to a very damaging truck accident (beyond-design-basis, most likely) or at the load-out station.

The consequences will be $1 / 3$ of those for "Mix and Transfer" as in that case about 17,000 gal was spilled. The probability is taken to be $10^{-5}$ per hookup due to design of the load and unload station and interlocks (or the like) between positive attachment and pumping. However, this will be 73 chances for a spill, so the probability is $7 \times 10^{-4}$.

\section{Summary}

Table A.14 presents the summary of the accidents, their consequences and probability.

\section{A.4.6 Mechanical Retrieval - Vacuum Transfer}

In this option, the waste is removed from the tank with a scarifier and transferred pneumatically to the receiver tank. It is assumed that the waste is under vacuum the entire route and allowed to gravity-feed into the receiver tank after going through a separator.

The accidents for "Mechanical Retrieval and Pump" are the same as those for "Mechanical Retrieval and Truck" and the "Receiver Tank" portion of "Sluice and Transfer," except that there is no pool release except in the receiver tank and there are no installation accidents in the receiver tank because the equipment is in place before waste is added.

Table A.14. Consequences and Probability for Dominant Accidents of the "Mechanical Retrieval - Truck" Option

\begin{tabular}{|c|c|c|c|c|}
\hline \multirow[b]{2}{*}{ Accident } & \multirow[b]{2}{*}{ Condition } & \multicolumn{2}{|c|}{ Dose, rem } & \multirow[b]{2}{*}{ Probability } \\
\hline & & Onsite & Offsite & \\
\hline 1. Load Drop & Installation & 0.4 & $4 \times 10^{-4}$ & $10^{-7}$ \\
\hline 2. Spill & Installation & neg. & neg. & $5 \times 10^{-4}$ \\
\hline $\begin{array}{l}\text { 3. Gas Release and Ignition } \\
\text { a. pump ejection } \\
\text { b. gas burn }\end{array}$ & Installation & $\begin{array}{c}\text { N/A } \\
13\end{array}$ & $\begin{array}{c}\text { N/A } \\
0.004\end{array}$ & $\begin{array}{c}\mathrm{N} / \mathrm{A} \\
1.4 \times 10^{-7}\end{array}$ \\
\hline 4. Gas Release and Ignition & Operation & 655 & 0.36 & $10^{-6}$ \\
\hline 5. Tank Bump & Operation & 3.9 & 0.02 & $10^{-6}$ \\
\hline 6. Loss of Confinement & Operation & 5 & 0.005 & $10^{-4}$ \\
\hline 7. Pool Release & Transfer & 10 & 1 & $7 \times 10^{-4}$ \\
\hline
\end{tabular}


The likelihood of a pool release is much less in this case because the opening of the pipe removes the vacuum and removes the motive force for the release. The pool forms only as a result of drainage from the line. A typical line drain volume is $1500 \mathrm{gal}^{(\mathrm{a})}$ So the consequences are 0.1 of those of "Mix and Transfer" where 18,000 gal are spilled. Table A.15 provides a summary of the accidents, their consequences and probability.

\section{A.4.7 Mechanical Retrieval - Pump}

If the transfer is made by pumping rather than by vacuum, the pool release values are the same as those of "Mix and Transfer." The doses are the same as "Mechanical Retrieval - Vacuum Transfer." Table A.15 provicles this summary.

Table A.15. Consequences and Probability for Dominant Accidents of the "Mechanical Retrieval - Vacuum Transfer" and "Mechanical Retrieval - Pump" Options

\begin{tabular}{|c|c|c|c|c|c|}
\hline \multirow{2}{*}{\multicolumn{2}{|c|}{ Accident }} & \multirow{3}{*}{$\begin{array}{l}\text { Condition } \\
\text { Retrieved Tank - Installation }\end{array}$} & \multicolumn{2}{|c|}{ Dose, rem } & \multirow{3}{*}{$\frac{\text { Probability }}{10^{-7}}$} \\
\hline & & & \multirow{2}{*}{$\frac{\text { Onsite }}{0.3}$} & \multirow{2}{*}{$\frac{\text { Offsite }}{0.003}$} & \\
\hline 1 & Load Drop & & & & \\
\hline 2 & Spill & Retrieved Tank - Installation & neg. & neg. & $5 \times 10^{-4}$ \\
\hline 3 & $\begin{array}{l}\text { Gas Release and Ignition } \\
\text { a. pump ejection } \\
\text { b. gas burn }\end{array}$ & Retrieved Tank - Installation & $\begin{array}{c}\text { N/A } \\
13\end{array}$ & $\begin{array}{l}\text { N/A } \\
0.004\end{array}$ & $\begin{array}{c}10^{-7} \\
1.4 \times 10^{-6}\end{array}$ \\
\hline $4 A$ & Gas Release and Ignition & Retrieved Tank - Operation & 655 & 0.36 & $10^{-6}$ \\
\hline 5 & Tank Bump & Retrieved Tank - Operation & 3.9 & 0.02 & $10^{-6}$ \\
\hline $6 f$ & Loss of Confinement & Operation - Retrieved Tank & 5 & 0.005 & $10^{-4}$ \\
\hline $4 \mathrm{E}$ & Gas Release and Ignition & Receiver Tank -Operation & $19 *$ & $0.02 *$ & $10^{-6 *}$ \\
\hline & Tank Bump & Receiver Tank - Operation & $250^{*}$ & $0.2^{*}$ & $10^{-6 *}$ \\
\hline $6 \mathrm{E}$ & Loss of Confinement & Operations - Receiver Tank & 0.5 & 0.0005 & $10^{-4}$ \\
\hline 7 & $\begin{array}{l}\text { Pool Release } \\
\text { 7.1 Vacuum Transfer } \\
\text { 7.2 Pump }\end{array}$ & $\begin{array}{l}\text { Receiver Tank - Transfer } \\
\text { Receiver Tank - Transfer }\end{array}$ & $\begin{array}{c}3 \\
30\end{array}$ & $\begin{array}{c}0.3 \\
3\end{array}$ & $\begin{array}{l}4 \times 10^{-5} \\
4 \times 10^{-5}\end{array}$ \\
\hline 8 & $\begin{array}{l}\text { Total of "offsite dose tim } \\
\text { 8.1 Vacuum Transfer } \\
\text { 8.2 Pump }\end{array}$ & $\begin{array}{l}\text { obability" for all accidents. } \\
\times 10^{-5} \\
\times 10^{-4}\end{array}$ & & & \\
\hline
\end{tabular}

(a) Westinghouse Hanford Company (WHC). 1996. Safety Assessment for Initial Tank Retrieval Systems Project W-211. WHC-SD-W211-PSAD-001, DRAFT, Westinghouse Hanford Company, Richland, Washington. 


\section{A.5 Environment}

The events that fall under this category are potential for leaks from the tanks, potential for leaks from the transfer system, and air emissions.

\section{A.5.1 Leaks from the Tanks}

A tank leak can occur during normal operations, as well as from the operation should a failure or series of failure occur, or from conditions not associated with the operation (like corrosion). This section will not consider tank failures from conditions other than those associated with the operation itself. Long-term degradation of the tank is considered elsewhere. It is assumed that the effects of chemical addition or commingling of waste on tank integrity are addressed and resolved before the operation or the transfer. This leaves as the only aspect for ranking the likelihood of tank leak due to failures in the operation.

A cursory review of the operations shows that the likelihood of a tank failure due to operation is very unlikely and is the same for all four options. The chemical dissolution option would have had a much greater likelihood of tank failure, but that option was dropped.

Tank failure due to mixing is very unlikely. The effect of the jet on the tank is taken into account when the operational envelope is setup. The jet is about $20 \mathrm{ft}$ from the tank at its closest point and has expanded from the nozzle diameter. Both the expansion and the frictional loss while traveling through the fluid has greatly reduced the force of the jet. It would take a long duration failure to rotate the pump to cause enough erosion to fail the tank. LANL (1996b) showed (see Section 4.4.6.1) that erosion rates due to maximum jet velocity are 0.001 to 0.004 in. per year.

Tank failure due to sluicing and scarifying is also very unlikely. The liquid coming from the nozzles used in these operations is at a much greater pressure and smaller diameter. The jet typically only travels through a small amount of liquid. This combination makes it easier to pierce the wall then it is for mixer pump jets. These operations are performed under direct operator supervision via a TV camera mounted in the tank.

As a result of the above, the options have the same "score." The score is based on the following:

- Anticipated Score $=0$

- Unlikely Score $=50$

- Very Unlikely Score $=75$

- Extremely Unlikely Score $=100$.

\section{A.5.2 Leaks from the Transfer System}

The likelihood of a leak and its size are provided in Section A.4. The size is indicated by the onsite dose. Therefore, the score is the probability times size. The data are provided in Section A.4. 


\section{A.5.3 Air Emissions}

Air emissions are assumed to be proportional to the partition fraction times the duration of the activity. The partition fraction is the factor that relates radionuclide concentration in the dome space with that of the waste. The quantity of radionuclides released is given by

$$
\mathrm{Q}=(\mathrm{PF})(\text { Vent Flow Rate })\left(\mathrm{Ci} / \mathrm{m}^{3} \text { in waste }\right)
$$

where $\mathrm{PF}=$ the ratio of the $\mathrm{Ci} / \mathrm{m}^{3}$ of a radionuclide in the dome divided by that of the same radionuclide in the waste.

It is assumed that the vent flowrates and concentration in the waste are the same for all options. WHC (1995a) shows that PF for mixing is $10^{-8}$. Section 4.0 argued that PF for sluicing and scarifying is $10^{-7}$. The duration of sluicing and scarifying is 42 days. Therefore, if the factor of " $\mathrm{PF} *$ duration" for mixing is 1.0 the "PF * duration" for scarifying and sluicing is 30 .

Table A.16. Summary of Parameters for the "Environmental" Category

\begin{tabular}{|c|c|c|c|c|c|}
\hline \multirow[b]{2}{*}{ Parameter } & \multirow[b]{2}{*}{ Units } & \multicolumn{4}{|c|}{ Option } \\
\hline & & $\begin{array}{l}\text { Mix and } \\
\text { Transfer }\end{array}$ & $\begin{array}{l}\text { Sluice and } \\
\text { Transfer }\end{array}$ & $\begin{array}{l}\text { Mechanical } \\
\text { Truck }\end{array}$ & $\begin{array}{l}\text { Retrieval } \\
\text { Pump }\end{array}$ \\
\hline $\begin{array}{l}\text { Potential for } \\
\text { Tank Leak }\end{array}$ & $\begin{array}{l}\text { Likelihood } \\
\text { (Score) }\end{array}$ & $\begin{array}{l}\text { Very unlikely } \\
\text { (75) }\end{array}$ & $\begin{array}{l}\text { Very unlikely } \\
\text { (75) }\end{array}$ & $\begin{array}{l}\text { Very unlikely } \\
\text { (75) }\end{array}$ & $\begin{array}{l}\text { Very unlikely } \\
\text { (75) }\end{array}$ \\
\hline Leaks & $\begin{array}{l}\text { Probability times onsite } \\
\text { dose (proportional to } \\
\text { size times probability or } \\
\text { risk due to leak) }\end{array}$ & $1.2 \times 10^{-3}$ & $7.2 \times 10^{-3}$ & $7 \times 10^{-3}$ & $1.2 \times 10^{-4}$ \\
\hline $\begin{array}{l}\text { Air } \\
\text { Emissions }\end{array}$ & $\begin{array}{l}\text { Normalized value of } \\
\text { partition fraction times } \\
\text { duration (proportional to } \\
\text { quantity transported to } \\
\text { atmosphere). }\end{array}$ & 1 & 30 & 30 & 30 \\
\hline
\end{tabular}


Appendix B

Activities and Durations for the Alternative Retrieval Systems 


\section{Appendix B}

\section{Activities and Durations for the Alternative Retrieval Systems}

Tables B.1 through B.4 present the tasks and durations for the alternative retrieval systems.

Table B.1 shows activities and durations for the tasks for a generic tank. Tables B. 2, B. 3, and B.4 show activities and durations for the mixer system, the sluicer system, and mechanical retrieval with pipeline transfer, respectively. 
Table B.1. Activities and Durations for the Alternative Retrieval Systems - Generic Tank

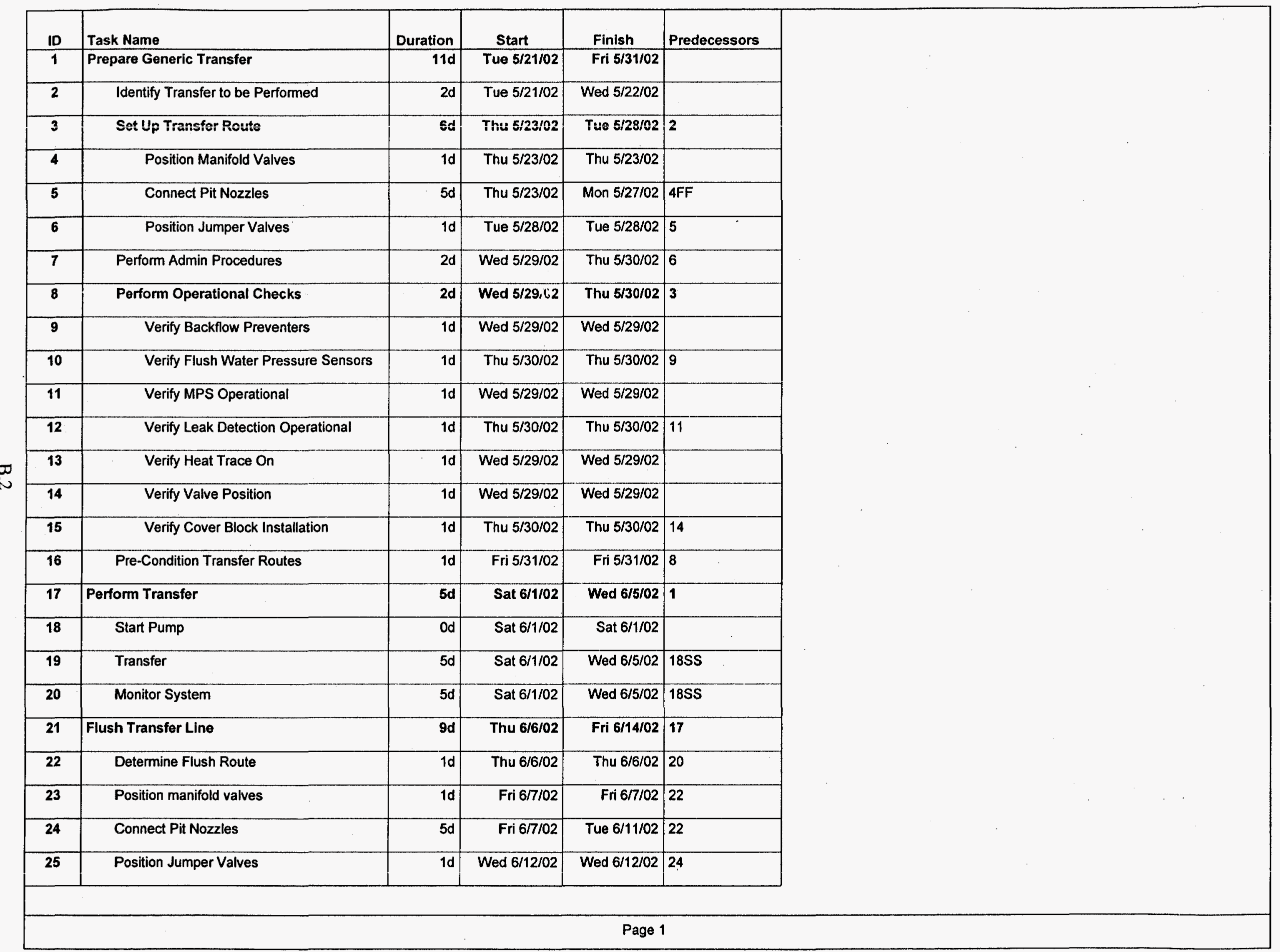




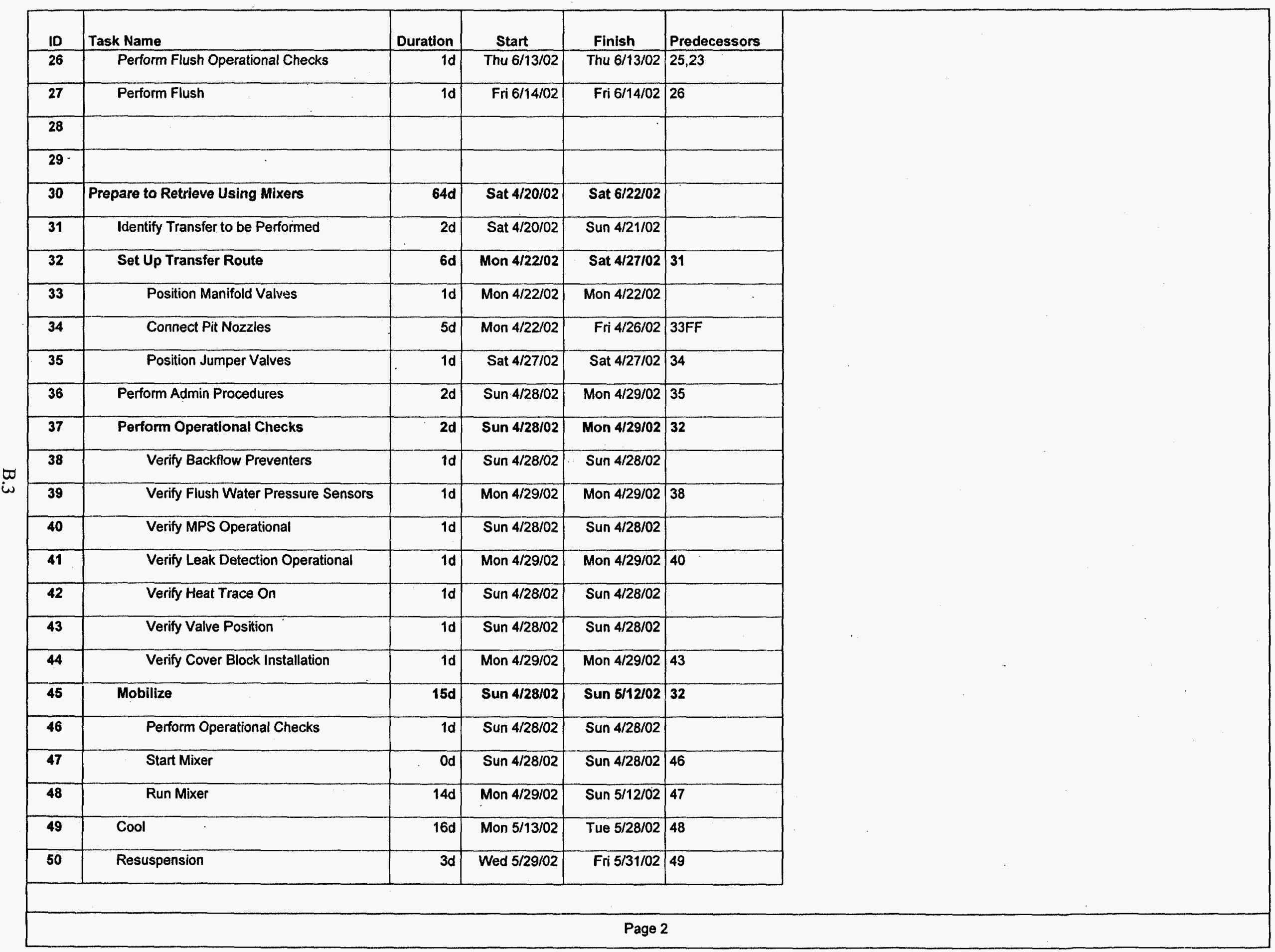




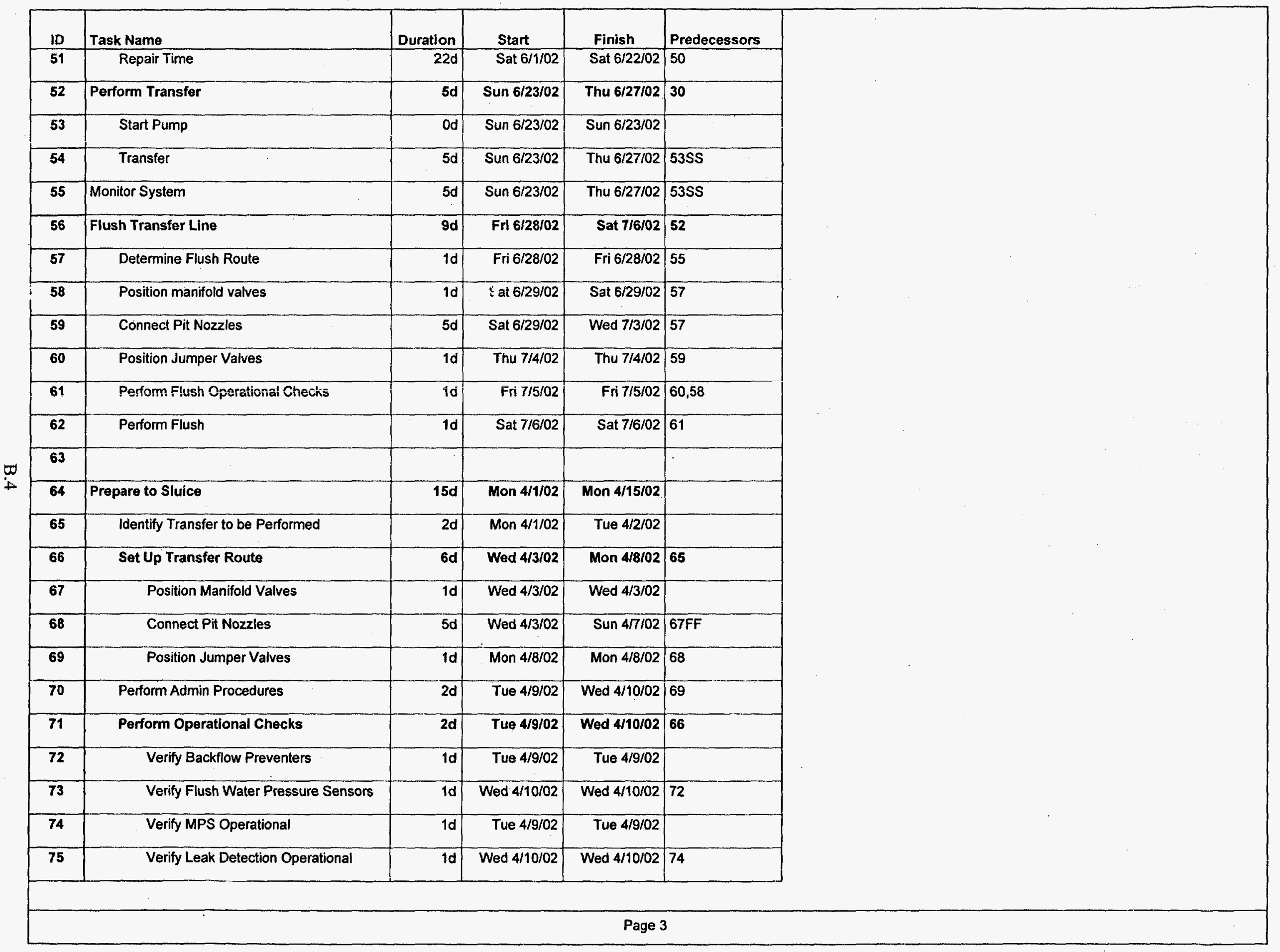




\begin{tabular}{|c|c|c|c|c|c|c|}
\hline ID & Task Name & Duration & Start & Finish & Predecessors & \multirow{27}{*}{ " } \\
\hline 76 & Verify Heat Trace On & $1 d$ & Tue 4/9/02 & Tue $4 / 9 / 02$ & & \\
\hline 77 & Verify Valve Position & 1d & Tue $4 / 9 / 02$ & Tue $4 / 9 / 02$ & & \\
\hline 78 & Verify Cover Block Installation & $1 d$ & Wed 4/10/02 & Wed 4/10/02 & 77 & \\
\hline 79 & Remove Supernatant & $5 d$ & Thu 4/11/02 & Mon 4/15/02 & 71 & \\
\hline 80 & Perform Transfer & $55 \mathrm{~d}$ & Tue 4/16/02 & Sun $6 / 9 / 02$ & 64 & \\
\hline 81 & Sluice & $27 \mathrm{~d}$ & Tue 4/16/02 & Sun $5 / 12 / 02$ & 79 & \\
\hline 82 & Monitor System & $27 \mathrm{~d}$ & Tue $4 / 16 / 02$ & Sun $5 / 12 / 02$ & $81 S S$ & \\
\hline 83 & Repair Time & $28 d$ & Mon 5/13/02 & Sun $6 / 9 / 02$ & 82 & \\
\hline 84 & Flush Transfer Line & $9 \mathrm{~d}$ & Mon 6/10/02 & Tue $6 / 18 / 02$ & 80 & \\
\hline 85 & Determine Flush Route & $1 \mathrm{~d}$ & Mon $6 / 10 / 02$ & Mon 6/10/02 & 83 & \\
\hline 86 & Position manifold valves & 1d & Tue $6 / 11 / 02$ & Tue $6 / 11 / 02$ & 85 & \\
\hline 87 & Connect Pit Nozzles & $5 d$ & Tue 6/11/02 & Sat $6 / 15 / 02$ & 85 & \\
\hline 88 & Position Jumper Valves & $1 d$ & Sun $6 / 16 / 02$ & Sun $6 / 16 / 02$ & 87 & \\
\hline 89 & Perform Flush Operational Checks & 1d & Mon 6/17/02 & Mon 6/17/02 & 88,86 & \\
\hline 90 & Perform Flush & $1 d$ & Tue $6 / 18 / 02$ & Tue $6 / 18 / 02$ & 89 & \\
\hline \multicolumn{6}{|l|}{91} & \\
\hline 92 & Prepare to Retrieve Mech w/Truck Transport & 24d & Mon 4/1/02 & Wed 4/24/02 & & \\
\hline 93 & Identify Transfer to be Performed & $2 d$ & Mon 4/1/02 & Tue 4/2/02 & & \\
\hline 94 & Set Up Transfer Route & 6d & Wed 4/3/02 & Mon 4/8/02 & 93 & \\
\hline 95 & Position Manifold Valves & 1d & Wed 4/3/02 & Wed 4/3/02 & & \\
\hline 96 & Connect Pit Nozzles & $5 d$ & Wed 4/3/02 & Sun $4 / 7 / 02$ & 95FF & \\
\hline 97 & Position Jumper Valves & $1 d$ & Mon 4/8/02 & Mon 4/8/02 & 96 & \\
\hline 98 & Perform Admin Procedures & $2 d$ & Tue 4/9/02 & Wed 4/10/02 & 97 & \\
\hline 99 & Perform Operational Checks & $2 d$ & Tue 4/9/02 & Wed 4/10/02 & 94 & \\
\hline 100 & Verify Backflow Preventers & 10 & Tue $4 / 9 / 02$ & Tue $4 / 9 / 02$ & & \\
\hline \multicolumn{6}{|c|}{ Page 4} & \\
\hline
\end{tabular}




\begin{tabular}{|c|c|c|c|c|c|c|}
\hline ID & Task Name & Duration & Start & Finish & Predecessors & \\
\hline 101 & Verify Flush Water Pressure Sensors & 1d & Wed 4/10/02 & Wed $4 / 10 / 02$ & 100 & \\
\hline 102 & Verify MPS Operational & 1d & Tue 4/9/02 & Tue 4/9/02 & & \\
\hline 103 & Verify Leak Detection Operational & 1d & Wed $4 / 10 / 02$ & Wed $4 / 10 / 02$ & 102 & \\
\hline 104 & Verify Heat Trace On & 1d & Tue $4 / 9 / 02$ & Tue 4/9/02 & & \\
\hline 105 & Verify Valve Position & 1d & Tue 4/9/02 & Tue 4/9/02 & & \\
\hline 106 & Verify Cover Block Installation & 1d & Wed 4/10/02 & Wed 4/10/02 & 105 & \\
\hline 107 & Remove Supernatant & $5 d$ & Thu $4 / 11 / 02$ & Mon $4 / 15 / 02$ & 99 & \\
\hline 108 & Arm Preparations & $4 d$ & Tue $4 / 1 \mathrm{j} / 02$ & Fri 4/19/02 & 107 & \\
\hline 109 & System Setup & 5d & Sat $4 / 20 / 02$ & Wed 4/24/02 & 108 & \\
\hline 110 & Perform Transfer & 74d & Thu 4/25/02 & Sun $7 / 7 / 02$ & 109 & \\
\hline 111 & Retrieve Sludge & $28 \mathrm{~d}$ & Thu 4/25/02 & Wed 5/22/02 & 109 & \\
\hline 112 & Monitor System & $28 \mathrm{~d}$ & Thu 4/25/02 & Wed 5/22/02 & $111 \mathrm{SS}$ & \\
\hline 113 & Repair Time & 28d & Thu 5/23/02 & Wed $6 / 19 / 02$ & 111 & \\
\hline 114 & Truck Transfer & 74d & Thu 4/25/02 & Sun $7 \pi / 02$ & $111 \mathrm{FF}$ & \\
\hline 115 & Arm System Takedown & 4d & Thu 6/20/02 & Sun $6 / 23 / 02$ & 113 & \\
\hline 116 & Flush Transfer Line & 9d & Mon $7 / 8 / 02$ & Tue 7/16/02 & 110 & \\
\hline 117 & Determine Flush Route & 10 & Mon 7/8/02 & Mon $7 / 8 / 02$ & 115 & \\
\hline 118 & Position manifold valves & 1d & Tue $7 / 9 / 02$ & Tue 7/9/02 & 117 & \\
\hline 119 & Connect Pit Nozzles & $5 d$ & Tue $7 / 9 / 02$ & Sat $7 / 13 / 02$ & 117 & \\
\hline 120 & Position Jumper Valves & 10 & Sun $7 / 14 / 02$ & Sun 7/14/02 & 119 & \\
\hline 121 & Perform Flush Operational Checks & $1 d$ & Mon 7/15/02 & Mon $7 / 15 / 02$ & 120,118 & \\
\hline 122 & Perform Flush & id & Tue $7 / 16 / 02$ & Tue $7 / 16 / 02$ & 121 & \\
\hline \multicolumn{6}{|l|}{123} & \\
\hline 124 & Prepare to Retrieve Mech w/Pipe Transport & 24d & Mon 4/1/02 & Wed 4/24/02 & & \\
\hline 125 & Identify Transfer to be Performed & $2 d$ & Mon 4/1/02 & Tue 4/2/02 & & \\
\hline \multicolumn{7}{|c|}{ Page 5} \\
\hline
\end{tabular}




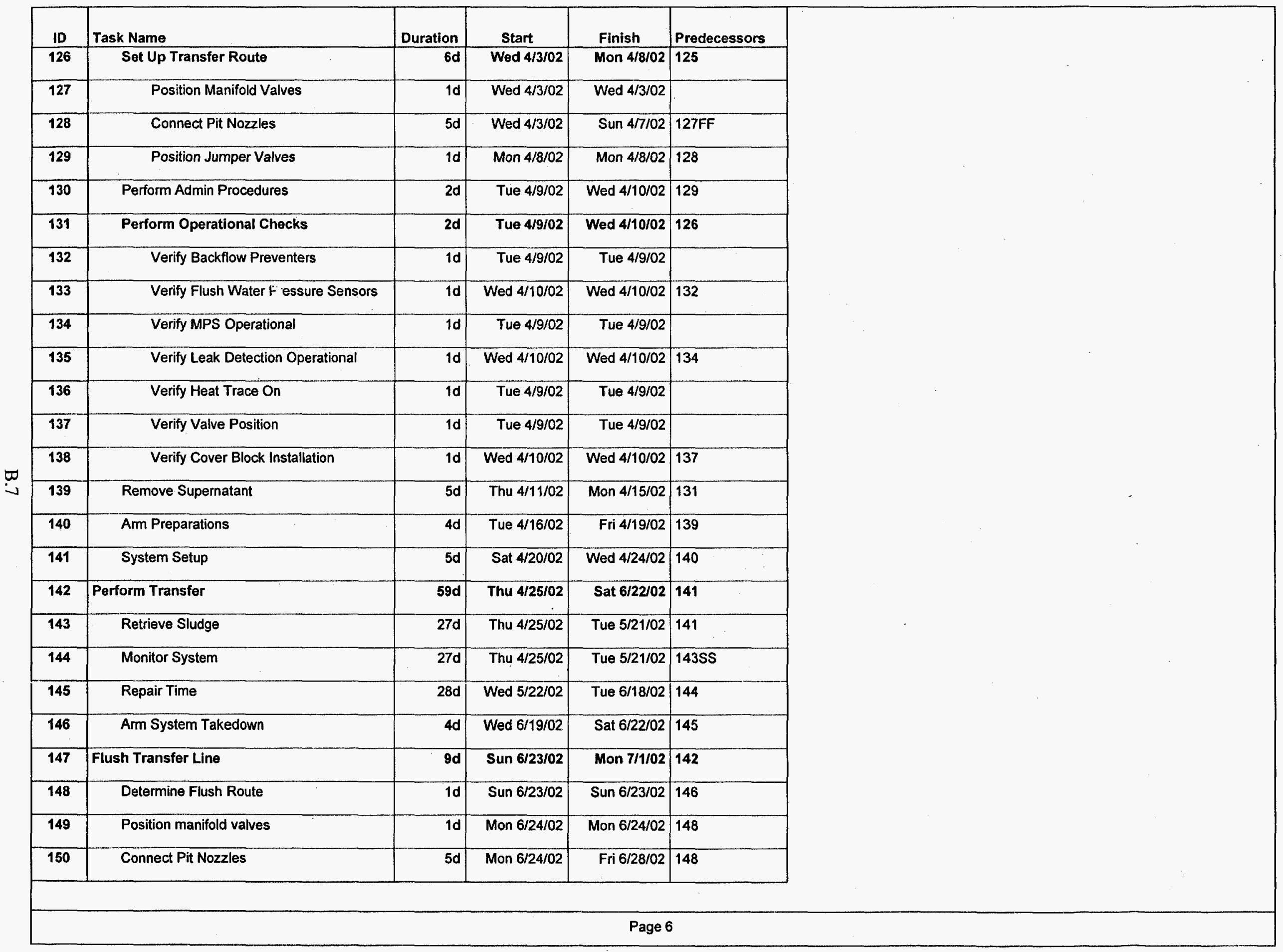




\begin{tabular}{|c|c|r|r|r|l|}
\hline ID & Task Name & Duration & Start & \multicolumn{1}{|c|}{ Finish } & Predecessors \\
\hline 151 & Position Jumper Valves & $1 \mathrm{~d}$ & Sat $6 / 29 / 02$ & Sat $6 / 29 / 02$ & 150 \\
\hline 152 & Perform Flush Operational Checks & $1 \mathrm{~d}$ & Sun $6 / 30 / 02$ & Sun $6 / 30 / 02$ & 151,149 \\
\hline 153 & Perform Flush & $1 \mathrm{~d}$ & Mon $7 / 1 / 02$ & Món $7 / 1 / 02$ & 152 \\
\hline
\end{tabular}


Table B.2. Phase 1 Activities and Durations - Mixer System

\begin{tabular}{|c|c|c|c|c|c|c|}
\hline ID & Task Name & Duration & Start & Finish & Predecessors & Resource Names \\
\hline 1 & AZ-101 "Bootstrap" Transfers & $56 d$ & Wed $6 / 7 / 00$ & Wed $8 / 2 / 00$ & & \\
\hline 2 & Transfer AY-101 Supernatant to AP & $28 \mathrm{~d}$ & Wed $6 / 7 / 00$ & Wed $7 / 5 / 00$ & & Tank Farm Program \\
\hline 3 & Transfer AZ-101 Supernatant to AY-101 & $28 \mathrm{~d}$ & Wed $7 / 5 / 00$ & Wed $8 / 2 / 00$ & 2 & Tank Farm Program \\
\hline 4 & - & & & & & \\
\hline 5 & AZ-101 Sludge Washing Operations & 252d & Sun $8 / 27 / 00$ & Sun $5 / 6 / 01$ & 1 & \\
\hline 6 & Transfer DN Supernatant from AP or AY to AZ-101 & $28 d$ & Sun $8 / 27 / 00$ & Sun $9 / 24 / 00$ & & Tank Farm Program \\
\hline 7 & Mix conents of $A Z 101$ & $28 \mathrm{~d}$ & Sun $9 / 24 / 00$ & Sun $10 / 22 / 00$ & 6 & Tank Farm Opns \\
\hline 8 & Decant AZ-101 Supernatant to AN, AW, or AP & 28d & Sun $10 / 22 / 00$ & Sun $11 / 19 / 00$ & 7 & Tank Farm Program \\
\hline 9 & Transfer DN Supernatant from AP or AY to AZ-101 & $28 d$ & Sun $11 / 19 / 00$ & Sun $12 / 17 / 00$ & 8 & Tank Farm Program \\
\hline 10 & Mix conents of AZ101 & 28d & Sun $12 / 17 / 00$ & Sun $1 / 14 / 01$ & 9 & Tank Farm Opns \\
\hline 11 & Decant AZ-101 Supernatant to AN, AW, or AP & $28 d$ & Sun $1 / 14 / 01$ & Sun $2 / 11 / 01$ & 10 & Tank Farm Program \\
\hline 12 & Transfer DN Supernatant from AP or AY to AZ-101 & $28 \mathrm{~d}$ & Sun $2 / 11 / 01$ & Sun $3 / 11 / 01$ & 11 & Tank Farm Program \\
\hline 13 & Mix conents of AZ101 & $28 \mathrm{~d}$ & Sun $3 / 11 / 01$ & Sun $4 / 8 / 01$ & 12 & Tank Farm Opns \\
\hline 14 & Decant AZ-101 Supernatant to AN, AW, or AP & 28d & Sun $4 / 8 / 01$ & Sun $5 / 6 / 01$ & 13 & Tank Farm Program \\
\hline \multicolumn{7}{|l|}{15} \\
\hline 16 & AZ-101 Feed Staging Operations & $636.54 \mathrm{~d}$ & Sun $5 / 6 / 01$ & Mon 2/3/03 & 5 & \\
\hline 17 & Add Transfer Solution from AP or AY to AZ-101 & $28 \mathrm{~d}$ & Sun $5 / 6 / 01$ & Sun $6 / 3 / 01$ & & Tank Farm Program \\
\hline 18 & Transfer AZ-101 Slurry to Private Contractor (Batch \#1) & $28 \mathrm{~d}$ & Fri $5 / 17 / 02$ & Fri 6/14/02 & 17 & Tank Farm Program \\
\hline 19 & Transfer AZ-101 Slurry to Private Contractor (Batch \#2) & $28 \mathrm{~d}$ & Mon 1/6/03 & Mon 2/3/03 & 18 & Tank Farm Opns \\
\hline \multicolumn{7}{|l|}{20} \\
\hline 21 & AZ-102 "Bootstrap" Transfers & 28d & Fri 10/12/01 & Fri 11/9/01 & & \\
\hline 22 & Transfer AZ-102 Supernatant to AY-101 and/or AP & 28d & Fri 10/12/01 & Fri 11/9/01 & & Tank Farm Program \\
\hline \multicolumn{7}{|l|}{23} \\
\hline 24 & AZ-102 Sludge Washing Operations & $348.27 \mathrm{~d}$ & Fri 11/9/01 & Thu 10/24/02 & 21 & \\
\hline 25 & Transfer DN Supernatant from AP or AY to AZ-102 & $28 d$ & Fri 11/9/01 & Fri $12 / 7 / 01$ & & Tank Farm Program \\
\hline
\end{tabular}




\begin{tabular}{|c|c|c|c|c|c|c|}
\hline ID & Task Name & Duration & Start & Finish & Predecessors & Resource Names \\
\hline 26 & Mix contents of AZ-102 & $28 d$ & Fri $12 / 7 / 01$ & Fri $1 / 4 / 02$ & 25 & Tank Farm Opns \\
\hline 27 & Decant AZ-102 Supernatant to AN, AW, or AP & 28d & Fri $1 / 4 / 02$ & Fri 2/1/02 & 26 & Tank Farm Program \\
\hline 28 & Transfer DN Supernatant from AP or AY to AZ-102 & 2âd & Friziiiúz & Fri $3 i 1 / 0 \overline{2} 2$ & 27 & Tank Farm Program \\
\hline 29 & Mix contents of AZ-102 & $28 d$ & Fri $3 / 1 / 02$ & Fri $3 / 29 / 02$ & 28 & Tank Farm Opns \\
\hline 30 & Decant AZ-102 Supernatant to AN, AW, or AP & 28d & Fri 3/29/02 & Fri 4/26/02 & 29 & Tank Farm Program \\
\hline 31 & Transfer DN Supernatant from AP or AY to AZ-102 & $28 \mathrm{~d}$ & Fri $4 / 26 / 02$ & Fri $5 / 24 / 02$ & 30 & Tank Farm Program \\
\hline 32 & Mix contents of AZ-102 & 28d & Fri 5/24/02 & Fri 6/21/02 & 31 & Tank Farm Opns \\
\hline 33 & Decant AZ-102 Supernatant to AN, AW, or AP & $\therefore 8 \mathrm{~d}$ & Wed 6/26/02 & Wed $7 / 24 / 02$ & 32 & Tank Farm Program \\
\hline 34 & Transfer DN Supernatant from AP or AY to AZ-102 & 28d & Fri $7 / 26 / 02$ & Fri 8/23/02 & 33 & Tank Farm Program \\
\hline 35 & Mix contents of AZ-102 & $28 \mathrm{~d}$ & Fri $8 / 23 / 02$ & Fri 9/20/02 & 34 & Tank Farm Opns \\
\hline 36 & Decant AZ-102 Supernatant to AN, AW, or AP & 28d & Thu 9/26/02 & Thu $10 / 24 / 02$ & 35 & Tank Farm Program \\
\hline \multicolumn{7}{|l|}{37} \\
\hline 38 & AZ-102 Feed Staging Operations & 544.86d & Thu 10/24/02 & Thu 4/22/04 & 24 & \\
\hline 39 & Add Transfer Solution from AP or AY to AZ-102 & $28 \mathrm{~d}$ & Thu 10/24/02 & Thu 11/21/02 & & Tank Farm Program \\
\hline 40 & Transfer AZ-102 Slurry to Private Contractor (Batch \#3) & $28 \mathrm{~d}$ & Thu $8 / 28 / 03$ & Thu 9/25/03 & 39 & Tank Farm Program \\
\hline 41 & Transfer AZ-102 Slurry to Private Contractor (Batch \#4) & 28d & Thu 3/25/04 & Thu 4/22/04 & 40 & Tank Farm Opns \\
\hline \multicolumn{7}{|l|}{42} \\
\hline 43 & AY-102 "Bootstrap" Transfers & 28d & Thu 6/12/03 & Thu $7 / 10 / 03$ & & \\
\hline 44 & Transfer AY-102 Supernatant to AP & 28d & Thu $6 / 12 / 03$ & Thu $7 / 10 / 03$ & & Tank Farm Program \\
\hline \multicolumn{7}{|l|}{45} \\
\hline 46 & AY-102 Sludge Washing Operations & 84d & Thu $7 / 10 / 03$ & Thu 10/2/03 & 43 & \\
\hline 47 & Transfer DN Supernatant from AP or AY to AY-102 & 28d & Thu $7 / 10 / 03$ & Thu $8 / 7 / 03$ & & Tank Farm Program \\
\hline 48 & Mix contents of $A Y-102$ & 28d & Thu $8 / 7 / 03$ & Thu 9/4/03 & 47 & Tank Farm Opns \\
\hline 49 & Decant AY-102 Supernatant to AN, AW, or AP & 28d & Thu 9/4/03 & Thu 10/2/03 & 48 & Tank Farm Program \\
\hline 50 & & & & & & \\
\hline
\end{tabular}




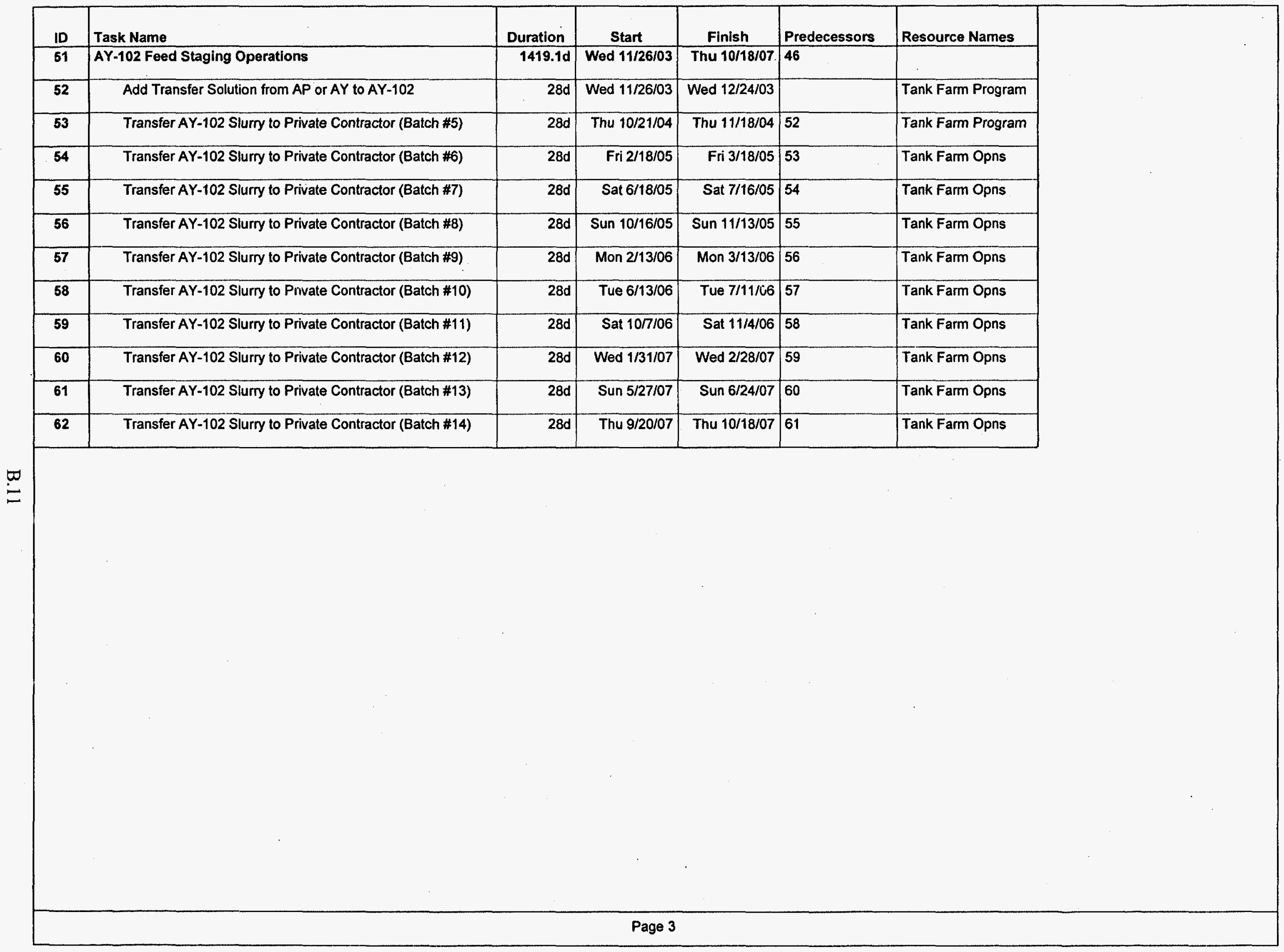


Table B.3. Phase 1 Activities and Durations - Sluicer System

\begin{tabular}{|c|c|c|c|c|c|c|}
\hline ID & Task Name & Duration & Start & Finish & Predecessors & Resource Names \\
\hline 1 & AZ-101 "Bootstrap" Transfers & $56 \mathrm{~d}$ & Wed $6 / 7 / 00$ & Wed $8 / 2 / 00$ & & \\
\hline 2 & Transfer AY-101 Supernatant to AP & $28 \mathrm{~d}$ & Wed $6 / 7 / 00$ & Wed $7 / 5 / 00$ & & Tank Farm Program \\
\hline 3 & Transfer AZ-101 Supernatant to AY-101 & $28 \mathrm{~d}$ & Vived $7 / 5 / 00$ & Wed $8 / 2 / 00$ & 2 & Tank Farm Program \\
\hline \multicolumn{7}{|l|}{4} \\
\hline 5 & AZ-101 Sludge Washing Operations & $252 \mathrm{~d}$ & Sun $8 / 27 / 00$ & Sun $5 / 6 / 01$ & 1 & \\
\hline 6 & Transfer DN Supernatant from AP or AY to AZ-101 & $28 \mathrm{~d}$ & Sun $8 / 27 / 00$ & Sun $9 / 24 / 00$ & . & Tank Farm Program \\
\hline 7 & Mix contents of $A Z-101$ & $28 \mathrm{~d}$ & Sun $9 / 24 / 00$ & Sun $10 / 22 / 00$ & 6 & Tanik Farm Opns \\
\hline 8 & Decant AZ-101 Supernatant to AN, AW, or AP & $\therefore 3 \mathrm{~d}$ & Sun $10 / 22 / 00$ & Sun $11 / 19 / 00$ & 7 & Tank Farm Program \\
\hline 9 & Transfer DN Supernatant from AP or AY to AZ-101 & 28d & Sun $11 / 19 / 00$ & Sun $12 / 17 / 00$ & 8 & Tank Farm Program \\
\hline 10 & Mix contents of AZ-101 & $28 d$ & Sun $12 / 17 / 00$ & Sun $1 / 14 / 01$ & 9 & Tank Farm Opns \\
\hline 11 & Decant AZ-101 Supernatant to AN, AW, or AP & $28 d$ & Sun $1 / 14 / 01$ & Sun $2 / 11 / 01$ & 10 & Tank Farm Program \\
\hline 12 & Transfer DN Supernatant from AP or AY to AZ-101 & 28d & Sun $2 / 11 / 01$ & Sun $3 / 11 / 01$ & 11 & Tank Farm Program \\
\hline 13 & Mix contents of $A Z-101$ & $28 d$ & Sun $3 / 11 / 01$ & Sun $4 / 8 / 01$ & 12 & Tank Farm Opns \\
\hline 14 & Decant AZ-101 Supernatant to AN, AW, or AP & $28 \mathrm{~d}$ & Sun $4 / 8 / 01$ & Sun $5 / 6 / 01$ & 13 & Tank Farm Program \\
\hline \multicolumn{7}{|l|}{15} \\
\hline 16 & AZ-101 Feed Staging Operations & $636.54 \mathrm{~d}$ & Sun $5 / 6 / 01$ & Mon 2/3/03 & 5 & \\
\hline 17 & Add Transfer Solution from AP or AY to AZ-101 & $28 d$ & Sun $5 / 6 / 01$ & Sun $6 / 3 / 01$ & & Tank Farm Program \\
\hline 18 & Transfer AZ-101 Slurry to Private Contractor (Batch \#1) & $28 d$ & Fri 5/17/02 & Fri $6 / 14 / 02$ & 17 & Tank Farm Program \\
\hline 19 & Transfer AZ-101 Slurry to Private Contractor (Batch \#2) & $28 d$ & Mon $1 / 6 / 03$ & Mon 2/3/03 & 18 & Tank Farm Opns \\
\hline \multicolumn{7}{|l|}{20} \\
\hline 21 & Sluice $A Z-102$ to $A Z-101$ & 41d & Mon 2/3/03 & Sun $3 / 16 / 03$ & 16 & \\
\hline 22 & Prepare to Sluice & $5 d$ & Mon 2/3/03 & Sat $2 / 8 / 03$ & & Tank Farm Program \\
\hline 23 & Perform Sluicing Operation & $27 d$ & Sat $2 / 8 / 03$ & Fri $3 / 7 / 03$ & 22 & Tank Farm Opns \\
\hline 24 & Flush & $9 d$ & Fri $3 / 7 / 03$ & Sun $3 / 16 / 03$ & 23 & Tank Farm Opns \\
\hline 25 & & & & & & \\
\hline
\end{tabular}




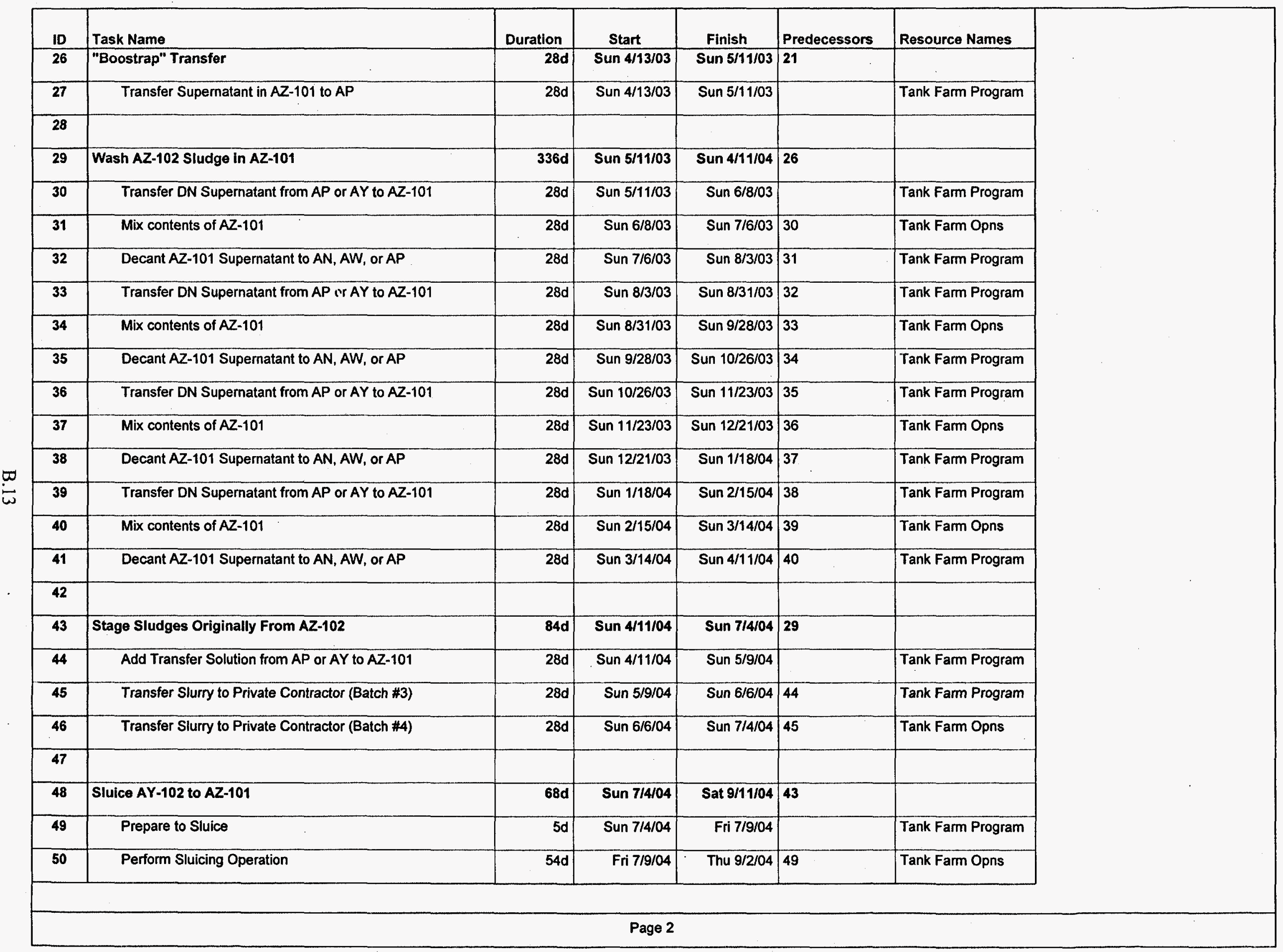




\begin{tabular}{|c|c|c|c|c|c|c|}
\hline ID & Task Name & Duration & Start & Finish & Predecessors & Resource Names \\
\hline 51 & Flush & $9 d$ & Thu $9 / 2 / 04$ & Sat $9 / 11 / 04$ & 50 & Tank Farm Opns \\
\hline \multicolumn{7}{|l|}{52} \\
\hline 53 & "Boostrap" Transfer & $28 \mathrm{~d}$ & Sun ज̂íziô & Sun 10/10/04 & 48 & \\
\hline 54 & Transfer Supernatant in AZ-101 to AP & $28 d$ & Sun $9 / 12 / 04$ & Sun $10 / 10 / 04$ & & Tank Farm Program \\
\hline \multicolumn{7}{|l|}{55} \\
\hline 56 & Wash AY-102 Sludge in AZ-101 & $84 d$ & Sun $10 / 10 / 04$ & Sun $1 / 2 / 05$ & 53 & \\
\hline 57 & Transfer DN Supernatant from AP or AY to AY-102 & $28 \mathrm{~d}$ & Sun $10 / 10 / 04$ & Sun $11 / 7 / 04$ & & Tank Farm Program \\
\hline 58 & Mix contents of AZ-101 & $28 d$ & Sun $11 / 7 / 04$ & Sun $12 / 5 / 04$ & 57 & Tank Farm Opns \\
\hline 59 & Decant AY-102 Supernatant to AN, AW, or AP & $28 d$ & Sun $12 / 5 / 04$ & Sun $1 / 2 / 05$ & 58 & Tank Farm Program \\
\hline \multicolumn{7}{|l|}{60} \\
\hline 61 & Stage Sludges Originally From AY-102 & $1017.04 d$ & Sun $1 / 2 / 05$ & Thu $10 / 18 / 07$ & 56 & \\
\hline 62 & Add Transfer Solution from AP or AY to AZ-101 & $28 d$ & Sun $1 / 2 / 05$ & Sun $1 / 30 / 05$ & & Tank Farm Program \\
\hline 63 & Transfer Slurry to Private Contractor (Batch \#5) & $28 d$ & Sun $1 / 30 / 05$ & Sun $2 / 27 / 05$ & 62 & Tank Farm Program \\
\hline 64 & Transfer Slurry to Private Contractor (Batch \#6) & $28 d$ & Sun $2 / 27 / 05$ & Sun $3 / 27 / 05$ & 63 & Tank Farm Opns \\
\hline 65 & Transfer Slurry to Private Contractor (Batch \#7) & $28 d$ & Sat $6 / 18 / 05$ & Sat $7 / 16 / 05$ & 64 & Tank Farm Opns \\
\hline 66 & Transfer Slurry to Private Contractor (Batch \#8) & $28 d$ & Sun $10 / 16 / 05$ & Sun $11 / 13 / 05$ & 65 & Tank Farm Opns \\
\hline 67 & Transfer Slurry to Private Contractor (Batch \#9) & $28 d$ & Mon 2/13/06 & Mon 3/13/06 & 66 & Tank Farm Opns \\
\hline 68 & Transfer Slurry to Private Contractor (Batch \#10) & $28 \mathrm{~d}$ & Tue $6 / 13 / 06$ & Tue $7 / 11 / 06$ & 67 & Tank Farm Opns \\
\hline 69 & Transfer Slurry to Private Contractor (Batch \#11) & $28 d$ & Sat $10 / 7 / 06$ & Sat $11 / 4 / 06$ & 68 & Tank Farm Opns \\
\hline 70 & Transfer Slurry to Private Contractor (Batch \#12) & 28d & Wed $1 / 31 / 07$ & Wed 2/28/07 & 69 & Tank Farm Opns \\
\hline 71 & Transfer Slurry to Private Contractor (Batch \#13) & $28 \mathrm{~d}$ & Sun $5 / 27 / 07$ & Sun $6 / 24 / 07$ & 70 & Tank Farm Opns \\
\hline 72 & Transfer Slurry to Private Contractor (Batch \#14) & $28 d$ & Thu $9 / 20 / 07$ & Thu $10 / 18 / 07$ & 71 & Tank Farm Opns \\
\hline
\end{tabular}


Table B.4 Phase 1 Activities and Durations - Mechanical Retrieval with Pipeline Transfer'

\begin{tabular}{|c|c|c|c|c|c|c|c|}
\hline ID & Task Name & Duration & Start & Finish & Predecessors & Resource Names & \\
\hline 1 & AZ-101 "Bootstrap" Transfers & $56 \mathrm{~d}$ & Wed $6 / 7 / 00$ & Wed 8/2/00 & & & \\
\hline 2 & Transfer AY-101 Supernatant to AP & $28 \mathrm{~d}$ & Wed $6 / 7 / 00$ & Wed 7/5/00 & & Tank Farm Program & \\
\hline 3 & Transfer AZ-101 Supernatant to $A Y-101$ & $28 \mathrm{~d}$ & Wed $7 / 5 / 00$ & Wed $8 / 2 / 00$ & 2 & Tank Farm Program & \\
\hline 4 & . & & & & & & \\
\hline 5 & AZ-101 Sludge Washing Operations & 252d & Sun $8 / 27 / 00$ & Sun $5 / 6 / 01$ & 1 & & \\
\hline 6 & Transfer DN Supernatant from AP or AY to AZ-101 & $28 \mathrm{~d}$ & Sun $8 / 27 / 00$ & Sun $9 / 24 / 00$ & & Tank Farm Program & \\
\hline 7 & Mix contents of AZ-101 & $28 \mathrm{~d}$ & Sun $9 / 24 / 00$ & $\operatorname{Sun} 10 / 22 / 00$ & 6 & Tank Farm Opns & \\
\hline 8 & Decant $A Z-101$ Supernatant to $A N, A W$, or $A P$ & 28d & Sun 10/22/00 & Sun 11/19/00 & 7 & Tank Farm Program & \\
\hline 9 & Transfer DN Supernatant from AP or AY to AZ-101 & $28 \mathrm{~d}$ & Sun $11 / 19 / 00$ & Sun $12 / 17 / 00$ & 8 & Tank Farm Program & \\
\hline 10 & Mix contents of AZ-101 & 28d & Sun $12 / 17 / 00$ & Sun $1 / 14 / 01$ & 9 & Tank Farm Opns & \\
\hline 11 & Decant AZ-101 Supernatant to AN, AW, or AP & 28d & Sun $1 / 14 / 01$ & Sun $2 / 11 / 01$ & 10 & Tank Farm Program & \\
\hline 12 & Transfer DN Supernatant from AP or AY to AZ-101 & 28d & Sun $2 / 11 / 01$ & Sun $3 / 11 / 01$ & 11 & Tank Farm Program & \\
\hline 13 & Mix contents of AZ-101 & 28d & Sun $3 / 11 / 01$ & $\operatorname{Sun} 4 / 8 / 01$ & 12 & Tank Farm Opns & \\
\hline 14 & Decant AZ-101 Supernatant to AN, AW, or AP & $28 \mathrm{~d}$ & Sun $4 / 8 / 01$ & Sun $5 / 6 / 01$ & 13 & Tank Farm Program & \\
\hline 15 & & & & & & & \\
\hline 16 & AZ-101 Feed Staging Operations & 636.54d & Sun $5 / 6 / 01$ & Mon 2/3/03 & 5 & & \\
\hline 17 & Add Transfer Solution from AP or AY to AZ-101 & 28d & Sun $5 / 6 / 01$ & Sun $6 / 3 / 01$ & & Tank Farm Program & \\
\hline 18 & Transfer AZ-101 Slurry to Private Contractor (Batch \#1) & 28d & Fri 5/17/02 & Fri 6/14/02 & 17 & Tank Farm Program & \\
\hline 19 & Transfer AZ-101 Slurry to Private Contractor (Batch \#2) & 28d & Mon $1 / 6 / 03$ & Mon 2/3/03 & 18 & Tank Farm Opns & \\
\hline 20 & & & & & & & \\
\hline 21 & Retrieve Using Mech Arm AZ-102 to AZ-101 & 49d & Mon 2/3/03 & Mon $3 / 24 / 03$ & 16 & & \\
\hline 22 & Prepare to Retrieve & $9 d$ & Mon 2/3/03 & Wed 2/12/03 & & Tank Farm Program & \\
\hline 23 & Retrieve Sludge & $31 d$ & Wed $2 / 12 / 03$ & Sat $3 / 15 / 03$ & 22 & Tank Farm Opns & \\
\hline 24 & Flush & $9 d$ & Sat $3 / 15 / 03$ & Mon 3/24/03 & 23 & Tank Farm Opns & \\
\hline 25 & & & & & & & \\
\hline \multicolumn{8}{|c|}{ Page 1} \\
\hline
\end{tabular}




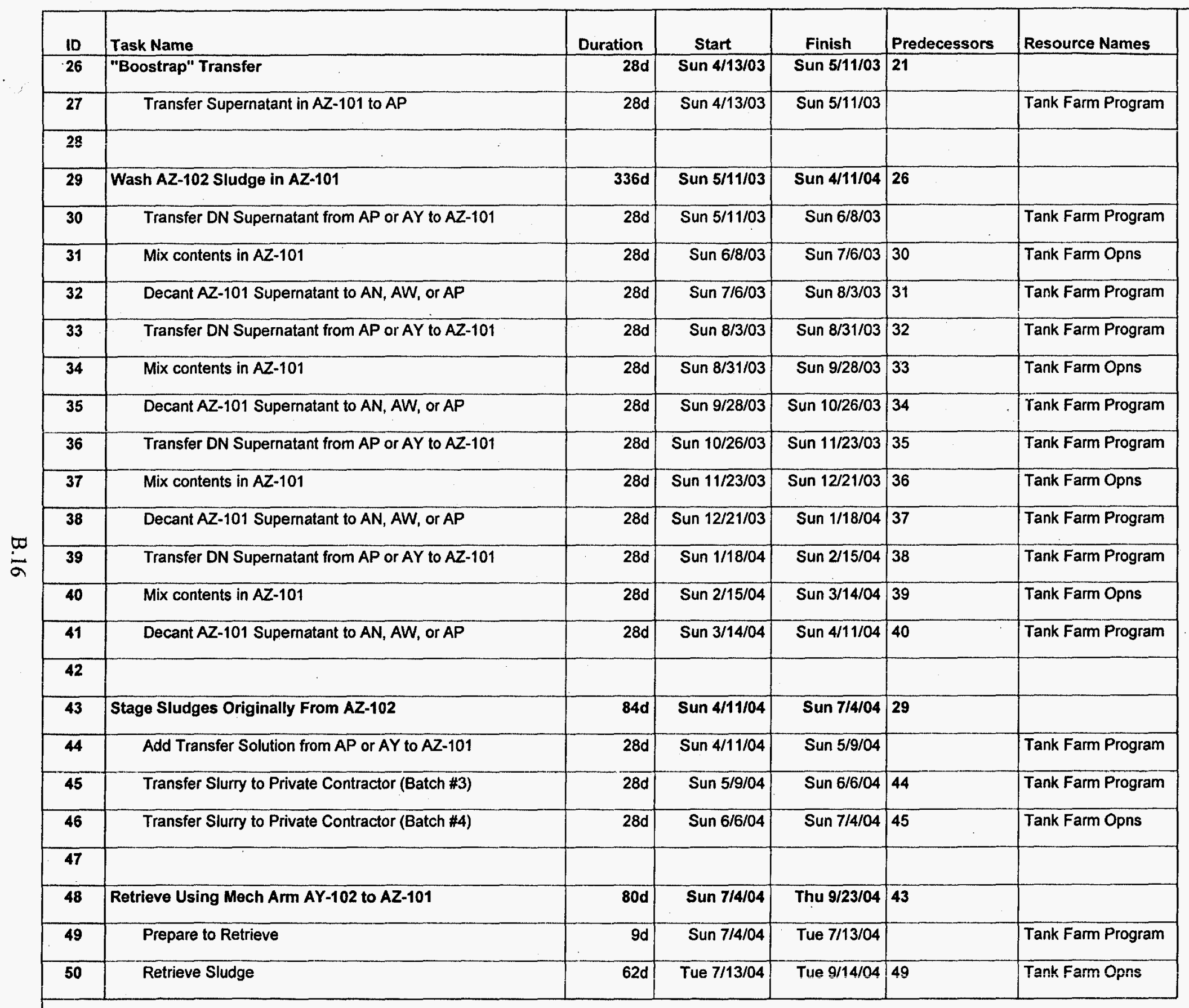




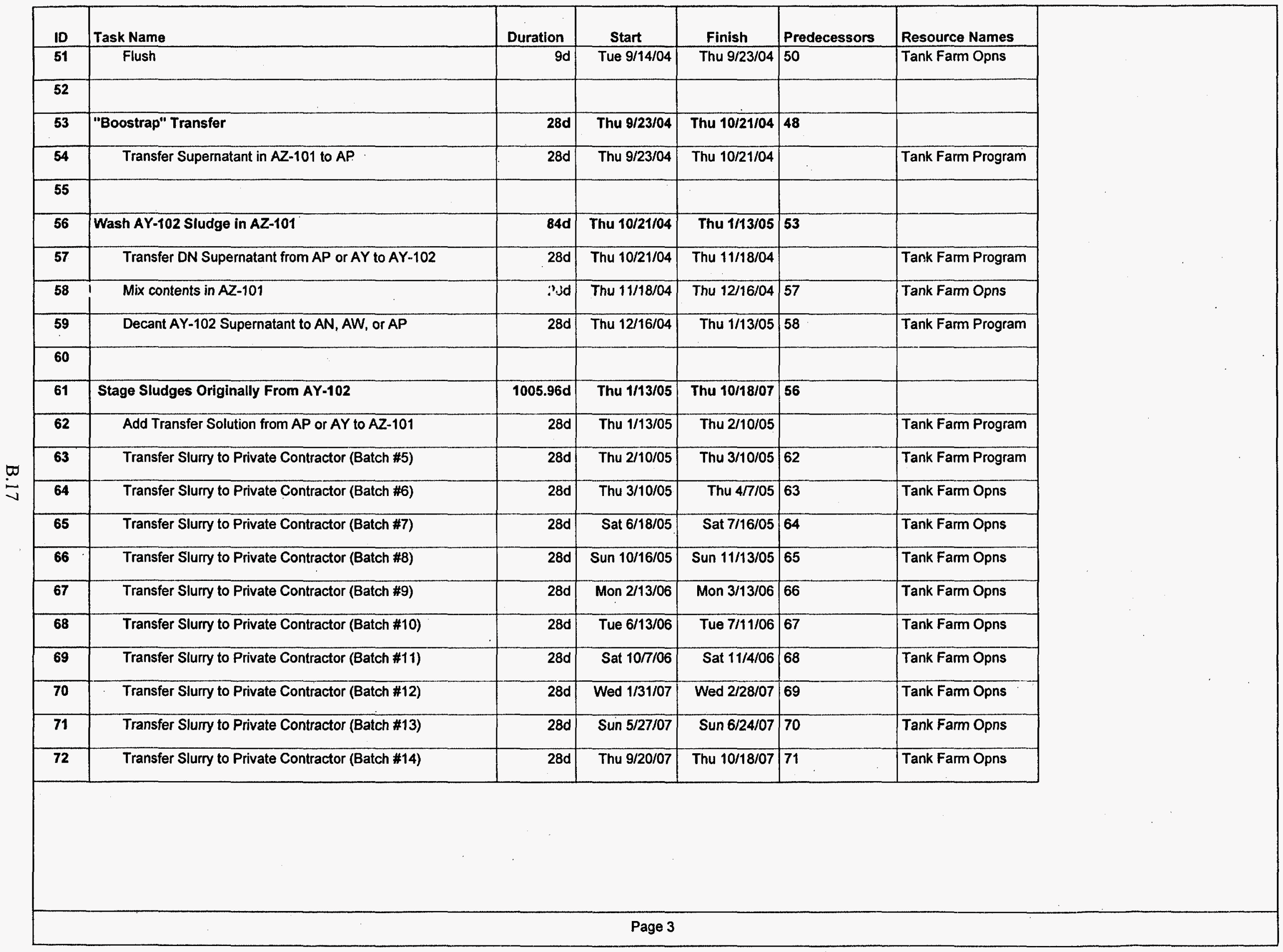


Appendix C

Operating Efficiency Risk Analysis 


\section{Appendix C}

\section{Operating Efficiency Risk Analysis}

\section{C.1 Modeling Approach Used}

Each alternative will be evaluated on the basis of a mission of completed retrieval of $2 \mathrm{ft}$ of sludge (approximately $70000 \mathrm{gal}$ ) from one tank.

Reliability is defined as the probability of successful accomplishment of the defined mission. Component reliability is the probability that a component is available and performing its function throughout the defined mission. System reliability is the probability that the whole system performs its function throughout the defined mission. The corresponding unreliabilities are the complementary events, that is, the probability that the component or system will not perform its function, as required, throughout the defined mission.

Availability at time $t$ is the probability that the component or system is "up" at time $t$. Average availability over some time interval is the expected fraction of that time interval that component or system is "up." Component and system availabilities do not seem to be particularly relevant for evaluating the various retrieval alternatives because 1) the expected mission times and expected mission costs vary significantly among the alternatives, and, paradoxically, 2) a large expected mission time (which may not be particularly desirable) tends to be associated with high availability (since the repair downtime is a smaller fraction of the long mission time).

The components required to perform the defined mission are those specified in the January 14,1997 , R. Claghorn memo, although as a simplifying assumption some of the components identified in the Claghorn memo have been assumed to function without failure.

The computations described below were performed in three steps. First, major component reliabilities and unreliabilities were calculated. These values depend on the assumed mission times (from information in the Claghorn memo, with subsequent revisions of the mission times provided by N. Williams) and the assumed failure distributions for the components. Second, component reliabilities and unreliabilities are used to calculate the probability of occurrence of several scenarios. Roughly speaking, the scenarios are

- completed mission with no failures

- completed mission with one failure of a defined equipment system followed by repair of the failed system and resumption of the retrieval mission 
- completed mission with multiple failures of required systems followed by repair and resumption (i.e., the assumed sequence is: retrieval, failure 1, repair 1, retrieval, failure 2, repair 2, completion of mission).

Notice that, although a probability is calculated for "multiple" failures, only two failure/repair episodes will be assumed for calculation of expected mission time and expected mission cost. The final step is to calculate the mission time and mission cost associated with each of the scenarios and to use the previously calculated scenario probabilities to calculate expected mission time and expected mission cost.

The Claghorn memo assumes a mean time to repair (MTTR) of one week for failures allowing contact maintenance (roughly, aboveground failures) and a MTTR of one month for failures requiring non-contact maintenance (roughly, in-tank failures). In these calculations, we have assumed that half of the failures would allow contact maintenance and half would require non-contact maintenance and have used a MTTR $=0.5 * 7 * 24+0.5 * 30 * 24=444 \mathrm{hr}$.

The unit of time used for all mean times to failure (MTTF), MTTRs, and assumed failure distributions is hours.

\section{C.2 Failure Distribution Assumptions Used in the Calculations}

Calculations have been made for two major sets of failure distribution assumptions:

- All component failure distributions are assumed to be exponential distributions.

- All component failure distributions are assumed to be triangular distributions (i.e., with a failure rate that increases linearly with time).

Various component mean lifetime assumptions have been evaluated. Since there is a major program to develop advanced mixer pumps with longer mean life than the current pumps, mixer pump MTTFs of $2000 \mathrm{hr}, 6000 \mathrm{hr}$, and $7000 \mathrm{hr}$ have been assumed. In general, for other pumps, a MTTF of $2000 \mathrm{hr}$ has been assumed. A MTTF of $6000 \mathrm{hr}$ has been used for the control systems and the pump/sluicer turntables. A MTTF of $2000 \mathrm{hr}$ have been assumed for the cyclone separator and associated equipment, for the truck transfer system, and for the retrieval tank HVAC system. A MTTF of $1000 \mathrm{hr}$ has been assumed for the robotic arm.

The exponential distribution is most appropriate for equipment that tends to suffer "infant mortality," but which has no tendency to wear out, such as many types of electronic components. The triangular distribution defined above represents equipment with no significant infant mortality, but both an upper bound on life length and a tendency to wear out. These two distributions were chosen for simplicity in carrying out the calculations; taken together, they give us some sense for all three parts of the traditional "bathtub curve" that is typical of failure distributions for many types of mechanical equipment. By repeating the calculation for these two failure distribution assumptions, we can see if the choice of retrieval alternatives is sensitive to the assumed equipment failure distributions. These two distributions were 
chosen, out of all the possible choices, because they model two different aspects of the actual (unknown) failure distributions and because they are simple enough to allow easy calculation of all the relevant quantities.

There is a major difference between the exponential and triangular distributions. The exponential distribution has a constant hazard rate. Basically, that means that the conditional probability of failure in the time interval from $T$ to $T+d t$, given that the component has survived up until time $T$, is independent of $T$. This is another way of saying that the component does not wear out and may survive (with increasingly small probabilities) till arbitrarily large times $T$.

The triangular distribution, on the other hand, has an upper bound on the component life: no component will survive longer than $1.5^{*}$ MTTF. In addition, the components wear out, in the sense that the above-described conditional probability of failure in the time interval $\mathrm{T}$ to $\mathrm{T}+\mathrm{dt}$ will increase steadily as $\mathrm{T}$. approaches $1.5 *$ MTTF. This means that the reliability of a component with a triangular failure distribution will depend on how much of the component lifetime has been used prior to the start of the retrieval campaign. To account for this, each evaluation of the four alternatives for assumed triangular failure distributions is done three times: for Beginning of Life conditions, for Middle of Life conditions (roughly, each component has operated for $0.5^{*} \mathrm{MTTF}$ hr prior to start of the campaign), and for End of Life conditions (roughly, each component has operated for MTTF hr prior to start of the campaign).

Intuitively, the exponential distribution is a reasonable model for equipment with significant infant mortality for which no "burn-in" period is utilized by the manufacturer to eliminate the infant failures. The triangular distribution is a reasonable model for equipment which both wears out as its time in service approach the end of a finite lifetime and for which a "burn-in" period has been used to eliminate infant failures.

\section{C.3 Assumptions Used for the Mixing/Transfer Alternative}

For each piece of equipment required for the 56-day mission, the reliability $R_{-}$i (for the ith piece of required equipment) will be calculated. We have assumed that mixer pumps operate for only 40 days of that mission (unless there are failures, in which case, a 3-day resuspension period of mixer pump operation is required after each repair shutdown). The transfer pumps are assumed to operate for 22 days of the 56-day mission. The control systems operate for the entire 56-day mission. The overall system reliability, $R$ (i.e., the probability that the system will successfully complete its 56-day mission), will be the product of all the $R_{-} i$. This calculation assumes statistical independence of the separate reliabilities; we may decide later that it would be useful to adjust these calculations to account for possible common cause failures. As noted above, in the event of a failure (or two failures), it is assumed that when the repair is complete, three additional days of mixing will be required to return the waste tank to its condition prior to the failure, at which time the retrieval campaign will resume at the point it had reached at the time of the failure. Thus, one failure will lengthen the mission time by 3 days plus $444 \mathrm{hr}$ (or $516 \mathrm{hr}$ ) and two failures will lengthen mission time by 6 days plus $888 \mathrm{hr}$ (or $1032 \mathrm{hr}$ ). Operating costs during this mission are $\$ 213 \mathrm{per} \mathrm{hr}$, and pump amortization costs are assumed to be $\$ 250$ per hr. 


\section{C.4 Assumptions Used for the Sluicing/Transfer and the Mechanical Retrieval Alternatives}

The other three alternatives differ from mixing/transfer in that they do not involve campaigns, per se. Each alternative can operate until something fails and then be down until the failed equipment is repaired. When the repair is complete, retrieval can resume immediately. We have assumed a 52-day mission, with the sluicing and transfer pumps operating for 49 days. Operating costs during this mission are $\$ 213$ per hr, and pump amortization costs are assumed to be $\$ 250$ per hr.

\section{C.5 Assumptions Used to Calculated Expected Costs for Each Case}

We have assumed a cost of operating the entire retrieval facility of $\$ 500 / \mathrm{hr}$ which depends on the specific alternative (to be multiplied by the scenario mission time) and a cost of amortizing the pumps of $\$ 250$ \%perating hr (to be multiplied by the scenario pump operating time). In addition, contact maintenance was assumed to cost $\$ 25 \mathrm{~K}$ and non-contact maintenance to cost $\$ 100 \mathrm{~K}$. This cost function is crude, but gives an idea of relative costs of the various cases. Capital costs have not been included, other than the estimated cost for pump amortization. Assumed operating costs are $\$ 213 / \mathrm{hr}$ for the Mixing Pump/ TransferPump and the Sluicing/Transfer alternatives, $\$ 254 / \mathrm{hr}$ for the MechArm/PipeTransfer alternative, and $\$ 533 / \mathrm{hr}$ for the MechArm/TruckTransfer alternative. The bases for these cost assumptions are described in Section 4 of this report.

\section{C.6 Testing Sensitivity to the Simplifying Assumptions}

If the results prove to be highly sensitive to the simplifying assumptions or to the failure distribution assumptions, it might be necessary/desirable to more realistically model the alternatives with industrial strength modeling tools.

\section{C.7 Summary Description of the Cases}

\section{Case 1]}

Case 1 is a special case for the Mixing/Transfer Alternative which assumes two failure processes operating on the Mixing Pumps. First, an exponential distribution with MTTF $=2000 \mathrm{hr}$, representing failures subject to repair, and second, an exponential distribution with MTTF $=6000 \mathrm{hr}$, representing "death" of the pump and replacement by a new pump.

\section{Cases 2-4}

For the Mixing/Transfer Alternative, these three cases assume that the mixing pumps and the transfer pump have exponential failure distributions with MTTF of $2000 \mathrm{hr}$ (Case 2), $6000 \mathrm{hr}$ (Case 3), and 
$7000 \mathrm{hr}$ (Case 4), respectively. These correspond to current performance and the design goals for the Advanced Design Mixer Pump projects at Lawrence Pump, Inc., and Westinghouse Electro-Mechanical Division, respectively.

\section{Case 5}

For the Sluicing/Transfer Alternative, this case assumes that all four pumps and the retrieval tank HVAC system have exponential failure distributions with MTTF $=2000 \mathrm{hr}$. The sluicing pump turntable and the control systems are assumed to have exponential failure distributions with MTTF $=6000 \mathrm{hr}$.

\section{Case 6}

For the Mechanical/TruckTransfer Alternative, this case assumes all major systems have exponential failure distributions with MTTF $=2000 \mathrm{hr}$, except for the robotic arm (exponential with MTTF $=1000 \mathrm{hr}$ ) and the control systems (exponential with MTTF $=6000 \mathrm{hr}$ ).

\section{Case 7}

For the Mechanical/PumpTransfer Alternative, this case assumes all major systems have exponential distributions with MTTF $=2000$, except for the robotic arm (exponential with MTTF $=1000 \mathrm{hr}$ ), pipe transfer system (exponential with MTTF $=4000 \mathrm{hr}$ ), and the control systems (exponential with MTTF $=$ $6000 \mathrm{hr}$ ).

\section{Cases 8-10}

For the Mixing/Transfer Alternative, we assume mixer pump MTTF $=2000 \mathrm{hr}$, transfer pump MTTF $=2000 \mathrm{hr}$, and control system $\mathrm{MTTF}=6000 \mathrm{hr}$.

\section{Cases 11-13}

For the Mixing/Transfer Alternative, we assume mixer pump MTTF $=6000 \mathrm{hr}$, transfer pump MTTF $=2000 \mathrm{hr}$, and control system $\mathrm{MTTF}=6000 \mathrm{hr}$.

\section{Cases 14-16}

For the Sluicing/Transfer Alternative, all major systems assumed to have MTTF $=2000$ $\mathrm{hr}$, except for the sluicing pump turntable and the control systems with MTTF $=6000 \mathrm{hr}$.

Cases 8-22 all assume triangular failure distributions. These differ from the exponential distribution in that the current failure probability for equipment that has survived to date (i.e., the hazard rate) increases steadily (as is the case, for example, with the nortality rate for adult humans as they get older). Thus, for each of alternatives, we consider three cases:

- all equipment at the Beginning of its Tife $(\mathrm{BOL}=0.0 \mathrm{MTIF})$

- all equipment at the Middle of Life MOL= $0.5 *$ MTTIT)

- most equipment at the End of Life (EOI $1.0 *$ MTIF).

In addition, for the Mixing/transfer Alternative, we look at six cases in all, three assuming mixer pump MITIF $=2000 \mathrm{hr}$ and three assuming mixer pump MTIF $=6000 \mathrm{hr}$. 


\section{Cases 17-19}

For the Mechanical/TruckTransfer Alternative, all major systems are assumed to have MTTF = $2000 \mathrm{hr}$, expect for the robotic arm at MTTF $=1000 \mathrm{hr}$ and the control systems at MTTF $=6000 \mathrm{hr}$. For Case 19, it was necessary to assume that the mechanical arm was at Beginning of Life, or the calculation of reliability and unreliability blew up.

\section{Cases 20-22}

For the Mechanical/PipeTransfer Alternative, all major systems assumed to have MTTF $=2000 \mathrm{hr}$, expect for the robotic arm at MTTF $=1000 \mathrm{hr}$, the pipe transfer system at MTTF $=4000 \mathrm{hr}$, and the control systems at MTTF $=5000 \mathrm{hr}$. For Case 22, it was necessary to assume that the mechanical arm was at Beginning of Life, or the calculation of reliability and unreliability blew up.

\section{C.8 Discussion of Results}

Broadly speaking, expected mission times are similar for all alternatives, with the longest expected mission time being roughly twice the shortest. The high-reliability Mixer pump alternatives have the shortest expected mission times with Sluicing/Transfer (S/Tr) cases being 10-20\% longer. The Mechanical Retrieval (Mech/TTr and Mech/PTr) alternative have significantly longer expected mission times.

For expected mission costs, the high-reliability Mixing pump alternatives have the smallest expected cost. Costs for Sluicing and Mechanical Retrieval are two to four times greater, depending on the failure distribution assumptions.

Case 1 was included to see if a somewhat more realistic treatment of the mixing pump failure processes had a significant impact on the results. Case 1 assumes that two separate failure processes are operating on the mixer pumps. First, there is an "illness/health" process by which the pump is assumed to suffer a repairable failure with a MTTF of $2000 \mathrm{hr}$. The pump is repaired, and the retrieval scenario resumes and is carried to completion. The second failure process is a pump "death" process with MTTF of $6000 \mathrm{hr}$. When the pump dies, it is replaced with a new pump; the retrieval process resumes and is carried to completion. Both failure processes assume an exponential failure distribution. The first four rows of Table C. 1 show that the "two failure process" do not significantly impact the expected mission time and expected mission cost for the MixP/Tr cases.

The fact that the expected mission cost and expect mission duration for the triangular distribution $\mathrm{BOL}$ cases are so much lower than the other cases suggests a significant benefit to "burning in" equipment before it is placed in service. 
Table C.1. Summary of Calculation Results

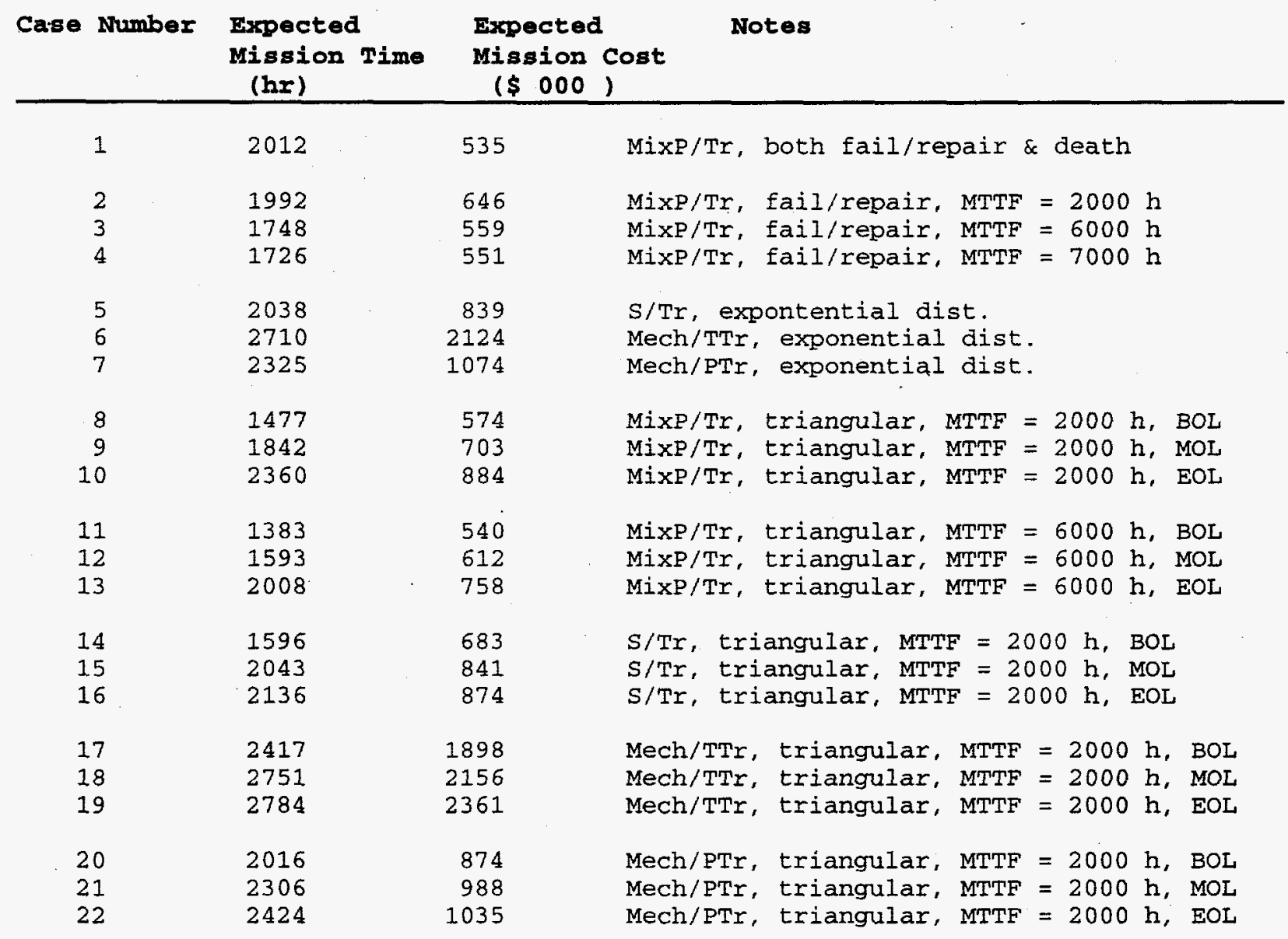

\section{C.9 Possible Extensions of This Analysis}

This analysis can be extended and refined in several ways.

Maintenance histories of existing applications of tank mixing pumps and pilot retrieval projects can be reviewed to obtain better estimates and application-specific estimates of system and component failure distributions. These more realistic estimates might model both infant mortality and wear-out processes or might distinguish (as does Case 1, in part) between repairable failures and failures requiring system replacement.

More detailed modeling (using tools such as event trees, fault trees, and Markov processes) can be used as a design tool for reliability allocation, hazard assessment, preliminary safety analysis, and life-cycle modeling. This more detailed analysis can capture the effects of time-phasing of the retrieval process, relationships between front-line and support systems, susceptibility to common-cause failures, and the impact of external events. 
Table C.2. Comparison of No-Failure Mission Times and Costs with Expected Mission Times and Costs

\begin{tabular}{|c|c|c|c|c|c|}
\hline \multicolumn{2}{|r|}{ Case Description } & $\begin{array}{l}\text { No-Failure } \\
\text { Mission Time } \\
\text { (hr) }\end{array}$ & \multirow[t]{2}{*}{$\begin{array}{l}\text { Expected } \\
\text { Mission Time } \\
\text { (br) }\end{array}$} & \multirow[t]{2}{*}{$\begin{array}{l}\text { No-Failure } \\
\text { Mission Cost } \\
(\$ 000 \mathrm{~s})\end{array}$} & \multirow[t]{2}{*}{$\begin{array}{r}\text { Expecte } \\
\text { Mission Co } \\
(\$ 0008)\end{array}$} \\
\hline \multicolumn{3}{|c|}{ Exponential failure distribution cases } & & & \\
\hline 1 & MixP/Tr, pump "death" & 1344 & 2012 & 286 & 535 \\
\hline 2 & $\mathrm{MixP} / \mathrm{Tr}, \mathrm{MTTF}=2000 \mathrm{hr}$ & 1344 & 1992 & 418 & 646 \\
\hline 3 & $\mathrm{MixP} / \mathrm{Tr}, \mathrm{MTTF}=6000 \mathrm{hr}$ & 1344 & 1748 & 418 & 559 \\
\hline 4 & $\mathrm{MixP} / \mathrm{Tr}, \mathrm{MTTF}=7000 \mathrm{hr}$ & 1344 & 1726 & 418 & 551 \\
\hline 5 & $\mathrm{~S} / \mathrm{Tr}$ & 1248 & 2037 & 560 & 839 \\
\hline 6 & Mech/TTr & 1896 & 2710 & 1494 & 2124 \\
\hline 7 & Mech/PTr & 1536 & 2325 & 390 & 1074 \\
\hline \multicolumn{6}{|c|}{ Triangular failure distribution cases } \\
\hline 8 & $\mathrm{MixP} / \mathrm{Tr}, 2000 \mathrm{hr}, \mathrm{BOL}$ & 1344 & 1477 & 526 & 574 \\
\hline 11 & $\mathrm{MixP} / \mathrm{Tr}, 6000 \mathrm{hr}, \mathrm{BOL}$ & 1344 & 1383 & 526 & 540 \\
\hline 14 & $\mathrm{~S} / \mathrm{T}, \mathrm{BOL}$ & 1248 & 1596 & 560 & 683 \\
\hline 17 & Mech/TTr, BOL & 1896 & 2417 & 1494 & 1898 \\
\hline 20 & $\mathrm{Mech} / \mathrm{PTr}, \mathrm{BOL}$ & 1536 & 2016 & 684 & 874 \\
\hline 9 & $\mathrm{MixP} / \mathrm{Tr}, 2000 \mathrm{hr}, \mathrm{MOL}$ & 1344 & 1842 & 526 & 703 \\
\hline 12 & $\mathrm{MixP} / \mathrm{Tr}, 6000 \mathrm{hr}, \mathrm{MOL}$ & 1344 & 1593 & 526 & 613 \\
\hline 15 & $S / T, M O L$ & 1248 & 2043 & 560 & 841 \\
\hline 18 & Mech/TTr, MOL & 1896 & 2751 & 1494 & 2156 \\
\hline 21 & Mech/PTr, MOL & 1536 & 2306 & 684 & 988 \\
\hline 10 & MixP/Tr, $2000 \mathrm{hr}$, EOL & 1344 & 1842 & 526 & 703 \\
\hline 13 & $\mathrm{MixP} / \mathrm{Tr}, 6000 \mathrm{hr}, \mathrm{EOL}$ & 1344 & 2008 & 526 & 758 \\
\hline 16 & $\mathrm{~S} / \mathrm{T}, \mathrm{EOL}$ & 1248 & 2136 & 560 & 874 \\
\hline 19 & Mech/TTr, EOL & 1896 & 2784 & 1494 & 2181 \\
\hline 22 & Mech/PTr, EOL & 1536 & 2424 & 684 & 1035 \\
\hline
\end{tabular}

Finally, this analysis considers a single tank and a single mission of retrieving $2 \mathrm{ft}$ of sludge from the tank. The DST retrieval mission will involve retrieving waste from multiple tanks over multiple years, with a critical concern being whether the retrieval system will be able to meet, with high probability, its schedule for providing waste feed to the vitrification plant(s). These single mission reliability results (or the results of a more detailed/realistic analysis) can be extended to analysis of a multi-tank, multi-campaign retrieval system to determine design and reliability requirements for meeting the feed schedule with acceptably high probability.

\section{C.10 Spreadsheet Output}

Note: Even though the crude assumptions do not justify more than 2 to 3 significant digits in the output, the spreadsheet results below are given in 9 to 12 places. 


\section{Case 2:}

Mixing/Transfer - assume Mpump failure/repair only $(\mathrm{MTTF}=2000 \mathrm{hr})$

\begin{tabular}{|c|c|c|c|c|c|}
\hline \multicolumn{2}{|r|}{$\begin{array}{l}\text { Failure } \\
\text { Rate }\end{array}$} & $\begin{array}{l}\text { Mission } \\
\text { Time }\end{array}$ & lamda*t & Reliab. & Unreliab. \\
\hline Mixer $\mathrm{P} f / \mathrm{r}$ & 0.0005 & 960 & 0.48 & 0.618783392 & 0.381216 \\
\hline Transfer P & 0.0005 & .528 & 0.264 & 0.76797354 & 0.232026 \\
\hline Control Sys & 0.000166667 & 1344 & 0.224 & 0.799315134 & 0.200684 \\
\hline \multicolumn{6}{|c|}{ Failure down time $(1 / 2) *(1$ week $)+(1 / 2) *(30$ days $)=444 \mathrm{hr}$} \\
\hline \multicolumn{3}{|c|}{ Repair cost (contact) } & \multicolumn{2}{|c|}{25000} & \\
\hline \multicolumn{3}{|c|}{ Repair cost (non-contact) } & \multicolumn{2}{|c|}{100000} & \\
\hline \multicolumn{3}{|c|}{ Operating cost } & \multicolumn{2}{|c|}{213 per hr } & \\
\hline \multicolumn{3}{|c|}{ Mpump amortization } & \multicolumn{2}{|c|}{250 per hr } & \\
\hline Scenario & Probab. & $\begin{array}{c}\text { Mission } \\
\text { Time }\end{array}$ & Mpump & Mission & \\
\hline No failure & 0.235039898 & 1344 & 528 & 418272 & \\
\hline Mpump failure & 0.144802065 & 1860 & 600 & 608680 & \\
\hline Tpump failure & 0.07101218 & 1860 & 528 & 590680 & \\
\hline ContSys Eailure & 0.059011707 & 1860 & 528 & 590680 & \\
\hline Mult. failures & 0.49013415 & 2376 & 600 & 781088 & \\
\hline \multicolumn{2}{|c|}{ Expected Mission Time $=$} & \multicolumn{2}{|c|}{1991.6286339} & & \\
\hline & \multicolumn{2}{|c|}{573.715407449} & & \\
\hline \multicolumn{2}{|c|}{ Expected Mission Cost $=$} & 646089.14 & & & \\
\hline
\end{tabular}

C. 10 


\section{Case 3:}

Mixing/Transfer - assume Mpump failure/repair only $(\mathrm{MTTF}=6000 \mathrm{hr})$

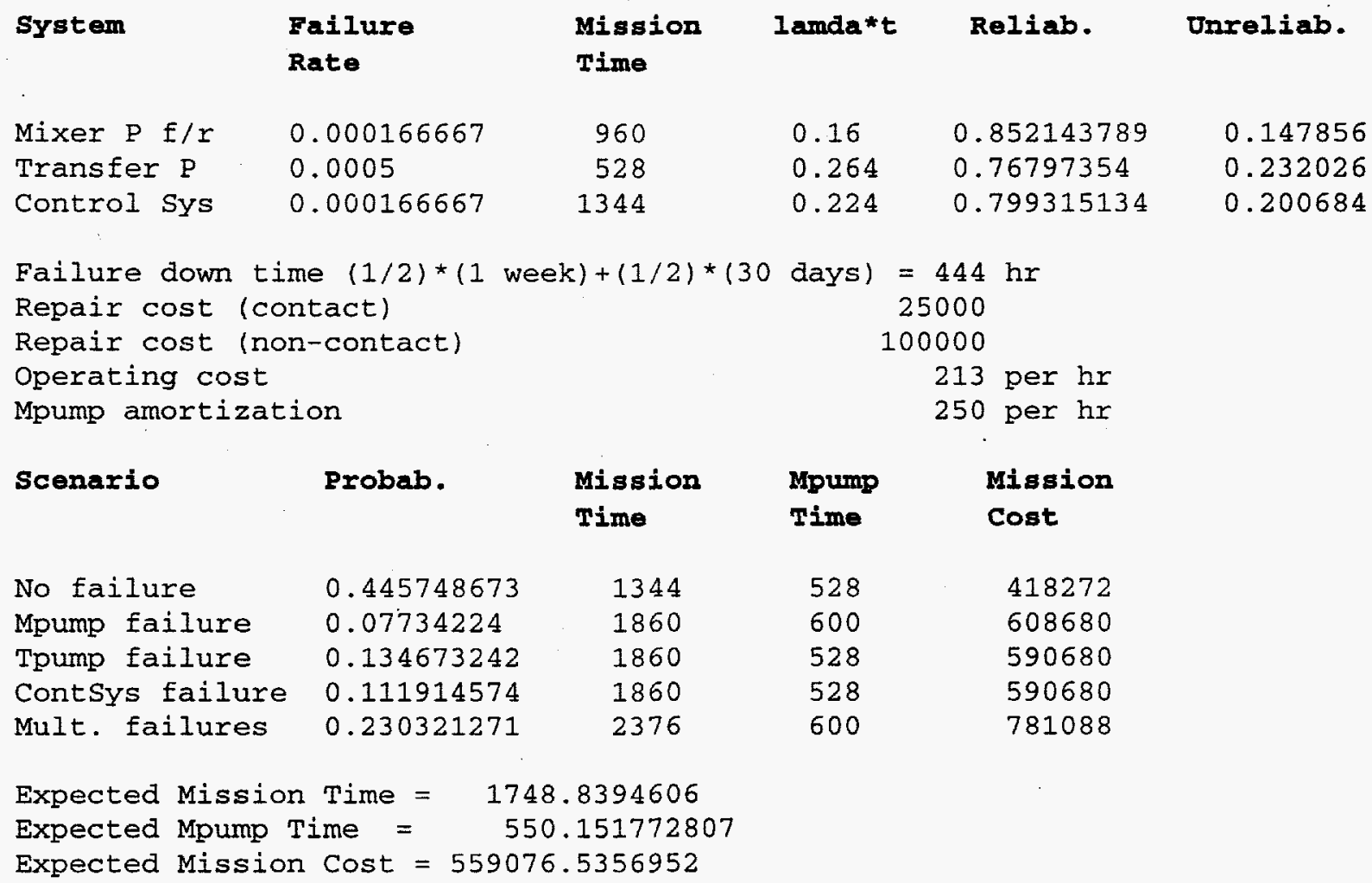




\section{Case 4:}

Mixing/Transfer - assume Mpump failure/repair only $(\mathrm{MTTF}=7000 \mathrm{hr})$

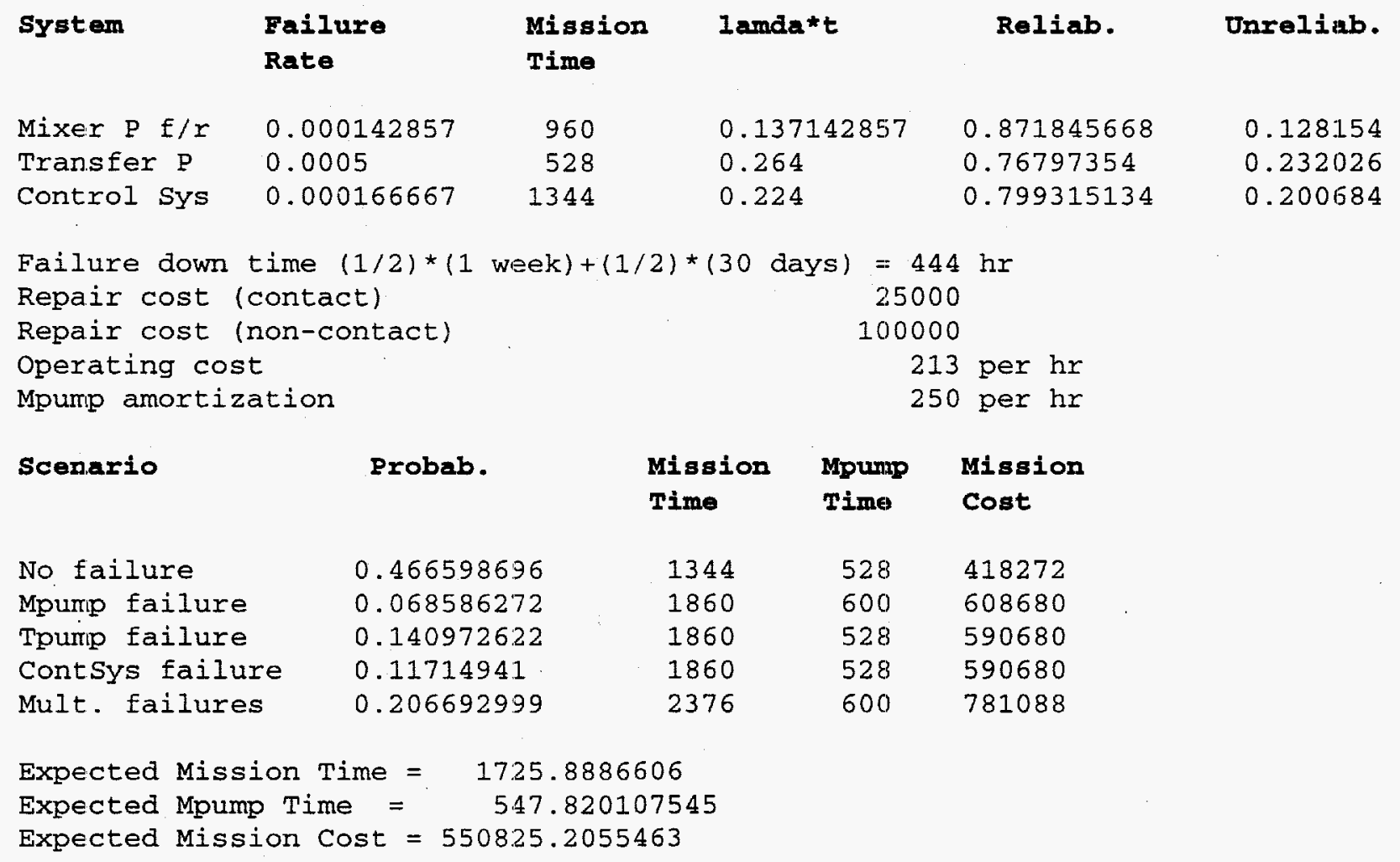




\section{Case 5:}

Sluicing/Transfer - assume Tpump failure/repair MTTF $=2000 \mathrm{hr}$

$\begin{array}{llcccr}\text { System } & \begin{array}{l}\text { Failure } \\ \text { Rate }\end{array} & \begin{array}{c}\text { Mission } \\ \text { Time }\end{array} & \text { lamakt } & \text { Reliab. } & \text { Unreliab. } \\ \text { Transfer P } & 0.0005 & 1176 & 0.588 & 0.555437049 & 0.444562 \\ \text { Sluicing P } & 0.0005 & 1176 & 0.588 & 0.555437049 & 0.444562 \\ \text { Transfer B P } & 0.0005 & 1176 & 0.588 & 0.555437049 & 0.444562 \\ \text { Sluicing B P } & 0.0005 & 1176 & 0.588 & 0.555437049 & 0.444562 \\ \text { Turntable } & 0.000166667 & 1176 & 0.196 & 0.822012235 & 0.177987 \\ \text { Retrieval HVAC } & 0.0005 & 1248 & 0.624 & 0.535796958 & 0.464203 \\ \text { Control Sys } & 0.000166667 & 1248 & 0.208 & 0.812207037 & 0.187792\end{array}$

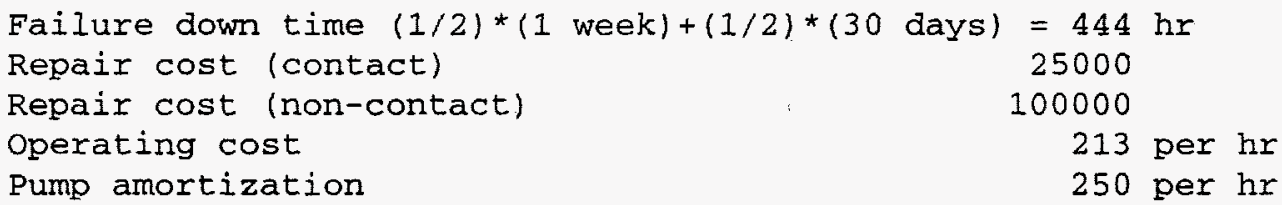

$\begin{array}{lllll}\text { Scenario } & \text { Probab. } & \begin{array}{l}\text { Mission } \\ \text { Time }\end{array} & \begin{array}{l}\text { Pumpoper } \\ \text { Time }\end{array} & \begin{array}{l}\text { Mission } \\ \text { Cost }\end{array} \\ \text { No failure } & 0.034047455 & 1248 & 1176 & 559824 \\ \text { IPump failure } & 0.109004158 & 1692 & 1176 & 716896 \\ \text { TTable failure } & 0.00737219 & 1692 & 1176 & 716896 \\ \text { HVAC failure } & 0.029497988 & 1692 & 1176 & 716896 \\ \text { ContSys failure } & 0.00787222 & 1692 & 1176 & 716896 \\ \text { Mult. failures } & 0.81220599 & 2136 & 1176 & 873968\end{array}$

Expected Mission Time $=2037.5023895$

Expected Pump OpTime $=480$

Expected Mission Cost $=839122.917384$ 


\section{Case 6:}

MechRetrieval/TruckTransfer - assume major equipment MTTF $=2000 \mathrm{hr}$ except RobotArm MTTF $=1000 \mathrm{hr}$

$\begin{array}{lllccc}\text { System } & \begin{array}{l}\text { Failure } \\ \text { Rate }\end{array} & \begin{array}{l}\text { Mission } \\ \text { Time }\end{array} & \text { lamda*t } & \text { Reliab. } & \text { Unreliab. } \\ \text { Pneu'Transfer } & 0.0005 & 1176 & 0.588 & 0.555437049 & 0.444562 \\ \text { Scarifier } & 0.0005 & 1176 & 0.588 & 0.555437049 & 0.444562 \\ \text { RoboticArm } & 0.001 & 1176 & 1.176 & 0.308510315 & 0.691489 \\ \text { Cyclsep, etc. } & 0.0005 & 1176 & 0.588 & 0.555437049 & 0.444562 \\ \text { TruckTransfer } & 0.0005 & 1176 & 0.588 & 0.555437049 & 0.444562 \\ \text { Control Sys } & 0.000166667 & 1896 & 0.316 & 0.72905945 & 0.270940\end{array}$

\begin{tabular}{|c|c|c|c|c|}
\hline $\begin{array}{l}\text { Failure down } t \\
\text { Repair cost (c }\end{array}$ & $t)=$ & & 25 & \\
\hline Repair cost (n & ontact) & & 100 & \\
\hline Operating cost & & & & per $h r$ \\
\hline Equipment amor. & Eion $=$ & & & per hr \\
\hline Scenario & Probab. & $\begin{array}{l}\text { Mission } \\
\text { Time }\end{array}$ & $\begin{array}{l}\text { Pumpoper } \\
\text { Time }\end{array}$ & $\begin{array}{l}\text { Mission } \\
\text { Cost }\end{array}$ \\
\hline No Eailure & 0.021407799 & 1896 & 1176 & $1.494168 \mathrm{E}+06$ \\
\hline PneuT'r fails & 0.01713446 & 2340 & 1176 & $1.83772 E+06$ \\
\hline Scarif fails & 0.01713446 & 2340 & 1176 & $1.83772 E+06$ \\
\hline RoboA.rm fails & 0.04798307 & 2340 & 1176 & $1.83772 E+06$ \\
\hline Cycsep fails & 0.01713446 & 2340 & 1176 & $1.83772 \mathrm{E}+06$ \\
\hline TruckTr fails & 0.01713446 & 2340 & 1176 & $1.83772 \mathrm{E}+06$ \\
\hline Contsys fails & 0.007955786 & 2340 & 1176 & $1.83772 E+06$ \\
\hline Mult. failures & 0.854115504 & 2784 & 1176 & $2.181277 \mathrm{E}+06$ \\
\hline
\end{tabular}

Expected Mission Time $=2709.7222212$

Expected Mpump Time $=\mathrm{NA}$

Expected Mission Cost $=2.1237984 \mathrm{E}+06$ 


\section{Case 7:}

MechRetrieval/PipeTransfer - assume major equipment $\mathrm{MTTF}=2000 \mathrm{hr}$ except RobotArm MTTF $=1000 \mathrm{hr}$ and PipeTransfer MTTF $=4000 \mathrm{hr}$

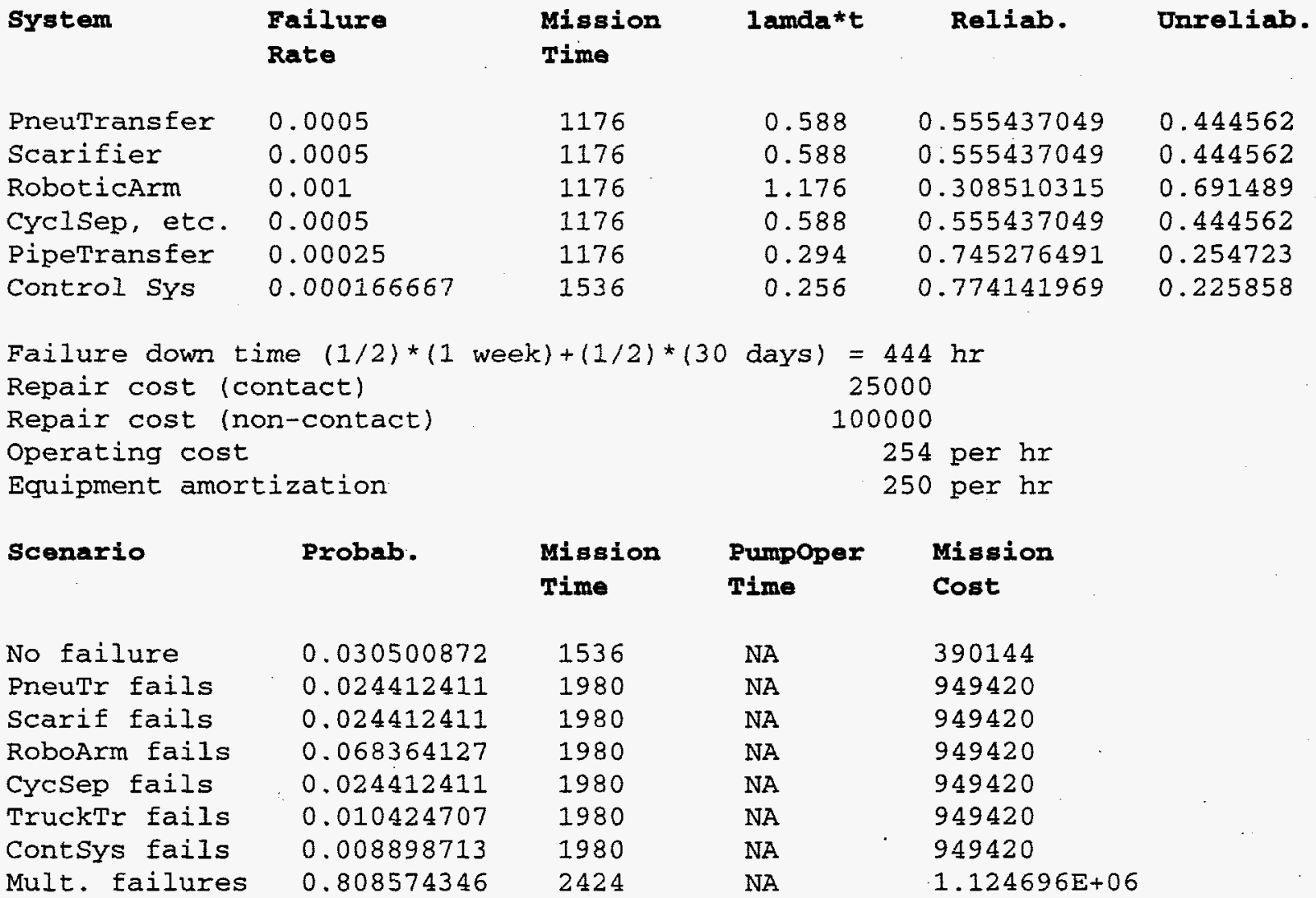

Expected Mission Time $=2325.4646225$

Expected Mpump Time $=\mathrm{NA}$

Expected Mission Cost $=1.07408527 \mathrm{E}+06$ 
The following cases will assume a triangular failure distribution of the form $p(t)=a * t$. This distribution models an increasing failure rate and finite lifetime (i.e., the component "wears out"). Two userdefined functions will be used to automate the calculations. The first, SLOPE(MTTF), will calculate the slope of the triangular failure distribution as a function of MTTF. The second, CONDFAIL(B,a,t), will calculate the conditional probability of component failure between times $\mathrm{B}$ and $\mathrm{B}+t$, given that the component has survived up until time $B$.

\section{Case 8:}

Mixing/Transfer - assume Mpump failure/repair only $(\mathrm{MTTF}=2000 \mathrm{hr})$ assume Beginning of Life ( $\mathrm{B}=0 \mathrm{hr})$ conditions

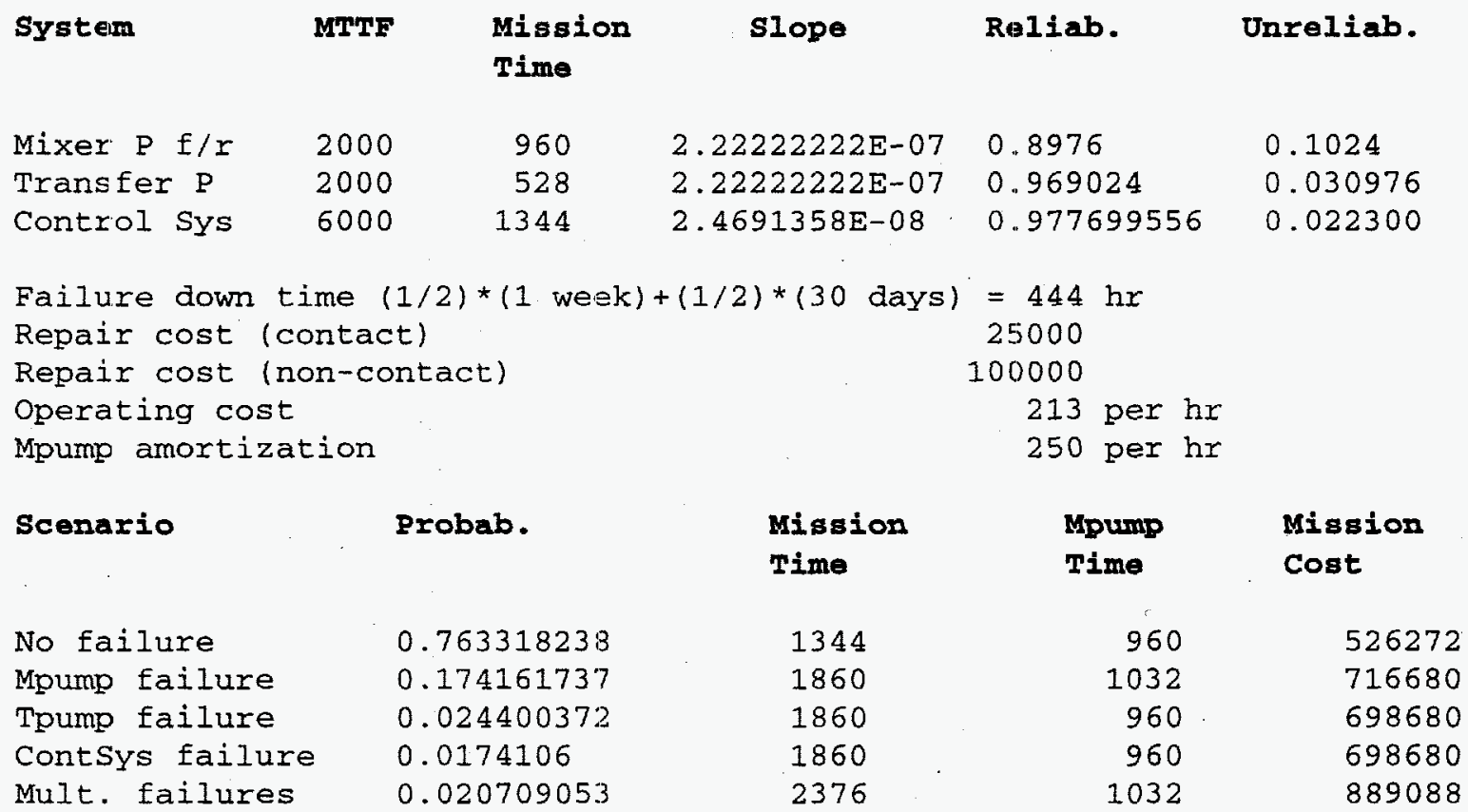

Expected Mission Time $=1476.8136609$

Expected Mpump Time $=974.030696913$

Expected Mission Cost $=574155.9099746$ 


\section{Case 9:}

Mixing/Transfer - assume Mpump failure/repair only $(\mathrm{MTTF}=2000 \mathrm{hr}$ ) assume Middle of Life $(B=1000 \mathrm{hr})$ conditions

\begin{tabular}{lrrrrr} 
System & MTTF & \multicolumn{1}{l}{$\begin{array}{l}\text { Mission } \\
\text { Time }\end{array}$} & \multicolumn{1}{c}{ Slope } & Reliab. & Unreliab. \\
& & & & & \\
Mixer P F/r & 2000 & 960 & $2.22222222 \mathrm{E}-07$ & 0.6448 & 0.3552 \\
Transfer P & 2000 & 528 & $2.22222222 \mathrm{E}-07$ & 0.833152 & 0.166848 \\
Control Sys & 6000 & 1344 & $2.4691358 \mathrm{E}-08$ & 0.862912 & 0.137088
\end{tabular}

Failure down time $(1 / 2) *(1$ week $)+(1 / 2) *(30$ days $)=444 \mathrm{hr}$ Repair cost (contact)

Repair cost (non-contact)

25000

Operating cost

Mpump amortization

213 per hr

250 per hr

Scenario

Probab.

Mission

Mpump

Mission

Time

Time

Cost

No failure

0.29891025

1344

960

526272

Mpump failure

0.329320474

1860

Tpump failure

0.059860118

1860

0.047486891

1860

1032

716680

ContSys failure

0.264422267

2376

960

960

698680

698680

Mult. failures

1842.204201

$\begin{array}{lr}\text { Expected Mpump Time }= & 1002.7494773 \\ \text { Expected Mission Cost }= & 703421.3652465\end{array}$ 


\section{Case 10:}

Mixing/Transfer - assume Mpump failure/repair only $(\mathrm{MTTF}=2000 \mathrm{hr})$ assume End of Life $(B=2000 \mathrm{hr})$ conditions

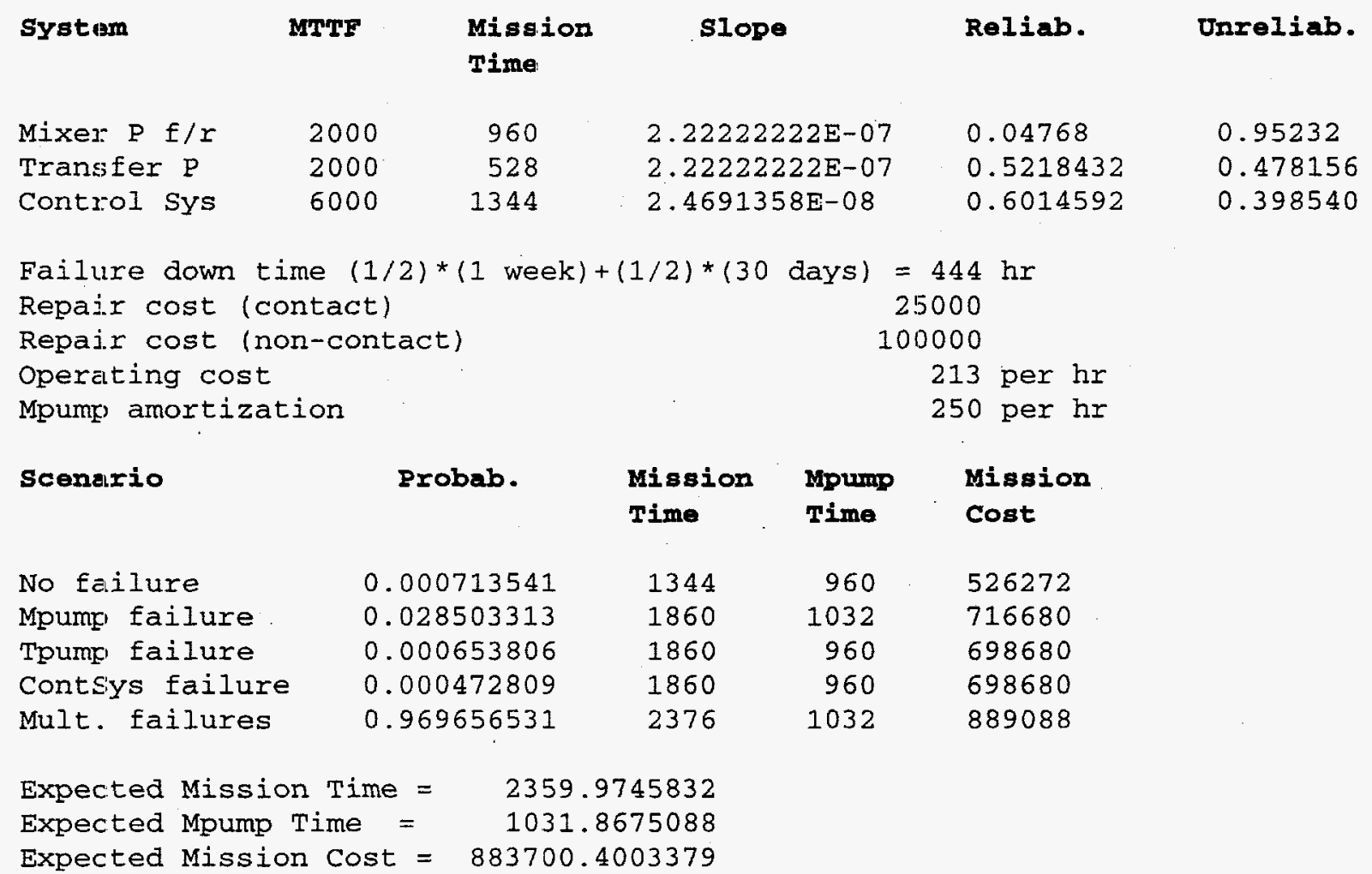




\section{Case 11:}

Mixing/Transfer - assume Mpump failure/repair only $(\mathrm{MTTF}=6000 \mathrm{hr}$ ) assume Beginning of Life $(B=0 \mathrm{hr})$ conditions

\begin{tabular}{lrrlll} 
System & MTTF & \multicolumn{1}{c}{$\begin{array}{l}\text { Mission } \\
\text { Time }\end{array}$} & \multicolumn{1}{c}{ Slope } & \multicolumn{1}{c}{ Reliab. } & Unreliab \\
& & & & & \\
Mixer P f/r & 6000 & 960 & $2.4691358 E-08$ & 0.988622222 & 0.011377 \\
Transfer P & 2000 & 528 & $2.22222222 E-07$ & 0.969024 & 0.030976 \\
Control Sys & 6000 & 1344 & $2.4691358 E-08$ & 0.977699556 & 0.022300
\end{tabular}

Failure down time $(1 / 2) *(1$ week $)+(1 / 2) *(30$ days $)=444 \mathrm{hr}$

Repair cost (contact)

Repair cost (non-contact)

Operating cost

Mpump amortization

Scenario

Probab.

No failure

0.925978041

0.021313647

0.029599985

Toump failure

ContSys failure

Mult. Eailures
Mission

Time

1344

1860

1860

1860

2376
25000

100000

213 per hr

250 per hr

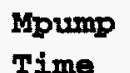

Time

960

1032

960

960

1032
Mission

Cost

526272

716680

698680

698680

889088

Expected Mission Time $=1383.230489$

Expected Mpump Time $=961.679023236$

Expected Mission Cost $=539799.604933$ 


\section{Case 12:}

Mixing/Transfer - assume Mpump failure/repair only $(\mathrm{MTTF}=6000 \mathrm{hr}$ ) assume Middle of Life $(B=3000 \mathrm{hr})$ conditions

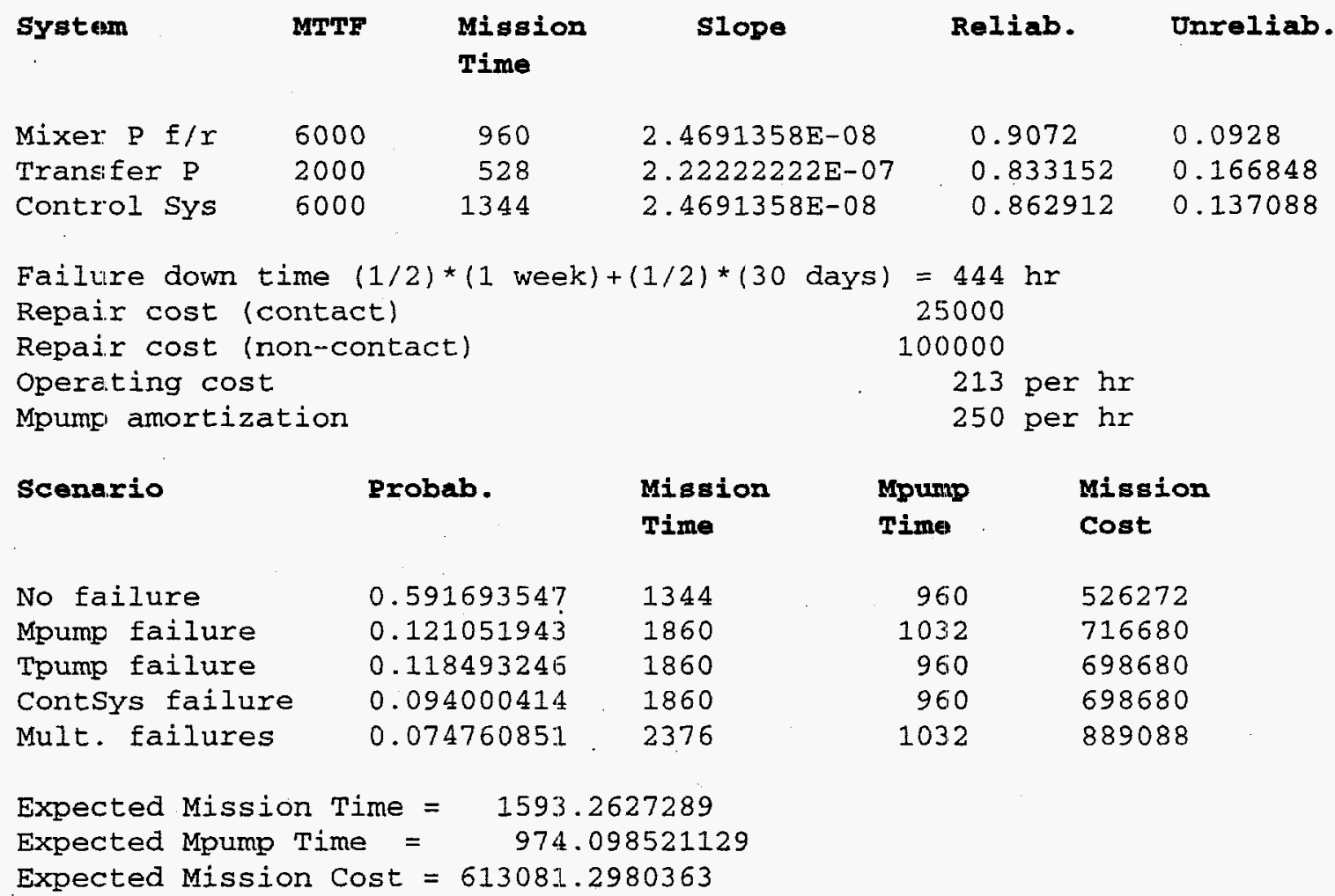


Case 13:

Mixing/Transfer - assume Mpump failure/repair only $(\mathrm{MTTF}=6000 \mathrm{hr})$ assume End of Life $(B=6000 \mathrm{hr})$ conditions

\begin{tabular}{lccccc} 
System & MTTF & $\begin{array}{l}\text { Mission } \\
\text { Time }\end{array}$ & \multicolumn{1}{c}{ Slope } & Reliab. & Unreliab. \\
Mixer P f/r & 6000 & 960 & $2.4691358 \mathrm{E}-08$ & 0.72352 & 0.27648 \\
Transfer P & 2000 & 528 & $2.22222222 \mathrm{E}-07$ & 0.5218432 & 0.478156 \\
Control Sys & 6000 & 1344 & $2.4691358 \mathrm{E}-08$ & 0.6014592 & 0.398540
\end{tabular}

Failure down time $(1 / 2) *(1$ week $)+(1 / 2) *(30$ days $)=444 \mathrm{hr}$

Repair cost (contact)

25000

Repair cost (non-contact)

100000

Operating cost

Mpump amortization

213 per hr

250 per hr

Scenario

No failure

Mpump failure

Tpump failure

Contsys failure

Mult. failures

\section{Probab.}

0.164303677

0.12557132

0.150548901

0.108871423

0.45070468

\section{Mission \\ Time}

1344

1860

1860

1860

2376

\section{Mpump Mission \\ Time Cost}

$\begin{array}{rr}960 & 526272 \\ 1032 & 716680 \\ 960 & 698680 \\ 960 & 698680 \\ 1032 & 889088\end{array}$

Expected Mission Time $=2007.7829175$

Expected Mpump Time $=1001.4918719$

Expected Mission Cost $=758430.7920943$ 


\section{Case 14:}

Sluicing/Transfer - assume Tpump failure/repair MTTF $=2000 \mathrm{hr}$ assume Beginning of Life $(\mathrm{B}=0 \mathrm{hr})$ conditions

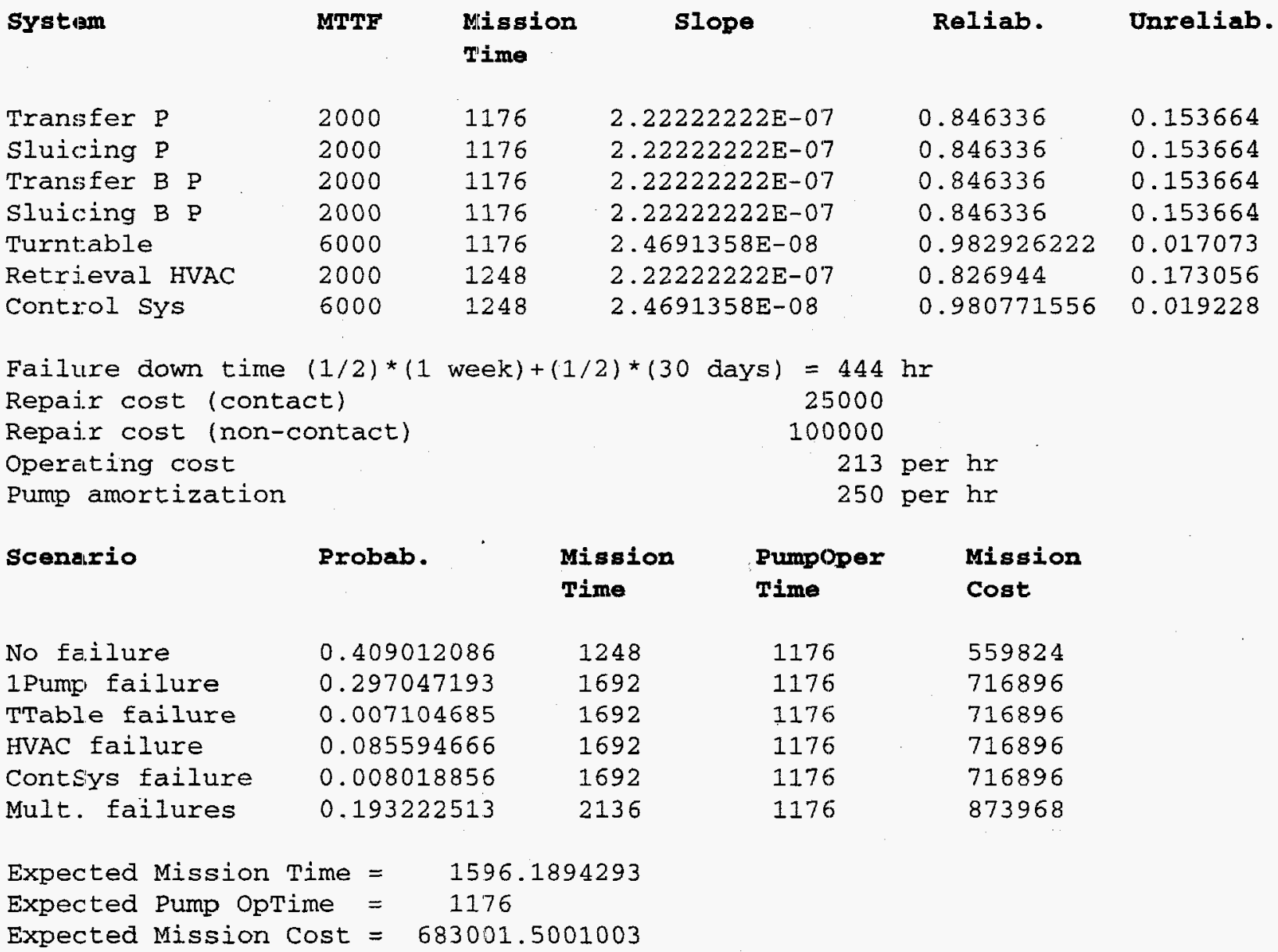




\section{Case 15:}

Sluicing/Transfer - assume Tpump failure/repair MTTF $=2000 \mathrm{hr}$ assume Middle of Life $(B=1000 \mathrm{hr})$ conditions

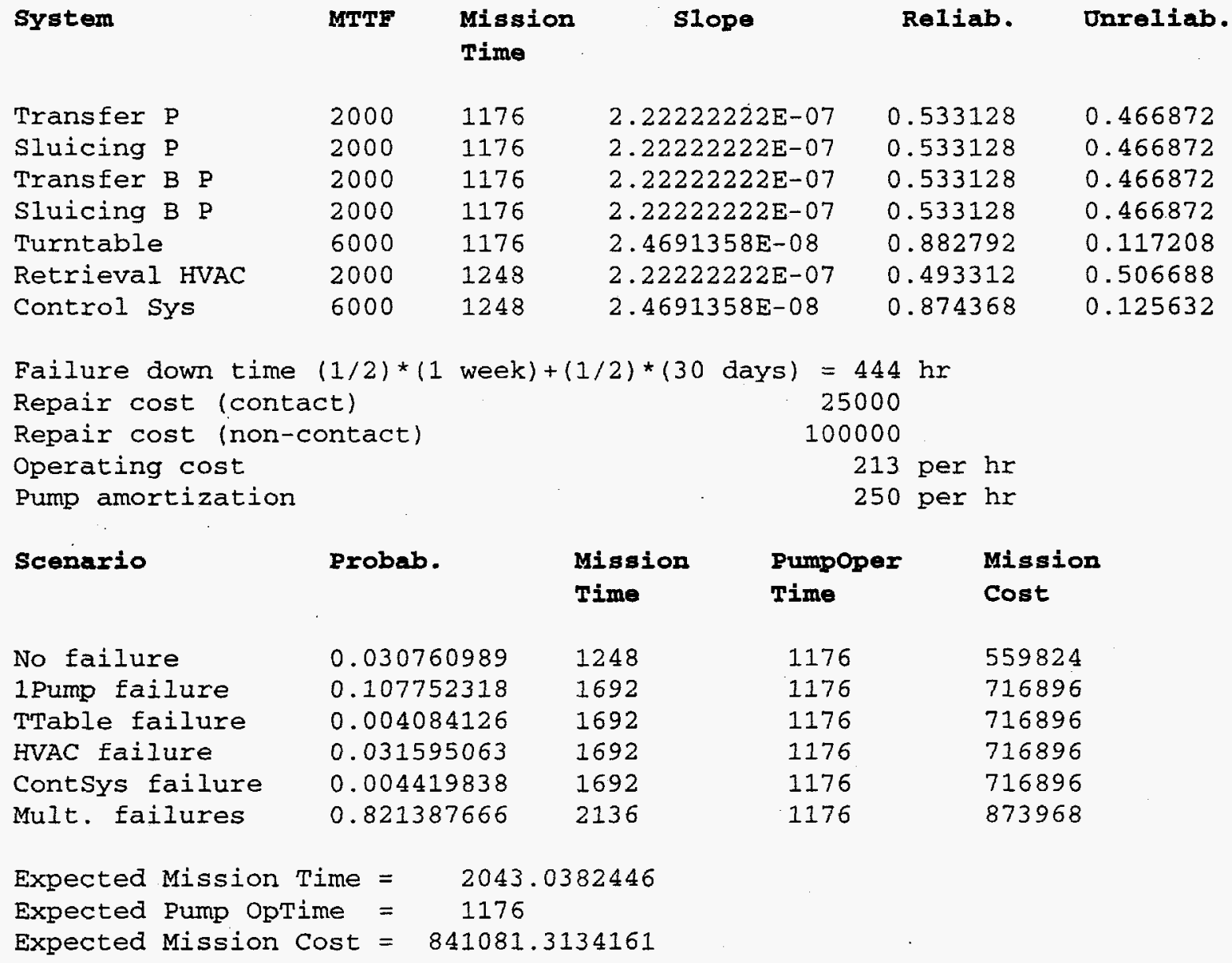




\section{Case 16:}

Sluicing/Transfer - assume Tpump failure/repair MTTF $=2000 \mathrm{hr}$ assume End of Life $(B=2000 \mathrm{hr})$ conditions

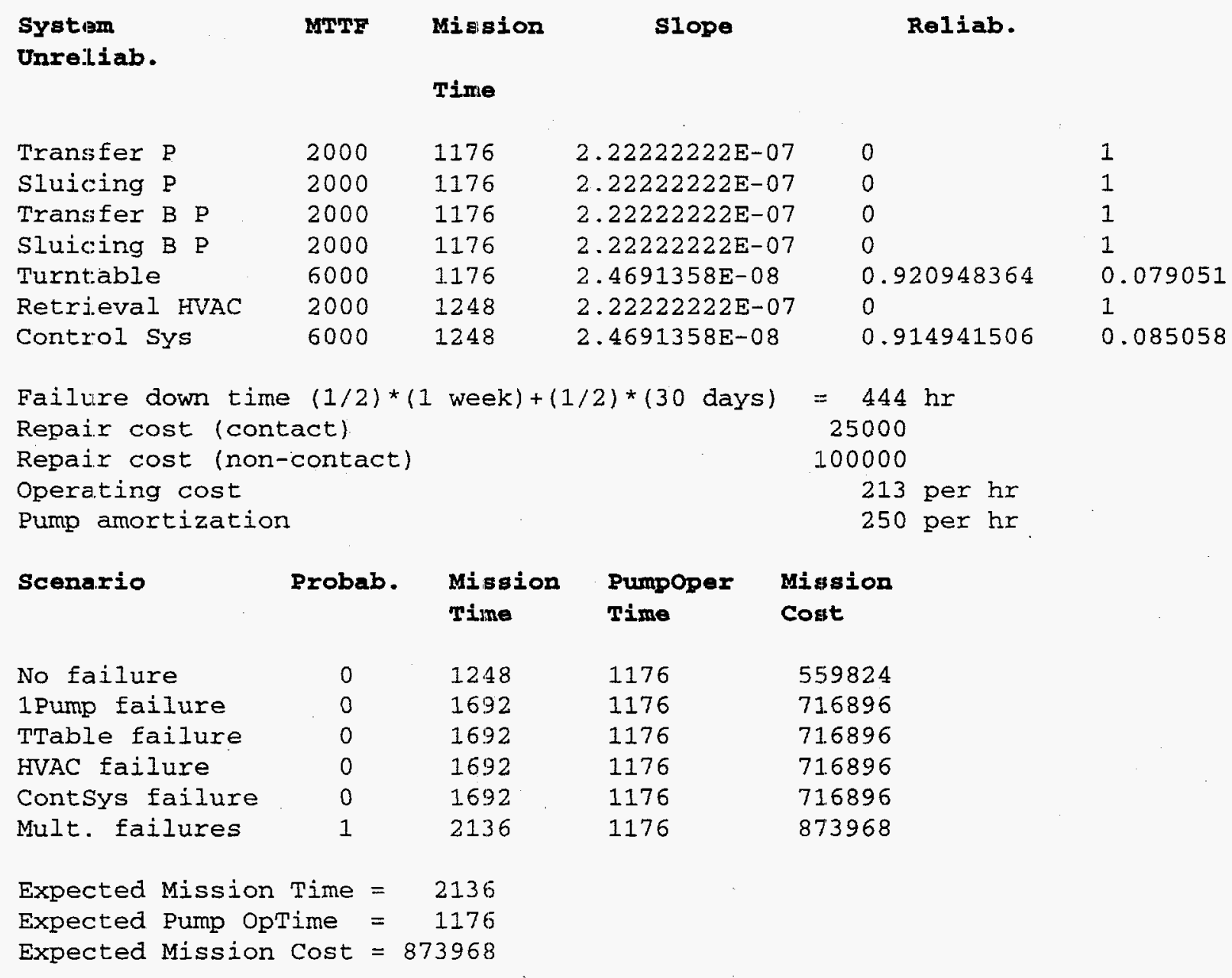




\section{Case 17:}

MechRetrieval/TruckTransfer - assume major equipment MTTF $=2000 \mathrm{hr}$ except RobotArm MTTF $=1000 \mathrm{hr}$ assume Beginning of Life ( $\mathrm{B}=0 \mathrm{hr})$ conditions

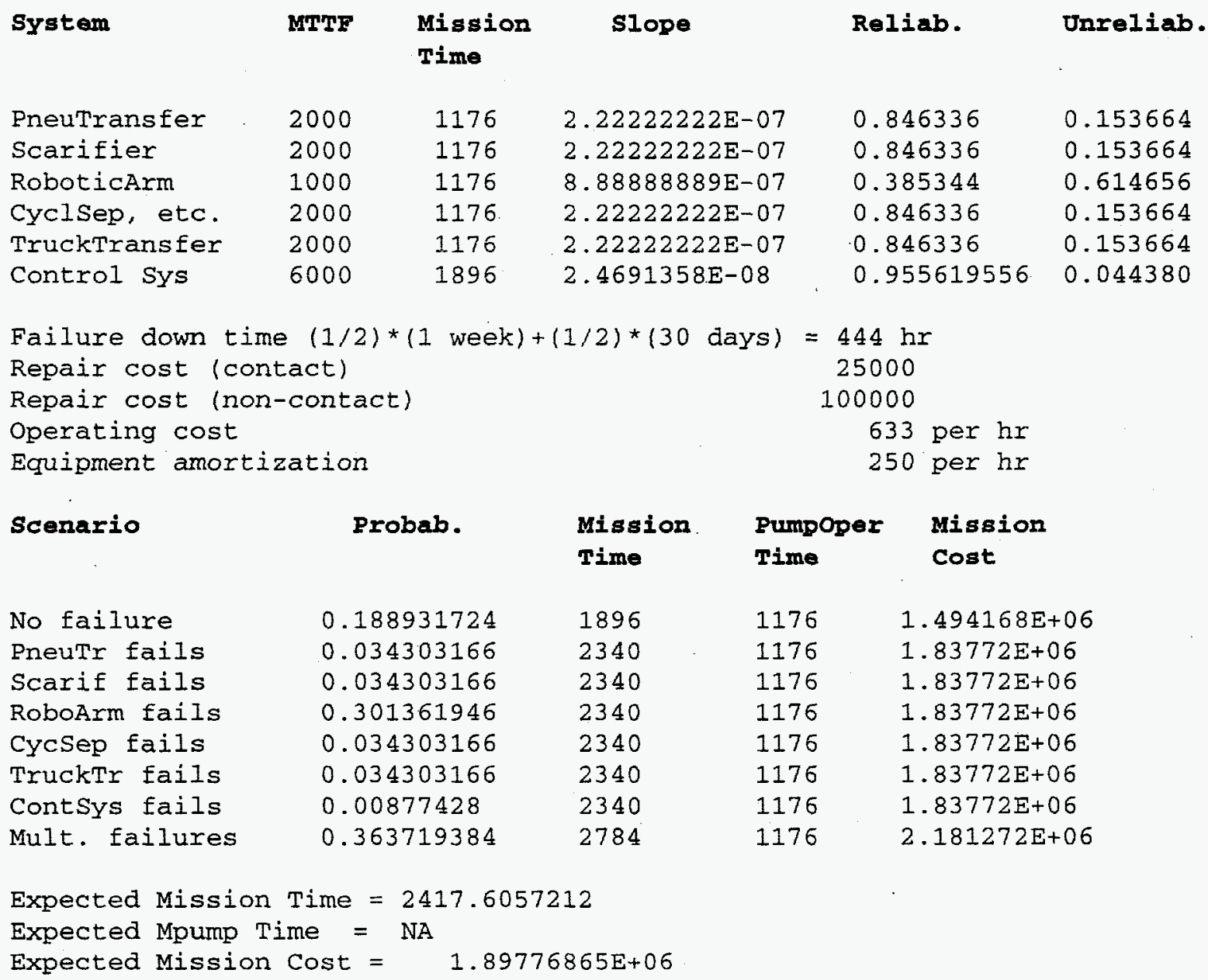




\section{Case 18:}

MechRetrieval/TruckTransfer - assume major equipment MTTF $=2000 \mathrm{hr}$ except RobotArm MTTF $=1000 \mathrm{hr}$ assume Middle of Life $(B=1000 \mathrm{hr})$ conditions

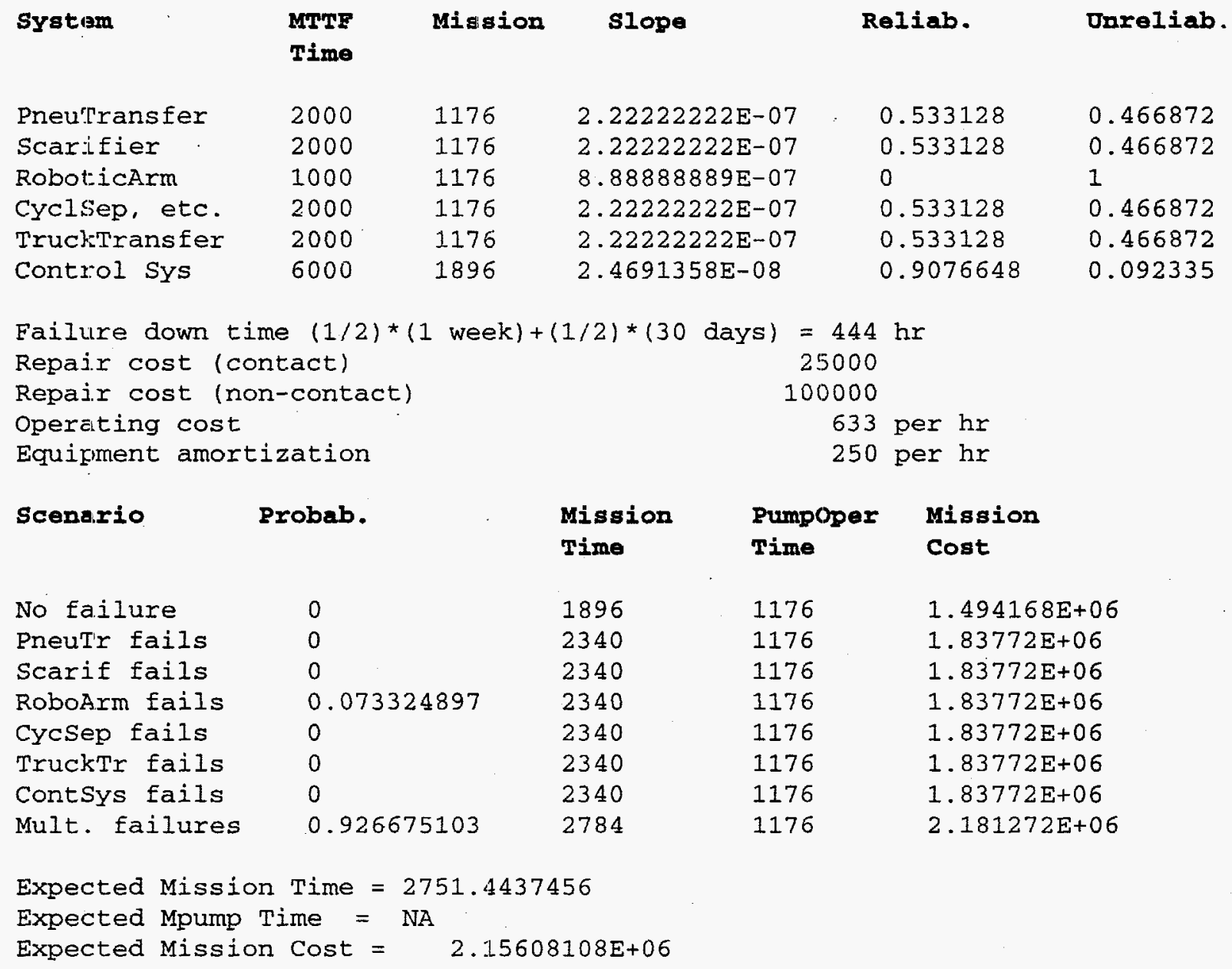




\section{Case 19:}

MechRetrieval/TruckTransfer - assume major equipment MTTF $=2000 \mathrm{hr}$ except RobotArm MTTF $=1000 \mathrm{hr}$ assume End of Life $(B=2000 \mathrm{hr})$ conditions

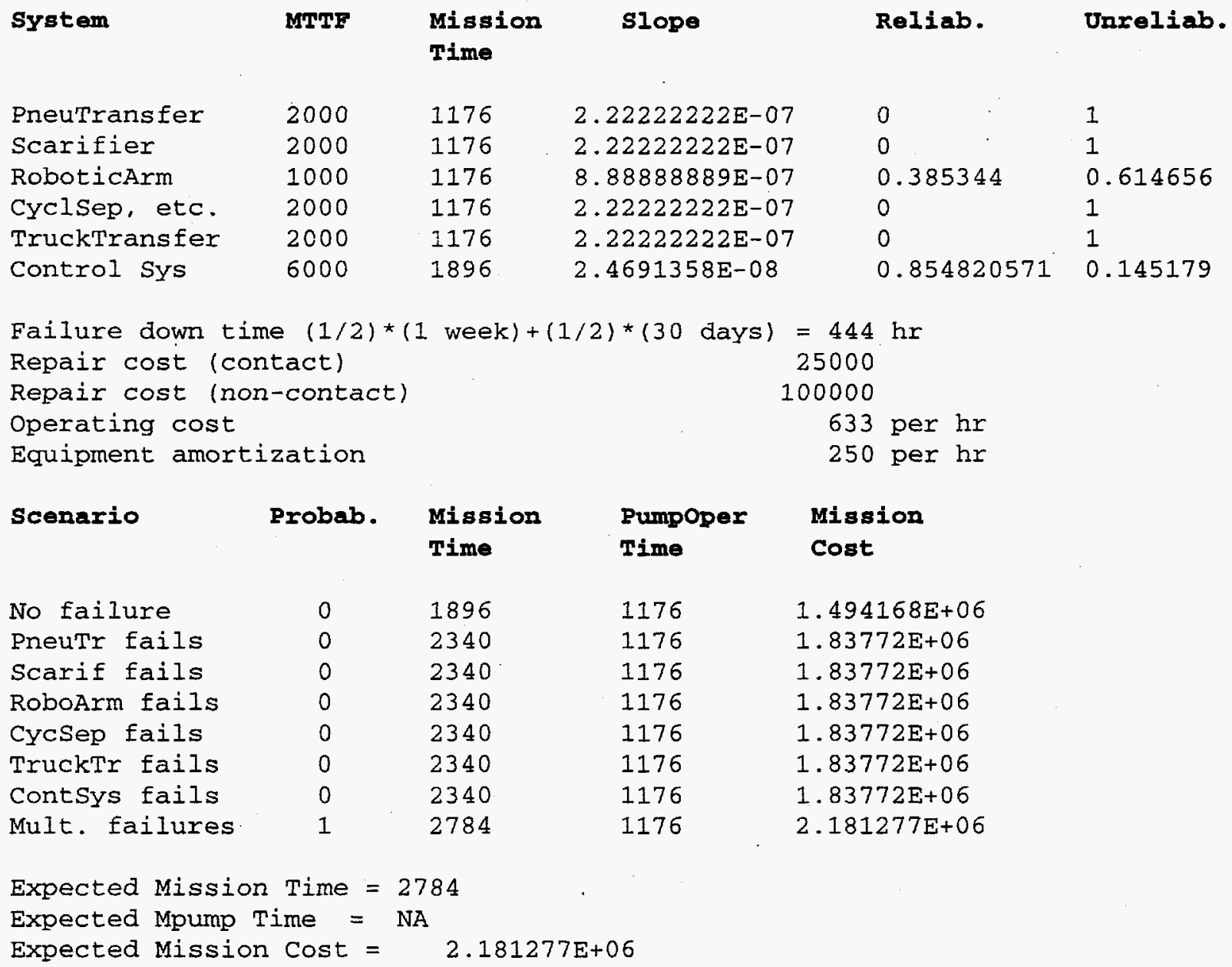


Case 20:

MechRetrieval/PipeTransfer - assume major equipment MTTF $=2000 \mathrm{hr}$ except RobotArm MTTF $=1000 \mathrm{hr}$ and PipeTransfer MTTF $=4000 \mathrm{hr}$ assume Beginning of Life $(\mathrm{B}=0 \mathrm{hr})$ conditions

$\begin{array}{lclccr}\text { System } & \text { MTTF } & \begin{array}{l}\text { Mission } \\ \text { Time }\end{array} & \text { Slope } & \text { Reliab. } & \text { Unreliab. } \\ & & & & & \\ \text { Pneu'Transfer } & 2000 & 1176 & 2.22222222 \mathrm{E}-07 & 0.846336 & 0.153664 \\ \text { Scarifier } & 2000 & 1176 & 2.22222222 \mathrm{E}-07 & 0.846336 & 0.153664 \\ \text { RoboticArm } & 1000 & 1176 & 8.88888889 \mathrm{E}-07 & 0.385344 & 0.614656 \\ \text { Cyclisep, etc. } & 2000 & 1176 & 2.22222222 \mathrm{E}-07 & 0.846336 & 0.153664 \\ \text { Pipe'Transfer } & 4000 & 1176 & 5.55555556 \mathrm{E}-08 & 0.961584 & 0.038416 \\ \text { Control Sys } & 6000 & 1536 & 2.4691358 \mathrm{E}-08 & 0.970872889 & 0.029127\end{array}$

Failure down time $(1 / 2) *(1$ week $)+(1 / 2) *(30$ days $)=444 \mathrm{hr}$

Repair cost (contact)

Repaix cost (non-contact)

25000

operating cost

100000

Equipment amortization

254 per hr

250 per hr

\section{Scenurio}

No failure

Pneulr fails

Scarif fails

Robofrm fails

Cycsep fails

Truck:Tr fails

Contsys fails

Mult. failures

\section{Probab.}

0.218085428
0.039596424
0.039596424
0.347864548
0.039596424
0.008712676
0.00654277
0.300005305

0.218085428

0.039596424

0.039596424

0.347864548

0.008712676

0.300005305

\section{Mission \\ Time}

1536

1980

1980

1980

1980

1980

1980

2424

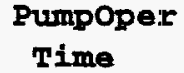

1176

1176

1176

1176

1176

1176

1176

1176

\section{Mission \\ Cost}

684144

859420

859420

859420

859420

859420

859420

$1.034696 \mathrm{E}+06$

Expected Mission Time $=2016.3724258$

Expected Mpump Time $=$ NA

Expected Mission Cost $=873778.5885111$ 


\section{Case 21:}

MechRetrieval/PipeTransfer - assume majór equipment MTTF $=2000 \mathrm{hr}$ except RobotArm MTTF $=1000 \mathrm{hr}$ and PipeTransfer MTTF $=4000 \mathrm{hr}$ assume Middle of Life $(B=1000 \mathrm{hr})$ conditions

$\begin{array}{lclccr}\text { System } & \text { MTTF } & \begin{array}{l}\text { Mission } \\ \text { Time }\end{array} & \text { Slope } & \text { Reliab. } & \text { Onreliab. } \\ & & & & & \\ \text { PneuTransfer } & 2000 & 1176 & 2.22222222 \mathrm{E}-07 & 0.533128 & 0.466872 \\ \text { Scarifier } & 2000 & 1176 & 2.22222222 \mathrm{E}-07 & 0.533128 & 0.466872 \\ \text { RoboticArm } & 1000 & 1176 & 8.88888889 \mathrm{E}-07 & 0.385344 & 0.614656 \\ \text { CyclSep, etc. } & 2000 & 1176 & 2.22222222 \mathrm{E}-07 & 0.533128 & 0.466872 \\ \text { PipeTransfer } & 4000 & 1176 & 5.55555556 \mathrm{E}-08 & 0.809782 & 0.190218 \\ \text { Control Sys } & 6000 & 1536 & 2.4691358 \mathrm{E}-08 & 0.839232 & 0.160768\end{array}$

Failure down time $(1 / 2) *(1$ week $)+(1 / 2) *(30$ days $)=444 \mathrm{hr}$ Repair cost (contact)

Repair cost (non-contact)

Operating cost

Equipment amortization

25000

100000

254 per hr

250 per hr

$\begin{array}{lccll}\text { Scenario } & \text { Probab. } & \begin{array}{l}\text { Mission } \\ \text { Time }\end{array} & \begin{array}{l}\text { Pumpoper } \\ \text { Time }\end{array} & \begin{array}{l}\text { Mission } \\ \text { Cost }\end{array} \\ \text { No failure } & 0.039681971 & 1536 & 1176 & 684144 \\ \text { PneuTr fails } & 0.034750381 & 1980 & 1176 & 859420 \\ \text { Scarif fails } & 0.034750381 & 1980 & 1176 & 859420 \\ \text { RoboArm fails } & 0.063296072 & 1980 & 1176 & 859420 \\ \text { CycSep fails } & 0.034750381 & 1980 & 1176 & 859420 \\ \text { TruckTr fails } & 0.009321305 & 1980 & 1176 & 859420 \\ \text { ContSys fails } & 0.007601701 & 1980 & 1176 & 859420 \\ \text { Mult. failures } & 0.775847809 & 2424 & 1176 & 1.034696 \mathrm{E}+06\end{array}$

Expected Mission Time $=2306.857632$

Expected Mpump Time $=$ NA

Expected Mission Cost $=988452.203406$ 


\section{Case 22:}

Mech/Retrieval/PipeTransfer - assume major equipment MTTF $=2000 \mathrm{hr}$ except RobotArm MTTF $=1000 \mathrm{hr}$ and PipeTransfer MTTF $=4000 \mathrm{hr}$ assume End of Life $(B=2000 \mathrm{hr})$ conditions

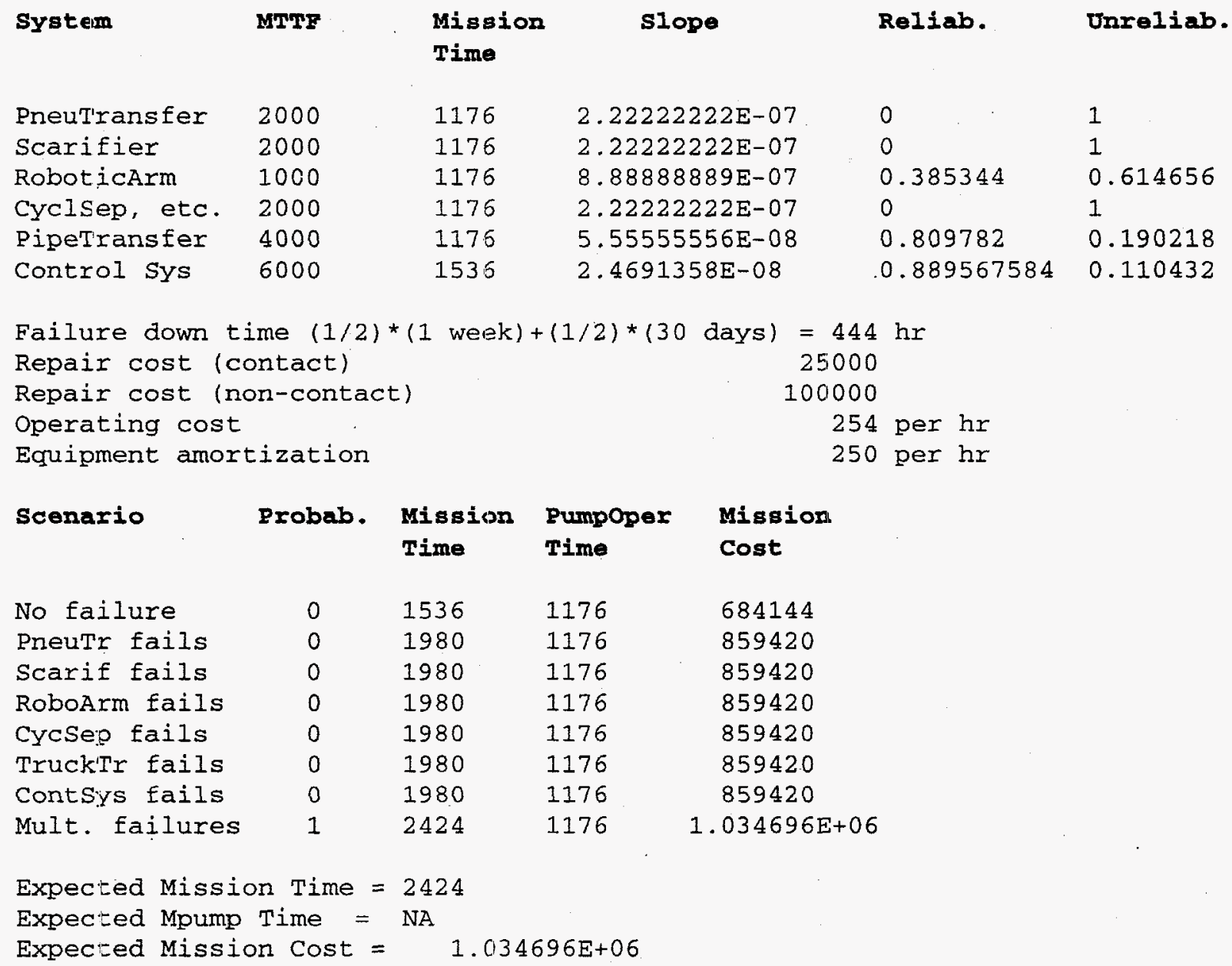




\section{C.11 Equations Used in the Spreadsheet Calculations}

Using the notation DefInt $(a, b, f(x))$ to represent the definite integral of the integrand $f(x) * d x$ between lower limit a and upper limit $b$.

Assuming a failure distribution $p(t)$,

$$
\begin{aligned}
F(t)=\text { Unreliability at } t & =\text { probability of failure before } t \\
& =\operatorname{DefInt}(0, t, p(t)) \\
R(t)=\text { Reliability at } t & =\text { probability of survival until } t \\
& =1-F(t)=\operatorname{DefInt}(t, \operatorname{infinity}, p(t))
\end{aligned}
$$

For an exponential distribution, $p(t)=1$ amda*exp $(-1$ amda*t), and lamda $=1 / \mathrm{MTTF}$.

$$
\begin{aligned}
& F(T)=\operatorname{DefInt}(0, T, p(t))=1-\exp \left(-\operatorname{Iamda}{ }^{*} T\right) \\
& R(T)=1-F(T)=\exp (-\operatorname{lamda} * T)
\end{aligned}
$$

For a triangular distribution, $p(t)=a * t$, with MTTF, we have a = 8.0/(9.0*MTTF*MTTF) and, if we assume that the component/system has survived until time $t=B$, then the conditional probability of failure in the future, given survival to time $B$, is given by

$$
P(\text { survival till time } B)=1-\operatorname{DefInt}(0, B, a * t)=1-a{ }^{*} B / 2.0
$$

and $P$ (failure at time $t$ after $B \mid$ survival until time $B$ )

$=\operatorname{DefInt}(B, B+t, a * t) /(1.0-(a * B * B / 2.0))$

$=a * t *(2.0 * B+t) /(2.0-a * B * B)$

The probability of the "no failures" scenarios is the product of the reliabilities of all of the required equipment.

The probability of a single-failure scenario = the unreliability of that component/system with an adjustment to account for intersections of various failure events.

The "adjustment" uses the formulas

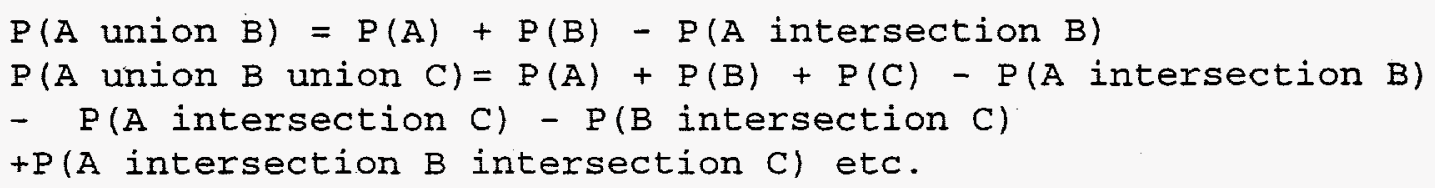


As noted above, the two different equipment failure distributions used to calculate the component were 1) the exponential distribution, and 2) the triangular distribution. Assuming a mean lifetime of $6000 \mathrm{hr}$ for both cases, the distributions will be

Exponential --

$$
\begin{aligned}
P(\text { Eailure during t to } t+d t)= & (1 / 6000) * \exp (-t / 6000) * d t, \\
& \text { with } 0<=t, \text { in hr Triangular - } \\
P(\text { Eailure during } t \text { to } t+d t)= & a^{*} t * d t, \text { where } a=0.24691 \mathrm{E}-7 / \mathrm{hr} / \mathrm{hr} \text { for } \\
& 0<=t<=9000 \mathrm{hr}
\end{aligned}
$$

and will look like

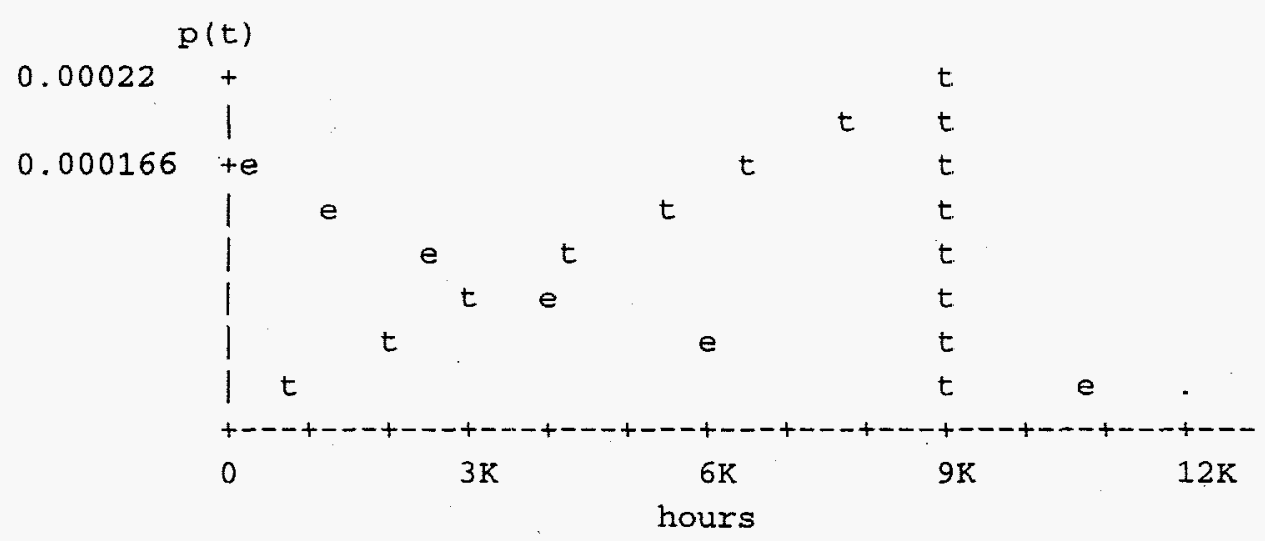

C.32 


\section{Distribution}

No. of

Copies

OFFSITE

2 Office of Scientific and Technical Information

D. Von Winterfeldt

Decision Insights, Inc.

2062 Business Center Drive, Suite 110

Irvine, CA 92613

T. Eppel

Decision Insights, Inc.

2062 Business Center Drive, Suite 110

Irvine, CA 92613

R. I. Hanson

2390 E. Camelback Rd., Suite 230

Phoenix, AZ 85016

\section{QNSITE}

3 DOE Richland Operations Office

D. J. Francis

K6-51

B. L. Nicoll

R. W. Unger

S7-53

H6-35

$\underline{D E \& S}$

R. E. Bauer

S7-14

Fluor Daniel Hanford

D. J. Washenfelder
No. of

Copies

Fluor Daniel Northwest

R. M. Marusich

A3-34

17 Numatec Hanford Corporation

AM Choho

H6-35

R. D. Claghorn (9) H5-49

T. A. Flament K9-46

J. D. Galbraith H5-49

J. S. Garfield H5-49

D. L. Lamberd H5-61

A. F. Manuel H5-49

R. P. Marshall H5-61

J. E. VanBeek S2-48

3 Lockheed Martin Hanford Corporation

W. E. Ross S5-07

R. L. Treat H5-03

B. D. Zimmerman H6-35

$\underline{\text { SGN Eurisys Services }}$

$\begin{array}{ll}\text { C. E. Grenard } \quad \text { H5-61 } & \text { H }\end{array}$

28 Pacific Northwest National Laboratory

A. J. Brothers (10) K8-07

P. M. Daling K8-07

J. S. Dukelow K8-37

A. L. Franklin K8-07

W. A. Hesser K6-51

M. S. Madden K8-07

P. D. McLaughlin K7-10

M. J. Quadrel K9-70

D. A. Seaver (5) K8-07

N. C. Williams K8-18

Technical Report Files (5) 